\title{
Dendritic development of GABAergic cortical interneurons revealed by biolistic transfection with GFP
}

Xiaoming Jin

West Virginia University

Follow this and additional works at: https://researchrepository.wvu.edu/etd

\section{Recommended Citation}

Jin, Xiaoming, "Dendritic development of GABAergic cortical interneurons revealed by biolistic transfection with GFP" (2002). Graduate Theses, Dissertations, and Problem Reports. 1708.

https://researchrepository.wvu.edu/etd/1708

This Dissertation is protected by copyright and/or related rights. It has been brought to you by the The Research Repository @ WVU with permission from the rights-holder(s). You are free to use this Dissertation in any way that is permitted by the copyright and related rights legislation that applies to your use. For other uses you must obtain permission from the rights-holder(s) directly, unless additional rights are indicated by a Creative Commons license in the record and/ or on the work itself. This Dissertation has been accepted for inclusion in WVU Graduate Theses, Dissertations, and Problem Reports collection by an authorized administrator of The Research Repository @ WVU.

For more information, please contact researchrepository@mail.wvu.edu. 


\title{
Dendritic Development of GABAergic Cortical Interneurons Revealed
} by Biolistic Transfection with GFP

\author{
Xiaoming Jin \\ Dissertation submitted to the \\ School of Medicine \\ at West Virginia University \\ in partial fulfillment of the requirements \\ for the degree of \\ Doctor of Philosophy \\ in \\ Anatomy \\ Ariel Agmon, Ph.D., Chair \\ Albert Berrebi, Ph.D. \\ Richard Dey, Ph.D. \\ Peter Mathers, Ph.D. \\ Adrienne Salm, Ph.D.
Department of Neurobiology and Anatomy
Morgantown, West Virginia
2002

Keywords: neocortex, GAD, gene gun, dendrite, growth, BDNF, neuronal activity, organotypic, brain slice, culture. 


\section{ABSTRACT \\ Dendritic Development of GABAergic Cortical Interneurons Revealed by Biolistic Transfection with GFP}

\section{Xiaoming Jin}

Neurons using $\gamma$-aminobutyric acid (GABA) as a neurotransmitter are critically important as inhibitory neurons in the CNS. A major hindrance to further studies of this important and highly diverse class of neurons is their relative scarcity, which makes it difficult to identify and target them for morphological and physiological studies. To overcome this difficulty, we developed a novel protocol for visualizing detailed morphology of GABAergic neurons in living mouse brain slice cultures, using biolistic transfection with GAD67-GFP. The morphological, immunocytochemical and physiological characteristics of GAD67-GFP expressing neurons indicated that they were functional GABAergic neurons. Additionally, our data demonstrate that this technique allows patch-clamp recording of firing patterns and postsynaptic currents from GABAergic cortical interneurons, and unitary inhibitory postsynaptic currents from neurons postsynaptic to them. We imaged and reconstructed dendritic morphology of 150 GAD67-GFP expressing cortical interneurons in organotypic slice cultures. Using a novel computational metric of dendritic polarization, we demonstrated that dendrites of about two thirds of these GAD67-GFP expressing neurons were not randomly oriented, but instead showed a highly significant tendency to extend along the vertical axis of the cortex, indicating that GABAergic interneurons make an important contribution to the vertical bias of the neocortical neuropil. We further tested the hypothesis that brain derived neurotrophic factor (BDNF) is involved in activity-dependent dendritic growth of cortical GABAergic interneurons. By repeated confocal imaging of the same living GFPexpressing neurons at 5-day intervals, we demonstrated that both high $\mathrm{KCl}$ medium and BDNF enhance dendritic growth of GABAergic neurons, and that the enhancing effect of depolarization on dendritic growth is mediated by BDNF, while the BDNF effect is not dependent on neuronal activity. These results suggest that enhanced neuronal activity acts to promote dendritic growth of GABAergic interneurons by increasing expression and release of BDNF from neighboring neurons. Altogether, we demonstrated two modes of dendritic development in GABAergic cortical interneurons: vertically-oriented growth and activity-dependent growth, with each probably serving different functional requirements of the cerebral cortex. Our results also demonstrate that biolistic transfection with GAD67-GFP is an efficient, flexible and reliable technique for electrophysiological and morphological studies of living GABAergic interneurons. 


\section{Acknowledgments}

I would like to express my sincere gratitude to my graduate advisor Dr. Ariel Agmon for providing constant guidance, support and encouragement, and for promoting tremendous professional growth through the years of my graduate studies. His diligence and motivation have made a deep impression on me and will continue to motivate me in my future career.

I would like to thank each of my committee members for always making themselves available, and for their kind support, guidance and encouragement. This work could not have been completed without their insight and help. In particular, I thank Dr. Peter Mathers for his collaboration on the whole research project, for generating the DNA constructs, and for his critical comments and suggestions on molecular biology and on the manuscripts. I gratefully acknowledge the help of Dr. Albert Berrebi with the immunocytochemistry method and for his critical comments on the data and the manuscripts. Many thanks go to Dr. Richard Dey and Dr. Adrienne Salm, for their help as graduate program coordinators during my graduate studies, for allowing me to use their lab facilities, and for their invaluable suggestions and comments on the research project. I would also like to thank Dr. Gabor Szabo for providing the GAD67 promoter. Appreciation is extended to Cary Johnson for excellent lab support, to Jeffery Altemus for technical support in confocal imaging, to Colette Ramsburg for preparing the DNA constructs, and to Jim Porter for help in patch-clamp recording. I would also like to thank Jason Wells, Yunyong Ma and Jen Leasa for their help and friendship in the lab.

I thank my parents, my sister and brothers, for their understanding, support and encouragement.

And most importantly, I'd like to thank my wife Jianhua Gao, for her ongoing understanding, contribution, love and support. 


\section{Table of Contents}

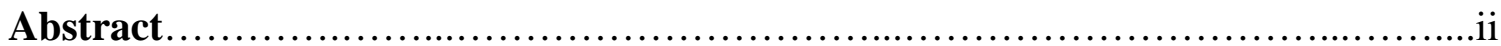

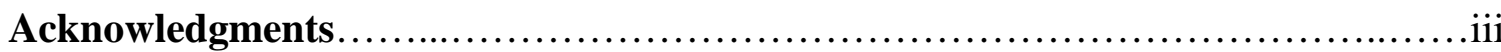

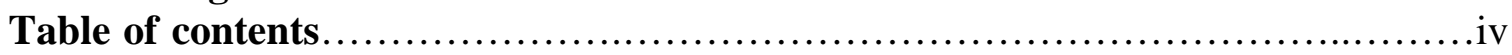

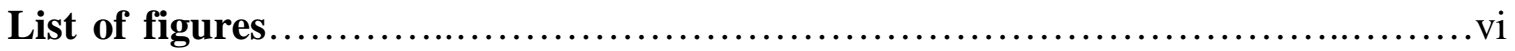

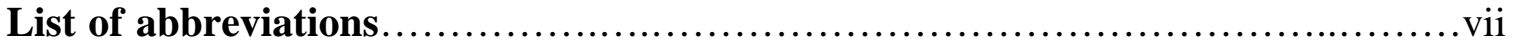

Chapter 1: Introduction (Literature Review)

A. GABAergic interneurons in the cerebral cortex................................. 02

1. Physiological functions of GABAergic cortical interneurons.......................02

2. Pyramidal neurons and interneurons in the cerebral cortex .........................09

3. GAD67 and GAD65 ...........................................................

4. Classification of GABAergic cortical interneurons............................... 13

5. Development of GABAergic cortical interneurons..............................22

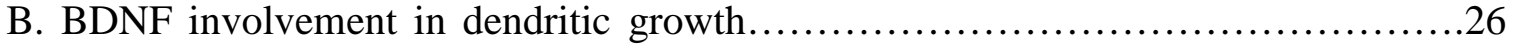

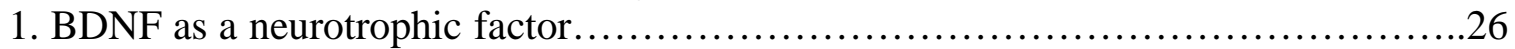

2. Developmental and activity-dependent regulation of BDNF and trkB receptors.......29

3. Physiological roles of BDNF............................................ 34

4. BDNF involvement in activity-dependent development of GABAergic interneurons..41

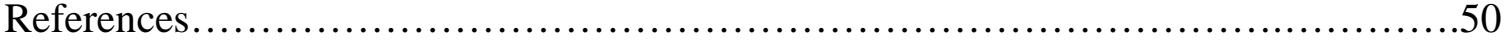

Chapter 2: Biolistic Transfection with GAD67-GFP Reveals Functional GABAergic Interneurons in Organotypic Mouse Brain Slice Culture

Abstract....................................................................... 82

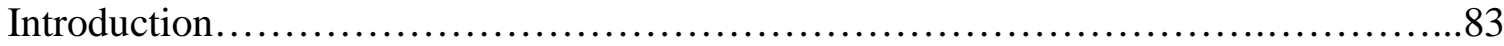

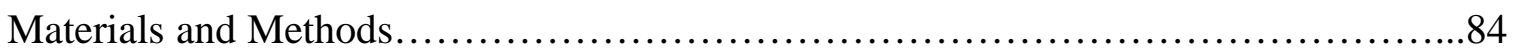

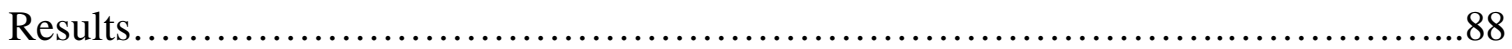

Discussion................................................................ 91

References.................................................................... 101

Chapter 3: Vertical Bias in Dendritic Trees of Non-pyramidal Neocortical Neurons Expressing GAD67-GFP In Vitro

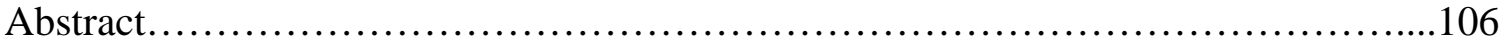

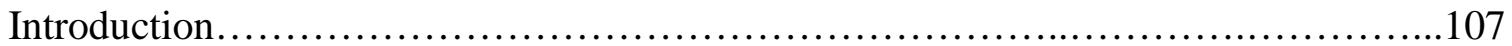

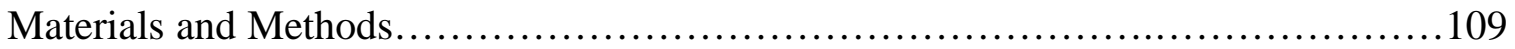

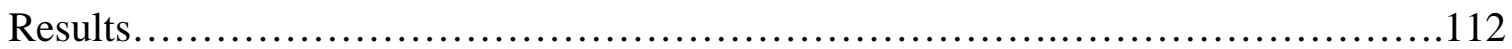

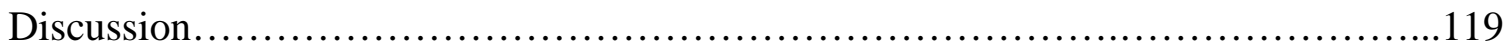

References......................................................................... 140

Chapter 4: BDNF Mediates Activity-Dependent Dendritic Growth in Developing Non-pyramidal Neocortical Interneurons in Vitro

Abstract...................................................................... 152

Introduction.............................................................. 153

Materials and Methods........................................................ 154

Results..................................................................... 160 


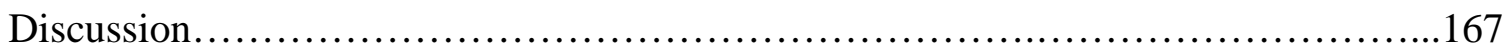

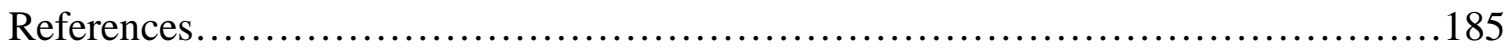

Chapter 5: General Discussion

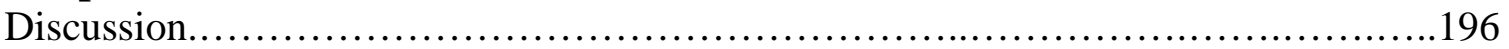

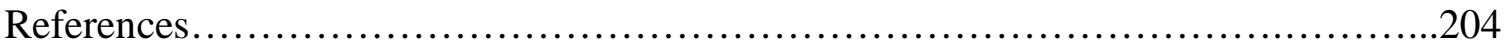

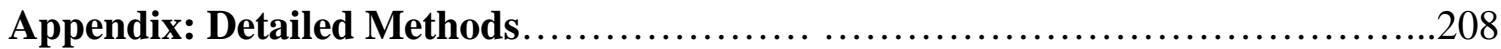

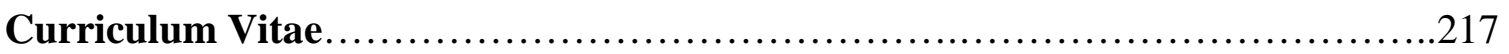




\section{List of Figures}

\section{Chapter 1}

Figure 1.1 Classification of GABAergic cortical neurons...........................48

Figure 1.2 Synaptic contacts of GABAergic cortical interneurons...................49

Figure 1.3 Interneuron migration and neocortical development .....................50

\section{Chapter 2}

Figure 2.1 GAD67-GFP transfection revealed GABAergic neurons..................96

Figure 2.2 Action potential firing patterns of GAD67-GFP expressing neurons.........97

Figure 2.3 Spontaneous postsynaptic currents from GFP expressing neurons............99

Figure 2.4 Putative unitary IPSCs generated by GFP expressing neurons..............100

\section{Chapter 3}

Figure 3.1 Confocal images of GAD67-GFP expressing neurons....................133

Figure 3.2 GAD67-GFP expressing neurons with extensive axonal arborizations......135

Figure 3.3 Computer-assisted tracings of neurons with axonal morphologies...........136

Figure 3.4 Scatterplot matrix of 4 morphometric somatodendritic parameters...........137

Figure 3.5 Classification of GAD67-GFP expressing multipolar neurons..............138

Figure 3.6 Tracings of dendritic trees of representative multipolar neurons.............138

\section{Chapter 4}

Figure 4.1 Gene-gun mediated transfection of mouse cortical slice cultures...........175

Figure 4.2 GAD67-GFP neurons immunopositive for GABAergic markers............176

Figure 4.3 Comparison between GAD67-GFP fluorescence and biocytin labeling......177

Figure 4.4 Dendritic growth of GAD67-GFP expressing neurons in control medium...178

Figure 4.5 BDNF enhanced dendritic growth in GAD67-GFP expressing neurons......180

Figure 4.6 High $\mathrm{KCl}$ enhanced dendritic growth in GAD67-GFP expressing neurons.. 182

Figure 4.7 Effects of all tested treatments on dendritic growth and branching..........183

Figure 4.8 Sholl analysis of change in average total dendritic length (TDL) ...........184 


\section{List of Abbreviations}

$\begin{array}{ll}\text { ACSF } & \text { artificial cerebrospinal fluid } \\ \text { AHP } & \text { after hyperpolarization } \\ \text { AMPA } & \text { alpha-amino-3-hydroxy-5-methyl-4-isoxazolepropionate } \\ \text { BDNF } & \text { brain derived neurotrophic factor } \\ \text { BSNP } & \text { burst spiking nonpyramidal (cells) } \\ \text { CB } & \text { calbindin } \\ \text { CCK } & \text { cholecystokinin } \\ \text { CMV } & \text { cytomegalovirus } \\ \text { CNQX } & \text { 6-cyano-7-nitroquinoxaline-2,3-dione } \\ \text { CNS } & \text { central nervous system } \\ \text { CR } & \text { calretinin } \\ \text { CREB } & \text { Ca2+/cAMP responsive element binding protein } \\ \text { DIV } & \text { days in vitro } \\ \text { EP } & \text { equivalent postnatal day } \\ \text { FS } & \text { fast spiking } \\ \text { GABA } & \text { gamma-aminobutyric acid } \\ \text { GAD } & \text { glutamic acid decarboxylase } \\ \text { GFP } & \text { green fluorescent protein } \\ \text { IOP } & \text { index of polarization } \\ \text { IPSC } & \text { inhibitory postsynaptic current } \\ \text { IPSP } & \text { inhibitory postsynaptic potential } \\ \text { IS } & \text { irregular spiking (cells) } \\ \text { LS } & \text { late spiking (cells) } \\ \text { LTP } & \text { long-term potentiation } \\ \text { NGF } & \text { nerve growth factor } \\ \text { NMDA } & \text { N-methyl-D- aspartate } \\ \text { NPY } & \text { neuropeptide Y } \\ \text { NT3 } & \text { neurotrophin-3 } \\ \text { NT4/5 } & \text { neurotrophin-4/5 } \\ \text { PNS } & \text { peripheral nervous system } \\ \text { PSC } & \text { postsynaptic current } \\ \text { PTP } & \text { post-tetanic potentiation } \\ \text { PV } & \text { parvalbumin } \\ \text { RGC } & \text { retinal ganglion cell } \\ \text { RSNP } & \text { regular spiking nonpyramidal (cells) } \\ \text { RT-PCR } & \text { reverse transcription polymerase chain reaction } \\ \text { SOM } & \text { somatostatin } \\ \text { TDBP } & \text { total dendritic branch points } \\ \text { TDL } & \text { total dendritic length } \\ \text { Trk } & \text { tyrosine kinase receptor } \\ \text { TTX } & \text { tetrodotoxin } \\ \text { VIP } & \text { vasoactive intestinal polypeptide } \\ & \end{array}$




\title{
Chapter One
}

\author{
Introduction
}




\section{Literature Review}

\section{A. GABAergic interneurons in the cerebral cortex}

\section{Physiological functions of GABAergic cortical interneurons}

GABAergic interneurons are a class of neurons that synthesize and utilize $\gamma$ aminobutyric acid (GABA) as a neurotransmitter. Although they account for only 15$25 \%$ of the total number of neurons in the neocortex (Hendry et al., 1987; Ren et al., 1992; Micheva and Beaulieu, 1995c), cortical GABAergic neurons have very important roles in the development and function of the cerebral cortex, including: (1) restricting the general excitability of the cortex through feedback and feedforward inhibition, thus preventing the initiation and spread of epileptiform activity (Connors et al., 1988; Avoli et al., 1997; Treiman, 2001); (2) restricting and shaping receptive fields in the sensory cortex (Sillito, 1975; Sillito and Kemp, 1983; Hicks and Dykes, 1983; Dykes, 1997). (3) acting as pacemakers for the synchronized processing of information (Avoli, 1996; Bland and Oddie, 2001); and (4) releasing GABA, which may function as a neurotrophic factor during development by promoting neuronal precursor proliferation, neurite growth, synaptogenesis and expression of GABA receptors and certain other proteins (Barker et al., 1998; Lauder et al., 1998). All of these functions are exerted through the release of GABA, which activates $\mathrm{GABA}_{A}$ or $\mathrm{GABA}_{\mathrm{B}}$ receptors. Both $\mathrm{GABA}_{\mathrm{A}}$ and $\mathrm{GABA}_{\mathrm{B}}$ receptors play critical roles in cortical inhibition, but their mechanisms of action and effects are quite different. The $\mathrm{GABA}_{\mathrm{A}}$ receptor is a ligand-gated chloride channel located on the postsynaptic membrane (Caruncho et al., 1993; Somogyi et al., 1996). In mature neurons, $\mathrm{GABA}_{\mathrm{A}}$ receptor activation causes hyperpolarization of postsynaptic 
neurons by an outward current through an increase in chloride conductance (Soltesz and Mody, 1994). However, in neonatal cortex, GABA depolarizes postsynaptic neurons by inducing an inward current at resting membrane potentials (Agmon et al., 1996, Owens et al 1996), presumably owing to a high intracellular chloride concentration maintained by furosemide-sensitive Cl- transport (Ikeda et al., 1997). In contrast, $\mathrm{GABA}_{\mathrm{B}}$ receptors are located on both presynaptic and postsynaptic membranes. They are metabotropic, i.e. they exert their control on neuronal excitability via coupling to G-proteins, and their activation results in hyperpolarization of the postsynaptic neuron due to opening of potassium channels. $\mathrm{GABA}_{\mathrm{B}}$ receptor mediated, potassium dependent IPSPs have been recorded in a variety of CNS regions, including the neocortex, hippocampus and thalamus (Newberry and Nicoll, 1985; Connors et al., 1988; McCormick, 1989; Misgeld et al., 1995; van Brederode and Spain, 1995). In addition to their postsynaptic action, $\mathrm{GABA}_{\mathrm{B}}$ receptors reduce transmitter release by affecting calcium channels located on presynaptic terminals (Scholz and Miller, 1991; Doze et al., 1995; Guyon and Leresche, 1995).

\subsection{Mediating cortical inhibition}

The normal functioning of the cerebral cortex critically depends on the balance between excitatory and inhibitory mechanisms. GABA released by GABAergic interneurons plays a key role in controlling cortical excitability and preventing the network from firing synchronous paroxysmal discharges (Connors et al., 1988). Many observations suggest that a long-lasting decrease in inhibition underlies epileptiform activity in the hippocampus (Kapur et al., 1989; Avoli et al., 1995; Isokawa, 1996; 
Mangan and Lothman, 1996). Alterations in one or more components of the GABAergic system might be sufficient to cause epileptiform discharges or to facilitate the generation of epileptiform activity (Roberts and Ribak, 1986; Olsen et al., 1992). Many types of epileptic disorders are associated with morphological (Sloper et al., 1980; Roberts and Ribak, 1986; Sloviter, 1987), metabolic (Kamphuis et al., 1989; Janjua et al., 1991) and functional (Bekenstein and Lothman, 1993) changes in the GABAergic system. For example, the blockade of $\mathrm{GABA}_{\mathrm{A}}$ receptors in hippocampal or neocortical slices by selective antagonists results in epileptiform events (Gutnick et al., 1982), and loss of excitatory input to inhibitory cells from damaged CA3 pyramidal cells can result in epilepsy (dormant basket cell hypothesis) (Sloviter, 1991; Bekenstein and Lothman, 1993). Although $\mathrm{GABA}_{\mathrm{A}}$ receptors seem to play a major role in the prevention of seizure activity, as has been extensively explored, participation of $\mathrm{GABA}_{\mathrm{B}}$ receptors in both inducing (Bernasconi et al., 1992; Snead, 1992) and preventing (Badran et al., 1997; (Vergnes et al., 1997) different seizures has also been proposed. In a model of chronic temporal lobe epilepsy, Mangan and Lothman (1996) describe the dysfunction of both pre- and postsynaptic $\mathrm{GABA}_{\mathrm{B}}$ receptor mediated processes (Mangan and Lothman, 1996). Furthermore, $\mathrm{GABA}_{\mathrm{B}}$-receptor antagonists prolong paroxysmal depolarizing shifts induced by $\mathrm{GABA}_{\mathrm{A}}$ receptor antagonists in hippocampal (Karlsson et al., 1992; Scanziani et al., 1994) and neocortical (McCormick, 1989) pyramidal cells.

\subsection{Restricting receptive fields}

One important consequence of GABAergic inhibition is to restrict receptive fields (RFs) of cortical neurons in sensory neocortex, making them appear smaller than the sum 
of all their excitatory inputs. Several groups have demonstrated this effect in rat, cat, monkey and raccoon by using microiontophoresis to deliver $\mathrm{GABA}_{\mathrm{A}}$ receptor antagonists such as picrotoxin and bicuculline directly onto neurons in the somatosensory (Dykes et al., 1984; Hicks and Dykes, 1983; Alloway and Burton, 1991; Tremere et al., 2001) and visual cortex (Sillito, 1975; Sillito and Kemp, 1983; Wang et al., 2002). A similar effect has been demonstrated also in subcortical neurons (Kulesza, 2002). In general, these studies found that the size of the neuronal receptive fields in sensory cortical areas expands markedly when GABAA receptors are blocked. The magnitude of this receptive field enlargement is related to the layer of cortex in which the neuron is located, with greater expansion observed for superficial neurons than for those below layer IV, indicating a greater GABAergic control over receptive field size in supragranular neurons. In contrast to the effect of $\mathrm{GABA}_{\mathrm{A}}$ receptor antagonists, glutamate administration alters the threshold for all inputs without eliciting significant changes in receptive field size (Hicks and Dykes, 1983; Dykes et al., 1984; Alloway et al., 1989), indicating that the increased receptive field size with $\mathrm{GABA}_{\mathrm{A}}$ receptor antagonists is due to a removal of inhibition rather than to non-specific lowering of thresholds for all inputs. Response latency is significantly longer for responses elicited from the expanded territory compared to those elicited from within the original receptive field, suggesting that receptive field expansion might be mediated by multisynaptic intracortical connections (Alloway and Burton, 1991). Although $\mathrm{GABA}_{\mathrm{A}}$ receptors play a major role in mediating this effect, $\mathrm{GABA}_{\mathrm{B}}$ receptors also participate in determining receptive field dimensions (Kaneko and Hicks, 1988; Kyriazi et al., 1996). 


\subsection{Synchronization of neuronal activity}

Synchronized firing of populations of neurons gives rise to "oscillations" in the brain: regularly occurring waveforms of similar shape and duration. Oscillations occur in diverse brain structures over a range of frequencies $(<1$ to $>200 \mathrm{~Hz})$ and in distinct behavioral states such as perception, movement initiation, memory, and sleep (Buzsaki and Chrobak, 1995; Singer and Gray, 1995). Overall, fast oscillations at beta $(12-30 \mathrm{~Hz})$ and gamma $(30-80 \mathrm{~Hz})$ frequencies are relevant to cognition, whereas slow oscillations of $\leq 1-4 \mathrm{~Hz}$ dominate during deep sleep (Steriade et al., 1993) or some epileptiform activities (Reiher et al., 1989; Gambardella et al., 1995; Normand et al., 1995).

Originating from principal neurons in the cortex, glutamatergic synaptic excitation via the AMPA type receptor usually desynchronizes, rather than synchronizes, repetitive spike firings of mutually coupled neurons (Hansel et al., 1995). Therefore, synchronizing mechanisms depend at least in part on the ability of populations of GABAergic neurons, such as fast-spiking interneurons (Buzsaki and Eidelberg, 1983; Lytton and Sejnowski, 1991), to entrain the firing of pyramidal cell populations (Cobb et al., 1995; Whittington et al., 1995; Whittington et al., 2000). Morphologically, many types of GABAergic interneurons have extensive axonal arborizations and heavy interconnections, forming distinct networks, which form the structural basis for generating coherent rhythms (Buzsaki and Chrobak, 1995; Freund and Buzsaki, 1996), and imposing synchronized inhibition onto a population of principal neurons in the local assembly (Buhl et al., 1994; Cobb et al., 1995). In the hippocampus and neocortex, when AMPA and NMDA receptor-mediated synaptic transmissions is blocked, excitation of GABAergic interneurons by metabotropic glutamate receptors results in $\mathrm{GABA}_{\mathrm{A}}$ 
receptor-dependent gamma oscillations (20-70 Hz) (Whittington et al., 1995; Jefferys et al., 1996). The frequency of these oscillations is directly influenced by the decay kinetics of $\mathrm{GABA}_{\mathrm{A}}$-mediated synaptic currents, supporting the concept that networks with reciprocal inhibition can produce synchronized activities (Traub et al., 1996; Wang and Buzsaki, 1996). Intracellular recordings show a post-tetanic depolarization that drives interneuron network activity to produce a gamma oscillation consisting of trains of $\mathrm{GABA}_{\mathrm{A}}$ receptor-mediated inhibitory synaptic potentials (Traub et al., 1999). This synaptic inhibition-based gamma oscillation entrains and synchronizes action potential generation in pyramidal cells, producing population spikes at gamma frequencies. This can be demonstrated by observing the effects of GABAergic modulators on IPSP trains or by the observation of population spike frequencies in field recordings (Faulkner et al., 1998, 1999). The IPSPs were assumed to originate from the firing activities of fastspiking interneurons synchronized by their interconnections. In the behaving rat, physiologically identified interneurons were shown to fire spikes in the gamma frequency range and phase-lock to the local field waves (Bragin et al., 1995). Results of computer simulations provide further evidence that gamma oscillations are dependent on synaptic inhibition between interneurons, and from interneurons to pyramidal cells (Whittington et al., 1995; Traub et al., 1996). It was also shown that slow oscillations of $\leq 5 \mathrm{~Hz}$ originate from a GABAergic interneuronal network that interacts through reciprocal inhibition mediated by $\mathrm{GABA}_{\mathrm{A}}$ receptors and gap junctions (Cobb et al., 1995).

Gap junctions commonly exist between cortical interneurons and provide for electrotonic coupling between subtypes of interneurons (Katsumaru et al., 1988; Deans et al., 2001; Priest et al., 2001). In recent years, more and more evidence shows that gap 
junctions contribute to the synchronization of inhibition. Studies of electrically coupled pairs of cortical GABAergic interneurons have shown that entraining occurs if both cells are electrically coupled (Galarreta and Hestrin, 1999; Gibson et al., 1999) or if both cells are electrically and chemically coupled (Tamas et al., 2000). Gap junctions can enhance the synchronization of IPSP-mediated gamma oscillations in pharmacologically isolated interneuron networks (Yang and Michelson, 2001), and synchronize neocortical lowthreshold spiking (LTS) interneurons in a 3-6 Hz rhythm, which persists when ionotropic glutamate and $\mathrm{GABA}_{\mathrm{A}}$ receptors are blocked (Beierlein et al., 2000). Knockout of the gap junction protein connexin 36 results in weaker and more spatially restricted synchrony of rhythmic inhibitory potentials elicited by a metabotropic glutamate receptor agonist (Deans et al., 2001).

\subsection{Neurotrophic effects}

In addition to serving as an inhibitory neurotransmitter in mature neurons, GABA released from GABAergic neurons also functions as a neurotrophic factor during early development. Many of the neurotrophic effects of GABA are thought to occur during the embryonic and early postnatal periods when $\mathrm{GABA}_{\mathrm{A}}$ receptor activation produces membrane depolarization (Cherubini et al., 1991; Berninger et al., 1995; Owens et al., 1996). $\mathrm{GABA}_{\mathrm{A}}$ receptor activation has been shown to promote neuronal precursor proliferation (Fiszman et al., 1999; Haydar et al., 2000) or to inhibit proliferation and promote exit from the mitotic cycle (LoTurco et al., 1995), affect neuronal migration (Behar et al., 1996), promote cell survival (Ikeda et al., 1997), promote neurite growth and differentiation (Spoerri and Wolff, 1981; Perry et al., 1984; Spoerri, 1988; Michler, 
1990; Barbin et al., 1993), influence gene expression (Marty et al., 1996), facilitate synaptogenesis, and enhance the expression of GABA receptors (Madtes and Redburn, 1983; Meier et al., 1984; Messersmith and Redburn, 1993).

The depolarizing action of $\mathrm{GABA}_{\mathrm{A}}$-receptor activation has been shown to open voltage-gated $\mathrm{Ca}^{2+}$ channels, thereby increasing intracellular calcium and initiating intracellular signaling cascades (Yuste and Katz, 1991; LoTurco et al., 1995; Ikeda et al., 1997), supporting the hypothesis that $\mathrm{Ca}^{2+}$-dependent second-messenger pathways may mediate the developmental effects of GABA (Ben-Ari et al., 1997). For example, GABA-induced depolarization in embryonic hippocampal cultures has been shown to activate L-type voltage-gated $\mathrm{Ca}^{2+}$ channels and upregulate BDNF and c-fos expression (Berninger et al., 1995). The mechanism may involve downstream activation of the transcription factor CREB because a pathway involving depolarization, voltagedependent $\mathrm{Ca}^{2+}$ increase, and activation of CREB has been shown to induce BDNF expression (Shieh et al., 1998; Tao et al., 1998). The depolarizing effect of GABA may function in concert with NMDA-receptor activation to facilitate synaptogenesis and synaptic consolidation. NMDA receptors underlie the robust synaptic and developmental plasticity seen in immature animals (Neuhoff et al., 1999; Chevaleyre et al., 2002). Because GABAergic synapses in the cerebral cortex develop early and have depolarizing effects, GABA can relieve the $\mathrm{Mg}^{2+}$ block of the NMDA receptors in the immature brain, allowing calcium influx. The increased intracellular calcium may trigger a variety of processes, such as neuronal growth, synapse formation and stabilization. 


\section{Pyramidal neurons and interneurons in the cerebral cortex}

In the cerebral cortex, there are mainly two types of neurons based on their morphology and functions: the majority are glutamatergic, excitatory neurons (mostly pyramidal), and the rest are GABAergic nonpyramidal interneurons. Pyramidal neurons exist in all layers of the neocortex except layer I. They share common morphological features including a pyramid-shaped soma, a long apical dendrite extending towards the pial surface, and several shorter basal dendrites growing in all directions. Their axon usually emerges from the basal side of the soma and extends downward to the white matter, to project to other cortical areas or subcortical targets, while also giving rise to several upward branches (termed collaterals) that terminate locally. Most pyramidal neurons fire action potentials with a marked frequency accommodation and are termed "regular spiking" (RS) (Connors and Gutnick, 1990). They make asymmetric synapses, often on dendritic spines, and exert an excitatory effect by releasing the neurotransmitter glutamate.

In contrast to pyramidal cells, neocortical nonpyramidal neurons are generally inhibitory, GABAergic interneurons, except for spiny stellate neurons in layer IV of some sensory areas, and a small percentage of the bipolar neuron population, which are excitatory ( Peters and Kimerer, 1981; Houser et al., 1983; Meinecke and Peters, 1987). GABAergic interneurons account for about $15-25 \%$ of the total population of neocortical neurons (Hendry et al., 1987). These neurons often have smooth or sparsely spiny dendrites, and diverse dendritic morphologies. Their classification into bipolar, bitufted, different sized multipolar (stellate) and horizontal neurons is mainly based on their dendritic trees (Feldman and Peters, 1978; see Section 4 for other classifications). The 
axons of GABAergic neurons almost always terminate in the immediate vicinity of the parent neuron, and make symmetric synapses with various postsynaptic targets including somata, dendrites and initial segments of axons of other neurons, or even on their own somata and dendrites (autapses; Peters and Proskauer, 1980; Thomson et al., 1996). GABAergic interneurons exist in all layers of the cerebral cortex. Most of layer I neurons are GABAergic, including Cajal-Retzius neurons (Imamoto et al., 1994). The supragranular layers have the greatest density of GABA immunopositive neurons whereas GABAergic punctate profiles are more numerous in layer IV. The largest GABAergic somata are located in layers III and V, while layer VI has the most heterogeneous population of GABAergic neurons (Meinecke and Peters, 1987; Chmielowska et al., 1988; Prieto et al., 1994).

\section{GAD67 and GAD65}

GABA is synthesized from glutamate by the enzyme glutamic acid decarboxylase (GAD). GAD has two isoforms, encoded by distinct genes, one with a molecular weight of $65 \mathrm{kDa}(\mathrm{GAD} 65)$ and the other of $67 \mathrm{kDa}(\mathrm{GAD} 67)$. Although the mRNAs of GAD67 and GAD65 have been detected in excitatory pyramidal neurons (Cao et al., 1996), the proteins of both enzymes are localized only in GABAergic neurons (Rimvall and Martin, 1991; Martin and Rimvall, 1993). The brain distributions of these isoforms are nearly identical, but their subcellular localization and affinities for the cofactor pyridoxal phosphate are different, reflecting different regulatory mechanisms and physiological functions. GAD67 is a cytosolic enzyme that is widely distributed throughout the neuron including the soma, dendrites and axon. It exists in an active holoenzyme form saturated 
with its cofactor pyridoxal phosphate. Therefore, GAD67 functions in synthesizing GABA to meet basal functional requirements for inhibitory neurotransmission (Kaufman et al., 1991), and is regulated at the transcriptional level through the production of new enzyme protein. In the cerebral cortex of the newborn GAD67 knockout mouse, GAD activities and GABA content were reduced to $20 \%$ and $7 \%$ of the normal level, respectively, supporting the essential role of GAD67 in maintaining basal GABA concentration in interneurons (Asada et al., 1997). In contrast, GAD65 is primarily located in axon terminals and reversibly anchored to the membrane of synaptic vesicles that store and secrete GABA (Kaufman et al., 1991; Esclapez et al., 1994). Only about half of GAD65 exists as active holoenzyme in combination with its cofactor pyridoxal phosphate. Since the interaction of GAD with the cofactor pyridoxal phosphate is a major factor in the short-term regulation of GAD activity, GAD65 may provide reserve pools of GABA for maintaining the level of inhibitory neurotransmission and function at times of increased synaptic activity. This idea is supported by the fact that knockout of GAD65 does not affect brain GABA content or animal behavior, but increases the animals' susceptibility to seizures (Kash et al., 1997). In CA1, deletion of the GAD65 gene does not affect basal GABAergic transmission, but it compromises the ability to sustain repetitive activation (Tian et al., 1999). Similarly, in the visual cortex, the steadystate response to prolonged stimulation is clearly reduced in GAD65 knockout mice, but the magnitude of the maximal IPSC is not affected by the mutation (Choi et al., 2002). Thus, the availability of GAD65 appears to be a limiting factor for the efficacy of transmission at high frequencies but not the potency or number of GABAergic inputs in the cortex (Kash et al., 1997; Hensch et al., 1998). 
The coding region of the GAD67 gene comprises 18 exons spanning $42 \mathrm{~kb}$ of genomic DNA, with Exon 1 and 64 bp of exon 2 defining the 5' untranslated region of GAD67 mRNA. Neuron-specific and cell type-specific expression of GAD67 is regulated by a combination of restrictive silencers and spatial enhancers in the 5' region of the GAD67 gene. The first intron is necessary for GAD67 expression in postnatal and adult brain (Szabo et al., 1996; Katarova et al., 1998). In this study, we used the GAD67 promoter, including the first intron and first two exons, to drive the transcription of green fluorescent protein (GFP). Because GAD67 is exclusively expressed in GABAergic neurons and is constitutively active, the expression of GFP was expected to be limited to GABAergic neurons and to be maintained at a constant level.

\section{Classification of GABAergic cortical interneurons}

Cortical GABAergic neurons have been identified and visualized by different techniques, ranging from autoradiographic localization of $\left({ }^{3} \mathrm{H}\right)$ GABA following its uptake, to GAD and GABA immunocytochemistry. While all GABAergic neurons share several common features such as synthesizing GAD and GABA, being non-pyramidal in shape, lacking axonal projections to subcortical or other cortical areas, and forming symmetric synapses, GABAergic neurons are heterogeneous in their morphological, neurochemical and electrophysiological characteristics. This diversity makes it difficult to classify interneurons into clear morphological or functional subgroups, which greatly hinders our further understanding of their physiological functions in the cortical neuronal network. 


\subsection{Morphological types}

Although there is not a universally accepted morphological classification of the cortical GABAergic neurons, some well-characterized types of GABAergic neurons are widely recognized based on dendritic and axonal morphologies together with ultrastructural features of their postsynaptic targets and their patterns of synapses (Figures 1.1 and 1.2).

1). Basket cells are multipolar cells located in different layers of the cortex with long aspiny dendrites and ascending axons. The unique characteristics of basket cells is that their axon terminals end in baskets of symmetric axosomatic synapses on the somata of pyramidal cells and spiny stellate cells, providing powerful perisomatic inhibitory input to these neurons. Based on their somata sizes, basket cells can be further divided into large, medium and small basket cells, each having distinct laminar location and morphological characteristics (DeFelipe et al., 1986; Kisvarday et al., 1993; Kawaguchi, 1995).

2). Chandelier cells are located in layer II and III of the neocortex, and are characterized by their chandelier-like, vertically oriented strings of axonal boutons, which form axo-axonic synapses with the axon initial segments of pyramidal neurons in layer II and III, to "veto" the generation of action potentials. Their sparsely spinous dendritic trees are usually bitufted and vertically oriented (Peters et al., 1982; Kisvarday et al., 1986; DeFelipe et al., 1989). These neurons express the calcium binding protein parvalbumin (PV; Kawaguchi, 1995).

3). Double bouquet cells are small to medium sized multipolar cells located in layer II/III of the primate cortex. They have long vertically oriented axons with the 
ascending branches spreading through layer II and I, and the descending branches reaching layer $\mathrm{V}$ or even the white matter. These neurons form axodendritic synapses with dendritic shafts or spines of pyramidal cells. Double bouquet cells express calbindin (Somogyi and Cowey, 1981; DeFelipe et al., 1989; Lund and Lewis, 1993).

4). Martinotti cells are found in layers V and VI and have multipolar or bitufted dendritic trees. Their typical feature is their ascending axon, which emerges from a primary dendrite or from the soma and forms a terminal plexus in layer $\mathrm{V}$ and in layer II/III. Some collaterals ascend to layer I and branch horizontally within it. These neurons express somatostatin or calbindin (Wahle, 1993; Kawaguchi and Kubota, 1996).

5). Neurogliaform cells are small aspiny cells located in layers I, II/III and IV. These cells have short dendrites and a very dense local axonal arborization. They express calbindin and are of the late-spiking (LS) physiological subtype (see below; Hedlich and Werner, 1986; Kawaguchi, 1995; Hestrin and Armstrong, 1996).

6). Bipolar cells are mainly located in layer II/III and have ascending and descending aspiny vertically-oriented dendrites arising from the upper and lower poles of small ovoid or fusiform somata. Their axons generally originate from the soma or from a primary dendrite and also follow a vertical trajectory to descend toward layers V/VI (Meinecke and Peters, 1987; Peters, 1990). The majorities of vasoactive intestinal polypeptide (VIP) expressing neurons are bipolar cells (Connor and Peters, 1984; Porter et al., 1998) 


\subsection{Neurochemical types}

By using immunohistochemistry and RT-PCR techniques, it was found that the majority of GABAergic cortical neurons express one or more of a subset of three well studied calcium binding proteins: calbindin (CB), calretinin (CR) and parvalbumin (PV), and four neuropeptides: somatostatin (SOM), neuropeptide Y (NPY), cholecystokinin $(\mathrm{CCK})$ and vasoactive intestinal polypeptide (VIP). With the exception of calbindin and calretinin expression in some cortical pyramidal neurons (Alcantara and Ferrer, 1995; Fonseca et al., 1995), calcium-binding proteins and neuropeptides are almost exclusively confined within the cerebral cortex to GABAergic interneurons. Of the three calcium binding proteins, PV has the highest rate of expression, followed by $\mathrm{CB}$ and $\mathrm{CR}$, each with a layer specific distribution (Kubota et al., 1994). CR and CB-positive neurons are most dense in layer II/III, while PV expression is highest in neurons of the middle cortical layers (Lund and Lewis, 1993; Gabbott et al., 1997). Co-expression of two calcium binding proteins, such as $\mathrm{CB}+\mathrm{PV}$ or $\mathrm{CB}+\mathrm{CR}$ in a single interneuron, is also detected frequently, but co-expression of PV and CR has never been observed (Kubota et al., 1994; Celio, 1990; Alcantara et al., 1996; Gonchar and Burkhalter, 1997). The majority of nonpyramidal GABAergic neurons also express one or more neuropeptides, with SOM being the most frequently detected neuropeptide in all cortical layers (ranging from 26 to $45 \%$ of interneurons depending on the cortical layer; Kubota et al., 1994). The majority of NPY cells are in layers II/III (Kubota et al., 1994; Alcantara et al., 1996). Among the four neuropeptides, SOM is often colocalized with NPY, and VIP with CCK (Kubota and Kawaguchi, 1997). SOM is frequently found in CB-containing cells, while VIP containing cells are often CR positive (Kawaguchi and Kubota, 1997). 
The expression of the above molecular markers can be correlated with distinct morphological or physiological GABAergic cell types. Thus, CB and CR appears to be present in double-bouquet cells, CB in neurogliaform cells, Martinotti cells and doublebouquet cells, PV in fast spiking chandelier and basket cells (Kawaguchi, 1993; Conde et al., 1994), VIP or NPY preferentially in bipolar cells (Connor and Peters, 1984; Magistretti et al., 1984; Porter et al., 1998), and both CR and CB in Cajal-Retzius neurons of layer I (Conde et al., 1994). Nevertheless, we often find that expression of neurochemical markers does not define a unique functional subtype of GABAergic interneurons (Kubota et al., 1994;Cauli et al., 1997).

The proportion and distribution of the calcium binding proteins and neuropeptides in cortical GABAergic neurons undergoes considerable change during postnatal maturation. Lineage analysis revealed that the neurochemical phenotypes are not inherited by clonal relation, but are induced and modified by environmental and epigenetic cues (Mione et al., 1994). In fact, many of the neurochemical molecules are transiently expressed during early development, and neurons may undergo phenotypic changes later on (Parnavelas and Cavanagh, 1988). For example, the percentages of NPY, SOM and CCK neurons increase postnatally to a peak during the first three postnatal weeks, before decreasing to adult values (Papadopoulos et al., 1993; Vogt Weisenhorn et al., 1998; Gao et al., 2000). The number of NPY neurons changes during postnatal development in an area- and layer-specific manner in the visual cortex (Obst and Wahle, 1995). CB-expressing interneurons are abundant by the second postnatal week and decrease concurrently with the onset of PV expression. There is a transient colocalization of $\mathrm{CB}$ and $\mathrm{PV}$, suggesting a phenotypic shift from $\mathrm{CB}$ to $\mathrm{PV}$ expression 
(Alcantara et al., 1993; 1996).

It is not quite clear what is the function of calcium binding proteins and neuropeptides in cortical GABAergic interneurons. It seems that we are familiar with them more as useful molecular markers of neuronal subpopulations than with their physiological function. Evidence from gene knockout and overexpression studies shows that calcium binding proteins may play important roles in controlling internal calcium homeostasis and regulating synaptic plasticity, while neuropeptides are involved in regulation of the excitability of cortical networks and in neuroprotection (Erickson et al., 1996; McQuiston and Colmers, 1996). For example, CB and CR have been shown to control calcium homeostasis in neurons by buffering calcium and regulating calcium channel activity (Lledo et al., 1992). Overexpression of CB results in modifications of the time course and spatial spreading of intracellular calcium transients (Mattson et al., 1991; Chard et al., 1995). Overexpression of CB in cultured hippocampal neurons suppresses posttetanic potentiation (PTP), probably by increasing the calcium buffering capacity to interfere with the residual calcium accumulation responsible for enhanced transmitter release during PTP (Chard et al., 1995). A similar mechanism has been postulated to explain the absence of long-term potentiation (LTP) induction in the dentate gyrus of $\mathrm{CR}$ knockout mice. In the absence of $\mathrm{CR}$, the decreased $\mathrm{Ca}^{2+}$ buffering capacity in presynaptic terminals results in enhanced release of GABA, which further causes the inhibition of LTP (Schurmans et al., 1997). PV is a slow $\mathrm{Ca}^{2+}$ buffer that may affect the amplitude and time course of intracellular $\mathrm{Ca}^{2+}$ transients in terminals after an action potential. In PV knockout mice, paired-pulse facilitation is observed instead of pairedpulse depression, which occurs in the GABAergic synapses of normal mice. Thus, PV 
potently modulates short-term synaptic plasticity by acting as a slow calcium buffer (Caillard et al., 2000). VIP can modulate the excitability of cortical neurons (Haas and Gahwiler, 1992), and enhance neuronal responses to sensory inputs in the visual cortex (Murphy et al., 1993). In addition, VIP is involved in the regulation of cerebral blood flow and energy supply, because it causes vasodilatation of pial blood vessels (McCulloch and Edvinsson, 1980; Yaksh et al., 1987), and some VIP-containing terminals are closely associated with intracortical blood vessels (Eckenstein and Baughman, 1984; Chedotal et al., 1994; Chedotal et al., 1994). SOM affects electrophysiological properties of neurons, modulates neurotransmission and hyperpolarizes hippocampal neurons during seizures (Vezzani and Hoyer, 1999). It inhibits the generation of epileptiform activity by specifically reducing recurrent excitation between CA3 neurons in the hippocampus, possibly through a presynaptic mechanism (Tallent and Siggins, 1999). NPY acts presynaptically to inhibit glutamatergic inputs on pyramidal neurons (McQuiston and Colmers, 1996); it is probably involved in preventing seizure activity in the adult brain (Gall et al., 1990; Erickson et al., 1996).

\subsection{Electrophysiological types}

Electrophysiological recordings from cortical GABAergic neurons have revealed diverse firing patterns of action potentials, some of which are unique to GABAergic neurons and closely related to their physiological functions, while others are also seen in cortical pyramidal neurons (Refer to Figure 1.1). 
Fast spiking neurons (FS) are a unique class of cortical GABAergic interneurons representing about one third (or more) of the total interneuron population. They have low input resistances and fire high frequency spikes of short duration without accommodation. Morphologically, these neurons correspond to basket and chandelier cells (Connors and Gutnick, 1990; Kawaguchi, 1995). A majority of FS cells express PV (Kawaguchi, 1993; Kawaguchi, 1995; Kawaguchi and Kubota, 1996). Therefore, a relatively homogeneous population of interneurons can be defined based on the association of firing pattern and PV expression. However, $\mathrm{CB}$ and/or neuropeptides are also expressed in this group of neurons, and a variable subunit composition of AMPA receptors has been found in FS cells by single-cell RT-PCR (Lambolez et al., 1996), indicating some heterogeneity in this population of GABAergic neurons.

Another large group of GABAergic interneurons are called regular spiking nonpyramidal (RSNP) cells because they fire action potentials with a longer duration, moderate accommodation, and a smaller after hyperpolarization (AHP) than those in FS cells, similar to pyramidal neurons. However, RSNP and pyramidal neurons can be differentiated by their intrinsic firing patterns. Pyramidal cells fire slower action potentials with stronger accommodation, smaller AHP and slower recovery of AHP than RSNP. Additionally, the second action potential of a spike train evoked in pyramidal cells is always slower than the first. This increase in action potential duration is not observed or is small in most RSNP cells (Connors and Gutnick, 1990; Kawaguchi, 1993; Cauli et al., 1997). The morphology of these neurons is heterogeneous; they include double bouquet cells, bipolar cells and some multipolar cells (Kawaguchi, 1995). RSNP cells also exhibit a large diversity in the expression pattern of neurochemical markers. 
$\mathrm{CB}$ is detected more frequently than $\mathrm{CR}$ and $\mathrm{PV}$. With regard to neuropeptide expression, SOM is the most frequently expressed, followed by NPY, CCK and VIP. Some RSNP cells co-express two or more calcium binding proteins or neuropeptides, with the CB and SOM having the highest occurrence (Cauli et al., 1997). Nevertheless, calcium binding proteins and neuropeptides in RSNP cells seem to be randomly associated, and therefore this type of association probably does not define homogeneous subpopulations of RSNP cells.

Irregular spiking (IS) neurons are characterized by their irregular firing behavior. Their firing patterns consist of an initial burst followed by intermittent action potentials at an irregular frequency. Higher stimulation intensity mainly results in an increase in the firing frequency within the initial burst. These neurons are a small population located in layers II/III and V of the neocortex. They are bipolar in morphology and co-express VIP, CR (Magistretti et al., 1984; Peters and Harriman, 1988; Kawaguchi, 1995; Kawaguchi and Kubota, 1996) and choline acetyltransferase (ChAT) mRNAs (Porter et al., 1998). These common features support the view that IS cells form a relatively homogeneous cell population that may serve a specific physiological function in the neocortex (Porter et al., 1998).

There are other physiological subtypes described. Burst spiking nonpyramidal $(B S N P)$ cells exhibit bursting activity (two or more spikes riding on a slow depolarizing hump) from hyperpolarized potentials and contain SOM, CB or VIP; their morphological types include Martinotti cells and double bouquet cells (Kawaguchi, 1995). Late spiking (LS) cells exhibit slowly developing ramp depolarizations near threshold. They exhibit 
neurogliaform morphology (Kawaguchi, 1995), and express CB, CR or PV ( Lund and Lewis, 1993; Gabbott et al., 1997).

It has also been proposed that there are two populations of inhibitory neurons that separately give rise to fast $\mathrm{GABA}_{\mathrm{A}}$ or slow $\mathrm{GABA}_{\mathrm{B}}$ responses, since glutamate microapplications onto cortical inhibitory interneurons results in completely separate activation of fast and slow IPSPs (Benardo, 1994). Additional studies suggest that the inhibitory cells that provide for fast and slow inhibition may be further distinguished on the basis of the presynaptic glutamate receptors they possess (Ling and Benardo, 1995).

\section{Development of cortical GABAergic interneurons}

\subsection{Neurogenesis and migration}

The cortical projection (pyramidal) neurons originate in the ventricular zone of the dorsal telencephalon, and migrate radially across the intermediate zone to the cortical plate. In contrast, GABAergic neurons are thought to originate in the subcortical ganglionic eminence of the ventral telencephalon, and follow a tangential migratory route through the intermediate zone into the cerebral cortex (Figure 1.3; Tan et al., 1998; Lavdas et al., 1999). A recent study demonstrates the existence of two distinct lineages of neocortical GABAergic neurons in humans. One lineage represents $65 \%$ of neocortical GABAergic neurons and originates from the ventricular and subventricular zone of the dorsal forebrain; while the other forms around $35 \%$ of the GABAergic neurons and originates from the ganglionic eminence of the ventral forebrain (Letinic et al., 2002). Cortical GABAergic neurons follow the same inside-out migration pattern as pyramidal neurons but become more diffusely distributed after the peak of neurogenesis (Cobas and 
Fairen, 1988; Peduzzi, 1988; Tan et al., 1998). In the ferret visual cortex, the genesis of GABAergic neurons follows an inside-out pattern: GABAergic neurons in the deep layers are the first to be born at embryonic day 20 , followed by outer layer neurons until postnatal day 14 (Peduzzi, 1988). In rodents, GABAergic neurons undergo progressive development after birth: their soma size, and the size and extent of their dendritic and axonal trees increase considerably during the first two postnatal weeks (Parnavelas, 1992).

\subsection{Activity-dependent development}

Cortical GABAergic inhibition exhibits a relatively slow postnatal development (Blue and Parnavelas, 1983; Guo et al., 1997; Luhmann and Prince, 1991). This is proposed to leave a time window for peripheral sensory input to modulate the development of the cortical network (Wolff et al., 1984; Agmon and O'Dowd, 1992; Huang et al., 1999; Rozas et al., 2001), because GABAergic inhibition restricts the induction of synaptic plasticity (Kirkwood and Bear, 1994), possibly by preventing the relieve of the $\mathrm{Mg}^{2+}$ blockade of NMDA receptors. Indeed, cortical GABAergic neurons, especially layer IV interneurons, undergo activity-dependent development, as has been demonstrated by sensory deprivation experiments. For example, sensory deprivation by continuously removing rows of whiskers causes a profound decrease in the number and proportion of GABA-immunopositive synaptic contacts in layer IV of the somatosensory cortex (Micheva and Beaulieu, 1995a). Furthermore, such activity-dependent development occurs only during a postnatal critical period. In the visual cortex, the developmental increase in GABAergic neurotransmission is prevented in animals 
deprived of light since birth but not in animals deprived of light after a period of normal experience (Morales et al., 2002). Similarly, the number of GAD and GABA immunoreactive neurons is also regulated by neuronal activity during development. In both visual and somatosensory cortex, deprivation of peripheral sensory input by removal of one eye or unilateral removal of vibrissae causes a profound decrease in the density of immunoreactive labeling for GAD or GABA (Benevento et al., 1995; Micheva and Beaulieu, 1995b; Micheva and Beaulieu, 1997). These effects seem to result from the competition between afferent input from the intact and sensory deprived sides, not by the absolute level of neuronal activity. This is suggested by the fact that elimination of all geniculo-cortical input by lesioning the lateral geniculate nucleus does not change GABA expression in the visual cortex, and neither binocular deprivation nor dark rearing reduces GAD or GABA expression in the visual cortex (Mower et al., 1988; Mower and Guo, 2001). It seems that the decrease in GAD or GABA immunoreactive neurons is not due to neuronal death; rather, it is because GAD or GABA expression decreases to an undetectable level, and this decrease in immunoreactivity is reversible (Micheva and Beaulieu, 1995b; 1997). Taken together, it seems that the expression of GAD and GABA in cortical GABAergic neurons can be reversibly regulated by the level of afferent input during development.

Calcium binding proteins in cortical GABAergic neurons and $\mathrm{GABA}_{\mathrm{A}}$ receptors on postsynaptic neurons are also regulated during development in a layer-specific manner by the level of neuronal activity. Whisker lesion or trimming in rodents results in downregulation of $\mathrm{GABA}_{\mathrm{A}}$ receptors' binding efficacy in the barrel cortex (SkangielKramska et al., 1994; Fuchs and Salazar, 1998). Similarly, monocular deprivation in rats 
results in a dramatic reduction of PV immunoreactivity in the visual cortex contralateral to the deprived eye. This effect is again due to competitive phenomena and not to visual deprivation itself, as it is restricted to the binocular portion of the visual cortex, and neither binocular deprivation, nor dark rearing can induce such an effect (Cellerino et al., 1992). The expression of NPY, SOM and CB is also influenced by afferent innervation in the visual and somatosensory cortices (Antonopoulos et al., 1992; Cellerino et al., 1992; Alcantara et al., 1996; Obst et al., 1998; Obst and Wahle, 1997). The number of SOM-immunoreactive neurons in slices cultured from postnatal hippocampus is tightly regulated by neuronal activity (Marty and Onteniente, 1997). In addition, the postnatal maturation of the expression of neuropeptides such as NPY, SOM and CCK (Cho et al., 1983; Allen et al., 1984; Naus et al., 1988) parallels the postnatal increase of neuronal activity in the hippocampus (Ben-Ari et al., 1997), suggesting a causal relationship between the two processes.

These studies have established a critical role for neuronal activity in regulating the development of the cortical GABAergic system. What are the molecular signals that transduce the level of neuronal activity into structural, neurochemical and physiological alterations in GABAergic inhibition? Recent studies indicate that brain-derived neurotrophic factor (BDNF), a member of the neurotrophin family, is a potential activitydependent regulator of the development of GABAergic neurons. BDNF and its involvement in cortical development in general, and GABAergic development in particular, are discussed in sub-chapter B below. 


\section{B. BDNF involvement in dendritic growth}

\section{BDNF as a neurotrophic factor}

\subsection{Neurotrophins and neurotrophic receptors}

Brain-derived neurotrophic factor (BNDF) is a member of the neurotrophin family of neurotrophic factors (Leibrock et al., 1989). Neurotrophic factors are secretory proteins that exert trophic effects on neurons of the peripheral and central nervous system, promoting their survival, migration and differentiation, and regulating neurite growth and synaptic efficacy both in the developing and mature nervous system (Gotz and Schartl, 1994; Lewin and Barde, 1996; Friedman and Greene, 1999). In mammalian species, the neurotrophin family consists of four structurally related proteins: nerve growth factor (NGF), brain-derived neurotrophic factor (BNDF), neurotrophin-3 (NT3) and neurotrophin-4/5 (NT4/5). All four consist of two identical subunits and share a similar molecular structure (Narhi et al., 1993). Two classes of neurotrophin receptors have been characterized: the high-affinity tyrosine kinase (trk) receptors, with trkA specific for NGF, trkB for BDNF and NT4, and trkC for NT3, and a low-affinity p75 receptor which binds all of these neurotrophins but has an obscure function. The trk receptors were originally cloned from a human colon cancer as an oncogene (MartinZanca et al., 1989; Kaplan et al., 1991). When the neurotrophic factor binds to the trk receptor, it causes dimerization of the trk receptor which leads to phosphorylation of intracellular proteins on tyrosine, serine, and threonine residues. These signals are in turn propagated to other messengers, ultimately leading to the effects on cell survival, migration and differentiation. To date, several trk substrates have been identified. They 
include phospholipase $\mathrm{C}$, phosphatidylinositol-3 kinase (PI3 kinase), Ras GTPase activation protein, adapter protein Shc, and the mitogen-activated protein (MAP) kinase. The activation of these multiple intracellular signaling pathways may account for the diverse effects of neurotrophins (Kaplan et al., 1991; Barbacid, 1994).

The low-affinity p75 receptor, named for its molecular weight of approximately $75 \mathrm{kDa}$, is more abundant than trk receptors, but binds with low affinity to all neurotrophic factors (Sutter et al., 1979). Its biological function is still obscure; it may facilitate trk ligand binding and neurotrophin responses (Davies et al., 1993; Chao, 1994), and initiate intracellular signaling independent of trk receptors to induce neuronal death in neocortical, hippocampal and retinal neurons (Frade et al., 1996; Roux et al., 1999).

The trkB and trkC receptors have truncated forms, which lack the intracellular tyrosine kinase domain (Klein et al., 1990). The truncated trkB receptors may function as inhibitory modulators of neurotrophin responsiveness. They bind BDNF with high affinity, followed by internalization of the ligand (Barbacid, 1994). When coexpressed with the full-length trkB receptor in Xenopus oocytes, they act as dominant negative receptors, inhibiting the BDNF signal by forming nonfunctional heterodimers with the full-length receptors (Eide et al., 1996). Mice overexpressing truncated trkC receptors show severe developmental defects in the peripheral nervous system and in the heart, and die in the first few postnatal days, suggesting that truncated receptors may act to sequester neurotrophin, producing effects similar to the NT3-deficient mouse model (Palko et al., 1999). In summary, the truncated trk receptors may function by sequestering excessive neurotrophins or as naturally occurring dominant negative elements of the full length 
receptor to modulate the availability and binding of neurotrophins (Biffo et al., 1995; Eide et al., 1996; Ninkina et al., 1996; Yacoubian and Lo, 2000).

\subsection{Expression of neurotrophins in the brain}

The localization of mRNAs and proteins for the various neurotrophins has been explored throughout the CNS. NGF expression has been localized to all target regions of basal forebrain cholinergic neurons, including the hippocampal formation, cortex, olfactory bulb (Shelton and Reichardt, 1986; Whittemore et al., 1986; Ernfors et al., 1990; Guthrie and Gall, 1991), basal forebrain (Lauterborn et al., 1991; Lauterborn et al., 1995), hypothalamus and brainstem (Ceccatelli et al., 1991). BDNF seems to be broadly distributed throughout the CNS including the neocortex and hippocampus. In the neocortex, expression of BDNF protein and mRNA is broadly distributed throughout all cortical areas in all layers except layer I, but their expression in layer IV is low (Ernfors et al., 1990; Phillips et al., 1990; Friedman et al., 1991; Ceccatelli et al., 1991; Castren et al., 1995). Only cortical pyramidal neurons express BDNF; cortical interneurons do not express neurotrophic factors (Cellerino et al., 1996; Yan et al., 1997; Gorba and Wahle, 1999). NT3 mRNA is the most narrowly distributed, with high levels of expression restricted to hippocampal CA1 and CA2 stratum pyramidale, the dentate gyrus granule cells, and cerebellar granule cells (Ernfors et al., 1990; Maisonpierre et al., 1990; Ceccatelli et al., 1991) and lower levels of NT-3 mRNA in substantia nigra, midline and intralaminar thalamus, and posterior amygdala (Lauterborn et al., 1994). NT-4/5 expression in the CNS seems to be very low (Timmusk et al., 1993), and its mRNA distribution has not been determined. 


\subsection{Expression of trkB receptors in the brain}

The effects of BDNF are mediated through its high affinity trkB receptor. TrkB mRNA and protein are widely detected on the surface of neuronal somata, axons and dendrites throughout the CNS, including the cerebral cortex, hippocampal formation, amygdala and cerebellar Purkinje cells (Masana et al., 1993; Yan et al., 1997). In the cerebral cortex, trkB receptors are expressed in pyramidal neurons of all cortical layers, with particularly prominent expression in layers III and V (Allendoerfer et al., 1994; Cabelli et al., 1996). Although they do not express neurotrophic factors (including BDNF), most subtypes of cortical interneurons express trkB to different degrees, with a particularly high rate of expression in PV containing interneurons (Cellerino et al., 1996; Rocamora et al., 1996). Specifically, trkB is expressed in about $80 \%$ of the PV containing interneurons, in about $50 \%$ of the $\mathrm{CB}$ immunopositive neurons, and in only $20 \%$ of NPY and SOM immunopositive neurons. Overall, about half of the GABAergic neurons in rat visual cortex and hippocampal CA1 region express trkB mRNA (Gorba and Wahle, 1999).

\section{Developmental and activity-dependent regulation of BDNF and trkB receptor}

\subsection{Developmental regulation of BDNF}

The synthesis and secretion of BDNF is developmentally regulated. In the visual cortex, BDNF mRNA and protein are dynamically regulated during early postnatal development, such that its expression increases specifically at the time of neuronal growth and synaptogenesis (Castren et al., 1992; Ringstedt et al., 1993; Schoups et al., 1995; Rossi et al., 1999; Capsoni et al., 1999; Lein et al., 2000). For example, in layer 4 
of cat visual cortex, BDNF mRNA expression is low initially, and rises to high levels by the end of the critical period for ocular dominance column formation (Lein et al., 2000). The developmental change in BDNF expression seems closely related to the level of afferent input. BDNF mRNA level in rat visual cortex increases during postnatal development and reaches mature levels around the third postnatal week. Dark-rearing from birth results in significantly lower BDNF mRNA expression, but it is reversed by light exposure (Schoups et al., 1995). A similar result is also observed in the somatosensory cortex after sensory deprivation (Singh et al., 1997). On the other hand, the developmental increase in neuronal activity can also reduce the level of BDNF expression in a laminar-specific manner. For example, after eye opening (P14-P15), BDNF mRNA positive neurons decrease significantly in layers IV and V of the rat visual cortex. This change is also triggered by light, since dark-rearing decreases the general levels of BDNF-mRNA, but increases the relative number of BDNF mRNA-positive cells in layers IV and V (Capsoni et al., 1999). In all, the expression of BDNF in the cortex is regulated during development by afferent sensory input.

\subsection{Developmental regulation of trkB receptor}

The developmental regulation of the trkB receptor is quite different from that of BDNF. First, trkB receptor is expressed at birth, with little change during development. However, there is a dramatic change in the ratio of the full-length receptor to the truncated receptors. The full length trkB receptor is expressed highly during early development, then gradually decreases, while the expression of truncated trkB increases dramatically during early development. The developmental shift from full-length to 
truncated trkB corresponds to the critical periods for cell fate determination, cell death and axonal remodeling, suggesting an important role for neurotrophic factors in these events (Allendoerfer et al., 1994; Schoups et al., 1995). Secondly, there is an age-related change in the subcellular localization of trkB receptor. During early development, the trkB receptor is localized mainly on axonal fibers, including the thalamocortical and corticofugal pathways; later in development it has a higher expression on cell bodies and dendritic processes (Cabelli et al., 1996). This developmental change of trkB localization is consistent with a role for BDNF as a trophic factor important for initial axonal growth (Cohen-Cory and Fraser, 1995; Cohen-Cory, 1999), and later in the regulation of neuronal phenotypes and synapse formation (Levine et al., 1995; Lu and Figurov, 1997). Finally, the expression of trkB is not regulated by sensory experience. The same level and pattern of TrkB expression are found in dark-reared and age-matched control animals in the visual cortex (Tropea and Domenici, 2001).

\subsection{Anterograde transport of BDNF}

The early studies with NGF led to the classical neurotrophin hypothesis, which postulated that neurotrophic factors, produced and released by target cells in limited amounts, are transported retrogradely and regulate the survival, differentiation and morphological development of the innervating neurons (Levi-Montalcini, 1987; Snider, 1994). However, more recent studies suggest that BDNF can be secreted anterogradely from axonal terminals in the CNS (Altar et al., 1997; Conner et al., 1997; Fawcett et al., 1998). This idea is supported by evidence from multiple studies. BDNF has been localized to secretory vesicles in presynaptic terminals of both peripheral (Zhou and 
Rush, 1996; Michael et al., 1997) and central neurons (Conner et al., 1997; Fawcett et al., 1997; Fawcett et al., 1998), while the TrkB receptor has been localized to postsynaptic densities in dendrites of both hippocampal and cortical pyramidal neurons (Fryer et al., 1996; Wu et al., 1996; Yan et al., 1997). In the CNS, many brain regions contain strong BDNF-immunoreactive fiber labeling without BDNF mRNA, and inhibition of axonal transport depletes BDNF immunostaining, indicating that BDNF is anterogradely transported to fibers and terminals (Altar et al., 1997; Fawcett et al., 1998). This anterograde transport of BDNF has the potential to affect the survival and differentiation of target noradrenergic neurons in the CNS during development (Fawcett et al., 1998). More recently, the dynamic anterograde transport of BDNF was demonstrated directly in cultured cortical neurons by microinjection of GFP-tagged BDNF. It was shown that BDNF-GFP moved anterogradely and was then secreted from axon terminals of the injected neuron and taken up by postsynaptic neurons in an activity-dependent manner (Haubensak et al., 1998; Kohara et al., 2001).

\subsection{Activity-dependent secretion of BDNF}

BDNF is localized in cell bodies and in large, dense-core vesicles at nerve terminals (Fawcett et al., 1997). In contrast to the constitutive secretory pathway of NGF, BDNF secretion follows a regulated pathway, as demonstrated in hippocampal slices and primary hippocampal neuronal cultures (Griesbeck et al., 1999; Mowla et al., 1999). The expression of BDNF is tightly connected to the level of neuronal activity: the synthesis and secretion of BDNF is enhanced by various forms of neuronal activation, including membrane depolarization with high potassium (Zafra et al., 1990; Ghosh et al., 
1994), activation of glutamate receptors (Zafra et al., 1990; Lindefors et al., 1992), seizures (Gall et al., 1991; Gall and Lauterborn, 1992), and stimuli that induce LTP (Hughes et al., 1999; Yin et al., 2002). Regulation of activity-dependent expression of neurotrophic factors is primarily mediated by non-NMDA glutamate receptors. Activation of either AMPA or kainate glutamate receptors increases neurotrophic factor expression (Zafra et al., 1990; Lauterborn et al., 2000). In contrast, reducing the level of neuronal activity by inhibiting neuronal depolarization or inducing hyperpolarization decreases BDNF mRNA expression (Zafra et al., 1991). Such activity-dependent regulation of BDNF expression was also demonstrated in vivo (Castren et al., 1992; Rocamora et al., 1996). BDNF mRNA expression is reduced in the primary visual cortex of rodents and cats after dark rearing (Castren et al., 1992; Schoups et al., 1995) or blockade of retinal input by intraocular injection of TTX (Bozzi et al., 1995; Lein et al., 2000). The decreased levels of BDNF mRNA in the visual cortex after dark rearing return to normal after subsequent exposure to light (Castren et al., 1992), suggesting that BDNF synthesis in visual cortex is tightly regulated by sensory experience. In the rodent somatosensory (barrel) cortex, BDNF mRNA is present in layers II/III and VI, and almost undetectable in layer IV. A six-hour whisker stimulation protocol increases the levels of BDNF mRNA in layers II to VI of the contralateral barrel cortex. In layer IV, dramatic BDNF upregulation is observed, confined to the barrels corresponding to the stimulated whiskers (Rocamora et al., 1996), indicating that activity-dependent regulation of BDNF expression has high temporal and spatial specificity. Taken together, these regulatory mechanisms of BDNF expression can be activated not only by extreme 
experimental procedures such as initiation of seizures, but also by rapid changes in the levels of sensory experience such as visual input and mechanical stimulation of whiskers.

It is believed that elevation of intracellular calcium is the triggering step for activity-dependent neurotrophin secretion. Membrane depolarization can result in the opening of the L-type voltage gated calcium channel (Ghosh et al., 1994; Berninger et al., 1995); the latter increases the level of internal calcium. Calcium influx triggers phosphorylation of the cAMP-response element binding protein (CREB), a transcription factor implicated in the control of adaptive neuronal responses (Lonze and Ginty, 2002), which by binding to a critical $\mathrm{Ca}^{2+}$ response element within the BDNF gene activates BDNF transcription (Tao et al., 1998). Blockade of internal calcium release by intracellular calcium chelators and by depletion of intracellular calcium stores inhibits neurotrophin release, indicating its dependence on internal calcium stores (Zafra et al., 1990; Zafra et al., 1992; Ghosh et al., 1994).

\section{Physiological roles of BDNF}

\subsection{BDNF promotes neuronal survival and migration}

The classical neurotrophin hypothesis states that neuronal survival is regulated by limited access to target-derived neurotrophic substances. BDNF can promote survival of several populations of cultured central neurons, including cortical and hippocampal neurons, nigral dopaminergic neurons, basal forebrain cholinergic neurons, motor neurons and retinal ganglion cells (Korsching, 1993; Ghosh et al., 1994; Meyer-Franke et al., 1995). It seems that neurons in the PNS are more dependent on neurotrophins for survival than those in the CNS. For instance, knockout of specific neurotrophin genes 
has demonstrated that neurotrophins are required for survival of distinct populations of neurons in the PNS during embryogenesis (Francis et al., 1999). In contrast, knockout of neurotrophin or trk receptor genes cause few defects in CNS neurons; a few examples are deficits in differentiation of cortical and hippocampal CB, PV and NPY positive interneurons and impaired maturation of cerebellar Purkinje cell dendritic trees in the BDNF mutant (Jones et al., 1994; Schwartz et al., 1997), and a small increase in hippocampal and cerebellar granule cell apoptosis in the trkB mutant (Minichiello and Klein, 1996; Alcantara et al., 1997). Although a null mutation for BDNF or NT4/5 has no apparent effect on the number of retinal ganglionic cells (RGCs), injection of BDNF into the superior colliculus of neonatal hamsters causes a 13-15-fold reduction in the rate of RGC pyknosis compared with the rates in controls, supporting the role of BDNF in the survival of developing RGCs (Ma et al., 1998). Recently, more precise analysis of trkB signaling has been possible using conditional knockout mice. By using Cre-mediated recombination to remove trkB from cortical pyramidal neurons expressing CaMKII, Xu and colleagues showed that the visual and somatosensory cortices of the conditional mutant are severely compressed, especially in layers II/III and V, together with altered dendritic morphology in pyramidal cells, indicating that BDNF is required for the survival and growth of cortical pyramidal neurons (Xu et al., 2000).

BDNF can also promote neuronal migration during early development. During telencephalic development, neuronal migration from the medial ganglionic eminence to the neocortex gives rise to many of the cortical GABAergic interneurons. This tangential migration is strongly stimulated by BDNF and NT4 and attenuated by the trk-family inhibitor K252a (Behar et al., 1997). TrkB-null mice show a significant decrease in the 
number of CB-positive neurons migrating tangentially in the embryonic cortex, suggesting that TrkB signaling plays an important role in controlling interneuron migration in the developing cerebral cortex (Polleux et al., 2002). Similarly, BDNF is reported to promote the migration of cerebellar granule cells (Borghesani et al., 2002).

\subsection{BDNF regulates dendritic development}

One of the important functions of neurotrophic factors is to promote neurite growth of CNS and PNS neurons (Davies, 2000). For example, NGF promotes axonal growth and regeneration in peripheral neurons (Campenot, 1994). BDNF also regulates dendritic growth in a variety of neurons. For example, BDNF and NT-4/5 promote dendritic growth of developing ferret cortical pyramidal neurons in slice culture in an activity-dependent manner; inhibition of neuronal activity dramatically reduces this effect (McAllister et al., 1996). In a CaMK/CRE-mediated trkB knockout model, in which TrkB receptors are deleted in cortical pyramidal neurons, pyramidal neurons have reduced apical dendrites diameters, retracted or degenerated secondary dendrites, and reduced overall dendritic complexity (Conover and Yancopoulos, 1997). Specific neurotrophins differentially affect the length and complexity of basal and apical dendrites of cortical pyramidal neurons developing in vitro, in a layer specific manner. For example, basal dendrites of neurons in cortical layer IV respond most strongly to BDNF, while those of neurons in layers V and VI respond mostly to NT-4/5. In contrast, apical dendrites respond to a wide range of neurotrophins (McAllister et al., 1995). In most cases, both BDNF and NT-4/5 increase the number of primary basal dendrites and the number of branches in both primary apical and basal dendrites. However, in layer VI, 
BDNF actually inhibits dendritic growth of developing neurons (McAllister et al., 1997). These results indicate that BDNF affects pyramidal dendritic growth in a layer-specific manner. Different trkB receptor isoforms also have different effects: whereas full-length trkB receptors increase proximal dendritic branching, truncated trkB receptors promote net elongation of distal dendrites (Yacoubian and Lo, 2000).

In addition to regulation of dendritic length and complexity, neurotrohpins can regulate the morphology and density of dendritic spines. Development of dendritic spines is regulated by intrinsic factors as well as environmental conditions such as neuronal activity and neurotrophic factors (Harris, 1999). BDNF was shown to increase spine density in hippocampal pyramidal cells (Tyler and Pozzo-Miller, 2001) and cerebellar Purkinje cells (Shimada et al., 1998). In neocortex, BDNF regulates dendritic and spine stability; increased BDNF causes a significant decrease in dendrite and spine stability in cortical pyramidal neurons (Horch et al., 1999).

\subsection{BDNF regulates axonal development}

Neurotrophins have been shown to play a role in regulating axonal growth by acting as target-derived trophic factors (Cabelli et al., 1995; Cohen-Cory and Fraser, 1995). One direct example of this is the role of BDNF during RGC axon arborization. Increasing endogenous BDNF in the optic tectum can promote RGC axon arborization in live Xenopus tadpoles, whereas neutralizing endogenous BDNF decreases axon arborization (Cohen-Cory and Fraser, 1994; 1995). The peak in BDNF expression in the

Xenopus visual system coincides with the period of active RGC axon arborization at its target (Cohen-Cory and Fraser, 1994), providing further support for BDNF as a target- 
derived modulator of axon morphology. In the pontine-cerebellar system, BDNF and NT4/5 increase pontocerebellar mossy fiber outgrowth, growth cone size, and elongation rate (Rabacchi et al., 1999). BDNF can also inhibit axonal growth by causing growth cone collapse and transient growth inhibition in rat dorsal root ganglion neurons (Wang and Zheng, 1998). BDNF can differentially modulate axonal and dendritic arborization within a single neuronal population in opposing manners; specifically, BDNF reduces RGC dendritic arborization within the retina, while it increases axon arborization in the tectum (Lom and Cohen-Cory, 1999). A recent in vivo study further showed that BDNF increases both axon arborization and synapse density in developing Xenopus optic axons (Alsina et al., 2001).

\subsection{BDNF regulates synaptic transmission}

The evidence for the physiological role of neurotrophins originated from observations of fast actions of neurotrophins on synaptic transmission (Lohof et al., 1993). The authors showed that the addition of BDNF or NT-3 to developing frog neuromuscular synapses in culture causes a rapid, but reversible, increase in the frequency of miniature EPSPs. Since then, many studies have shown that BDNF and other neurotrophins can facilitate synaptic function in different systems, including neuromuscular junction (Stoop and Poo, 1996; Wang et al., 1998), hippocampus (Lessmann et al., 1994; Levine et al., 1995; Li et al., 1998) and visual cortex (Akaneya et al., 1997; Carmignoto et al., 1997). Low concentration of BDNF has been shown to elicit action potentials in the hippocampus, cortex and cerebellum just as rapidly as the neurotransmitter glutamate (Kafitz et al., 1999), by activating TTX-insensitive sodium 
channels (Blum et al., 2002). BDNF can rapidly enhance spontaneous synaptic activity in dissociated cultures of hippocampal neurons, increase the expression levels of several synaptic vesicle proteins, and decrease inhibition in hippocampal slices (Tanaka et al., 1997; Frerking et al., 1998).

Trk receptors are found on both the pre- and postsynaptic sides of a given synapse in the hippocampus and neocortex, and neurotrophins have been shown to regulate synaptic transmission by both presynaptic and postsynaptic mechanisms (Lewin and Barde, 1996). At the presynaptic site, they facilitate glutamate release as indicated by an increase in the frequency of miniature synaptic events and a decrease in the possibility of synaptic failures at synapses of cortical and hippocampal neurons (Lessmann and Heumann, 1998; Schinder et al., 2000). Paired-pulse facilitation, a parameter reflecting probability of neurotransmitter release, is also enhanced by BDNF (Gottschalk et al., 1998). In neuronal cultures, BDNF increases the level of vesicle proteins such as synaptotagmin, synaptobrevin and synaptophysin (Takei et al., 1997). Conversely, BDNF knockout mice show a significant reduction in vesicle number at presynaptic active docking zones in the CA1 of hippocampus, together with a marked decrease in the levels of synaptophysin and synaptobrevin, suggesting a role for BDNF in the mobilization and/or docking of synaptic vesicles to presynaptic active zones (PozzoMiller et al., 1999). In addition, adenovirus-mediated expression of a truncated TrkB receptor in presynaptic, but not postsynaptic, neurons blocks BDNF facilitation of both evoked and spontaneous synaptic transmission (Li et al., 1998). In cultured hippocampal neurons, BDNF and NT-3 induce a rapid rise in intracellular calcium (Li et al., 1998). This may be one mechanism responsible for the presynaptic effect of neurotrophins. 
On the other hand, there is abundant evidence supporting a postsynaptic effect for BDNF and other neurotrophins; the mechanisms include regulation of postsynaptic receptor density and promotion of receptor phosphorylation, among others. Neurotrophins have been shown to regulate the level of NMDA and AMPA receptor (Levine et al., 1995; Rutherford et al., 1998), as well as GABA $A_{\mathrm{A}}$ receptors (Tanaka et al., 1997). Neurotrophins enhance synaptic transmission through NMDA receptors by promoting the phosphorylation of the NMDA receptor subunit 1 (Suen et al., 1997; Tanaka et al., 1997). In agreement with these findings, BDNF triggers calcium influx in dendritic spines and causes an immediate induction of LTP (Kovalchuk et al., 2002). Injection of a trk inhibitor into cultured hippocampal neurons prevents BDNF-induced increases in firing rate and a concomitant increases in spontaneous synaptic currents (Levine et al., 1995).

The involvement of BDNF in LTP has been extensively studied. Similar to the activity-dependent refinement of synaptic connections in the visual cortex, the availability of neurotrophins appears to be critical for the ability of synapses in the hippocampus to undergo LTP (Berninger and Poo, 1996; Lessmann, 1998; Lessmann and Heumann, 1998; McAllister et al., 1999; Kovalchuk et al., 2002). In BDNF knockout mice, LTP induction in the hippocampal Shaffer collateral-CA1 synapse is compromised, and can be rescued by bath application of exogenous BDNF or adenovirus-mediated transfection of the BDNF gene (Korte et al., 1996; Patterson et al., 1996). In agreement with these observations, inhibition of BDNF signaling with TrkB-IgG inhibits the generation of tetanus-induced LTP in slices of adult hippocampus and visual cortex (Korte et al., 1996; Patterson et al., 1996). During development these synapses gain the 
ability to undergo LTP at a time when BDNF expression dramatically increases. Before this developmental stage, exogenous BDNF permitted the induction of LTP, demonstrating that the availability of a minimal quantity of this neurotrophin is apparently a crucial factor for this form of neuronal plasticity (Figurov et al., 1996).

\section{BDNF involvement in activity-dependent development of GABAergic neurons}

Cortical neuronal networks are composed of extensive recurrent excitatory and inhibitory connections. Changes in neuronal activity can result in modulation of the excitability of the cortical network; one possible mechanism for this effect is through the regulation of neurotrophic factors (Domenici et al., 1991; Thoenen, 1995). BDNF is proposed to play a crucial role in homeostatic regulation of cortical excitability by selectively modifying excitation and inhibition within these networks (Rutherford et al., 1997; Rutherford et al., 1998). When neuronal activity rises and BDNF production increases, the properties of cortical networks are modified to favor inhibition; whereas when activity falls and BDNF production is reduced, the properties of these networks are altered to favor excitation (Rutherford et al., 1998). Specifically, BDNF is implicated in the development of the GABAergic system by promoting the maturation of GABAergic neurons (Marty et al., 1996; Mizuno et al., 1994), the formation of GABAergic synapses

(Rutherford et al., 1997; Vicario-Abejon et al., 1998; Huang et al., 1999) and the expression of neuropeptides and $\mathrm{GABA}_{\mathrm{A}}$ receptors (Thompson et al., 1998). 


\subsection{BDNF regulates activity-dependent development of GABAergic inhibition}

The level of neuronal activity regulates both the development of GABAergic neurons and the synthesis and secretion of BDNF, while BDNF has the effect of promoting GABAergic development and GABAergic inhibition. This leads to the hypothesis that BDNF may mediate activity-dependent development of the cortical GABAergic system, particularly GABAergic synaptogenesis and the developmental expression of GAD and GABA. BDNF is known to mediate activity-dependent regulation of inhibitory synaptogenesis in cultured Purkinje and hippocampal neurons (Seil et al., 1994; Marty et al., 2000; Seil and Drake-Baumann, 2000). Organotypic cerebellar cultures from neonatal mice exposed to TTX exhibit a reduced number of Purkinje cell inhibitory (axosomatic) synapses, while cultures treated with TTX and BDNF together develop a full complement of the synapses and display normal cortical discharge rates. Application of BDNF antibody prevents the increase of inhibitory synapses caused by the $\mathrm{GABA}_{\mathrm{A}}$ antagonist picrotoxin. These results indicate that BDNF may mediate the activity-dependent development of inhibitory synapses in the cerebellum (Seil et al., 1994; Seil and Drake-Baumann, 2000). In cultured hippocampal slices, the density of GAD65-immunoreactive terminals in the CA1 region increases following addition of the $\mathrm{GABA}_{\mathrm{A}}$ receptor antagonist bicuculline (which leads to enhanced neuronal activity), and decreases in the presence of the glutamate receptor antagonist DNQX. Application of exogenous BDNF partly mimicked the stimulatory effect of bicuculline, while BDNF antibody decreased the density of GAD65-immunoreactive terminals in bicuculline-treated slices, suggesting that neuronal activity regulates the 
density of inhibitory synapses made by postnatal hippocampal interneurons, and BDNF could be mediating part of this effect (Marty et al., 2000).

In rat visual cortex cultures, Rutherford and colleagues tested the hypothesis that activity regulates the strength of cortical inhibition through the regulation of BDNF. They showed that blocking spontaneous activity reversibly decreased the number of GABA-positive neurons, decreased GABA-mediated inhibition and raised firing rates of pyramidal neurons. Addition of BDNF during activity blockade specifically eliminated these effects, while blockade of neurotrophin signaling mimicked the effects of activity blockade on GABA expression, suggesting that activity regulates cortical GABAergic inhibition through a BDNF-dependent mechanism, thereby maintaining a homeostatic level of cortical excitation (Rutherford et al., 1997). Increased levels of neuronal activity cause increased expression and secretion of BDNF by pyramidal neurons, which in turn enhances GABAergic inhibition by increasing GABAergic synaptogenesis and GABA expression by inhibitory interneurons. In this way, the system reaches a new balance between inhibition and excitation at a higher level of activity.

\subsection{BDNF involvement in activity-dependent regulation of GABAergic neuron}

\section{phenotypes}

BDNF regulates the expression of calcium binding proteins and neuropeptides in cortical GABAergic neurons (Barnea et al., 1995; Carnahan and Nawa, 1995; Marty et al., 1996; Fiumelli et al., 2000). For example, Nawa and coworkers have observed a strong upregulation of NPY protein levels, and a smaller but significant upregulation of SOM and CCK in interneurons in response to BDNF, both in cortex cultures and 
following in vivo injections of BDNF (Nawa et al., 1993; 1994). In primary cultures of hypothalamic neurons, BDNF induces significant concentration-dependent SOM release (Marmigere et al., 2001). BDNF promotes expression of NPY in different regions of the brain, including the neocortex and hippocampus (Nawa et al., 1993; Barnea et al., 1995; Reibel et al., 2000). Chronic exposure of cultured cortical neurons for 5 days to increasing concentrations of BDNF resulted in a concentration-dependent increase in the number of CB-immunoreactive neurons and a concentration-dependent decrease in the number of CR-immunoreactive cells (Fiumelli et al., 2000). This is consistent with developmental changes in $\mathrm{CR}$ cell density: its decrease in density during the third postnatal postnatal week coincides with the increase in BDNF expression (Schierle et al., 1997). In hippocampus cultures, BDNF increases the number of $\mathrm{CB}$ and $\mathrm{CR}$ immunoreactive neurons (Marty et al., 1996), whereas in BDNF-knockout mice the number of NPY-, CB- and PV-expressing neurons in the cortex is reduced (Jones et al., 1994). BDNF is believed to regulate the expression of PV in the visual cortex. The developmental increase in PV matches the increase in BDNF expression during the second and third postnatal week (Castren et al., 1992; Alcantara et al., 1993), and BDNF accumulates in PV neurons expressing trkB (Cellerino et al., 1996). Furthermore, monocular deprivation reduces the number of PV neurons (Cellerino et al., 1992) and the level of BDNF mRNA (Bozzi et al., 1995). Taken together, these data suggest that the neurochemical patterns of interneurons in different brain regions and cortical layers may be regulated by BDNF during development.

Since enhanced neuronal activity increases BDNF synthesis and secretion, a causal relationship is proposed, whereby increased neuronal activity triggers an increase 
in BDNF availability, which in turn enhances the expression of calcium binding proteins and neuropeptides in the cortical interneurons (Carnahan and Nawa, 1995; Obst et al., 1998). This relationship is demonstrated in NPY and SOM expression in postnatal hippocampal slice cultures. Treatment with the $\mathrm{GABA}_{\mathrm{A}}$ receptor antagonist bicuculline increases the staining intensity and the number of NPY and SOM immunoreactive neurons, and the tyrosine kinase receptor inhibitor K252a prevents these effects of bicuculline. Treatment with BDNF or NT-4/5 mimics the effects of bicuculline treatment on NPY immunostaining, but does not induce conspicuous changes in the number or staining intensity of SOM-immunoreactive neurons. Therefore, neuronal activity may modulate the levels of these two neuropeptides through two different mechanisms, with or without the mediation of trkB ligands (Marty and Onteniente, 1999). GABAergic stimulation is known to switch from enhancing to repressing BDNF expression in rat hippocampal neurons during development (Berninger et al., 1995). In immature hippocampal neurons, in which GABA is depolarizing, the $\mathrm{GABA}_{\mathrm{A}}$ receptor agonist muscimol and BDNF increase the size and NPY immunoreactivity of hippocampal interneurons; but at later stages of development, when GABA is hyperpolarizing and represses BDNF synthesis, muscimol treatment causes a decrease in cell size and NPY immunoreactivity of interneurons. Muscimol failed to increase NPY immunoreactivity in cultures from BDNF knockout embryos (Marty et al., 1996). Therefore, GABAergic neurotransmission can regulate the phenotype of hippocampal interneurons through regulation of BDNF synthesis and/or release from adjacent pyramidal neurons.

The physiological significance of such activity-dependent regulation of interneuronal neurochemical properties by BDNF is not clear. Neuropeptides are 
proposed to be involved in regulating neuronal excitability and preventing seizure activity in the adult brain (Erickson et al., 1996; Gall et al., 1990), and calcium binding proteins are involved in the regulation of calcium homeostasis, protecting neurons from damage due to excessive calcium influx (Caillard et al., 2000). Therefore, regulation of the levels of these proteins by neuronal activity during development could serve for finetuning cortical excitability and for neuroprotection.

\subsection{BDNF regulates dendritic growth of GABAergic neurons}

Compared to the dendritic development of cortical pyramidal neurons, relatively few studies have addressed the effect of BDNF on dendritic morphology in GABAergic neurons. Although cortical GABAergic neurons do not express BDNF, there are trkB receptors on the majority of them, especially in PV positive neurons (Cellerino and Maffei, 1996). In the cerebellum, BDNF increases stellate and basket cell dendritic arborization and Purkinje cell spine density, while blockade of BDNF by TrkB-IgG not only decreases spine density, but also causes spines to have longer necks, indicating its specific effect in modulating spine morphology (Shimada et al., 1998; Mertz et al., 2000). In hippocampus slice cultures, BDNF promotes elongation of dendrites of stratum oriens nonpyramidal cells, and increases their calcium binding protein expression (Marty et al., 1996; Marty et al., 1996). In dissociated hippocampal cultures, BDNF causes a marked increase in the total number of branches and the total length of both dendrites and axons of GABAergic neurons (Vicario-Abejon et al., 1998). However, it has not been directly tested if BDNF regulates dendritic development in neocortical GABAergic neurons; it is possible that the effects of BDNF on GABAergic neuron dendritic development might 
differ from the results obtained from cortical pyramidal neurons or from interneurons in other brain regions. We tested this possibility in an organotypic brain slice culture system, in which cortical GABAergic neurons were specifically labeled by biolistic transfection with GAD67-GFP DNA (Chapter 4). 


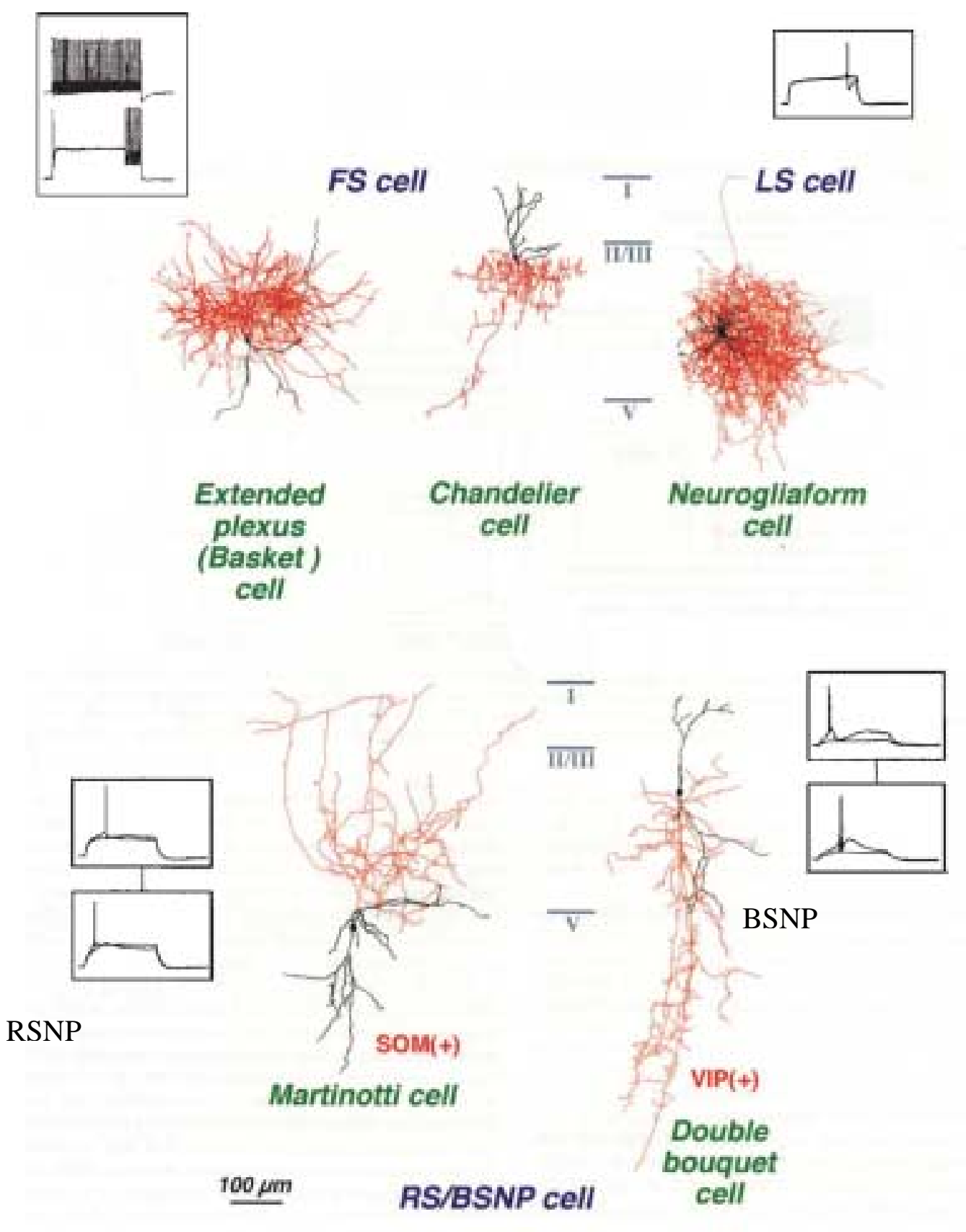

Figure 1.1. Tracing of GABAergic cortical neuron subtypes. The somata and dendrites are shown in black, and the axons in red. The inserts show their corresponding firing patterns. Modified from Kawaguchi (1997), Cerebral cortex 7: 476-486. 


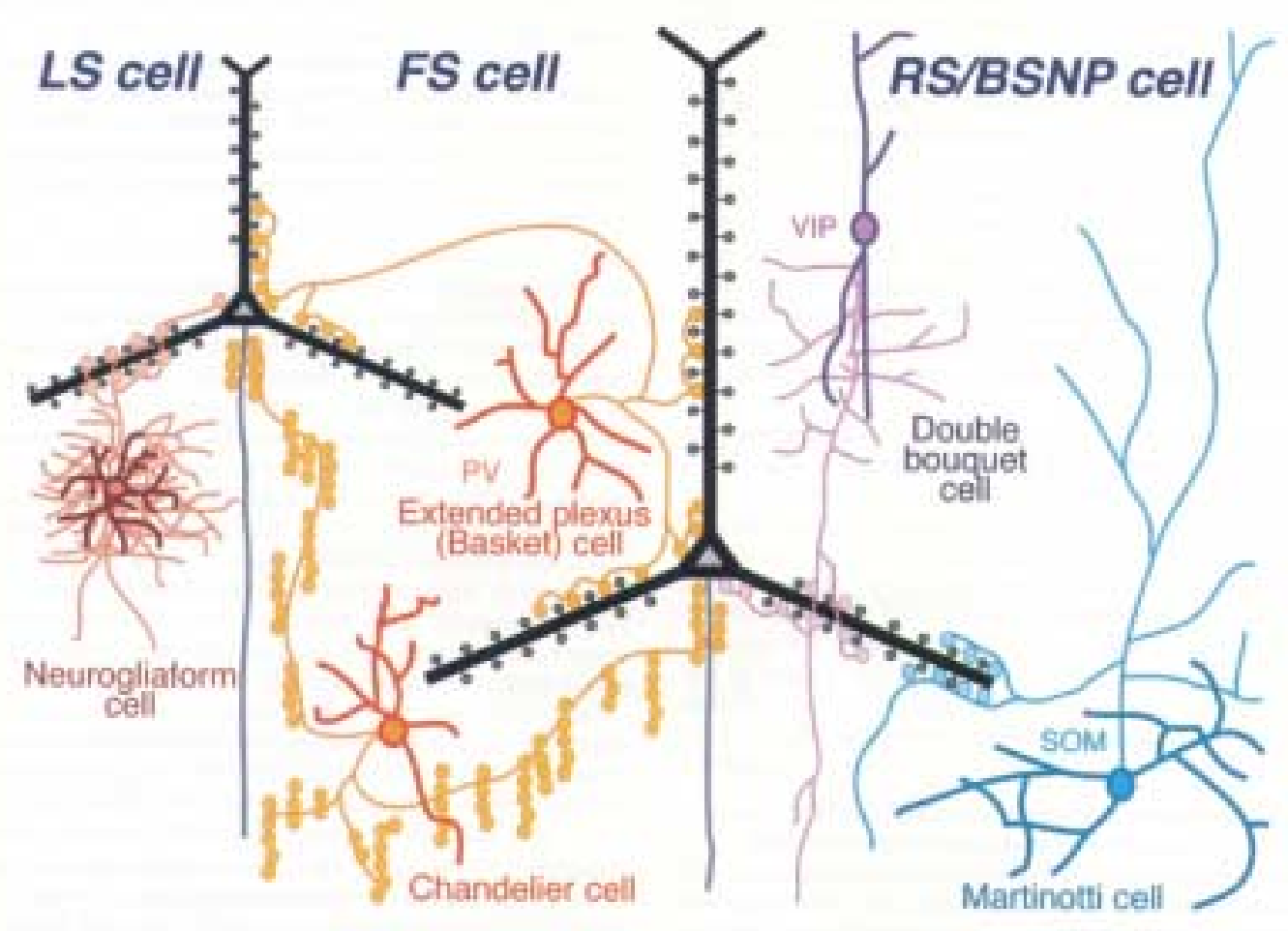

Figure 1.2. Schematic view of the known distributions of axon terminals of GABAergic cell subtypes on pyramidal cells in rat frontal cortex. From Kawaguchi (1997), Cerebral cortex 7: 476-486. 

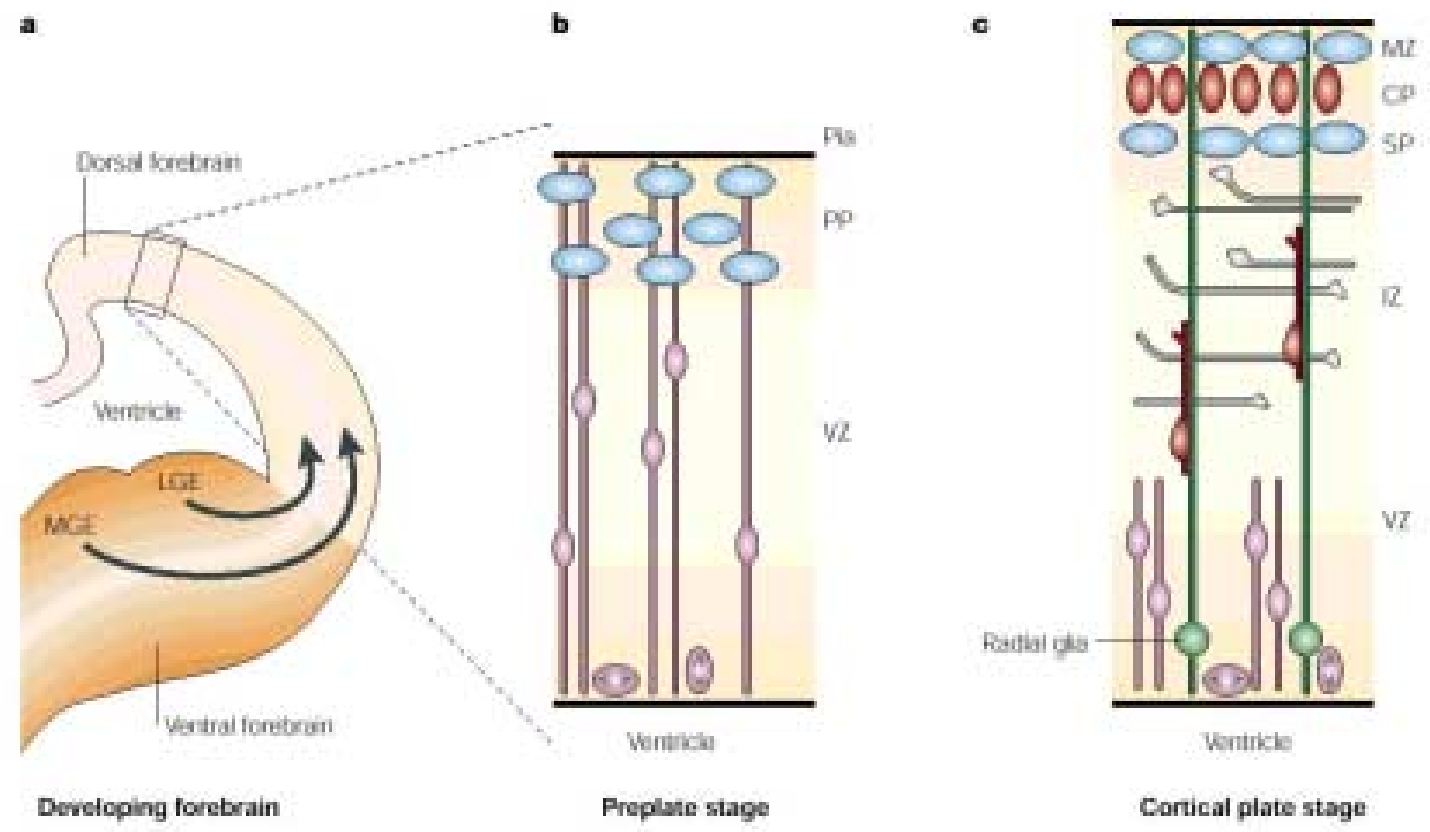

Figure 1.3. GABAergic interneuron migration and neocortical development. a. Schematic diagram of a section through the developing rodent forebrain. The dorsal forebrain gives rise to the cerebral cortex. The lateral ganglionic eminence (LGE) and medial ganglionic eminence (MGE) of the ventral forebrain generate the neurons of the basal ganglia and cortical GABAergic interneurons; the latter follow tangential migratory routes to the cortex (a; arrows). b,c. Illustrations of the different stages of neocortical development. $\mathrm{CP}$, cortical plate; IZ, intermediate zone; MZ, marginal zone; PP, preplate; SP, subplate; VZ, ventricular zone. Modified from Nadarajah and Parnavelas (2002), Nature Reviews Neuroscience 3: 423-432. 


\section{REFERENCES}

Agmon, A., and Connors, B. W. (1992) Correlation between intrinsic firing patterns and thalamocortical synaptic responses of neurons in mouse barrel cortex. J Neurosci 12: $319-29$.

Agmon, A., and O'Dowd, D. K. (1992) NMDA receptor-mediated currents are prominent in the thalamocortical synaptic response before maturation of inhibition. J Neurophysiol 68: 345-9.

Agmon, A., Hollrigel, G., and O'Dowd, D. K. (1996) Functional GABAergic synaptic connection in neonatal mouse barrel cortex. J Neurosci 16: 4684-95.

Akaneya, Y., Tsumoto, T., Kinoshita, S., and Hatanaka, H. (1997) Brain-derived neurotrophic factor enhances long-term potentiation in rat visual cortex. J Neurosci 17: 6707-16.

Alcantara, S., and Ferrer, I. (1995) Postnatal development of calbindin-D28k immunoreactivity in the cerebral cortex of the cat. Anat Embryol (Berl) 192: 369-84.

Alcantara, S., de Lecea, L., Del Rio, J. A., Ferrer, I., and Soriano, E. (1996) Transient colocalization of parvalbumin and calbindin D28k in the postnatal cerebral cortex: evidence for a phenotypic shift in developing nonpyramidal neurons. Eur J Neurosci 8: 1329-39.

Alcantara, S., Ferrer, I., and Soriano, E. (1993) Postnatal development of parvalbumin and calbindin D28K immunoreactivities in the cerebral cortex of the rat. Anat Embryol (Berl) 188: 63-73.

Alcantara, S., Frisen, J., del Rio, J. A., Soriano, E., Barbacid, M., and Silos-Santiago, I. (1997) TrkB signaling is required for postnatal survival of CNS neurons and protects hippocampal and motor neurons from axotomy-induced cell death. J Neurosci 17: 362333.

Allen, J. M., McGregor, G. P., Woodhams, P. L., Polak, J. M., and Bloom, S. R. (1984) Ontogeny of a novel peptide, neuropeptide Y (NPY) in rat brain. Brain Res 303: 197200.

Allendoerfer, K. L., Cabelli, R. J., Escandon, E., Kaplan, D. R., Nikolics, K., and Shatz, C. J. (1994) Regulation of neurotrophin receptors during the maturation of the mammalian visual system. J Neurosci 14: 1795-811.

Alloway, K. D., and Burton, H. (1991) Differential effects of GABA and bicuculline on rapidly- and slowly- adapting neurons in primary somatosensory cortex of primates. Exp Brain Res 85: 598-610. 
Alloway, K. D., Rosenthal, P., and Burton, H. (1989) Quantitative measurements of receptive field changes during antagonism of GABAergic transmission in primary somatosensory cortex of cats. Exp Brain Res 78: 514-32.

Alsina, B., Vu, T., and Cohen-Cory, S. (2001) Visualizing synapse formation in arborizing optic axons in vivo: dynamics and modulation by BDNF. Nat Neurosci 4: 1093-101.

Altar, C. A., Cai, N., Bliven, T., Juhasz, M., Conner, J. M., Acheson, A. L., Lindsay, R. M., and Wiegand, S. J. (1997) Anterograde transport of brain-derived neurotrophic factor and its role in the brain. Nature 389: 856-60.

Altar, C. A., Cai, N., Bliven, T., Juhasz, M., Conner, J. M., Acheson, A. L., Lindsay, R. M., and Wiegand, S. J. (1997) Anterograde transport of brain-derived neurotrophic factor and its role in the brain [see comments]. Nature 389: 856-60.

Antonopoulos, J., Papadopoulos, G. C., Michaloudi, H., Cavanagh, M. E., and Parnavelas, J. G. (1992) Postnatal development of neuropeptide Y-containing neurons in the visual cortex of normal- and dark-reared rats. Neurosci Lett $145: 75-8$.

Asada, H., Kawamura, Y., Maruyama, K., Kume, H., Ding, R. G., Kanbara, N., Kuzume, H., Sanbo, M., Yagi, T., and Obata, K. (1997) Cleft palate and decreased brain gammaaminobutyric acid in mice lacking the $67-\mathrm{kDa}$ isoform of glutamic acid decarboxylase. Proc Natl Acad Sci U S A 94: 6496-9.

Avoli, M. (1996) GABA-mediated synchronous potentials and seizure generation. Epilepsia 37: 1035-42.

Avoli, M., Hwa, G., Louvel, J., Kurcewicz, I., Pumain, R., and Lacaille, J. C. (1997) Functional and pharmacological properties of GABA-mediated inhibition in the human neocortex. Can J Physiol Pharmacol 75: 526-34.

Avoli, M., Louvel, J., Drapeau, C., Pumain, R., and Kurcewicz, I. (1995) GABAAmediated inhibition and in vitro epileptogenesis in the human neocortex. J Neurophysiol 73: 468-84.

Barbacid, M. (1994) The Trk family of neurotrophin receptors. J Neurobiol 25: 1386403.

Barbin, G., Pollard, H., Gaiarsa, J. L., and Ben-Ari, Y. (1993) Involvement of GABAA receptors in the outgrowth of cultured hippocampal neurons. Neurosci Lett 152: 150-4.

Badran, S., Schmutz, M., and Olpe, H. R. (1997) Comparative in vivo and in vitro studies with the potent GABAB receptor antagonist, CGP 56999A. Eur J Pharmacol 333: 13542 . 
Barker, J. L., Behar, T., Li, Y. X., Liu, Q. Y., Ma, W., Maric, D., Maric, I., Schaffner, A. E., Serafini, R., Smith, S. V., Somogyi, R., Vautrin, J. Y., Wen, X. L., and Xian, H. (1998) GABAergic cells and signals in CNS development. Perspect Dev Neurobiol 5: 305-22.

Barnea, A., Cho, G., Lu, G., and Mathis, M. (1995) Brain-derived neurotrophic factor induces functional expression and phenotypic differentiation of cultured fetal neuropeptide Y-producing neurons. J Neurosci Res 42: 638-47.

Behar, T. N., Dugich-Djordjevic, M. M., Li, Y. X., Ma, W., Somogyi, R., Wen, X., Brown, E., Scott, C., McKay, R. D., and Barker, J. L. (1997) Neurotrophins stimulate chemotaxis of embryonic cortical neurons. Eur J Neurosci 9: 2561-70.

Behar, T. N., Li, Y. X., Tran, H. T., Ma, W., Dunlap, V., Scott, C., and Barker, J. L. (1996) GABA stimulates chemotaxis and chemokinesis of embryonic cortical neurons via calcium-dependent mechanisms. J Neurosci 16: 1808-18.

Beierlein, M., Gibson, J. R., and Connors, B. W. (2000) A network of electrically coupled interneurons drives synchronized inhibition in neocortex. Nat Neurosci 3: 90410 .

Bekenstein, J. W., and Lothman, E. W. (1993) Dormancy of inhibitory interneurons in a model of temporal lobe epilepsy. Science 259: 97-100.

Benardo, L. S. (1994) Separate activation of fast and slow inhibitory postsynaptic potentials in rat neocortex in vitro. J Physiol 476: 203-15.

Ben-Ari, Y., Khazipov, R., Leinekugel, X., Caillard, O., and Gaiarsa, J. L. (1997) GABAA, NMDA and AMPA receptors: a developmentally regulated 'menage a trois'. Trends Neurosci 20: 523-9.

Benevento, L. A., Bakkum, B. W., and Cohen, R. S. (1995) gamma-Aminobutyric acid and somatostatin immunoreactivity in the visual cortex of normal and dark-reared rats. Brain Res 689: 172-82.

Bernasconi, R., Lauber, J., Marescaux, C., Vergnes, M., Martin, P., Rubio, V., Leonhardt, T., Reymann, N., and Bittiger, H. (1992) Experimental absence seizures: potential role of gamma-hydroxybutyric acid and GABAB receptors. J Neural Transm Suppl 35: 155-77.

Berninger, B., Marty, S., Zafra, F., da Penha Berzaghi, M., Thoenen, H., and Lindholm, D. (1995) GABAergic stimulation switches from enhancing to repressing BDNF expression in rat hippocampal neurons during maturation in vitro. Development 121 : 2327-35.

Berninger, B., and Poo, M. (1996) Fast actions of neurotrophic factors. Curr Opin Neurobiol 6: 324-30. 
Biffo, S., Offenhauser, N., Carter, B. D., and Barde, Y. A. (1995) Selective binding and internalisation by truncated receptors restrict the availability of BDNF during development. Development 121: 2461-70.

Bland, B. H., and Oddie, S. D. (2001) Theta band oscillation and synchrony in the hippocampal formation and associated structures: the case for its role in sensorimotor integration. Behav Brain Res 127: 119-36.

Blue, M. E., and Parnavelas, J. G. (1983) The formation and maturation of synapses in the visual cortex of the rat. II. Quantitative analysis. J Neurocytol 12: 697-712.

Blum, R., Kafitz, K. W., and Konnerth, A. (2002) Neurotrophin-evoked depolarization requires the sodium channel $\mathrm{Na}(\mathrm{V}) 1.9$. Nature 419: 687-93.

Borghesani, P. R., Peyrin, J. M., Klein, R., Rubin, J., Carter, A. R., Schwartz, P. M., Luster, A., Corfas, G., and Segal, R. A. (2002) BDNF stimulates migration of cerebellar granule cells. Development 129: 1435-42.

Bozzi, Y., Pizzorusso, T., Cremisi, F., Rossi, F. M., Barsacchi, G., and Maffei, L. (1995) Monocular deprivation decreases the expression of messenger RNA for brain-derived neurotrophic factor in the rat visual cortex. Neuroscience 69: 1133-44.

Bragin, A., Jando, G., Nadasdy, Z., Hetke, J., Wise, K., and Buzsaki, G. (1995) Gamma (40-100 Hz) oscillation in the hippocampus of the behaving rat. J Neurosci 15: 47-60.

Buhl, E. H., Halasy, K., and Somogyi, P. (1994) Diverse sources of hippocampal unitary inhibitory postsynaptic potentials and the number of synaptic release sites. Nature 368 : 823-8.

Buzsaki, G., and Chrobak, J. J. (1995) Temporal structure in spatially organized neuronal ensembles: a role for interneuronal networks. Curr Opin Neurobiol 5: 504-10.

Buzsaki, G., and Eidelberg, E. (1983) Phase relations of hippocampal projection cells and interneurons to theta activity in the anesthetized rat. Brain Res 266: 334-9.

Cabelli, R. J., Allendoerfer, K. L., Radeke, M. J., Welcher, A. A., Feinstein, S. C., and Shatz, C. J. (1996) Changing patterns of expression and subcellular localization of TrkB in the developing visual system. J Neurosci 16: 7965-80.

Cabelli, R. J., Hohn, A., and Shatz, C. J. (1995) Inhibition of ocular dominance column formation by infusion of NT-4/5 or BDNF. Science 267: 1662-6.

Caillard, O., Moreno, H., Schwaller, B., Llano, I., Celio, M. R., and Marty, A. (2000) Role of the calcium-binding protein parvalbumin in short-term synaptic plasticity. Proc Natl Acad Sci U S A 97: 13372-7. 
Campenot, R. B. (1994) NGF and the local control of nerve terminal growth. J Neurobiol 25: 599-611.

Cao, Y., Wilcox, K. S., Martin, C. E., Rachinsky, T. L., Eberwine, J., and Dichter, M. A. (1996) Presence of mRNA for glutamic acid decarboxylase in both excitatory and inhibitory neurons. Proc Natl Acad Sci U S A 93: 9844-9.

Capsoni, S., Tongiorgi, E., Cattaneo, A., and Domenici, L. (1999) Dark rearing blocks the developmental down-regulation of brain-derived neurotrophic factor messenger RNA expression in layers IV and V of the rat visual cortex. Neuroscience 88: 393-403.

Capsoni, S., Tongiorgi, E., Cattaneo, A., and Domenici, L. (1999) Differential regulation of brain-derived neurotrophic factor messenger RNA cellular expression in the adult rat visual cortex. Neuroscience 93: 1033-40.

Carmignoto, G., Pizzorusso, T., Tia, S., and Vicini, S. (1997) Brain-derived neurotrophic factor and nerve growth factor potentiate excitatory synaptic transmission in the rat visual cortex. J Physiol 498: 153-64.

Carnahan, J., and Nawa, H. (1995) Regulation of neuropeptide expression in the brain by neurotrophins. Potential role in vivo. Mol Neurobiol 10: 135-49.

Caruncho, H. J., Puia, G., Slobodyansky, E., da Silva, P. P., and Costa, E. (1993) Freezefracture immunocytochemical study of the expression of native and recombinant GABAA receptors. Brain Res 603: 234-42.

Castren, E., Thoenen, H., and Lindholm, D. (1995) Brain-derived neurotrophic factor messenger RNA is expressed in the septum, hypothalamus and in adrenergic brain stem nuclei of adult rat brain and is increased by osmotic stimulation in the paraventricular nucleus. Neuroscience 64: 71-80.

Castren, E., Zafra, F., Thoenen, H., and Lindholm, D. (1992) Light regulates expression of brain-derived neurotrophic factor mRNA in rat visual cortex. Proc Natl Acad Sci U S A 89: 9444-8.

Cauli, B., Audinat, E., Lambolez, B., Angulo, M. C., Ropert, N., Tsuzuki, K., Hestrin, S., and Rossier, J. (1997) Molecular and physiological diversity of cortical nonpyramidal cells. J Neurosci 17: 3894-906.

Ceccatelli, S., Ernfors, P., Villar, M. J., Persson, H., and Hokfelt, T. (1991) Expanded distribution of mRNA for nerve growth factor, brain-derived neurotrophic factor, and neurotrophin 3 in the rat brain after colchicine treatment. Proc Natl Acad Sci U S A 88: 10352-6.

Celio, M. R. (1990) Calbindin D-28k and parvalbumin in the rat nervous system. 
Neuroscience 35: 375-475.

Cellerino, A., and Maffei, L. (1996) The action of neurotrophins in the development and plasticity of the visual cortex [published erratum appears in Prog Neurobiol 1996 Oct;50(2-3):333]. Prog Neurobiol 49: 53-71.

Cellerino, A., Maffei, L., and Domenici, L. (1996) The distribution of brain-derived neurotrophic factor and its receptor trkB in parvalbumin-containing neurons of the rat visual cortex. Eur J Neurosci 8: 1190-7.

Cellerino, A., Siciliano, R., Domenici, L., and Maffei, L. (1992) Parvalbumin immunoreactivity: a reliable marker for the effects of monocular deprivation in the rat visual cortex. Neuroscience 51: 749-53.

Chao, M. V. (1994) The p75 neurotrophin receptor. J Neurobiol 25: 1373-85.

Chard, P. S., Jordan, J., Marcuccilli, C. J., Miller, R. J., Leiden, J. M., Roos, R. P., and Ghadge, G. D. (1995) Regulation of excitatory transmission at hippocampal synapses by calbindin D28k. Proc Natl Acad Sci U S A 92: 5144-8.

Chedotal, A., Cozzari, C., Faure, M. P., Hartman, B. K., and Hamel, E. (1994) Distinct choline acetyltransferase (ChAT) and vasoactive intestinal polypeptide (VIP) bipolar neurons project to local blood vessels in the rat cerebral cortex. Brain Res 646: 181-93.

Chedotal, A., Umbriaco, D., Descarries, L., Hartman, B. K., and Hamel, E. (1994) Light and electron microscopic immunocytochemical analysis of the neurovascular relationships of choline acetyltransferase and vasoactive intestinal polypeptide nerve terminals in the rat cerebral cortex. J Comp Neurol 343: 57-71.

Cherubini, E., Gaiarsa, J. L., and Ben-Ari, Y. (1991) GABA: an excitatory transmitter in early postnatal life. Trends Neurosci $14: 515-9$.

Chevaleyre, V., Moos, F. C., and Desarmenien, M. G. (2002) Interplay between presynaptic and postsynaptic activities is required for dendritic plasticity and synaptogenesis in the supraoptic nucleus. J Neurosci 22: 265-73.

Chmielowska, J., Stewart, M. G., and Bourne, R. C. (1988) gamma-Aminobutyric acid (GABA) immunoreactivity in mouse and rat first somatosensory (SI) cortex: description and comparison. Brain Res 439: 155-68.

Cho, H. J., Shiotani, Y., Shiosaka, S., Inagaki, S., Kubota, Y., Kiyama, H., Umegaki, K., Tateishi, K., Hashimura, E., Hamaoka, T., and Tohyama, M. (1983) Ontogeny of cholecystokinin-8-containing neuron system of the rat: an immunohistochemical analysis. I. Forebrain and upper brainstem. J Comp Neurol 218: 25-41.

Choi, S. Y., Morales, B., Lee, H. K., and Kirkwood, A. (2002) Absence of long-term 
depression in the visual cortex of glutamic Acid decarboxylase-65 knock-out mice. J Neurosci 22: 5271-6.

Cobas, A., and Fairen, A. (1988) GABAergic neurons of different morphological classes are cogenerated in the mouse barrel cortex. J Neurocytol 17: 511-9.

Cobb, S. R., Buhl, E. H., Halasy, K., Paulsen, O., and Somogyi, P. (1995) Synchronization of neuronal activity in hippocampus by individual GABAergic interneurons. Nature 378: 75-8.

Cohen-Cory, S. (1999) BDNF modulates, but does not mediate, activity-dependent branching and remodeling of optic axon arbors in vivo. J Neurosci 19: 9996-10003.

Cohen-Cory, S., and Fraser, S. E. (1994) BDNF in the development of the visual system of Xenopus. Neuron 12: 747-61.

Cohen-Cory, S., and Fraser, S. E. (1995) Effects of brain-derived neurotrophic factor on optic axon branching and remodelling in vivo. Nature 378: 192-6.

Conde, F., Lund, J. S., Jacobowitz, D. M., Baimbridge, K. G., and Lewis, D. A. (1994) Local circuit neurons immunoreactive for calretinin, calbindin D-28k or parvalbumin in monkey prefrontal cortex: distribution and morphology. J Comp Neurol 341: 95-116.

Conner, J. M., Lauterborn, J. C., Yan, Q., Gall, C. M., and Varon, S. (1997) Distribution of brain-derived neurotrophic factor (BDNF) protein and mRNA in the normal adult rat CNS: evidence for anterograde axonal transport. J Neurosci 17: 2295-313.

Connor, J. R., and Peters, A. (1984) Vasoactive intestinal polypeptide-immunoreactive neurons in rat visual cortex. Neuroscience 12: 1027-44.

Connors, B. W., and Gutnick, M. J. (1990) Intrinsic firing patterns of diverse neocortical neurons. Trends Neurosci 13: 99-104.

Connors, B. W., Malenka, R. C., and Silva, L. R. (1988) Two inhibitory postsynaptic potentials, and GABAA and GABAB receptor- mediated responses in neocortex of rat and cat. J Physiol 406: 443-68.

Conover, J. C., and Yancopoulos, G. D. (1997) Neurotrophin regulation of the developing nervous system: analyses of knockout mice. Rev Neurosci 8: 13-27.

Davies, A. M. (2000) Neurotrophins: neurotrophic modulation of neurite growth. Curr Biol 10: R198-200.

Davies, A. M., Lee, K. F., and Jaenisch, R. (1993) p75-deficient trigeminal sensory neurons have an altered response to NGF but not to other neurotrophins. Neuron 11: 56574. 
Deans, M. R., Gibson, J. R., Sellitto, C., Connors, B. W., and Paul, D. L. (2001) Synchronous activity of inhibitory networks in neocortex requires electrical synapses containing connexin36. Neuron 31: 477-85.

DeFelipe, J., Hendry, S. H., and Jones, E. G. (1986) A correlative electron microscopic study of basket cells and large GABAergic neurons in the monkey sensory-motor cortex. Neuroscience 17: 991-1009.

DeFelipe, J., Hendry, S. H., and Jones, E. G. (1989) Synapses of double bouquet cells in monkey cerebral cortex visualized by calbindin immunoreactivity. Brain Res 503: 49-54.

DeFelipe, J., Hendry, S. H., and Jones, E. G. (1989) Visualization of chandelier cell axons by parvalbumin immunoreactivity in monkey cerebral cortex. Proc Natl Acad Sci U S A 86: 2093-7.

Domenici, L., Berardi, N., Carmignoto, G., Vantini, G., and Maffei, L. (1991) Nerve growth factor prevents the amblyopic effects of monocular deprivation. Proc Natl Acad Sci U S A 88: 8811-5.

Doze, V. A., Cohen, G. A., and Madison, D. V. (1995) Calcium channel involvement in GABAB receptor-mediated inhibition of GABA release in area CA1 of the rat hippocampus. J Neurophysiol 74: 43-53.

Dykes, R. W. (1997) Mechanisms controlling neuronal plasticity in somatosensory cortex. Can J Physiol Pharmacol 75: 535-45.

Dykes, R. W., Landry, P., Metherate, R., and Hicks, T. P. (1984) Functional role of GABA in cat primary somatosensory cortex: shaping receptive fields of cortical neurons. J Neurophysiol 52: 1066-93.

Eckenstein, F., and Baughman, R. W. (1984) Two types of cholinergic innervation in cortex, one co-localized with vasoactive intestinal polypeptide. Nature 309: 153-5.

Eide, F. F., Vining, E. R., Eide, B. L., Zang, K., Wang, X. Y., and Reichardt, L. F. (1996) Naturally occurring truncated trkB receptors have dominant inhibitory effects on brainderived neurotrophic factor signaling. J Neurosci 16: 3123-9.

Erickson, J. C., Clegg, K. E., and Palmiter, R. D. (1996) Sensitivity to leptin and susceptibility to seizures of mice lacking neuropeptide Y. Nature 381: 415-21.

Ernfors, P., Wetmore, C., Olson, L., and Persson, H. (1990) Identification of cells in rat brain and peripheral tissues expressing mRNA for members of the nerve growth factor family. Neuron 5: 511-26.

Esclapez, M., Tillakaratne, N. J., Kaufman, D. L., Tobin, A. J., and Houser, C. R. (1994) 
Comparative localization of two forms of glutamic acid decarboxylase and their mRNAs in rat brain supports the concept of functional differences between the forms. J Neurosci 14: $1834-55$.

Faulkner, H. J., Traub, R. D., and Whittington, M. A. (1999) Anaesthetic/amnesic agents disrupt beta frequency oscillations associated with potentiation of excitatory synaptic potentials in the rat hippocampal slice. Br J Pharmacol 128: 1813-25.

Faulkner, H. J., Traub, R. D., and Whittington, M. A. (1998) Disruption of synchronous gamma oscillations in the rat hippocampal slice: a common mechanism of anaesthetic drug action. Br J Pharmacol 125: 483-92.

Fawcett, J. P., Aloyz, R., McLean, J. H., Pareek, S., Miller, F. D., McPherson, P. S., and Murphy, R. A. (1997) Detection of brain-derived neurotrophic factor in a vesicular fraction of brain synaptosomes. J Biol Chem 272: 8837-40.

Fawcett, J. P., Bamji, S. X., Causing, C. G., Aloyz, R., Ase, A. R., Reader, T. A., McLean, J. H., and Miller, F. D. (1998) Functional evidence that BDNF is an anterograde neuronal trophic factor in the CNS. J Neurosci 18: 2808-21.

Feldman, M. L., and Peters, A. (1978) The forms of non-pyramidal neurons in the visual cortex of the rat. J Comp Neurol 179: 761-93.

Figurov, A., Pozzo-Miller, L. D., Olafsson, P., Wang, T., and Lu, B. (1996) Regulation of synaptic responses to high-frequency stimulation and LTP by neurotrophins in the hippocampus. Nature 381: 706-9.

Fiszman, M. L., Borodinsky, L. N., and Neale, J. H. (1999) GABA induces proliferation of immature cerebellar granule cells grown in vitro. Brain Res Dev Brain Res 115: 1-8.

Fiumelli, H., Kiraly, M., Ambrus, A., Magistretti, P. J., and Martin, J. L. (2000) Opposite regulation of calbindin and calretinin expression by brain- derived neurotrophic factor in cortical neurons. J Neurochem 74: 1870-7.

Fonseca, M., del Rio, J. A., Martinez, A., Gomez, S., and Soriano, E. (1995) Development of calretinin immunoreactivity in the neocortex of the rat. J Comp Neurol 361: 177-92.

Frade, J. M., Rodriguez-Tebar, A., and Barde, Y. A. (1996) Induction of cell death by endogenous nerve growth factor through its p75 receptor. Nature 383: 166-8.

Francis, N., Farinas, I., Brennan, C., Rivas-Plata, K., Backus, C., Reichardt, L., and Landis, S. (1999) NT-3, like NGF, is required for survival of sympathetic neurons, but not their precursors. Dev Biol 210: 411-27.

Frerking, M., Malenka, R. C., and Nicoll, R. A. (1998) Brain-derived neurotrophic factor 
(BDNF) modulates inhibitory, but not excitatory, transmission in the CA1 region of the hippocampus. J Neurophysiol 80: 3383-6.

Freund, T. F., and Buzsaki, G. (1996) Interneurons of the hippocampus. Hippocampus 6: 347-470.

Friedman, W. J., and Greene, L. A. (1999) Neurotrophin signaling via Trks and p75. Exp Cell Res 253: 131-42.

Friedman, W. J., Olson, L., and Persson, H. (1991) Cells that Express Brain-Derived Neurotrophic Factor mRNA in the Developing Postnatal Rat Brain. Eur J Neurosci 3: 688-697.

Fryer, R. H., Kaplan, D. R., Feinstein, S. C., Radeke, M. J., Grayson, D. R., and Kromer, L. F. (1996) Developmental and mature expression of full-length and truncated TrkB receptors in the rat forebrain. J Comp Neurol 374: 21-40.

Fuchs, J. L., and Salazar, E. (1998) Effects of whisker trimming on GABA(A) receptor binding in the barrel cortex of developing and adult rats. J Comp Neurol 395: 209-16.

Gabbott, P. L., Dickie, B. G., Vaid, R. R., Headlam, A. J., and Bacon, S. J. (1997) Localcircuit neurones in the medial prefrontal cortex (areas 25, 32 and 24b) in the rat: morphology and quantitative distribution. J Comp Neurol 377: 465-99.

Galarreta, M., and Hestrin, S. (1999) A network of fast-spiking cells in the neocortex connected by electrical synapses. Nature 402: 72-5.

Gall, C., and Lauterborn, J. (1992) The dentate gyrus: a model system for studies of neurotrophin regulation. Epilepsy Res Suppl 7: 171-85.

Gall, C., Lauterborn, J., Bundman, M., Murray, K., and Isackson, P. (1991) Seizures and the regulation of neurotrophic factor and neuropeptide gene expression in brain. Epilepsy Res Suppl 4: 225-45.

Gall, C., Lauterborn, J., Isackson, P., and White, J. (1990) Seizures, neuropeptide regulation, and mRNA expression in the hippocampus. Prog Brain Res 83: 371-90.

Gambardella, A., Gotman, J., Cendes, F., and Andermann, F. (1995) Focal intermittent delta activity in patients with mesiotemporal atrophy: a reliable marker of the epileptogenic focus. Epilepsia 36: 122-9.

Gao, W. J., Wormington, A. B., Newman, D. E., and Pallas, S. L. (2000) Development of inhibitory circuitry in visual and auditory cortex of postnatal ferrets: immunocytochemical localization of calbindin- and parvalbumin-containing neurons. $\mathbf{J}$ Comp Neurol 422: 140-57. 
Ghosh, A., Carnahan, J., and Greenberg, M. E. (1994) Requirement for BDNF in activitydependent survival of cortical neurons. Science 263: 1618-23.

Gibson, J. R., Beierlein, M., and Connors, B. W. (1999) Two networks of electrically coupled inhibitory neurons in neocortex. Nature 402: 75-9.

Gonchar, Y., and Burkhalter, A. (1997) Three distinct families of GABAergic neurons in rat visual cortex. Cereb Cortex 7: 347-58.

Gorba, T., and Wahle, P. (1999) Expression of TrkB and TrkC but not BDNF mRNA in neurochemically identified interneurons in rat visual cortex in vivo and in organotypic cultures. Eur J Neurosci 11: 1179-90.

Gottschalk, W., Pozzo-Miller, L. D., Figurov, A., and Lu, B. (1998) Presynaptic modulation of synaptic transmission and plasticity by brain- derived neurotrophic factor in the developing hippocampus. J Neurosci 18: 6830-9.

Gotz, R., and Schartl, M. (1994) The conservation of neurotrophic factors during vertebrate evolution. Comp Biochem Physiol Pharmacol Toxicol Endocrinol 108: 1-10.

Griesbeck, O., Canossa, M., Campana, G., Gartner, A., Hoener, M. C., Nawa, H., Kolbeck, R., and Thoenen, H. (1999) Are there differences between the secretion characteristics of NGF and BDNF? Implications for the modulatory role of neurotrophins in activity- dependent neuronal plasticity. Microsc Res Tech 45: 262-75.

Guo, Y., Kaplan, I. V., Cooper, N. G., and Mower, G. D. (1997) Expression of two forms of glutamic acid decarboxylase (GAD67 and GAD65) during postnatal development of the cat visual cortex. Brain Res Dev Brain Res 103: 127-41.

Guthrie, K. M., and Gall, C. M. (1991) Differential expression of mRNAs for the NGF family of neurotrophic factors in the adult rat central olfactory system. J Comp Neurol 313: 95-102.

Gutnick, M. J., Connors, B. W., and Prince, D. A. (1982) Mechanisms of neocortical epileptogenesis in vitro. J Neurophysiol 48: 1321-35.

Guyon, A., and Leresche, N. (1995) Modulation by different GABAB receptor types of voltage-activated calcium currents in rat thalamocortical neurones. J Physiol 485: 29-42.

Haas, H. L., and Gahwiler, B. H. (1992) Vasoactive intestinal polypeptide modulates neuronal excitability in hippocampal slices of the rat. Neuroscience 47: 273-7.

Hansel, D., Mato, G., and Meunier, C. (1995) Synchrony in excitatory neural networks. Neural Comput 7: 307-37.

Harris, K. M. (1999) Structure, development, and plasticity of dendritic spines. Curr Opin 
Neurobiol 9: 343-8.

Haubensak, W., Narz, F., Heumann, R., and Lessmann, V. (1998) BDNF-GFP containing secretory granules are localized in the vicinity of synaptic junctions of cultured cortical neurons. J Cell Sci 111: 1483-93.

Haydar, T. F., Wang, F., Schwartz, M. L., and Rakic, P. (2000) Differential modulation of proliferation in the neocortical ventricular and subventricular zones. J Neurosci 20: 5764-74.

Hedlich, A., and Werner, L. (1986) [Classification of neurons of the visual cortex of the guinea pig (Cavia porcellus). A Golgi study]. J Hirnforsch 27: 651-77.

Hendry, S. H., Schwark, H. D., Jones, E. G., and Yan, J. (1987) Numbers and proportions of GABA-immunoreactive neurons in different areas of monkey cerebral cortex. $\mathrm{J}$ Neurosci 7: 1503-19.

Hensch, T. K., Fagiolini, M., Mataga, N., Stryker, M. P., Baekkeskov, S., and Kash, S. F. (1998) Local GABA circuit control of experience-dependent plasticity in developing visual cortex. Science 282: 1504-8.

Hestrin, S., and Armstrong, W. E. (1996) Morphology and physiology of cortical neurons in layer I. J Neurosci 16: 5290-300.

Hicks, T. P., and Dykes, R. W. (1983) Receptive field size for certain neurons in primary somatosensory cortex is determined by GABA-mediated intracortical inhibition. Brain Res 274: 160-4.

Horch, H. W., Kruttgen, A., Portbury, S. D., and Katz, L. C. (1999) Destabilization of cortical dendrites and spines by BDNF. Neuron 23: 353-64.

Houser, C. R., Hendry, S. H., Jones, E. G., and Vaughn, J. E. (1983) Morphological diversity of immunocytochemically identified GABA neurons in the monkey sensorymotor cortex. J Neurocytol 12: 617-38.

Huang, Z. J., Kirkwood, A., Pizzorusso, T., Porciatti, V., Morales, B., Bear, M. F., Maffei, L., and Tonegawa, S. (1999) BDNF regulates the maturation of inhibition and the critical period of plasticity in mouse visual cortex. Cell 98: 739-55.

Hughes, P. E., Alexi, T., Walton, M., Williams, C. E., Dragunow, M., Clark, R. G., and Gluckman, P. D. (1999) Activity and injury-dependent expression of inducible transcription factors, growth factors and apoptosis-related genes within the central nervous system. Prog Neurobiol 57: 421-50.

Ikeda, Y., Nishiyama, N., Saito, H., and Katsuki, H. (1997) Furosemide-sensitive calcium rise induced by GABAA-receptor stimulation in cultures of embryonic rat striatal 
neurons. Jpn J Pharmacol 74: 165-9.

Ikeda, Y., Nishiyama, N., Saito, H., and Katsuki, H. (1997) GABAA receptor stimulation promotes survival of embryonic rat striatal neurons in culture. Brain Res Dev Brain Res 98: 253-8.

Imamoto, K., Karasawa, N., Isomura, G., and Nagatsu, I. (1994) Cajal-Retzius neurons identified by GABA immunohistochemistry in layer I of the rat cerebral cortex. Neurosci Res 20: 101-5.

Isokawa, M. (1996) Decrement of GABAA receptor-mediated inhibitory postsynaptic currents in dentate granule cells in epileptic hippocampus. J Neurophysiol 75: 1901-8.

Janjua, N. A., Mori, A., and Hiramatsu, M. (1991) Gamma-aminobutyric acid uptake is decreased in the hippocampus in a genetic model of human temporal lobe epilepsy. Epilepsy Res 8: 71-4.

Jefferys, J. G., Traub, R. D., and Whittington, M. A. (1996) Neuronal networks for induced '40 Hz' rhythms. Trends Neurosci 19: 202-8.

Jones, K. R., Farinas, I., Backus, C., and Reichardt, L. F. (1994) Targeted disruption of the BDNF gene perturbs brain and sensory neuron development but not motor neuron development. Cell 76: 989-99.

Kafitz, K. W., Rose, C. R., Thoenen, H., and Konnerth, A. (1999) Neurotrophin-evoked rapid excitation through TrkB receptors. Nature 401: 918-21.

Kamphuis, W., Huisman, E., Wadman, W. J., and Lopes da Silva, F. H. (1989) Decrease in GABA immunoreactivity and alteration of GABA metabolism after kindling in the rat hippocampus. Exp Brain Res 74: 375-86.

Kaneko, T., and Hicks, T. P. (1988) Baclofen and gamma-aminobutyric acid differentially suppress the cutaneous responsiveness of primary somatosensory cortical neurones. Brain Res 443: 360-6.

Kaplan, D. R., Hempstead, B. L., Martin-Zanca, D., Chao, M. V., and Parada, L. F. (1991) The trk proto-oncogene product: a signal transducing receptor for nerve growth factor. Science 252: 554-8.

Kapur, J., Michelson, H. B., Buterbaugh, G. G., and Lothman, E. W. (1989) Evidence for a chronic loss of inhibition in the hippocampus after kindling: electrophysiological studies. Epilepsy Res 4: 90-9.

Kapur, J., Stringer, J. L., and Lothman, E. W. (1989) Evidence that repetitive seizures in the hippocampus cause a lasting reduction of GABAergic inhibition. J Neurophysiol 61: 417-26. 
Karlsson, G., Klebs, K., Hafner, T., Schmutz, M., and Olpe, H. R. (1992) Blockade of GABAB receptors accelerates amygdala kindling development. Experientia 48: 748-51.

Kash, S. F., Johnson, R. S., Tecott, L. H., Noebels, J. L., Mayfield, R. D., Hanahan, D., and Baekkeskov, S. (1997) Epilepsy in mice deficient in the 65-kDa isoform of glutamic acid decarboxylase. Proc Natl Acad Sci U S A 94: 14060-5.

Katarova, Z., Mugnaini, E., Sekerkova, G., Mann, J. R., Aszodi, A., Bosze, Z., Greenspan, R., and Szabo, G. (1998) Regulation of cell-type specific expression of lacZ by the 5'-flanking region of mouse GAD67 gene in the central nervous system of transgenic mice. Eur J Neurosci 10: 989-99.

Katsumaru, H., Kosaka, T., Heizmann, C. W., and Hama, K. (1988) Gap junctions on GABAergic neurons containing the calcium-binding protein parvalbumin in the rat hippocampus (CA1 region). Exp Brain Res 72: 363-70.

Kaufman, D. L., Houser, C. R., and Tobin, A. J. (1991) Two forms of the gammaaminobutyric acid synthetic enzyme glutamate decarboxylase have distinct intraneuronal distributions and cofactor interactions. J Neurochem 56: 720-3.

Kawaguchi, Y. (1995) Physiological subgroups of nonpyramidal cells with specific morphological characteristics in layer II/III of rat frontal cortex. J Neurosci 15: 2638-55.

Kawaguchi, Y. (1993) Physiological, morphological, and histochemical characterization of three classes of interneurons in rat neostriatum. J Neurosci 13: 4908-23.

Kawaguchi, Y., and Kubota, Y. (1997) GABAergic cell subtypes and their synaptic connections in rat frontal cortex. Cereb Cortex 7: 476-86.

Kawaguchi, Y., and Kubota, Y. (1996) Physiological and morphological identification of somatostatin- or vasoactive intestinal polypeptide-containing cells among GABAergic cell subtypes in rat frontal cortex. J Neurosci 16: 2701-15.

Kirkwood, A., and Bear, M. F. (1994) Hebbian synapses in visual cortex. J Neurosci 14: 1634-45.

Kisvarday, Z. F., Adams, C. B., and Smith, A. D. (1986) Synaptic connections of axoaxonic (chandelier) cells in human epileptic temporal cortex. Neuroscience 19: 1179-86.

Kisvarday, Z. F., Beaulieu, C., and Eysel, U. T. (1993) Network of GABAergic large basket cells in cat visual cortex (area 18): implication for lateral disinhibition. J Comp Neurol 327: 398-415.

Klein, R., Conway, D., Parada, L. F., and Barbacid, M. (1990) The trkB tyrosine protein kinase gene codes for a second neurogenic receptor that lacks the catalytic kinase 
domain. Cell 61: 647-56.

Kohara, K., Kitamura, A., Morishima, M., and Tsumoto, T. (2001) Activity-dependent transfer of brain-derived neurotrophic factor to postsynaptic neurons. Science 291: 241923.

Korsching, S. (1993) The neurotrophic factor concept: a reexamination. J Neurosci 13: 2739-48.

Korte, M., Griesbeck, O., Gravel, C., Carroll, P., Staiger, V., Thoenen, H., and Bonhoeffer, T. (1996) Virus-mediated gene transfer into hippocampal CA1 region restores long- term potentiation in brain-derived neurotrophic factor mutant mice. Proc Natl Acad Sci U S A 93: 12547-52.

Kovalchuk, Y., Hanse, E., Kafitz, K. W., and Konnerth, A. (2002) Postsynaptic Induction of BDNF-Mediated Long-Term Potentiation. Science 295: 1729-34.

Kubota, Y., Hattori, R., and Yui, Y. (1994) Three distinct subpopulations of GABAergic neurons in rat frontal agranular cortex. Brain Res 649: 159-73.

Kubota, Y., and Kawaguchi, Y. (1997) Two distinct subgroups of cholecystokininimmunoreactive cortical interneurons. Brain Res 752: 175-83.

Kulesza, R. J. J. (2002). Anatomical and Physiological Properties of the Superior Paraolivary Nucleus in the Rat. In Dissertation, pp. 113-146.

Kyriazi, H. T., Carvell, G. E., Brumberg, J. C., and Simons, D. J. (1996) Effects of baclofen and phaclofen on receptive field properties of rat whisker barrel neurons. Brain Res 712: 325-8.

Lambolez, B., Ropert, N., Perrais, D., Rossier, J., and Hestrin, S. (1996) Correlation between kinetics and RNA splicing of alpha-amino-3-hydroxy- 5-methylisoxazole-4propionic acid receptors in neocortical neurons. Proc Natl Acad Sci U S A 93: 1797-802.

Lauder, J. M., Liu, J., Devaud, L., and Morrow, A. L. (1998) GABA as a trophic factor for developing monoamine neurons. Perspect Dev Neurobiol 5: 247-59.

Lauterborn, J. C., Bizon, J. L., Tran, T. M., and Gall, C. M. (1995) NGF mRNA is expressed by GABAergic but not cholinergic neurons in rat basal forebrain. J Comp Neurol 360: 454-62.

Lauterborn, J. C., Isackson, P. J., and Gall, C. M. (1994) Cellular localization of NGF and NT-3 mRNAs in postnatal rat forebrain. Mol Cell Neurosci 5: 46-62.

Lauterborn, J. C., Isackson, P. J., and Gall, C. M. (1991) Nerve growth factor mRNAcontaining cells are distributed within regions of cholinergic neurons in the rat basal 
forebrain. J Comp Neurol 306: 439-46.

Lauterborn, J. C., Lynch, G., Vanderklish, P., Arai, A., and Gall, C. M. (2000) Positive modulation of AMPA receptors increases neurotrophin expression by hippocampal and cortical neurons. J Neurosci 20: 8-21.

Lavdas, A. A., Grigoriou, M., Pachnis, V., and Parnavelas, J. G. (1999) The medial ganglionic eminence gives rise to a population of early neurons in the developing cerebral cortex. J Neurosci 19: 7881-8.

Leibrock, J., Lottspeich, F., Hohn, A., Hofer, M., Hengerer, B., Masiakowski, P., Thoenen, H., and Barde, Y. A. (1989) Molecular cloning and expression of brain-derived neurotrophic factor. Nature 341: 149-52.

Lein, E. S., Hohn, A., and Shatz, C. J. (2000) Dynamic regulation of BDNF and NT-3 expression during visual system development. J Comp Neurol 420: 1-18.

Lessmann, V. (1998) Neurotrophin-dependent modulation of glutamatergic synaptic transmission in the mammalian CNS. Gen Pharmacol 31: 667-74.

Lessmann, V., Gottmann, K., and Heumann, R. (1994) BDNF and NT-4/5 enhance glutamatergic synaptic transmission in cultured hippocampal neurones. Neuroreport 6 : $21-5$.

Lessmann, V., and Heumann, R. (1998) Modulation of unitary glutamatergic synapses by neurotrophin- $4 / 5$ or brain-derived neurotrophic factor in hippocampal microcultures: presynaptic enhancement depends on pre-established paired-pulse facilitation. Neuroscience 86: 399-413.

Letinic, K., Zoncu, R., and Rakic, P. (2002) Origin of GABAergic neurons in the human neocortex. Nature 417: 645-9.

Levi-Montalcini, R. (1987) The nerve growth factor 35 years later. Science 237: 1154-62.

Levine, E. S., Dreyfus, C. F., Black, I. B., and Plummer, M. R. (1995) Brain-derived neurotrophic factor rapidly enhances synaptic transmission in hippocampal neurons via postsynaptic tyrosine kinase receptors. Proc Natl Acad Sci U S A 92: 8074-7.

Lewin, G. R., and Barde, Y. A. (1996) Physiology of the neurotrophins. Annu Rev Neurosci 19: 289-317.

Li, Y. X., Zhang, Y., Lester, H. A., Schuman, E. M., and Davidson, N. (1998) Enhancement of neurotransmitter release induced by brain-derived neurotrophic factor in cultured hippocampal neurons. J Neurosci 18: 10231-40.

Lindefors, N., Ballarin, M., Ernfors, P., Falkenberg, T., and Persson, H. (1992) 
Stimulation of glutamate receptors increases expression of brain- derived neurotrophic factor mRNA in rat hippocampus. Ann N Y Acad Sci 648: 296-9.

Ling, D. S., and Benardo, L. S. (1995) Recruitment of GABAA inhibition in rat neocortex is limited and not NMDA dependent. J Neurophysiol 74: 2329-35.

Lledo, P. M., Somasundaram, B., Morton, A. J., Emson, P. C., and Mason, W. T. (1992) Stable transfection of calbindin-D28k into the GH3 cell line alters calcium currents and intracellular calcium homeostasis. Neuron 9: 943-54.

Lohof, A. M., Ip, N. Y., and Poo, M. M. (1993) Potentiation of developing neuromuscular synapses by the neurotrophins NT-3 and BDNF. Nature 363: 350-3.

Lom, B., and Cohen-Cory, S. (1999) Brain-derived neurotrophic factor differentially regulates retinal ganglion cell dendritic and axonal arborization in vivo. J Neurosci 19: 9928-38.

Lonze, B. E., and Ginty, D. D. (2002) Function and regulation of CREB family transcription factors in the nervous system. Neuron 35: 605-23.

LoTurco, J. J., Owens, D. F., Heath, M. J., Davis, M. B., and Kriegstein, A. R. (1995) GABA and glutamate depolarize cortical progenitor cells and inhibit DNA synthesis. Neuron 15: 1287-98.

Lu, B., and Figurov, A. (1997) Role of neurotrophins in synapse development and plasticity. Rev Neurosci 8: 1-12.

Luhmann, H. J., and Prince, D. A. (1991) Postnatal maturation of the GABAergic system in rat neocortex. J Neurophysiol 65: 247-63.

Lund, J. S., and Lewis, D. A. (1993) Local circuit neurons of developing and mature macaque prefrontal cortex: Golgi and immunocytochemical characteristics. J Comp Neurol 328: 282-312.

Lytton, W. W., and Sejnowski, T. J. (1991) Simulations of cortical pyramidal neurons synchronized by inhibitory interneurons. J Neurophysiol 66: 1059-79.

Ma, Y. T., Hsieh, T., Forbes, M. E., Johnson, J. E., and Frost, D. O. (1998) BDNF injected into the superior colliculus reduces developmental retinal ganglion cell death. J Neurosci 18: 2097-107.

Madtes, P., Jr., and Redburn, D. A. (1983) GABA as a trophic factor during development. Life Sci 33: 979-84.

Magistretti, P. J., Morrison, J. H., Shoemaker, W. J., and Bloom, F. E. (1984) Morphological and functional correlates of VIP neurons in cerebral cortex. Peptides 5: 
Maisonpierre, P. C., Belluscio, L., Friedman, B., Alderson, R. F., Wiegand, S. J., Furth, M. E., Lindsay, R. M., and Yancopoulos, G. D. (1990) NT-3, BDNF, and NGF in the developing rat nervous system: parallel as well as reciprocal patterns of expression. Neuron 5: 501-9.

Mangan, P. S., and Lothman, E. W. (1996) Profound disturbances of pre- and postsynaptic GABAB-receptor-mediated processes in region CA1 in a chronic model of temporal lobe epilepsy. J Neurophysiol 76: 1282-96.

Marmigere, F., Choby, C., Rage, F., Richard, S., and Tapia-Arancibia, L. (2001) Rapid stimulatory effects of brain-derived neurotrophic factor and neurotrophin-3 on somatostatin release and intracellular calcium rise in primary hypothalamic cell cultures. Neuroendocrinology 74: 43-54.

Martin, D. L., and Rimvall, K. (1993) Regulation of gamma-aminobutyric acid synthesis in the brain. J Neurochem 60: 395-407.

Martin-Zanca, D., Oskam, R., Mitra, G., Copeland, T., and Barbacid, M. (1989) Molecular and biochemical characterization of the human trk proto- oncogene. Mol Cell Biol 9: 24-33.

Marty, S., Berninger, B., Carroll, P., and Thoenen, H. (1996) GABAergic stimulation regulates the phenotype of hippocampal interneurons through the regulation of brainderived neurotrophic factor. Neuron 16: 565-70.

Marty, S., Carroll, P., Cellerino, A., Castren, E., Staiger, V., Thoenen, H., and Lindholm, D. (1996) Brain-derived neurotrophic factor promotes the differentiation of various hippocampal nonpyramidal neurons, including Cajal-Retzius cells, in organotypic slice cultures. J Neurosci 16: 675-87.

Marty, S., and Onteniente, B. (1999) BDNF and NT-4 differentiate two pathways in the modulation of neuropeptide protein levels in postnatal hippocampal interneurons. Eur $\mathbf{J}$ Neurosci 11: 1647-56.

Marty, S., and Onteniente, B. (1997) The expression pattern of somatostatin and calretinin by postnatal hippocampal interneurons is regulated by activity-dependent and independent determinants. Neuroscience 80: 79-88.

Marty, S., Wehrle, R., and Sotelo, C. (2000) Neuronal activity and brain-derived neurotrophic factor regulate the density of inhibitory synapses in organotypic slice cultures of postnatal hippocampus. J Neurosci 20: 8087-95.

Masana, Y., Wanaka, A., Kato, H., Asai, T., and Tohyama, M. (1993) Localization of trkB mRNA in postnatal brain development. J Neurosci Res 35: 468-79. 
Mattson, M. P., Rychlik, B., Chu, C., and Christakos, S. (1991) Evidence for calciumreducing and excito-protective roles for the calcium-binding protein calbindin-D28k in cultured hippocampal neurons. Neuron 6: 41-51.

McAllister, A. K., Katz, L. C., and Lo, D. C. (1996) Neurotrophin regulation of cortical dendritic growth requires activity. Neuron 17: 1057-64.

McAllister, A. K., Katz, L. C., and Lo, D. C. (1999) Neurotrophins and synaptic plasticity. Annu Rev Neurosci 22: 295-318.

McAllister, A. K., Katz, L. C., and Lo, D. C. (1997) Opposing roles for endogenous BDNF and NT-3 in regulating cortical dendritic growth. Neuron 18: 767-78.

McAllister, A. K., Lo, D. C., and Katz, L. C. (1995) Neurotrophins regulate dendritic growth in developing visual cortex. Neuron 15: 791-803.

McCormick, D. A. (1989) GABA as an inhibitory neurotransmitter in human cerebral cortex. J Neurophysiol 62: 1018-27.

McCulloch, J., and Edvinsson, L. (1980) Cerebral circulatory and metabolic effects of vasoactive intestinal polypeptide. Am J Physiol 238: H449-56.

McQuiston, A. R., and Colmers, W. F. (1996) Neuropeptide Y2 receptors inhibit the frequency of spontaneous but not miniature EPSCs in CA3 pyramidal cells of rat hippocampus. J Neurophysiol 76: 3159-68.

Meier, E., Drejer, J., and Schousboe, A. (1984) GABA induces functionally active lowaffinity GABA receptors on cultured cerebellar granule cells. J Neurochem 43: 1737-44.

Meinecke, D. L., and Peters, A. (1987) GABA immunoreactive neurons in rat visual cortex. J Comp Neurol 261: 388-404.

Mertz, K., Koscheck, T., and Schilling, K. (2000) Brain-derived neurotrophic factor modulates dendritic morphology of cerebellar basket and stellate cells: an in vitro study. Neuroscience 97: 303-10.

Messersmith, E. K., and Redburn, D. A. (1993) The role of GABA during development of the outer retina in the rabbit. Neurochem Res 18: 463-70.

Meyer-Franke, A., Kaplan, M. R., Pfrieger, F. W., and Barres, B. A. (1995) Characterization of the signaling interactions that promote the survival and growth of developing retinal ganglion cells in culture. Neuron 15: 805-19.

Michael, G. J., Averill, S., Nitkunan, A., Rattray, M., Bennett, D. L., Yan, Q., and Priestley, J. V. (1997) Nerve growth factor treatment increases brain-derived 
neurotrophic factor selectively in TrkA-expressing dorsal root ganglion cells and in their central terminations within the spinal cord. J Neurosci 17: 8476-90.

Micheva, K. D., and Beaulieu, C. (1995a) An anatomical substrate for experiencedependent plasticity of the rat barrel field cortex. Proc Natl Acad Sci U S A 92: 11834-8.

Micheva, K. D., and Beaulieu, C. (1995b) Neonatal sensory deprivation induces selective changes in the quantitative distribution of GABA-immunoreactive neurons in the rat barrel field cortex. J Comp Neurol 361: 574-84.

Micheva, K. D., and Beaulieu, C. (1995c) Postnatal development of GABA neurons in the rat somatosensory barrel cortex: a quantitative study. Eur J Neurosci 7: 419-30.

Micheva, K. D., and Beaulieu, C. (1997) Development and plasticity of the inhibitory neocortical circuitry with an emphasis on the rodent barrel field cortex: a review. Can J Physiol Pharmacol 75: 470-8.

Michler, A. (1990) Involvement of GABA receptors in the regulation of neurite growth in cultured embryonic chick tectum. Int J Dev Neurosci 8: 463-72.

Minichiello, L., and Klein, R. (1996) TrkB and TrkC neurotrophin receptors cooperate in promoting survival of hippocampal and cerebellar granule neurons. Genes Dev 10: 284958 .

Mione, M. C., Danevic, C., Boardman, P., Harris, B., and Parnavelas, J. G. (1994) Lineage analysis reveals neurotransmitter (GABA or glutamate) but not calcium-binding protein homogeneity in clonally related cortical neurons. J Neurosci 14: 107-23.

Misgeld, U., Bijak, M., and Jarolimek, W. (1995) A physiological role for GABAB receptors and the effects of baclofen in the mammalian central nervous system. Prog Neurobiol 46: 423-62.

Mizuno, K., Carnahan, J., and Nawa, H. (1994) Brain-derived neurotrophic factor promotes differentiation of striatal GABAergic neurons. Dev Biol 165: 243-56.

Morales, B., Choi, S. Y., and Kirkwood, A. (2002) Dark rearing alters the development of GABAergic transmission in visual cortex. J Neurosci 22: 8084-90.

Mower, G. D., and Guo, Y. (2001) Comparison of the expression of two forms of glutamic acid decarboxylase (GAD67 and GAD65) in the visual cortex of normal and dark- reared cats. Brain Res Dev Brain Res 126: 65-74.

Mower, G. D., Rustad, R., and White, W. F. (1988) Quantitative comparisons of gammaaminobutyric acid neurons and receptors in the visual cortex of normal and dark-reared cats. J Comp Neurol 272: 293-302. 
Mowla, S. J., Pareek, S., Farhadi, H. F., Petrecca, K., Fawcett, J. P., Seidah, N. G., Morris, S. J., Sossin, W. S., and Murphy, R. A. (1999) Differential sorting of nerve growth factor and brain-derived neurotrophic factor in hippocampal neurons. J Neurosci 19: 2069-80.

Murphy, P. C., Grieve, K. L., and Sillito, A. M. (1993) Effects of vasoactive intestinal polypeptide on the response properties of cells in area 17 of the cat visual cortex. $\mathrm{J}$ Neurophysiol 69: 1465-74.

Narhi, L. O., Rosenfeld, R., Talvenheimo, J., Prestrelski, S. J., Arakawa, T., Lary, J. W., Kolvenbach, C. G., Hecht, R., Boone, T., Miller, J. A., and et al. (1993) Comparison of the biophysical characteristics of human brain-derived neurotrophic factor, neurotrophin3, and nerve growth factor. J Biol Chem 268: 13309-17.

Naus, C. C., Miller, F. D., Morrison, J. H., and Bloom, F. E. (1988) Immunohistochemical and in situ hybridization analysis of the development of the rat somatostatin-containing neocortical neuronal system. J Comp Neurol 269: 448-63.

Nawa, H., Bessho, Y., Carnahan, J., Nakanishi, S., and Mizuno, K. (1993) Regulation of neuropeptide expression in cultured cerebral cortical neurons by brain-derived neurotrophic factor. J Neurochem 60: 772-5.

Nawa, H., Pelleymounter, M. A., and Carnahan, J. (1994) Intraventricular administration of BDNF increases neuropeptide expression in newborn rat brain. J Neurosci 14: 375165.

Neuhoff, H., Roeper, J., and Schweizer, M. (1999) Activity-dependent formation of perforated synapses in cultured hippocampal neurons. Eur J Neurosci 11: 4241-50.

Newberry, N. R., and Nicoll, R. A. (1985) Comparison of the action of baclofen with gamma-aminobutyric acid on rat hippocampal pyramidal cells in vitro. J Physiol 360: 161-85.

Ninkina, N., Adu, J., Fischer, A., Pinon, L. G., Buchman, V. L., and Davies, A. M. (1996) Expression and function of TrkB variants in developing sensory neurons. Embo J 15: 6385-93.

Normand, M. M., Wszolek, Z. K., and Klass, D. W. (1995) Temporal intermittent rhythmic delta activity in electroencephalograms. J Clin Neurophysiol 12: 280-4.

Obst, K., Bronzel, M., and Wahle, P. (1998) Visual activity is required to maintain the phenotype of supragranular NPY neurons in rat area 17. Eur J Neurosci 10: 1422-8.

Obst, K., and Wahle, P. (1995) Areal differences of NPY mRNA-expressing neurons are established in the late postnatal rat visual cortex in vivo, but not in organotypic cultures. Eur J Neurosci 7: 2139-58. 
Obst, K., and Wahle, P. (1997) Phenotype specification of cortical neurons during a period of molecular plasticity. Eur J Neurosci 9: 2571-80.

Olsen, R. W., Bureau, M., Houser, C. R., Delgado-Escueta, A. V., Richards, J. G., and Mohler, H. (1992) GABA/benzodiazepine receptors in human focal epilepsy. Epilepsy Res Suppl 8: 383-91.

Owens, D. F., Boyce, L. H., Davis, M. B., and Kriegstein, A. R. (1996) Excitatory GABA responses in embryonic and neonatal cortical slices demonstrated by gramicidin perforated-patch recordings and calcium imaging. J Neurosci 16: 6414-23.

Palko, M. E., Coppola, V., and Tessarollo, L. (1999) Evidence for a role of truncated trkC receptor isoforms in mouse development. J Neurosci 19: 775-82.

Papadopoulos, G. C., Cavanagh, M. E., Antonopoulos, J., Michaloudi, H., and Parnavelas, J. G. (1993) Postnatal development of somatostatin-containing neurons in the visual cortex of normal and dark-reared rats. Exp Brain Res 92: 473-8.

Parnavelas, J. G. (1992) Development of GABA-containing neurons in the visual cortex. Prog Brain Res 90: 523-37.

Parnavelas, J. G., and Cavanagh, M. E. (1988) Transient expression of neurotransmitters in the developing neocortex. Trends Neurosci 11: 92-3.

Patterson, S. L., Abel, T., Deuel, T. A., Martin, K. C., Rose, J. C., and Kandel, E. R. (1996) Recombinant BDNF rescues deficits in basal synaptic transmission and hippocampal LTP in BDNF knockout mice. Neuron 16: 1137-45.

Peduzzi, J. D. (1988) Genesis of GABA-immunoreactive neurons in the ferret visual cortex. J Neurosci 8: 920-31.

Perry, T. L., Ito, M., Jones, K., and Hansen, S. (1984) Elevation of gamma-aminobutyric acid in human brain may increase dopaminergic neuronal function. Neurosci Lett 50: 6771.

Peters, A. (1990) The axon terminals of vasoactive intestinal polypeptide (VIP)containing bipolar cells in rat visual cortex. J Neurocytol 19: 672-85.

Peters, A., and Harriman, K. M. (1988) Enigmatic bipolar cell of rat visual cortex. J Comp Neurol 267: 409-32.

Peters, A., and Kimerer, L. M. (1981) Bipolar neurons in rat visual cortex: a combined Golgi-electron microscope study. J Neurocytol 10: 921-46.

Peters, A., and Proskauer, C. C. (1980) Synaptic relationships between a multipolar 
stellate cell and a pyramidal neuron in the rat visual cortex. A combined Golgi-electron microscope study. J Neurocytol 9: 163-83.

Peters, A., Proskauer, C. C., and Ribak, C. E. (1982) Chandelier cells in rat visual cortex. J Comp Neurol 206: 397-416.

Phillips, H. S., Hains, J. M., Laramee, G. R., Rosenthal, A., and Winslow, J. W. (1990) Widespread expression of BDNF but not NT3 by target areas of basal forebrain cholinergic neurons. Science 250: 290-4.

Polleux, F., Whitford, K. L., Dijkhuizen, P. A., Vitalis, T., and Ghosh, A. (2002) Control of cortical interneuron migration by neurotrophins and PI3- kinase signaling. Development 129: 3147-60.

Porter, J. T., Cauli, B., Staiger, J. F., Lambolez, B., Rossier, J., and Audinat, E. (1998) Properties of bipolar VIPergic interneurons and their excitation by pyramidal neurons in the rat neocortex. Eur J Neurosci 10: 3617-28.

Pozzo-Miller, L. D., Gottschalk, W., Zhang, L., McDermott, K., Du, J., Gopalakrishnan, R., Oho, C., Sheng, Z. H., and Lu, B. (1999) Impairments in high-frequency transmission, synaptic vesicle docking, and synaptic protein distribution in the hippocampus of BDNF knockout mice. J Neurosci 19: 4972-83.

Priest, C. A., Thompson, A. J., and Keller, A. (2001) Gap junction proteins in inhibitory neurons of the adult barrel neocortex. Somatosens Mot Res 18: 245-52.

Prieto, J. J., Peterson, B. A., and Winer, J. A. (1994) Morphology and spatial distribution of GABAergic neurons in cat primary auditory cortex (AI). J Comp Neurol 344: 349-82.

Rabacchi, S. A., Kruk, B., Hamilton, J., Carney, C., Hoffman, J. R., Meyer, S. L., Springer, J. E., and Baird, D. H. (1999) BDNF and NT4/5 promote survival and neurite outgrowth of pontocerebellar mossy fiber neurons. J Neurobiol 40: 254-69.

Reibel, S., Vivien-Roels, B., Le, B. T., Larmet, Y., Carnahan, J., Marescaux, C., and Depaulis, A. (2000) Overexpression of neuropeptide Y induced by brain-derived neurotrophic factor in the rat hippocampus is long lasting. Eur J Neurosci 12: 595-605.

Reiher, J., Beaudry, M., and Leduc, C. P. (1989) Temporal intermittent rhythmic delta activity (TIRDA) in the diagnosis of complex partial epilepsy: sensitivity, specificity and predictive value. Can J Neurol Sci 16: 398-401.

Ren, J. Q., Aika, Y., Heizmann, C. W., and Kosaka, T. (1992) Quantitative analysis of neurons and glial cells in the rat somatosensory cortex, with special reference to GABAergic neurons and parvalbumin-containing neurons. Exp Brain Res 92: 1-14.

Rimvall, K., and Martin, D. L. (1991) GAD and GABA in an enriched population of 
cultured GABAergic neurons from rat cerebral cortex. Neurochem Res 16: 859-68.

Ringstedt, T., Lagercrantz, H., and Persson, H. (1993) Expression of members of the trk family in the developing postnatal rat brain. Brain Res Dev Brain Res 72: 119-31.

Roberts, R. C., and Ribak, C. E. (1986) Anatomical changes of the GABAergic system in the inferior colliculus of the genetically epilepsy-prone rat. Life Sci 39: 789-98.

Rocamora, N., Welker, E., Pascual, M., and Soriano, E. (1996) Upregulation of BDNF mRNA expression in the barrel cortex of adult mice after sensory stimulation. $\mathrm{J}$ Neurosci 16: 4411-9.

Rossi, F. M., Bozzi, Y., Pizzorusso, T., and Maffei, L. (1999) Monocular deprivation decreases brain-derived neurotrophic factor immunoreactivity in the rat visual cortex. Neuroscience 90: 363-8.

Roux, P. P., Colicos, M. A., Barker, P. A., and Kennedy, T. E. (1999) p75 neurotrophin receptor expression is induced in apoptotic neurons after seizure. J Neurosci 19: 6887-96.

Rozas, C., Frank, H., Heynen, A. J., Morales, B., Bear, M. F., and Kirkwood, A. (2001) Developmental inhibitory gate controls the relay of activity to the superficial layers of the visual cortex. J Neurosci 21: 6791-801.

Rutherford, L. C., DeWan, A., Lauer, H. M., and Turrigiano, G. G. (1997) Brain-derived neurotrophic factor mediates the activity-dependent regulation of inhibition in neocortical cultures. J Neurosci 17: 4527-35.

Rutherford, L. C., Nelson, S. B., and Turrigiano, G. G. (1998) BDNF has opposite effects on the quantal amplitude of pyramidal neuron and interneuron excitatory synapses. Neuron 21: 521-30.

Scanziani, M., Debanne, D., Muller, M., Gahwiler, B. H., and Thompson, S. M. (1994) Role of excitatory amino acid and GABAB receptors in the generation of epileptiform activity in disinhibited hippocampal slice cultures. Neuroscience 61: 823-32.

Schierle, G. S., Gander, J. C., D'Orlando, C., Ceilo, M. R., and Vogt Weisenhorn, D. M. (1997) Calretinin-immunoreactivity during postnatal development of the rat isocortex: a qualitative and quantitative study. Cereb Cortex 7: 130-42.

Schinder, A. F., Berninger, B., and Poo, M. (2000) Postsynaptic target specificity of neurotrophin-induced presynaptic potentiation. Neuron 25: 151-63.

Scholz, K. P., and Miller, R. J. (1991) GABAB receptor-mediated inhibition of Ca2+ currents and synaptic transmission in cultured rat hippocampal neurones. J Physiol 444: 669-86. 
Schoups, A. A., Elliott, R. C., Friedman, W. J., and Black, I. B. (1995) NGF and BDNF are differentially modulated by visual experience in the developing geniculocortical pathway. Brain Res Dev Brain Res 86: 326-34.

Schurmans, S., Schiffmann, S. N., Gurden, H., Lemaire, M., Lipp, H. P., Schwam, V., Pochet, R., Imperato, A., Bohme, G. A., and Parmentier, M. (1997) Impaired long-term potentiation induction in dentate gyrus of calretinin-deficient mice. Proc Natl Acad Sci U S A 94: 10415-20.

Schwartz, P. M., Borghesani, P. R., Levy, R. L., Pomeroy, S. L., and Segal, R. A. (1997) Abnormal cerebellar development and foliation in BDNF-/- mice reveals a role for neurotrophins in CNS patterning. Neuron 19: 269-81.

Seil, F. J., and Drake-Baumann, R. (2000) TrkB receptor ligands promote activitydependent inhibitory synaptogenesis. J Neurosci 20: 5367-73.

Seil, F. J., Drake-Baumann, R., Leiman, A. L., Herndon, R. M., and Tiekotter, K. L. (1994) Morphological correlates of altered neuronal activity in organotypic cerebellar cultures chronically exposed to anti-GABA agents. Brain Res Dev Brain Res 77: 123-32.

Shelton, D. L., and Reichardt, L. F. (1986) Studies on the expression of the beta nerve growth factor (NGF) gene in the central nervous system: level and regional distribution of NGF mRNA suggest that NGF functions as a trophic factor for several distinct populations of neurons. Proc Natl Acad Sci U S A 83: 2714-8.

Shieh, P. B., Hu, S. C., Bobb, K., Timmusk, T., and Ghosh, A. (1998) Identification of a signaling pathway involved in calcium regulation of BDNF expression. Neuron 20: 72740.

Shimada, A., Mason, C. A., and Morrison, M. E. (1998) TrkB signaling modulates spine density and morphology independent of dendrite structure in cultured neonatal Purkinje cells. J Neurosci 18: 8559-70.

Sillito, A. M. (1975) The contribution of inhibitory mechanisms to the receptive field properties of neurones in the striate cortex of the cat. J Physiol 250: 305-29.

Sillito, A. M., and Kemp, J. A. (1983) The influence of GABAergic inhibitory processes on the receptive field structure of $\mathrm{X}$ and $\mathrm{Y}$ cells in cat dorsal lateral geniculate nucleus (dLGN). Brain Res 277: 63-77.

Singer, W., and Gray, C. M. (1995) Visual feature integration and the temporal correlation hypothesis. Annu Rev Neurosci 18: 555-86.

Singh, T. D., Mizuno, K., Kohno, T., and Nakamura, S. (1997) BDNF and trkB mRNA expression in neurons of the neonatal mouse barrel field cortex: normal development and plasticity after cauterizing facial vibrissae. Neurochem Res 22: 791-7. 
Skangiel-Kramska, J., Glazewski, S., Jablonska, B., Siucinska, E., and Kossut, M. (1994) Reduction of GABAA receptor binding of $[3 \mathrm{H}]$ muscimol in the barrel field of mice after peripheral denervation: transient and long-lasting effects. Exp Brain Res 100: 39-46.

Sloper, J. J., Johnson, P., and Powell, T. P. (1980) Selective degeneration of interneurons in the motor cortex of infant monkeys following controlled hypoxia: a possible cause of epilepsy. Brain Res 198: 204-9.

Sloviter, R. S. (1987) Decreased hippocampal inhibition and a selective loss of interneurons in experimental epilepsy. Science 235: 73-6.

Sloviter, R. S. (1991) Permanently altered hippocampal structure, excitability, and inhibition after experimental status epilepticus in the rat: the "dormant basket cell" hypothesis and its possible relevance to temporal lobe epilepsy. Hippocampus 1: 41-66.

Snead, O. C., 3rd (1992) Evidence for GABAB-mediated mechanisms in experimental generalized absence seizures. Eur J Pharmacol 213: 343-9.

Snider, W. D. (1994) Functions of the neurotrophins during nervous system development: what the knockouts are teaching us. Cell 77: 627-38.

Soltesz, I., and Mody, I. (1994) Patch-clamp recordings reveal powerful GABAergic inhibition in dentate hilar neurons. J Neurosci 14: 2365-76.

Somogyi, P., and Cowey, A. (1981) Combined Golgi and electron microscopic study on the synapses formed by double bouquet cells in the visual cortex of the cat and monkey. $\mathrm{J}$ Comp Neurol 195: 547-66.

Somogyi, P., Fritschy, J. M., Benke, D., Roberts, J. D., and Sieghart, W. (1996) The gamma 2 subunit of the GABAA receptor is concentrated in synaptic junctions containing the alpha 1 and beta $2 / 3$ subunits in hippocampus, cerebellum and globus pallidus. Neuropharmacology 35: 1425-44.

Spoerri, P. E. (1988) Neurotrophic effects of GABA in cultures of embryonic chick brain and retina. Synapse 2: 11-22.

Spoerri, P. E., and Wolff, J. R. (1981) Effect of GABA-administration on murine neuroblastoma cells in culture. I. Increased membrane dynamics and formation of specialized contacts. Cell Tissue Res 218: 567-79.

Steriade, M., McCormick, D. A., and Sejnowski, T. J. (1993) Thalamocortical oscillations in the sleeping and aroused brain. Science 262: 679-85.

Stoop, R., and Poo, M. M. (1996) Synaptic modulation by neurotrophic factors: differential and synergistic effects of brain-derived neurotrophic factor and ciliary 
neurotrophic factor. J Neurosci 16: 3256-64.

Suen, P. C., Wu, K., Levine, E. S., Mount, H. T., Xu, J. L., Lin, S. Y., and Black, I. B. (1997) Brain-derived neurotrophic factor rapidly enhances phosphorylation of the postsynaptic N-methyl-D-aspartate receptor subunit 1. Proc Natl Acad Sci U S A 94: $8191-5$.

Sutter, A., Riopelle, R. J., Harris-Warrick, R. M., and Shooter, E. M. (1979) Nerve growth factor receptors. Characterization of two distinct classes of binding sites on chick embryo sensory ganglia cells. J Biol Chem 254: 5972-82.

Szabo, G., Katarova, Z., Kortvely, E., Greenspan, R. J., and Urban, Z. (1996) Structure and the promoter region of the mouse gene encoding the $67-\mathrm{kD}$ form of glutamic acid decarboxylase. DNA Cell Biol 15: 1081-91.

Takei, N., Sasaoka, K., Inoue, K., Takahashi, M., Endo, Y., and Hatanaka, H. (1997) Brain-derived neurotrophic factor increases the stimulation-evoked release of glutamate and the levels of exocytosis-associated proteins in cultured cortical neurons from embryonic rats. J Neurochem 68: 370-5.

Tallent, M. K., and Siggins, G. R. (1999) Somatostatin acts in CA1 and CA3 to reduce hippocampal epileptiform activity. J Neurophysiol 81: 1626-35.

Tamas, G., Buhl, E. H., Lorincz, A., and Somogyi, P. (2000) Proximally targeted GABAergic synapses and gap junctions synchronize cortical interneurons. Nat Neurosci 3: 366-71.

Tan, S. S., Kalloniatis, M., Sturm, K., Tam, P. P., Reese, B. E., and Faulkner-Jones, B. (1998) Separate progenitors for radial and tangential cell dispersion during development of the cerebral neocortex. Neuron 21: 295-304.

Tanaka, T., Saito, H., and Matsuki, N. (1997) Inhibition of GABAA synaptic responses by brain-derived neurotrophic factor (BDNF) in rat hippocampus. J Neurosci 17: 295966.

Tao, X., Finkbeiner, S., Arnold, D. B., Shaywitz, A. J., and Greenberg, M. E. (1998) $\mathrm{Ca} 2+$ influx regulates BDNF transcription by a CREB family transcription factordependent mechanism. Neuron 20: 709-26.

Thoenen, H. (1995) Neurotrophins and neuronal plasticity. Science 270: 593-8.

Thompson, C. L., Tehrani, M. H., Barnes, E. M., Jr., and Stephenson, F. A. (1998) Decreased expression of GABAA receptor alpha6 and beta3 subunits in stargazer mutant mice: a possible role for brain-derived neurotrophic factor in the regulation of cerebellar GABAA receptor expression? Brain Res Mol Brain Res 60: 282-90. 
Thomson, A. M., West, D. C., Hahn, J., and Deuchars, J. (1996) Single axon IPSPs elicited in pyramidal cells by three classes of interneurones in slices of rat neocortex. J Physiol 496: 81-102.

Timmusk, T., Belluardo, N., Metsis, M., and Persson, H. (1993) Widespread and developmentally regulated expression of neurotrophin-4 mRNA in rat brain and peripheral tissues. Eur J Neurosci 5: 605-13.

Tian, N., Petersen, C., Kash, S., Baekkeskov, S., Copenhagen, D., and Nicoll, R. (1999) The role of the synthetic enzyme GAD65 in the control of neuronal gammaaminobutyric acid release. Proc Natl Acad Sci U S A 96: 12911-6.

Traub, R. D., Jefferys, J. G., and Whittington, M. A. (1999) Functionally relevant and functionally disruptive (epileptic) synchronized oscillations in brain slices. Adv Neurol 79: 709-24.

Traub, R. D., Whittington, M. A., Colling, S. B., Buzsaki, G., and Jefferys, J. G. (1996) Analysis of gamma rhythms in the rat hippocampus in vitro and in vivo. J Physiol 493: 471-84.

Treiman, D. M. (2001) GABAergic mechanisms in epilepsy. Epilepsia 42: 8-12.

Tremere, L., Hicks, T. P., and Rasmusson, D. D. (2001) Role of inhibition in cortical reorganization of the adult raccoon revealed by microiontophoretic blockade of GABA(A) receptors. J Neurophysiol 86: 94-103.

Tropea, D., and Domenici, L. (2001) Expression of TrkB receptors in developing visual cortex is not regulated by light. Cell Mol Neurobiol 21: 545-52.

Tyler, W. J., and Pozzo-Miller, L. D. (2001) BDNF enhances quantal neurotransmitter release and increases the number of docked vesicles at the active zones of hippocampal excitatory synapses. J Neurosci 21: 4249-58.

van Brederode, J. F., and Spain, W. J. (1995) Differences in inhibitory synaptic input between layer II-III and layer V neurons of the cat neocortex. J Neurophysiol 74: 114966.

Vergnes, M., Boehrer, A., Simler, S., Bernasconi, R., and Marescaux, C. (1997) Opposite effects of GABAB receptor antagonists on absences and convulsive seizures. Eur $\mathbf{J}$ Pharmacol 332: 245-55.

Vezzani, A., and Hoyer, D. (1999) Brain somatostatin: a candidate inhibitory role in seizures and epileptogenesis. Eur J Neurosci 11: 3767-76.

Vicario-Abejon, C., Collin, C., McKay, R. D., and Segal, M. (1998) Neurotrophins induce formation of functional excitatory and inhibitory synapses between cultured 
hippocampal neurons. J Neurosci 18: 7256-71.

Vogt Weisenhorn, D. M., Celio, M. R., and Rickmann, M. (1998) The onset of parvalbumin-expression in interneurons of the rat parietal cortex depends upon extrinsic factor(s). Eur J Neurosci 10: 1027-36.

Wahle, P. (1993) Differential regulation of substance P and somatostatin in Martinotti cells of the developing cat visual cortex. J Comp Neurol 329: 519-38.

Wang, Q., and Zheng, J. Q. (1998) cAMP-mediated regulation of neurotrophin-induced collapse of nerve growth cones. J Neurosci 18: 4973-84.

Wang, X., Berninger, B., and Poo, M. (1998) Localized synaptic actions of neurotrophin4. J Neurosci 18: 4985-92.

Wang, X. J., and Buzsaki, G. (1996) Gamma oscillation by synaptic inhibition in a hippocampal interneuronal network model. J Neurosci 16: 6402-13.

Wang, Y., Fujita, I., Tamura, H., and Murayama, Y. (2002) Contribution of GABAergic inhibition to receptive field structures of monkey inferior temporal neurons. Cereb Cortex 12: 62-74.

Whittemore, S. R., Ebendal, T., Larkfors, L., Olson, L., Seiger, A., Stromberg, I., and Persson, H. (1986) Development and regional expression of beta nerve growth factor messenger RNA and protein in the rat central nervous system. Proc Natl Acad Sci U S A 83: 817-21.

Whittington, M. A., Traub, R. D., and Jefferys, J. G. (1995) Synchronized oscillations in interneuron networks driven by metabotropic glutamate receptor activation. Nature 373: $612-5$.

Whittington, M. A., Traub, R. D., Kopell, N., Ermentrout, B., and Buhl, E. H. (2000) Inhibition-based rhythms: experimental and mathematical observations on network dynamics. Int J Psychophysiol 38: 315-36.

Widmer, H. R., and Hefti, F. (1994) Stimulation of GABAergic neuron differentiation by NT-4/5 in cultures of rat cerebral cortex. Brain Res Dev Brain Res 80: 279-84.

Wolff, J. R., Balcar, V. J., Zetzsche, T., Bottcher, H., Schmechel, D. E., and Chronwall, B. M. (1984) Development of GABA-ergic system in rat visual cortex. Adv Exp Med Biol 181: 215-39.

Wu, K., Xu, J. L., Suen, P. C., Levine, E., Huang, Y. Y., Mount, H. T., Lin, S. Y., and Black, I. B. (1996) Functional trkB neurotrophin receptors are intrinsic components of the adult brain postsynaptic density. Brain Res Mol Brain Res 43: 286-90. 
Xu, B., Zang, K., Ruff, N. L., Zhang, Y. A., McConnell, S. K., Stryker, M. P., and Reichardt, L. F. (2000) Cortical degeneration in the absence of neurotrophin signaling: dendritic retraction and neuronal loss after removal of the receptor TrkB. Neuron 26: 233-45.

Yacoubian, T. A., and Lo, D. C. (2000) Truncated and full-length TrkB receptors regulate distinct modes of dendritic growth. Nat Neurosci 3: 342-9.

Yaksh, T. L., Wang, J. Y., and Go, V. L. (1987) Cortical vasodilatation produced by vasoactive intestinal polypeptide (VIP) and by physiological stimuli in the cat. J Cereb Blood Flow Metab 7: 315-26.

Yan, Q., Radeke, M. J., Matheson, C. R., Talvenheimo, J., Welcher, A. A., and Feinstein, S. C. (1997) Immunocytochemical localization of TrkB in the central nervous system of the adult rat. J Comp Neurol 378: 135-57.

Yan, Q., Rosenfeld, R. D., Matheson, C. R., Hawkins, N., Lopez, O. T., Bennett, L., and Welcher, A. A. (1997) Expression of brain-derived neurotrophic factor protein in the adult rat central nervous system. Neuroscience 78: 431-48.

Yang, Q., and Michelson, H. B. (2001) Gap junctions synchronize the firing of inhibitory interneurons in guinea pig hippocampus. Brain Res 907: 139-43.

Yin, Y., Edelman, G. M., and Vanderklish, P. W. (2002) The brain-derived neurotrophic factor enhances synthesis of Arc in synaptoneurosomes. Proc Natl Acad Sci U S A 99: 2368-73.

Yuste, R., and Katz, L. C. (1991) Control of postsynaptic Ca2+ influx in developing neocortex by excitatory and inhibitory neurotransmitters. Neuron 6: 333-44.

Zafra, F., Castren, E., Thoenen, H., and Lindholm, D. (1991) Interplay between glutamate and gamma-aminobutyric acid transmitter systems in the physiological regulation of brain-derived neurotrophic factor and nerve growth factor synthesis in hippocampal neurons. Proc Natl Acad Sci U S A 88: 10037-41.

Zafra, F., Hengerer, B., Leibrock, J., Thoenen, H., and Lindholm, D. (1990) Activity dependent regulation of BDNF and NGF mRNAs in the rat hippocampus is mediated by non-NMDA glutamate receptors. Embo J 9: 3545-50.

Zafra, F., Lindholm, D., Castren, E., Hartikka, J., and Thoenen, H. (1992) Regulation of brain-derived neurotrophic factor and nerve growth factor mRNA in primary cultures of hippocampal neurons and astrocytes. J Neurosci 12: 4793-9.

Zhou, X. F., and Rush, R. A. (1996) Endogenous brain-derived neurotrophic factor is anterogradely transported in primary sensory neurons. Neuroscience 74: 945-53. 


\section{Chapter Two}

Biolistic transfection with GAD67-GFP DNA reveals functional

GABAergic interneurons in organotypic mouse brain slice cultures 


\section{ABSTRACT}

Neurons using $\gamma$-aminobutyric acid (GABA) as a neurotransmitter are critically important as inhibitory neurons in the CNS. A major hindrance to further studies of this important, but highly diverse class of neurons is their relative scarcity, which makes it difficult to identify and target them for morphological and physiological studies in vivo or in vitro. To visualize specifically cortical GABAergic neurons in living preparations, we prepared a plasmid encoding green fluorescent protein (GFP) fused to the GAD67 promoter, and used a gene gun to transfect the construct into organotypic mouse brain slice cultures. We found that a small percentage of cortical neurons became brightly fluorescent after GAD67-GFP transfection, and could be imaged in their entirety, including dendritic spines and axonal boutons, in living slices. GFP expression was restricted specifically to GABAergic interneurons, as confirmed by morphological, immunocytochemical and electrophysiological criteria. GFP-expressing neurons fired action potential trains in patterns typical of GABAergic cortical interneurons, received spontaneous postsynaptic currents (PSCs) and generated inhibitory PSCs in postsynaptic neurons following minimal electrical stimulation. We conclude that gene gun-mediated transfection with the GAD67-GFP construct specifically labeled functional GABAergic interneurons in brain slice cultures, providing a useful approach for morphological, electrophysiological and developmental studies of these neurons in vitro. 


\section{INTRODUCTION}

Cortical inhibitory interneurons synthesize and utilize $\gamma$-aminobutyric acid (GABA) as a neurotransmitter. Although accounting for only about $20-30 \%$ of the total neuronal population in the neocortex (Hendry et al., 1987; Micheva and Beaulieu, 1995; Ren et al., 1992), they are critically important to proper development and function of the cerebral cortex. Among their known functions, they restrict the general excitability of the cortex through feedback and feedforward inhibitory mechanisms (Connors et al., 1988; Avoli, 1996; McBain and Fisahn, 2001), restrict and shape receptive fields (Dykes et al., 1984; Tremere et al., 2001), synchronize neuronal activity (Nguyen et al., 2001; Owens and Kriegstein, 2002), and the released GABA acts as a neurotrophic factor during development. GABAergic neurons are widely diverse in their morphological, neurochemical and electrophysiological properties (Houser et al., 1983; MartinezGuijarro and Freund, 1992; Kawaguchi and Kubota, 1997); this diversity, together with their relative scarcity, makes their identification difficult, especially in living preparations, and greatly hinders their study.

The goal of this study was to develop a method to specifically visualize GABAergic interneurons in vitro. We used a gene gun to transfect cultured mouse brain slices with a green fluorescent protein (GFP) gene driven by the glutamic acid decarboxylase 67 (GAD67) promoter. GAD67 is an essential enzyme for GABA biosynthesis and is expressed exclusively in GABAergic neurons in the CNS (Wolff et al., 1984; Esclapez et al., 1994). Transfection of GFP under the control of the GAD67 promoter should therefore specifically label GABAergic neurons. Here we document 
that this is indeed the case, and demonstrate the utility of this labeling method for electrophysiological studies.

\section{MATERIALS AND METHODS}

Organotypic culture preparation Organotypic cortical slice cultures were prepared using the previously described static membrane method (Stoppini et al., 1991). Postnatal day 13 mouse pups were anesthetized by cooling, decapitated, and the brains rapidly removed and immersed in ice-cold artificial cerebrospinal fluid (ACSF, containing $126 \mathrm{mM} \mathrm{NaCl}$, 3.0 mM KCl, $1.3 \mathrm{mM} \mathrm{MgSO}_{4}, 2.5 \mathrm{mM} \mathrm{CaCl}_{2}, 1.2 \mathrm{mM} \mathrm{NaH}_{2} \mathrm{PO}_{4}, 26 \mathrm{mM} \mathrm{NaHCO}$, and $20 \mathrm{mM}$ dextrose, saturated with 95\%:5\% $\mathrm{O}_{2}: \mathrm{CO}_{2}$ ). Under sterile conditions in a laminar flow hood, $350 \mu \mathrm{m}$ thick coronal brain slices of parietal cortex were cut with a Vibraslicer (WPI, Sarasota, FL). Slices were then placed on Millicell membrane inserts (Millipore, Bedford, MA), usually two slices/insert, in $30 \mathrm{~mm}$ Petri dishes containing 1 $\mathrm{ml}$ of culture medium. The culture medium was composed of $46 \%$ (volume/volume) Eagle's basal medium, 25\% Earle's balanced salt solution, $25 \%$ horse serum, $1 \%$ mixture of penicillin $(10,000 \mathrm{units} / \mathrm{ml})$-streptomycin $(10 \mathrm{mg} / \mathrm{ml})$-glutamine $(29.2 \mathrm{mg} / \mathrm{ml})($ all from Invitrogen, Carlsbad, CA), and $3 \%$ of a $20 \%$ (weight/volume) glucose solution, for a final glucose concentration of $6.5 \mathrm{mg} / \mathrm{ml}$. The $\mathrm{pH}$ was adjusted to 7.2 . The slices were kept in a humidified incubator at $35^{\circ} \mathrm{C}$ with a $5 \% \mathrm{CO}_{2}$-enhanced atmosphere, and the medium was changed twice a week. Gene gun transfection was done after 2-3 days in vitro.

GAD67-GFP DNA construct Two plasmids containing an enhanced green fluorescent protein gene (GFP) were used. One was CMV-GFP with the transcription being driven 
by a cytomegalovirus (CMV) promoter ('Greenlantern', from Invitrogen, Carlsbad, CA), and the other was GAD67-GFP, consisting of a $10.3 \mathrm{~kb}$ segment of the murine GAD67 genomic DNA, including the 5' upstream regulatory region, the first (untranslated) exon and intron and a portion of exon 2 (Jin et al., 2001; Katarova et al., 1998). The GAD67 promoter was provided by Gabor Szabo (the Institute of Biochemistry, Biological Research Center, Szeged, Hungary). GAD67-GFP DNA constructs were prepared by Peter Mathers of the Department of Otolaryngology at West Virginia University.

Gene gun cartridge preparation Cultured slices were transfected using a Helios gene gun (Bio-Rad, Hercules, CA). Cartridges were prepared according to the manufacturer's protocols with slight modification. $12 \mathrm{mg}$ gold particles (1.6 $\mu \mathrm{m}$ diameter, Bio-Rad) were suspended in $100 \mu \mathrm{l} 0.05 \mathrm{M}$ spermidine, $25 \mu \mathrm{g}$ plasmid DNA at $1 \mu \mathrm{g} / \mu \mathrm{l}$ concentration were added, followed by slow addition of $100 \mu 11 \mathrm{M} \mathrm{CaCl}_{2}$. After three washes with $100 \%$ ethanol, the DNA coated particles were resuspended in $0.05 \mathrm{mg} / \mathrm{ml}$ polyvinylpyrrolidone (PVP) in ethanol, and filled into a 25 inch long teflon tube ('Tefzel' tubing, Bio-Rad). After 4 minutes, allowing the DNA coated particles to precipitate onto the tubing wall, the supernatant was removed with a peristaltic pump. While continuously flushing with nitrogen to dry out the ethanol, the tube was rotated for about 5 minutes to distribute the particles more evenly along its inner wall. The tubing was cut into 0.5 inch pieces and the ensuing cartridges stored in a parafilm-sealed bottle at $4^{\circ} \mathrm{C}$.

Gene Gun Transfection Slice transfection was done under sterile conditions in a laminar flow hood. To reduce the helium shock wave and distribute the gold particles more 
evenly, a nylon mesh with a grid width of $70 \mu \mathrm{m}$ was attached to a plastic ring on the far end of the spacer (Wellmann et al., 1999). Slices were bombarded with one cartridge per insert under 120 psi helium pressure, and returned to the incubator for at least 2 more days in culture before confocal imaging, to allow for maximal GFP expression.

Whole-cell Recordings: For whole cell recordings, slices were cut with their adherent Millicell membrane, transferred to a recording chamber and superperfused with $95 \%$ $\mathrm{O}_{2}: 5 \% \mathrm{CO}_{2}$ bubbled ACSF at room temperature for $\geq 1 \mathrm{~h}$ before recording began. Patch pipettes were pulled from $1.5 \mathrm{~mm}$ outer diameter glass capillary tubes (WPI, Sarasota, FL) on a Flaming-Brown pipette puller (Sutter Instruments, Novato, CA). GFP and non GFP-expressing neurons were identified under an Olympus BX50 microscope equipped with fluorescence and differential interference contrast (DIC) optics and a Hamamatsu CCD camera, using a 40X, 0.8NA water immersion objective. Whole-cell recordings were performed using the Axopatch 200B patch-clamp amplifier (Axon Instruments, Foster City, CA). Records were low-pass filtered at 2-5 kHz, digitized at 10-20 kHz, saved to disk, and analyzed off-line. Data acquisition and processing was done with software written in LabView (National Instruments, Austin, TX).

For voltage-clamp recordings of postsynaptic currents (PSCs), patch pipettes were filled with a cesium methanesulfonate based internal solution containing (in mM): 136 cesium methanesulfonate, $2 \mathrm{MgCl}_{2}$, 0.6 EGTA, 10 HEPES, biocytin 5, pH 7.3, 275-285 mOsm. For current-clamp recording of action potentials, potassium methanesulfonate was substituted for cesium methanesulfonate. 
Unitary IPSCs recording: To evoke unitary IPSCs, a patch pipette filled with $0.9 \% \mathrm{NaCl}$ was placed close to the soma of a GFP-expressing neuron. Postsynaptic currents were recorded from neurons close to the axonal arbor of the GFP-expressing neuron using another patch pipette. The GFP-expressing presynaptic cell was stimulated with $100 \mu \mathrm{sec}$ anodal current pulses elicited every 10 seconds using a Master-8 pulse generator and stimulus isolation unit (AMPI, Jerusalem, Israel); stimulation intensity was gradually increased until an all-or-none, minimal postsynaptic response was seen (usually between 6-15 $\mu \mathrm{A}$ stimulus intensity). PSCs were recorded under different holding potentials between $-70 \mathrm{mV}$ to $30 \mathrm{mV}$ to determine their reversal potential. The AMPA receptor antagonist $\mathrm{CNQX}$ and the $\mathrm{GABA}_{\mathrm{A}}$ receptor antagonist bicuculline were then added in sequence to test if the postsynaptic currents were mediated through AMPA or $\mathrm{GABA}_{\mathrm{A}}$ receptors, respectively.

Confocal Microscopy Slice cultures were cut together with the adherent Millicell membrane and transferred to an imaging chamber filled with fresh oxygenated ACSF at room temperature. The imaging chamber was about $4 \mathrm{~mm}$ deep, made of stainless steel with a $17 \mathrm{~mm}$ wide circular opening on the bottom sealed by a cover glass. Strongly fluorescent, well-separated neurons were selected for imaging. An inverted Zeiss LSM510 laser-scanning confocal microscope was used to capture images. Neurons were generally imaged with a 20X, 0.7NA objective, using the $488 \mathrm{~nm}$ argon laser line and a $505-550 \mathrm{~nm}$ bandpass emission filter. Image stacks were collected at $\sim 1.5-2.5 \mu \mathrm{m}$ Z-axis steps through the full extent of the dendritic tree. At the end of each imaging session, images were taken at a lower magnification (X10 objective) in fluorescence and 
transmission modes to record the locations of the GFP-expressing neurons relative to the pia and white matter.

\section{RESULTS}

\section{GAD67-GFP expressing neurons in different regions of the brain in slice cultures}

We tested the efficacy of gene gun-mediated transfection with a GAD67-GFP construct in postnatal organotypic mouse brain slice cultures. Brain slices prepared from postnatal day 1-3 pups were cultured on static membranes, shot with a Helios gene gun after 2-4 days in vitro (DIV), and examined with a confocal microscope. About 8 hours after gene gun shooting, GFP expression became detectable in the soma and proximal dendrites of transfected neurons, and continued to increase over the following 24-48 hours to maximal levels. From 2-4 days after transfection and as long as the neurons were followed (up to 40 days post-transfection), GFP fluorescence remained stable and could easily be detected in distal dendrites, axons and dendritic spines. In each slice, several to several dozen neurons were found to express GFP fluorescence in different brain areas including neocortex, septal nuclei, hippocampus, hypothalamus and cerebellum. In the neocortex, about two-thirds of the GFP-expressing cells were morphologically identified as neurons; the rest were glial cells in morphology. Of the GFP-expressing neurons, more than 99\% ( $\mathrm{n}=262$ neurons in 38 slices $)$ were nonpyramidal interneurons (Figure 2.1C, D). In contrast, transfection of GFP under the control of the nonspecific CMV promoter (CMV-GFP) labeled both pyramidal and nonpyramidal neurons in the cortex (Figure 2.1A, B). Since almost all cortical nonpyramidal neurons are GABAergic interneurons (Houser et al., 1983; Meinecke and 
Peters, 1987; Prieto et al., 1994), these results indicated that the GAD67-GFP transfection specifically revealed GABAergic interneurons. In other regions of the brain slices, we also found that GABAergic neurons were specifically visualized by GAD67-GFP transfection. In the hippocampus, some interneurons were labeled by GAD67-GFP, but no pyramidal neurons were labeled by this method (Figure 2.1E). In the cerebellum, some Purkinje cells were found to express GFP (Figure 2.1F). Taken together, the expression patterns of GAD67-GFP transfection suggested that it specifically tagged GABAergic interneurons.

\section{Electrophysiological properties of GAD67-GFP expressing neurons}

Cortical GABAergic interneurons exhibit diverse action potential patterns associated with different morphological and neurochemical features. For example, fastspiking (FS) interneurons fire high frequency, non-adapting repetitive spikes in response to depolarizing currents, while regular spiking nonpyramidal (RSNP) cells show spike frequency accommodation. Individual spikes are followed by a characteristic afterhyperpolarization (AHP), which is much more pronounced in FS than in RSNP neurons (Cauli et al., 1997; Kawaguchi, 1993). To test if gene gun transfection or GFP expression would affect neuronal electrophysiological properties, we made whole cell current-clamp recordings of intrinsic spike trains from both GFP-expressing and nonexpressing cortical neurons in transfected cultures, and from neurons in untransfected cultured slices (Fig. 2.2). A total of 32 GFP-expressing neurons and 17 non-GFPexpressing neurons were recorded from slices maintained in vitro for 7-40 days (most were between 2-3 week in culture). GAD67-GFP expressing neurons had resting 
membrane potentials of $-53.8 \pm 2.3 \mathrm{mV}$, similar to non GFP-expressing neurons $(-48.5 \pm 2.6, \mathrm{p}=0.36, t$ test $)$. GFP-expressing neurons revealed different firing patterns and accommodation rates. Some GFP-expressing neurons fired in patterns similar to those of FS (figure 2.2B, left) and RSNP (figure 2.2B, right) nonpyramidal neurons. Similar firing patterns were also observed in non GFP-expressing nonpyramidal neurons (figure 2.2C, left). Pyramidal neuron firings were characterized by a doublet at the beginning of the spike trains (Figure 2.2C, right). These data indicate that GFP-expressing neurons retain normal firing properties and exhibit firing patterns similar to those of nontransfected nonpyramidal neurons in the same slice cultures, and distinct from those of pyramidal neurons.

To test if transfection with GAD67-GFP DNA interfered with synaptic connectivity and activity, we made voltage-clamp recording of spontaneous PSCs from GFP and non GFP-expressing neurons. Both GFP (Figs. 2.3, top traces, $n=13$ ) and non GFP-expressing (Figs. 2.3, bottom traces, $n=11$ ) neurons revealed spontaneous synaptic activity, suggesting that synaptic transmission in GAD67-GFP neurons was not interrupted by transfection.

\section{Minimal stimulation of GFP-expressing neurons elicited IPSCs in postsynaptic neurons}

The GAD67-GFP transfection revealed bright fluorescent GABAergic neurons, which not only made it much easier to target these cells for recording as shown above, but also helped to localize potential postsynaptic partners. To verify the GABAergic identity of GFP-expressing neurons, and to test the possibility of using this culture system 
for the study of synaptic coupling between GABAergic neurons or between GABAergic and pyramidal neurons, we recorded unitary inhibitory postsynaptic responses from neurons close to the axons of GFP-expressing neurons. Under visual guidance of the green fluorescence (figure 2.4A), we used an electrode placed close to the soma of a GAD67-GFP expressing neuron to deliver minimal electrical stimulation, and recorded whole-cell PSCs from neurons close to the axonal arbor of the GFP-expressing neuron. When a postsynaptic response was observed, $10 \mu \mathrm{M}$ CNQX and $10 \mu \mathrm{M}$ bicuculline were sequentially added to the perfusion solution to block AMPA and $\mathrm{GABA}_{\mathrm{A}}$ receptors respectively. In 6 slices, the PSCs were not sensitive to the AMPA receptor antagonist CNQX, but were blocked by the $\mathrm{GABA}_{\mathrm{A}}$ receptor antagonist bicuculline (figure 2.4B), indicating that the GFP-expressing neurons made GABAergic synapses and were therefore functional GABAergic interneurons.

\section{Discussion}

We report here that biolistic transfection of cultured brain slices with a GAD67GFP construct specifically labeled GABAergic interneurons. GAD67-GFP expressing neurons exhibited apparently normal physiological characteristics in that they (1) fired patterns of action potentials typical of cortical GABAergic interneurons, (2) received spontaneous synaptic inputs, and (3) generated GABAergic IPSCs in postsynaptic neurons. Together, these results indicate that GAD67-GFP transfection specifically labeled GABAergic interneurons, and that GFP-expressing neurons retain normal GABAergic electrophysiological functions. 


\section{Specificity of the labeling technique}

In this study, we used biolistic transfection with a GAD67-GFP construct to label cortical GABAergic interneurons in organotypic brain slices. Several lines of evidence indicate that biolistic transfection with GAD67-GFP DNA specifically labeled cortical GABAergic interneurons. Morphologically, almost all GAD67-GFP expressing neurons in the cerebral cortex were nonpyramidal neurons. Since all cortical nonpyramidal neurons, except for spiny stellate neurons in layer IV, are GABAergic interneurons (Houser et al., 1983; Meinecke and Peters, 1987; Prieto et al., 1994), it is very likely that GAD67-GFP labeled exclusively GABAergic interneurons. Neurochemically, some GAD67-GFP expressing neurons were immunopositive to various GABAergic neuron markers including GABA, parvalbumin, calbindin and somatostatin (Jin et al., submitted; refer to Chapter 4). Physiologically, GFP-expressing neurons fired action potentials in patterns typical of cortical GABAergic neurons, and generated GABAergic IPSCs in postsynaptic neurons, supporting the conclusion that they were functional GABAergic neurons.

In addition to the specifically labeled GABAergic interneurons, we also observed GFP-expressing glial cells. The reason for GAD67-GFP expression in glial cells is not clear. Glial cells in most brain regions do not express GAD (Ferraguti et al., 1990), but glia cells in the cerebellum and optic nerve have been shown to express GAD (MartinezRodriguez et al., 1993; Ochi et al., 1993). Therefore, one possibility is that some glia cells in slice may activate the GAD promoter and cause GFP expression. Regardless of the underlying reason, the labeling of glial cells should not interfere with specific 
visualization of GABAergic interneurons, since glial cells can be distinguished from neurons simply by their unique morphological features such as their small somata and short and dense processes.

\section{Advantages of biolistic transfection}

Currently, several methods are available to transfect neurons with GFP, each method having different applications, based on its unique advantages and disadvantages. Different lines of transgenic mice have been developed with bright GFP expression in specific and non-specific neuronal populations (van den Pol and Ghosh, 1998; Oliva et al., 2000; Spergel et al., 2001), but transgenic mice usually take a long time to generate and often too many neurons are labeled to allow morphological observation of individual neurons. Viral infection is an efficient and reliable technique for labeling neurons with various densities both in vivo and in vitro (Griesbeck et al., 1997; Chen et al., 2000; Miyaguchi et al., 2000). However, viral-induced GFP expression is often transient because of the short life of the infected neurons (Moriyoshi et al., 1996), and some of the viruses are potentially toxic and may affect neuronal functions and viability (Easton et al., 1998). Other approaches such as calcium phosphate precipitation or lipofection are used mainly in primary neuronal culture, owing to their limited penetration in the tissue. In contrast, biolistic transfection method is not as labor-intensive as transgenic mouse generation or viral transfection, and works nicely to physically carry DNA-coated gold

particles into brain slices and to label a limited number of neurons for morphological and physiological studies. 
A benefit of GFP expression being limited to a small number of neurons is that this distinguishes these labeled neurons from the whole neuronal population, making it possible to study their morphological properties in great detail. Unlike viral transfection, GFP can be detected in living neurons for weeks and even longer. Unlike the transgenic mouse technique, the biolistic transfection method allows cotransfection of different combinations of DNA simply by coating two plasmid DNAs onto a single gold particle so that the two genes are co-expressed in a single cell, or by bombarding the tissue with a mixture of particles carrying two or three different DNAs, so that different cells express different genes in a single slice. Provided that the proteins fluoresce at different wavelengths, this will allow specific visualization of interacting molecular components such as presynaptic and postsynaptic proteins. Finally, although the gene-gun method results in cells that are randomly transfected, a specific promoter driving GFP allows labeling of specific classes of neurons. Because of these advantages, gene gun mediated transfection has unique usage in neuroscientific studies.

Several groups have used the biolistic technique for the study of dendritic development and regulation in organotypic brain slices. By transfecting ferret organotypic cortical slices, McAllister and colleagues demonstrated that the dendritic development of cortical pyramidal neurons is regulated by neuronal activity and neurotrophic factors (McAllister et al., 1995; 1996; 1997). Development of dendritic spines of hippocampal pyramidal neurons was shown to be regulated by the small GTPases Rac and Rho (Nakayama et al., 2000). Our study was different in that the transfection was driven by a specific GAD67 promoter, which allowed us to image and record from relatively scarce GABAergic neurons. 


\section{Potential uses of biolistic transfection with GAD67-GFP DNA}

The GAD67-GFP transfection may be useful for the study of GABAergic neuron development in several different ways. As was demonstrated here, the GAD67-GFP transfection would be useful for electrophysiological studies because it would allow researchers to target GFP-expressing GABAergic interneurons for recordings, and to explore interconnections between GABAergic neurons, or between GABAergic neurons and pyramidal neurons. Traditionally, morphological identification of neurons is done after electrophysiological recordings. Using biolistic transfection with GAD67-GFP DNA, it is now possible to identify the neuron or locate potential postsynaptic partners before recording from it electrophysiologically. This should greatly speed up the analysis of the complex cortical network. Live visualization of GABAergic neurons would allow studying of dendritic and axonal dynamics and its regulation by different factors such as neuronal activity and neurotrophic factors (Jin et al., submitted; refer to Chapter 4). Finally, biolistic transfection of mouse brain slices may prove a useful and efficient way to test DNA constructs to be used in generation of transgenic mice. 

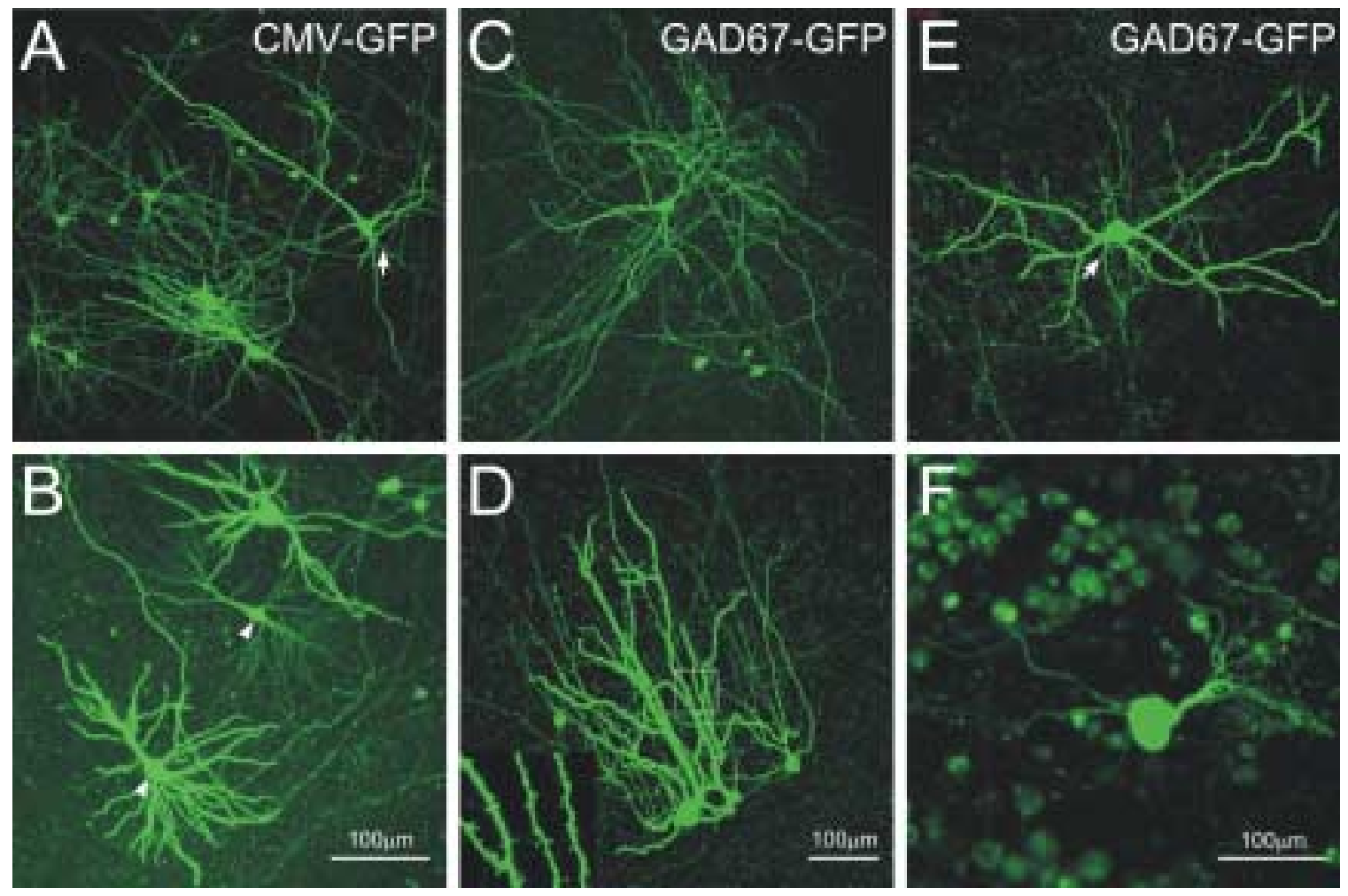

Figure 2.1. GAD67-GFP transfection revealed morphological details of different GABAergic neuronal types in the neocortex, hippocampus and cerebellum in organotypic slice cultures. $A$ and $B$, Transfection with CMV-GFP DNA labeled both pyramidal and nonpyramidal neurons in the neocortex (A), and in the hippocampal CA1 region. $C, D$ and $E, F$, neurons labeled by transfection with GAD67-GFP DNA. $C$, A nonpyramidal neuron in layer II/III of cerebral cortex; $D$, Several nonpyramidal neurons in layer VI of the cortex; $E$, A nonpyramidal neuron in the stratum oriens of the hippocampal CA1 region; $F$, A Purkinje cell in the cerebellum. Arrows in A and E indicate the initial segment of the axon. Arrowheads in B point to the somata of pyramidal neurons. Insert in D shows clearly labeled dendritic spines in a nonpyramidal neuron. The scale bars are $100 \mu \mathrm{m}$ and apply to both images in each column. 

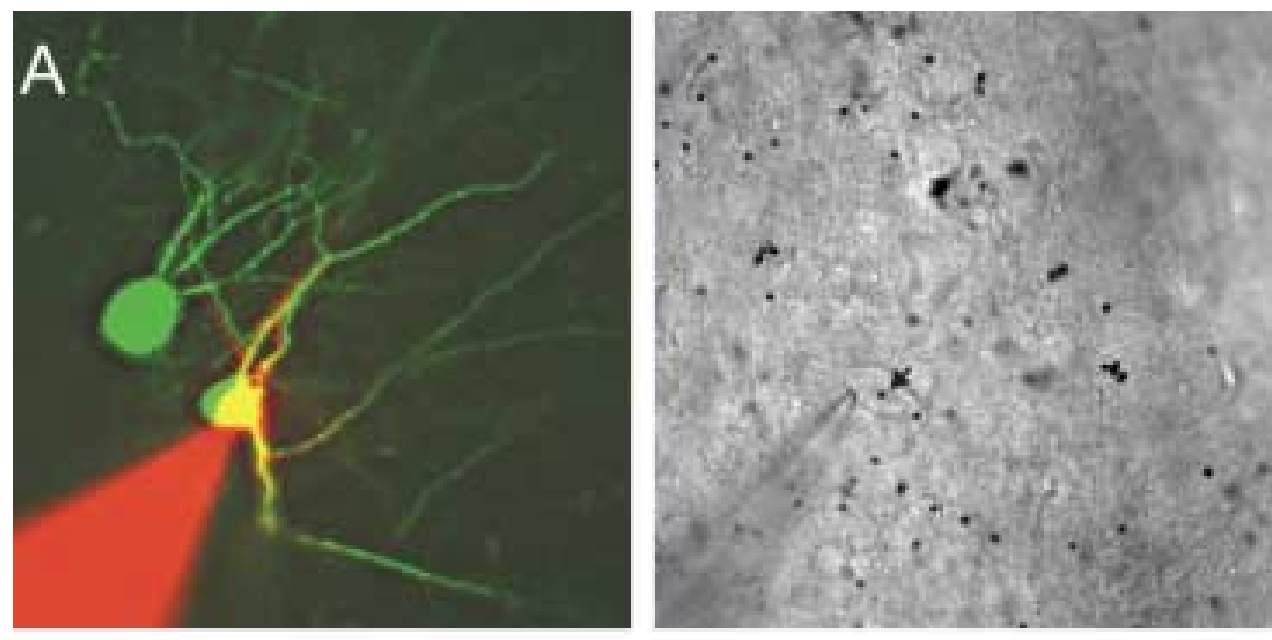

B

GFP neuron

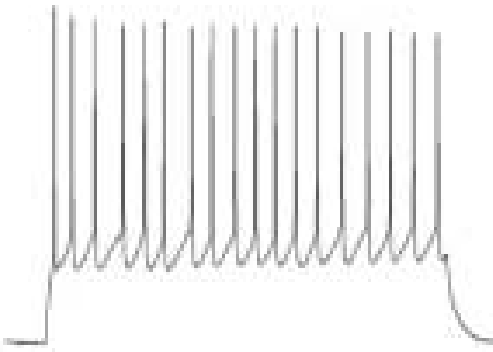

C

non-GFP neuron

nonpyramidal
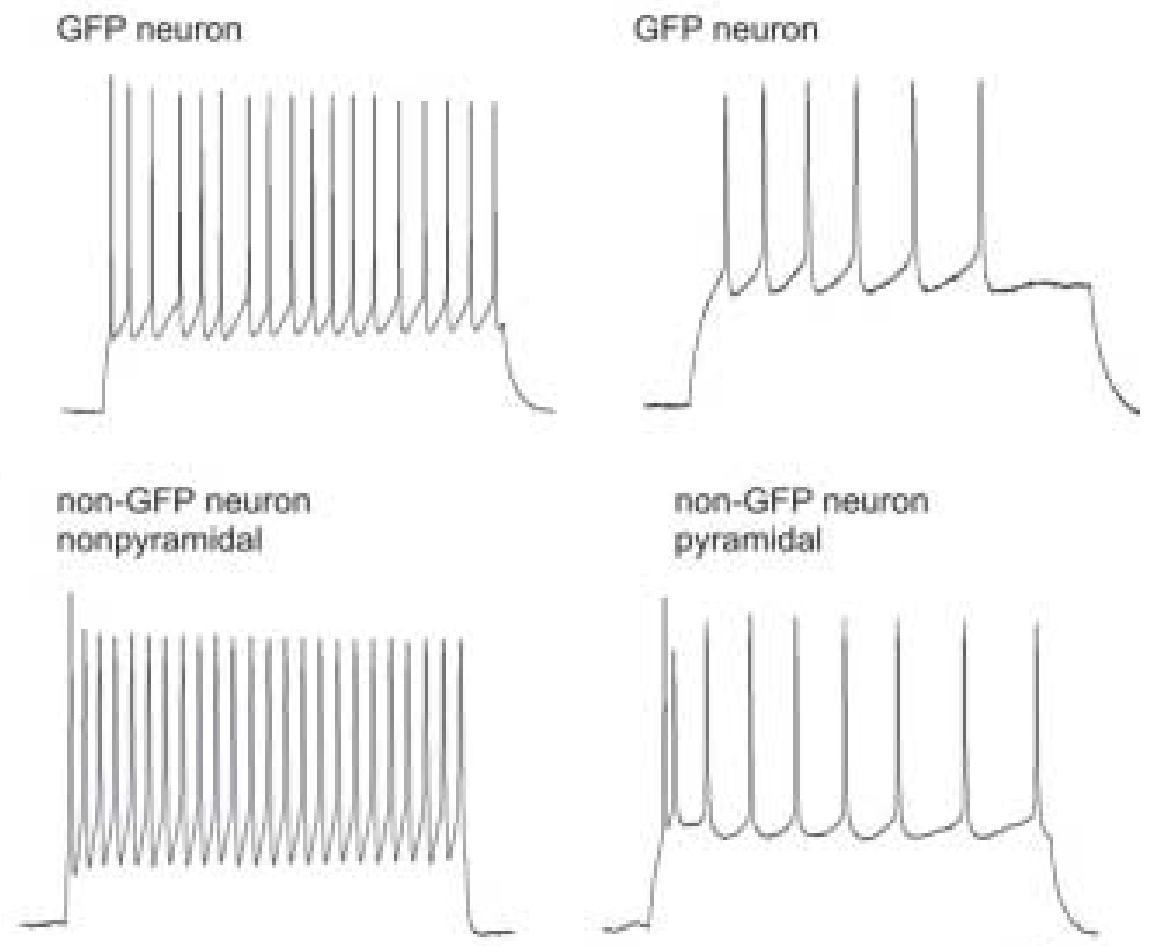

non-GFP neuron

pyramidal

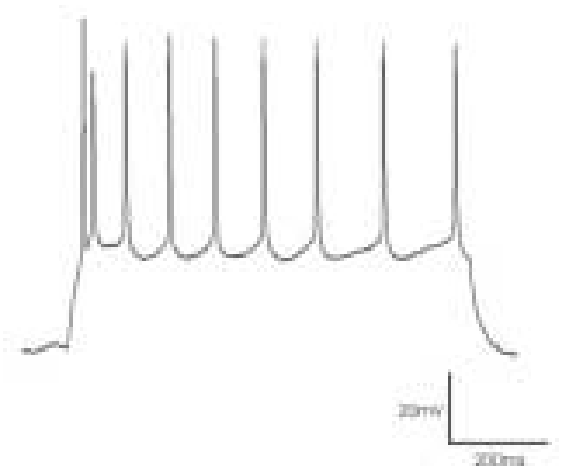


Figure 2.2. GAD67-GFP expressing neurons in slice culture exhibited different action potential firing patterns. A, fluorescent (left) and DIC (right) images of GFPexpressing neurons during patch-clamp recording (images taken from different slices). The neuron being recorded is labeled by diffusion of a fluorescent dye (sulforhodamine) from the recording pipette. An arrow in the right image indicates a gold particle inside the cell body. B. Current-clamp recordings from GAD67-GFP expressing neurons during injection of depolarizing current pulses, showing firing patterns typical of fast-spiking (FS) (left, a 30 DIV neuron) and RSNP (right, a 41 DIV neuron) GABAergic subtypes. Action potential firing patterns recorded from a non GFP-expressing nonpyramidal cell (left, 9 DIV) and a non GFP-expressing pyramidal cell (right, 14 DIV). 
A GFP neuron
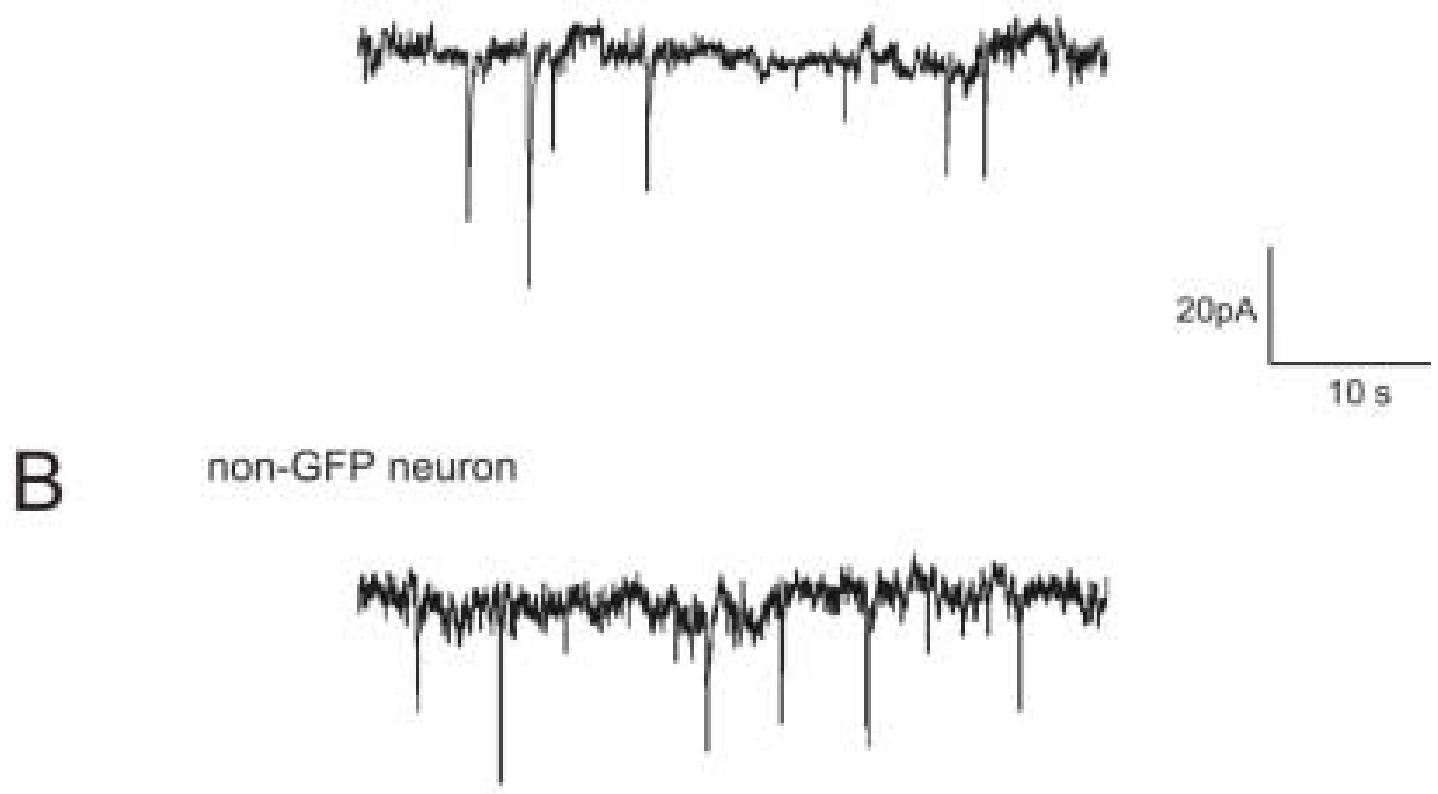

Figure 2.3. Spontaneous postsynaptic currents recorded in whole-cell voltage-clamp mode from a GFP-expressing neuron and a non GFP-expressing neuron (both are 13 DIV). 
A

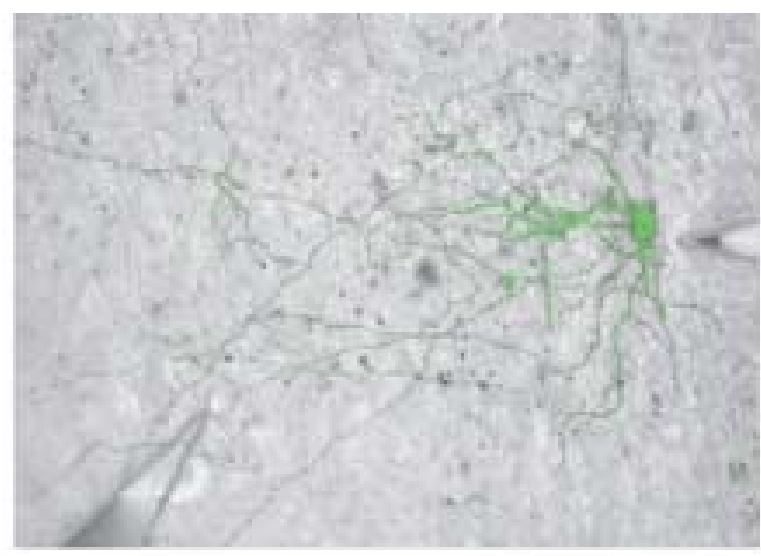

B
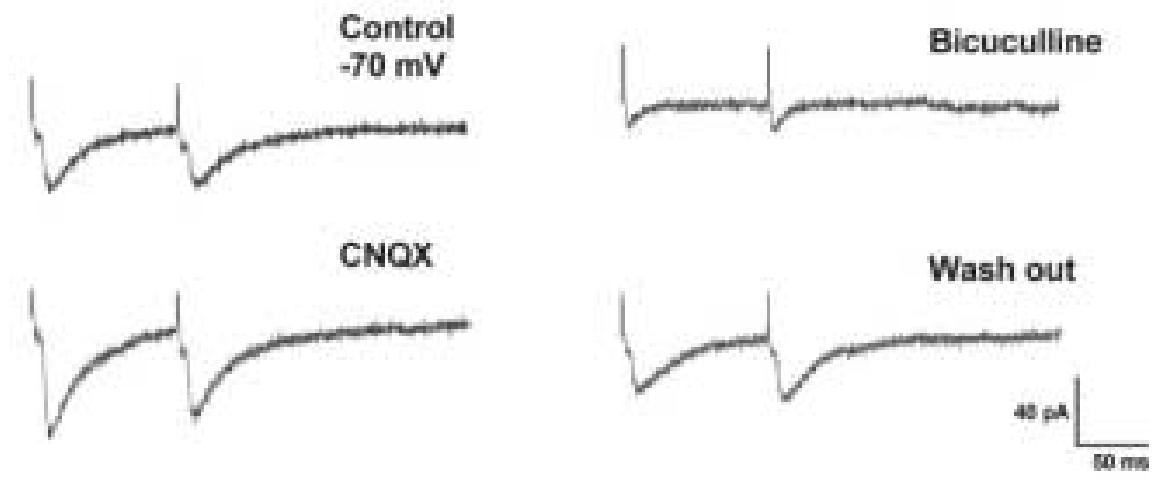

Figure 2.4. Putative unitary IPSCs generated by GFP-expressing neurons. $A$. Fluorescent image of a 10 DIV GFP neuron (green), superimposed on a DIC image of the same field to show pipettes position in relation to the GFP-expressing cell. The GFPexpressing neuron was electrically stimulated by a juxtacellular pipette (right) while PSCs were recorded from another neuron close to the GFP-filled axon (low left). $B$. PSCs were evoked by minimal electric stimulation at $-70 \mathrm{mV}$; responses, persisted in the presence of $10 \mu \mathrm{M}$ of the AMPA receptor antagonist CNQX, but were abolished by 10 $\mu \mathrm{M}$ of the $\mathrm{GABA}_{\mathrm{A}}$ antagonist bicuculline, and recovered after washout. 


\section{REFERENCES}

Avoli, M. (1996) GABA-mediated synchronous potentials and seizure generation. Epilepsia 37: 1035-42.

Cauli, B., Audinat, E., Lambolez, B., Angulo, M. C., Ropert, N., Tsuzuki, K., Hestrin, S., and Rossier, J. (1997) Molecular and physiological diversity of cortical nonpyramidal cells. J Neurosci 17: 3894-906.

Chen, B. E., Lendvai, B., Nimchinsky, E. A., Burbach, B., Fox, K., and Svoboda, K. (2000) Imaging high-resolution structure of GFP-expressing neurons in neocortex in vivo. Learn Mem 7: 433-41.

Connors, B. W., Malenka, R. C., and Silva, L. R. (1988) Two inhibitory postsynaptic potentials, and GABAA and GABAB receptor- mediated responses in neocortex of rat and cat. J Physiol 406: 443-68.

Dykes, R. W., Landry, P., Metherate, R., and Hicks, T. P. (1984) Functional role of GABA in cat primary somatosensory cortex: shaping receptive fields of cortical neurons. J Neurophysiol 52: 1066-93.

Easton, R. M., Johnson, E. M., and Creedon, D. J. (1998) Analysis of events leading to neuronal death after infection with E1- deficient adenoviral vectors. Mol Cell Neurosci 11: 334-47.

Esclapez, M., Tillakaratne, N. J., Kaufman, D. L., Tobin, A. J., and Houser, C. R. (1994) Comparative localization of two forms of glutamic acid decarboxylase and their mRNAs in rat brain supports the concept of functional differences between the forms. J Neurosci 14: $1834-55$.

Ferraguti, F., Zoli, M., Aronsson, M., Agnati, L. F., Goldstein, M., Filer, D., and Fuxe, K. (1990) Distribution of glutamic acid decarboxylase messenger RNA-containing nerve cell populations of the male rat brain. J Chem Neuroanat 3: 377-96.

Griesbeck, O., Korte, M., Gravel, C., Bonhoeffer, T., and Thoenen, H. (1997) Rapid gene transfer into cultured hippocampal neurons and acute hippocampal slices using adenoviral vectors. Brain Res Mol Brain Res 44: 171-7.

Hendry, S. H., Schwark, H. D., Jones, E. G., and Yan, J. (1987) Numbers and proportions of GABA-immunoreactive neurons in different areas of monkey cerebral cortex. J Neurosci 7: 1503-19.

Houser, C. R., Hendry, S. H., Jones, E. G., and Vaughn, J. E. (1983) Morphological diversity of immunocytochemically identified GABA neurons in the monkey sensorymotor cortex. J Neurocytol 12: 617-38. 
Jin, X., Mathers, P. H., Szabo, G., Katarova, Z., and Agmon, A. (2001) Vertical bias in dendritic trees of non-pyramidal neocortical neurons expressing GAD67-GFP in vitro. Cereb Cortex 11: 666-78.

Katarova, Z., Mugnaini, E., Sekerkova, G., Mann, J. R., Aszodi, A., Bosze, Z., Greenspan, R., and Szabo, G. (1998) Regulation of cell-type specific expression of lacZ by the 5'-flanking region of mouse GAD67 gene in the central nervous system of transgenic mice. Eur J Neurosci 10: 989-99.

Kawaguchi, Y. (1993) Physiological, morphological, and histochemical characterization of three classes of interneurons in rat neostriatum. J Neurosci 13: 4908-23.

Kawaguchi, Y., and Kubota, Y. (1997) GABAergic cell subtypes and their synaptic connections in rat frontal cortex. Cereb Cortex 7: 476-86.

Martinez-Guijarro, F. J., and Freund, T. F. (1992) Distribution of GABAergic interneurons immunoreactive for calretinin, calbindin D28K, and parvalbumin in the cerebral cortex of the lizard Podarcis hispanica. J Comp Neurol 322: 449-60.

Martinez-Rodriguez, R., Tonda, A., Gragera, R. R., Paz-Doel, R., Garcia-Cordovilla, R., Fernandez-Fernandez, E., Fernandez, A. M., Gonzalez-Romero, F., and Lopez-Bravo, A. (1993) Synaptic and non-synaptic immunolocalization of GABA and glutamate acid decarboxylase (GAD) in cerebellar cortex of rat. Cell Mol Biol (Noisy-le-grand) 39: 11523.

McAllister, A. K., Katz, L. C., and Lo, D. C. (1996) Neurotrophin regulation of cortical dendritic growth requires activity. Neuron 17: 1057-64.

McAllister, A. K., Katz, L. C., and Lo, D. C. (1997) Opposing roles for endogenous BDNF and NT-3 in regulating cortical dendritic growth. Neuron 18: 767-78.

McAllister, A. K., Lo, D. C., and Katz, L. C. (1995) Neurotrophins regulate dendritic growth in developing visual cortex. Neuron 15: 791-803.

McBain, C. J., and Fisahn, A. (2001) Interneurons unbound. Nat Rev Neurosci 2: 11-23.

Meinecke, D. L., and Peters, A. (1987) GABA immunoreactive neurons in rat visual cortex. J Comp Neurol 261: 388-404.

Micheva, K. D., and Beaulieu, C. (1995) Postnatal development of GABA neurons in the rat somatosensory barrel cortex: a quantitative study. Eur J Neurosci 7: 419-30.

Miyaguchi, K., Maeda, Y., Collin, C., and Sihag, R. K. (2000) Gene transfer into hippocampal slice cultures with an adenovirus vector driven by cytomegalovirus promoter: stable co-expression of green fluorescent protein and lacZ genes. Brain Res Bull 51: 195-202. 
Moriyoshi, K., Richards, L. J., Akazawa, C., O'Leary, D. D., and Nakanishi, S. (1996) Labeling neural cells using adenoviral gene transfer of membrane- targeted GFP. Neuron 16: $255-60$.

Nakayama, A. Y., Harms, M. B., and Luo, L. (2000) Small GTPases Rac and Rho in the maintenance of dendritic spines and branches in hippocampal pyramidal neurons. J Neurosci 20: 5329-38.

Nguyen, L., Rigo, J. M., Rocher, V., Belachew, S., Malgrange, B., Rogister, B., Leprince, P., and Moonen, G. (2001) Neurotransmitters as early signals for central nervous system development. Cell Tissue Res 305: 187-202.

Ochi, S., Lim, J. Y., Rand, M. N., During, M. J., Sakatani, K., and Kocsis, J. D. (1993) Transient presence of GABA in astrocytes of the developing optic nerve. Glia 9: 188-98.

Oliva, A. A., Jr., Jiang, M., Lam, T., Smith, K. L., and Swann, J. W. (2000) Novel hippocampal interneuronal subtypes identified using transgenic mice that express green fluorescent protein in GABAergic interneurons. J Neurosci 20: 3354-68.

Owens, D. F., and Kriegstein, A. R. (2002) Is there more to GABA than synaptic inhibition? Nat Rev Neurosci 3: 715-27.

Prieto, J. J., Peterson, B. A., and Winer, J. A. (1994) Morphology and spatial distribution of GABAergic neurons in cat primary auditory cortex (AI). J Comp Neurol 344: 349-82.

Ren, J. Q., Aika, Y., Heizmann, C. W., and Kosaka, T. (1992) Quantitative analysis of neurons and glial cells in the rat somatosensory cortex, with special reference to GABAergic neurons and parvalbumin-containing neurons. Exp Brain Res 92: 1-14.

Spergel, D. J., Kruth, U., Shimshek, D. R., Sprengel, R., and Seeburg, P. H. (2001) Using reporter genes to label selected neuronal populations in transgenic mice for gene promoter, anatomical, and physiological studies. Prog Neurobiol 63: 673-86.

Stoppini, L., Buchs, P. A., and Muller, D. (1991) A simple method for organotypic cultures of nervous tissue. J Neurosci Methods 37: 173-82.

Tremere, L., Hicks, T. P., and Rasmusson, D. D. (2001) Expansion of receptive fields in raccoon somatosensory cortex in vivo by $\mathrm{GABA}(\mathrm{A})$ receptor antagonism: implications for cortical reorganization. Exp Brain Res 136: 447-55.

van den Pol, A. N., and Ghosh, P. K. (1998) Selective neuronal expression of green fluorescent protein with cytomegalovirus promoter reveals entire neuronal arbor in transgenic mice. J Neurosci 18: 10640-51. 
Wellmann, H., Kaltschmidt, B., and Kaltschmidt, C. (1999) Optimized protocol for biolistic transfection of brain slices and dissociated cultured neurons with a hand-held gene gun. J Neurosci Methods 92: 55-64.

Wolff, J. R., Bottcher, H., Zetzsche, T., Oertel, W. H., and Chronwall, B. M. (1984) Development of GABAergic neurons in rat visual cortex as identified by glutamate decarboxylase-like immunoreactivity. Neurosci Lett 47: 207-12. 


\section{Chapter Three}

\section{Vertical Bias in Dendritic Trees of Non-Pyramidal Neocortical Neurons Expressing GAD67-GFP in Vitro}

Published in Cerebral Cortex: 11: 666-678 (2001) 


\section{ABSTRACT}

The neocortical neuropil has a strong vertical (orthogonal to pia) orientation, constraining the intracortical flow of information and forming the basis for the functional parcellation of the cortex into semi-independent vertical columns or "modules". Apical dendrites of excitatory pyramidal neurons are a major component of this vertical neuropil, but the extent to which inhibitory, GABAergic neurons conform to this structural and functional design is less well documented. We used a gene gun to transfect organotypic slice cultures of mouse and rat neocortex with the enhanced green fluorescent protein (eGFP) gene driven by the promoter for glutamic acid decarboxylase 67 (GAD67), an enzyme expressed exclusively in GABAergic cells. Many GAD67-GFP expressing cells were highly fluorescent, and their dendritic morphologies and axonal patterns, revealed in minute detail, were characteristic of GABAergic neurons. We traced 150 GFPexpressing neurons from confocal image stacks, and estimated the degree of vertical bias in their dendritic trees using a novel computational metric. Over $70 \%$ of the neurons in our sample had dendritic trees with a highly significant vertical bias. We conclude that GABAergic neurons make an important contribution to the vertical neocortical neuropil, and are likely to integrate synaptic inputs from axons terminating within their own module. 


\section{INTRODUCTION}

Neurons are inherently polarized, the result of having one process (the axon) structurally and functionally different from all their other processes (the dendrites) (Black and Baas, 1989; Mattson, 1999). While the morphological polarity between axon and dendrites is common to virtually all neurons, a significant subset of neurons exhibits morphological polarity also within their dendritic tree. For example, pyramidal neurons of the cerebral cortex extend a single, thick apical dendrite in one direction, and a multitude of smaller, basal dendrites in other directions. The apical dendrite is preferentially oriented upwards, towards the pial surface. The vertically oriented apical dendrites of pyramidal neurons (Escobar et al., 1986; Peters and Sethares, 1991; White and Peters, 1993), together with vertically oriented afferent, efferent and intrinsic axons (Lorente de No, 1949), are the major contributors to the predominantly vertical grain of the cortical neuropil and impart a strong vertical bias to the flow of information in the neocortex, forming the structural basis for the well-documented parcellation of the cerebral cortex into semi-autonomous anatomical and functional units, called "columns" or "modules" (Colonnier, 1966; Hubel and Wiesel, 1969; Mountcastle, 1997; Szentagothai, 1975).

Pyramidal neurons are the dominant cell type of the neocortex, and function to excite postsynaptic neurons, both locally and in other cortical areas and subcortical targets, by secreting glutamate as a neurotransmitter (Carder and Hendry, 1994; Ottersen and Storm-Mathisen, 1984). In contrast, about $15-25 \%$ of all neocortical neurons (Fitzpatrick et al., 1987; Ren et al., 1992; Micheva and Beaulieu, 1995; Gabbott et al., 1997) are inhibitory, non-pyramidal neurons, which utilize GABA as a neurotransmitter. 
Dendrites of GABAergic cortical neurons usually lack morphological polarity (i.e. all their dendrites appear morphologically equivalent), but may be spatially polarized. Indeed, some GABAergic neurons have bipolar or bitufted dendritic trees, in which dendrites emanate mainly from two opposite poles of the cell body. The majority of GABAergic neurons, however, have multipolar, or "stellate", morphology with dendrites emanating in all directions (Houser et al., 1983; Kisvarday et al., 1990; Prieto et al., 1994). Although many multipolar neurons appear to have vertically elongated dendritic trees (Feldman and Peters, 1978; Jones, 1975), this vertical bias has rarely been studied quantitatively (McMullen et al., 1984).

All GABAergic neurons express GAD, the major biosynthetic enzyme for GABA (Houser et al., 1983; Martin and Rimvall, 1993; Ribak, 1978). There are two known GAD isoforms, GAD65 and GAD67, which are the products of two different genes (Erlander et al., 1991; Esclapez et al., 1994; Kaufman et al., 1991). Neuron-specific and region-specific expression of the GAD67 gene is conferred by its complex 5' flanking region, which includes several neuron-restrictive silencer sequences and putative regionspecific enhancers (Katarova et al., 1998; Szabo et al., 1996). To visualize GABAergic neurons in living tissue, and to study their axonal and dendritic morphologies, we linked the cloned mouse GAD67 promoter region to an eGFP reporter gene, transfected neurons in organotypic cortical slices with the resulting construct, and used a novel metric to quantify the degree of vertical bias in dendrites of transfected neurons expressing GFP. Some of these results have been previously reported in abstract form (Jin et al., 1999). 


\section{METHODS}

AD67-GFP DNA preparation A $9 \mathrm{~kb}$ segment of the GAD67 5' regulatory region, including the first intron, drives expression of a lacZ reporter transgene in hippocampus and neocortex of transgenic mice in a partially cell-type specific pattern (Katarova et al., 1998). To improve specificity, we used a slightly longer segment, and to allow visualization of the reporter gene product in living tissue, we fused it in-frame to eGFP. We cloned a $10.3 \mathrm{~kb}$ segment of the murine GAD67 genomic DNA, including the 5' upstream regulatory region, the first (untranslated) exon and intron and a portion of exon 2, from the HindIII site (at the 5' end) to the BamH1 site (at the 3' end) (Katarova et al., 1998), and inserted it in-frame between the HindIII and the BamH1 insertion sites of the pEGFP-1 vector (Clontech, Palo Alto, CA). The resulting construct encodes a fusion protein consisting of the first 17 amino acids of GAD67, 4 amino acids of the vector and the full-length eGFP.

Organotypic culture preparation Organotypic cortical slice cultures were prepared using the method of (Stoppini et al., 1991). Postnatal day 2-7 mouse or rat pups (postnatal day 0 being the first 24 hours after birth) were deeply anesthetized by Metofane inhalation, decapitated, and the brains rapidly removed and immersed in icecold artificial cerebrospinal fluid (ACSF, containing $126 \mathrm{mM} \mathrm{NaCl}, 3.0 \mathrm{mM} \mathrm{KCl}, 1.3$ $\mathrm{mM} \mathrm{MgSO}_{4}, 2.5 \mathrm{mM} \mathrm{CaCl}_{2}, 1.2 \mathrm{mM} \mathrm{NaH}_{2} \mathrm{PO}_{4}, 26 \mathrm{mM} \mathrm{NaHCO}_{3}$, and $20 \mathrm{mM}$ dextrose, saturated with 95\%:5\% $\mathrm{O}_{2}: \mathrm{CO}_{2}$ ). The following procedures were performed under sterile conditions. Coronal brain slices of parietal cortex, $350 \mu \mathrm{m}$ thick, were cut with a Vibraslicer (WPI) into ice-cold ACSF. Slices were then placed on transparent Millicell 
membrane inserts (Millipore), usually 2 slices/insert, in $30 \mathrm{~mm}$ petri dishes containing 1 $\mathrm{ml}$ of culture medium, composed of $46 \%$ Eagle's basal medium, $25 \%$ Earle's balanced salt solution, $25 \%$ horse serum, $1 \%$ mixture of penicillin (10,000 units/ml)-streptomycin (10 mg/ml)-glutamine $(29.2 \mathrm{mg} / \mathrm{ml})$ (all from Invitrogen, Carlsbad, CA). Glucose was added to reach a final concentration of $6.5 \mathrm{mg} / \mathrm{ml}$. The slices were kept in a humidified incubator at $37^{0} \mathrm{C}$ with a $5 \% \mathrm{CO}_{2}$-enriched atmosphere, and the medium was changed twice a week.

Gene gun mediated transfection Cultured slices were transfected using a Helios gene gun (Bio-Rad, Hercules, CA). Cartridges were prepared according to the manufacturer's manual, using manufacturer's supplies. The full, supercoiled plasmid DNA (total size $14.6 \mathrm{~kb}$ ), prepared using an endotoxin-free kit (Qiagen, Valencia, CA), was used for transfection. Gold particles (1.6 $\mu \mathrm{m}$ diameter) were coated with plasmid DNA at a ratio of $1 \mathrm{mg}$ gold to $2 \mu \mathrm{g}$ plasmid DNA, precipitated onto the inner wall of Tefzel tubing, and the tubing cut into individual cartridges. Each cartridge contained approximately $1 \mu \mathrm{g}$ plasmid DNA. Assuming (arbitrarily) a 50\% coating efficiency, each gold particle carried on average 2700 copies of the DNA construct. After 1-2 days in culture, the slices were bombarded with one cartridge per insert under 100 PSI helium pressure. After 2-35 more days in culture, slices were removed for imaging.

Confocal microscopy Explants were cut out together with the membrane and transferred to an imaging chamber filled with fresh ACSF. Well-separated neurons with bright GFP expression and no signs of truncation were selected for imaging. An inverted Zeiss LSM510 laser-scanning confocal microscope was used to capture images. Images were 
generally taken with a 20X, 0.7NA objective, using the 488 Argon laser line and a 505$550 \mathrm{~nm}$ bandpass emission filter. Image stacks were collected at about 1.5-2 $\mu \mathrm{m} \mathrm{Z}$-axis steps to cover the full depth of the dendritic tree. Stacks were superimposed digitally, but in most cases the full 3-D dataset was saved for further analysis. At the end of each session, images were taken at a lower magnification (10X objective) in fluorescence and transmission modes, to record the locations of the GFP-expressing neurons relative to the pia and white matter.

Neuronal tracing Confocal image stacks of individual neurons were traced digitally using Neurolucida software (Microbrightfield, Colchester, VT); all subsequent analysis was done on the traced data. For each neuron, a line was drawn on a low-power image from the cell body to the nearest point on the pial surface, and the coordinates of the two endpoints measured; these were later used in the analysis to calculate angle of growth relative to the vertical axis.

Data analysis The Neuroexplorer software (Microbrightfield) was used to calculate numerical parameters of dendritic morphology, including soma area, total dendritic length and number of dendritic end points, and to measure the maximal vertical and horizontal extent of the dendritic tree. Dendritic coverage area was defined as the area of the smallest convex polygon that could encompass all the dendritic branches. Dendritic tree aspect ratio was defined as the ratio of the maximal vertical extent to the maximal horizontal extent of the dendritic tree. To analyze dendritic growth directions, Neurolucida data in ASCII format was imported into HiQ (National Instruments, Austin, TX) and calculations were carried out using custom-programmed HiQ scripts. Since 
organotypic slices grown in serum-supplemented medium tend to become quite thin, coordinates along the depth $(\mathrm{Z})$ dimension varied very little, compared to coordinates in the plane of the slice; we therefore ignored the depth dimension in this analysis and treated the neurons as planar projections. The program first converted all dendritic chords (i.e. the segments defined by two sequential data points along the dendrite) into vectors anchored at the origin of axes, then calculated the sum of the absolute values of the dot product of all vectors with a normalized vector representing the vertical direction (equivalent to the total length of the projections of the vectors on the vertical axis), and divided by the sum of all the vector norms (equivalent to the total dendritic length), resulting in the weighted average of the absolute value of the cosine of the angle of growth relative to the vertical axis (WACAV). The average WACAV of neurons with randomly oriented dendrites should be $2 / \pi$ or about 0.64 ; this applies both to a 2 dimensional neuron with dendrites oriented randomly in the plane, and to a 3dimensional neuron with dendrites oriented randomly in space, as long as the WACAV is calculated on the 2-dimensional projection of the neuron on a vertical plane (see Appendix).

To allow for an easier comparison of polarizations, we normalized the WACAV values by calculating an index of polarization (IOP) equal to

$I O P=\frac{W A C A V-2 / \pi}{1-2 / \pi}$

The IOP should give values ranging from $\sim(-1.75)$ for purely horizontal dendrites, to 0 for purely random dendrites, to 1 for purely vertical dendrites. 


\section{RESULTS}

\section{Morphology of neurons expressing GAD67-GFP in organotypic cortical slices}

The data presented here were collected from 143 organotypic slice cultures prepared from 40 mice and 8 rats. To visualize GABAergic, non-pyramidal cortical neurons, we biolistically transfected organotypic cortical slices with the eGFP gene controlled by the mouse GAD67 promoter (see Methods). The number of GFPexpressing neurons observed in successfully transfected slices varied from about 10 (or occasionally less) to more than 100 , possibly reflecting fluctuations in the number of gold particles deposited on the wall of each gene gun cartridge. Invariably, any GFPexpressing neuron examined was found to contain a gold particle in its nucleus. Levels of GFP expression varied between neurons: in many, mostly small neurons, GFP fluorescence was low and mostly restricted to the cell body, but in many medium and large transfected neurons, fluorescence level was high and allowed clear visualization of the full dendritic and axonal morphology. GFP expressing neurons occurred in all cortical layers, although in younger slices they had a tendency to be more concentrated in the deep layers.

With almost no exceptions, GAD67-GFP expressing neurons were nonpyramidal, as typical of GABAergic neurons. Their dendritic and axonal morphologies were varied; figs. 3.1-2 illustrate confocal images of neurons representative of the range of morphologies observed. The great majority of GFP-expressing neurons were either bitufted (Fig. 3.1A; 3.2A,C,D; 3.3B,D) or multipolar (Fig. 3.1B,D; 3.3C,E-G). While most of the GFP-expressing neurons had non-spiny or sparsely spiny dendrites typical of mature inhibitory cells in the cortex, some were more densely spiny (Fig. 3.1D), possibly 
reflecting an immature stage of development (Lund et al., 1977; McMullen et al., 1988; Seay-Lowe and Claiborne, 1992). The GFP fluorescence also revealed highly detailed axonal arbors, rivaling in complexity those visualized by the Golgi or the intracellular dye-filling methods (Figs. 3.2, 3.3). Some GFP-containing axons exhibited varicosities at regular intervals, which were potentially en passant synaptic boutons (Fig. 3.2B).

Many of the GFP-expressing neurons had dendritic and axonal morphologies comparable to previously described putative or confirmed GABAergic neurons of the cerebral cortex. For example, upper layers multipolar or bitufted neurons with large cell bodies (>20 $\mu \mathrm{m}$ in diameter) and with axons giving rise to horizontally directed branches (Fig. 3.1B, leftmost neuron; Fig. 3.2C,D), resembled Golgi-stained large basket cells in monkey somatosensory cortex (Type 1 of Jones, 1975) and parvalbumin-containing, axosomatic "fast spiking" cells in rat frontal cortex (Kawaguchi and Kubota, 1998, their figure 3.6A). Among neurons in our sample with less common morphologies were lower layer VI cells such as the fan-shaped neuron of Fig. 3.1A, which was similar to Golgiimpregnated neurons described in the rat sensorimotor cortex (Ferrer et al., 1986) (their figure 3.3C), and the inverted pyramidals in Fig. 3.1C (upper two neurons), which were comparable to the GAD-immunostained neurons described in cat auditory cortex (Prieto et al., 1994, their figures 13:4 and 14:4)), and to the somatostatin-immunopositive neurons in rabbit visual cortex (Ramon y Cajal-Agueras et al., 1989, their figures 5 and 7C). The bitufted GFP expressing neuron in layer I (Fig. 3.2D), with a horizontal axonal spread in layers I and II/III, resembled some intracellularly stained layer I neurons in the rat (Zhou and Hablitz, 1996), their Fig. 13). 
Computer-assisted reconstruction of neurons with well-visualized axonal arbors (Fig. 3.3) allowed comparison with additional recognized classes of non-pyramidal cortical neurons. Among upper-layers cells expressing GFP were small neurons with mostly ascending dendrites and many horizontal axonal branches (Fig. 3.3A), similar to small basket cells in monkey somatosensory cortex Type 6 of (Jones, 1975; compare also with Prieto et al., 1994, Fig. 8:3). Other neurons in the upper layers had initially ascending axons with downward recurving "arcades" giving rise to a loose bundle of parallel, vertically oriented descending axonal branches below the level of the cell body (Fig. 3.3B-D), similar to Type 2 of (Jones, 1975; compare also with the cholecystokininimmunopositive "regular spiking" neurons of Kawaguchi and Kubota, 1998, their figures 3 and 8:8). GFP expressing neurons in the deep layers often had ascending axons (Fig. 3.3E,F,G), and of these some had axonal tufts ascending to and extending in layer I, typical of Martinotti cells (Fig. 3.3G; compare with figure 1 of (Wahle, 1993), with figure 2 of Kawaguchi and Kubota, 1996 and with figure 11A of (Klostermann and Wahle, 1999).

Occasionally observed in our slices, but not included in the present report, were neurogliaform cells (type 5 of Jones, 1975) and bipolar neurons. Apparently missing from our sample were axo-axonic (“chandelier”) cells (type 4 of Jones, 1975), possibly because of the relative immaturity of our cultures, since the characteristic chandeliershaped terminals appear late in development (Meyer and Ferres-Torres, 1984). We were also not able to identify so-called double bouquet cells (type 3 of Jones, 1975), which to our knowledge have not been clearly documented in rodents. Very rarely (4 cells, not shown), neurons with classical pyramidal morphology and spiny dendrites were observed 
to express GFP, possibly reflecting a low-level expression of GAD mRNA in pyramidal neurons (Cao et al., 1996). Finally, we consistently observed a small number per slice of GFP expressing cells with astroglia-like morphology; these were most often found near the pial or white matter boundaries (not shown).

\section{Quantitative analysis of GFP-expressing multipolar cortical neurons}

For quantitative analysis, 150 multipolar neurons were selected, solely based on their being brightly fluorescent and well-separated from other neurons in their vicinity. (We defined as "multipolar" any non-pyramidal neuron with 3 or more primary dendrites, a definition that may include neurons traditionally classified as bitufted.) Initial analysis included computation of the following morphological features: soma cross-sectional area, number of primary dendrites, number of dendritic branch points, total dendritic length, vertical and horizontal extent of the dendritic tree and total area covered by the dendritic tree (see Methods for definitions). Fig. 3.4 shows a matrix of pairwise scatterplots of the main four parameters - soma cross-sectional area, number of dendritic ends (primary dendrites + branch points), total dendritic length and area of dendritic coverage. All plots showed some degree of linear correlation, but the strongest correlations were found between total dendritic length and the 3 other parameters (Fig. 3.4, bottom row), with correlation coefficients between 0.57 and 0.70 . Thus, total dendritic length increased nearly linearly with soma cross-sectional area, with number of dendritic end points and with dendritic coverage area. 


\section{Directional dendritic outgrowth in multipolar cortical neurons}

To determine if dendrites of multipolar neurons have a preferred direction of growth relative to the vertical axis, we calculated for each neuron an index of polarization (IOP, see Methods). A bitufted neuron with all dendrites oriented directly towards or away from the pia will have an IOP very close to one, while a horizontal neuron with all dendrites growing parallel to the pia will have an IOP close to -1.75 . A multipolar neuron with dendrites distributed in purely random orientations relative to the vertical axis will have, on average, an IOP of 0. Fig. 3.5A (solid line) shows a smoothed histogram of all IOP values in our sample of 150 GFP-expressing multipolar neurons. The histogram was multimodal, with the lowest major mode centered on 0 , suggesting random orientations, and several additional peaks at more positive values, suggesting vertically biased orientations. As expected, the computed IOP values were linearly correlated with the measured aspect ratios of the dendritic trees $(r=0.50, p<0.0001$, data not shown).

To determine whether the IOP values we calculated were statistically different from those of randomly oriented dendrites, we conducted a Monte-Carlo simulation of 10,000 neurons, each consisting of 1000 randomly oriented dendritic segments, and calculated their IOP values. The histogram of all simulated IOP values (Fig. 3.5A, dashed lines) had a peak at zero, and declined steeply on both sides of zero, so there were virtually no simulated neurons with IOP values higher than 0.1 , and less than $5 \%$ of the simulated neurons had IOP values higher than 0.05 (in other words, $\mathrm{p}<0.05$ for IOP>0.05). Since the IOP of a typical real neuron in our sample was calculated from 1500-2000 dendritic segments, and since the spread in the IOP of randomly oriented 
dendrites should decrease with the number of dendritic segments, the simulation results represented an upper limit on the possible statistical spread of IOP values in our sample of real neurons, if they were all taken from a population with purely random dendritic trees. Fig. 3.5A demonstrates that the lowest major mode in the histogram of the real neurons precisely overlapped the histogram of the simulated neurons when scaled to the same height, indicating that dendritic trees of this group of neurons were not significantly different than random. The majority of neurons, however, had IOP values considerably higher than could be explained by statistical spread, indicating a highly significant nonrandom bias of their dendrites towards the vertical axis.

Based on the histogram in Fig. 3.5A, we classified all the neurons in our sample as either non-polarized (NP), moderately polarized (MP) or highly polarized (HP), with the cutoff IOP values between these three groups being 0.05 and 0.3 , respectively. A small number of neurons had significantly non-random negative IOPs $(<-0.05)$, and these were designated tangentially polarized (TP). About half of the neurons in our sample were classified as MP, while NP and HP comprised roughly $20 \%$ each, and about $10 \%$ were classified as TP (Fig. 3.5B). Thus, about $70 \%$ of the neurons in our sample had dendritic trees with varying degrees of vertical bias, but a well-separated subset, about $20 \%$ of the total, had randomly oriented dendritic trees.

Fig. 3.6 shows representative dendritic tracings of neurons from the 4 groups defined above. The HP group included many neurons that would otherwise be classified as bitufted, but some of the HP neurons, and most of the MP neurons, would fall under the multipolar category. Some of the neurons in the MP group (e.g. the leftmost neuron) had dendritic trees that would not be considered polarized had they been classified by 
more traditional metrics such as dendritic aspect ratio, illustrating the increased sensitivity of our method of analysis.

\section{DISCUSSION}

We describe here a novel method for visualizing the detailed morphology of nonpyramidal, presumed GABAergic neurons in living neocortical slice cultures by GAD67GFP transfection. Using a novel computational metric of dendritic polarization, we demonstrated that dendrites of about $70 \%$ of the medium and large GAD67-GFP expressing neurons are not randomly oriented, but instead show a highly significant tendency to extend along the vertical axis of the cortex.

\section{Novel method for visualizing GABAergic neuronal morphology in living slice cultures}

In this study we used particle-mediated transfection with the eGFP cDNA linked to the GAD67 5' regulatory region, to tag specifically GABAergic neurons in living cortical cultures. A similar DNA construct, using a much shorter segment of the GAD67 promoter, was inserted as a transgene into transgenic mice, but GFP expression in these animals was reported to be restricted to a small subset of all GABAergic neurons (Oliva et al., 2000). Our construct appeared to label a wide variety of non-pyramidal neurons, but virtually never pyramidal neurons. With the exception of spiny stellate neurons in layer IV, which were also never observed in our cultures, all non-pyramidal neurons in the cortex are GABAergic (Houser et al., 1983; Prieto et al., 1994), so there is little doubt that our construct labeled specifically GABAergic neurons, but with no apparent subtype 
specificity (see Results and the next section of the Discussion for morphological identification of the neurons in our sample vis a vis accepted classifications of GABAergic cortical neurons).

In its level of morphological detail, GFP transfection appears to equal or rival the Golgi and intracellular staining methods, revealing even fine dendritic and axonal processes. Like the Golgi method, gene-gun mediated transfection labels neurons in a spatially random and scattered pattern, which in favorable cases allows one to follow dendrites and even axons of isolated neurons for their full length. Unlike the Golgi technique, however, our transfection method is cell-type specific, in that it labels selectively GABAergic neurons, and allows visualization of neuronal morphology in the living state. These features of the method have important potential applications. For example, this method could be used to follow changes in morphology of live neurons during development in vitro, and to test whether such development is dependent on neuronal activity or on various growth factors. Another application would be electrophysiological recordings of synaptic responses in postsynaptic neurons, upon minimal stimulation of GFP-tagged axons (Jin et al., 2000). Finally, future studies could take advantage of the well-characterized activity-dependent regulation of GAD expression in the cortex (Hendry and Jones, 1988; Akhtar and Land, 1991; Martin and Rimvall, 1993; Benson et al., 1994) and use dynamic changes in GAD67-GFP expression to identify activation patterns in the cortex at the single-cell level.

\section{Novel metric for dendritic polarization}

The observation that dendrites of multipolar cortical neurons have a vertical orientation bias was made by numerous previous studies (e.g. (Jones, 1975; McMullen 
and Glaser, 1982; Winer, 1984; DeFelipe et al., 1986; Lund et al., 1988; McMullen et al., 1988), but has rarely been examined quantitatively (McMullen et al., 1984). Polarization of dendritic trees has been quantified previously using a variety of metrics (reviewed in (Uylings et al., 1986), most of which are adequate for describing and comparing the spatial distribution of dendritic branches, but provide little insight into the mechanisms guiding dendritic growth. In this study, we followed a small number of previous studies (Glaser et al., 1979; McMullen et al., 1984) by measuring the local orientation of each dendritic chord in the brain coordinate system, rather than in a coordinate system centered on its parent cell body. Assuming that the trajectory of the mature dendrite closely resembles the trajectory taken by the dendritic growth cone during development, such analysis can provide important clues on the factors influencing dendritic growth. We expanded upon previous studies by employing a novel metric, the WACAV (or its normalized equivalent, the IOP), as a single quantity indicating the degree of directional bias in the dendritic tree of a given neuron. This novel approach allowed us to clearly distinguish between vertically biased and randomly oriented dendritic trees, the latter having IOP values scattered closely around zero. A major advantage of this method of analysis is that it applies equally well to the 2-dimensional projection of neurons growing in 3-dimensional space, and to neurons confined to the nearly planar organotypic slice (see Appendix).

\section{Potential caveats}

Three potential caveats need to be considered before accepting our interpretation. The first is that these data were acquired from neurons whose morphological 
development occurred mostly in cultured slices, since at the age of culturing (first postnatal week) non-pyramidal neurons are only poorly developed morphologically (Parnavelas and Uylings, 1980; Miller, 1986; McMullen et al., 1988). This implies that the neurons in our sample developed, to a large degree, without sensory input, and may therefore have abnormal properties. Previous studies have documented similarities in many of the morphological and electrophysiological properties of neurons which developed in organotypic slice cultures to those of neurons which developed in vivo, suggesting that proper development of these properties does not require intact sensory input (Bolz et al., 1990; Behan et al., 1991; Bolz et al., 1992; Annis et al., 1993; Novak and Bolz, 1993; Massengill et al., 1997; Sieg et al., 1998). Similar conclusions were reached in a recent study that focused specifically on morphological and physiological properties of inhibitory cortical interneurons (Klostermann and Wahle, 1999). On the other hand, dendritic orientation does depend on afferent input (Pinto Lord and Caviness, 1979). A classic example of this dependence is the morphology of both excitatory and inhibitory layer IV neurons in rodent somatosensory cortex, which display strong dendritic (and to a lesser degree axonal) polarization towards the center of their "barrel" ( Woolsey and Van der Loos, 1970; Lorente de No, 1992). Development of this polarity requires intact thalamocortical afferents during a "critical period" in early development (Harris and Woolsey, 1981; Steffen and Van der Loos, 1980). Similar (though less dramatic) dependence of dendritic orientation on patterned sensory input has been described in the visual cortex (Borges and Berry, 1978; Coleman et al., 1981; Tieman and Hirsch, 1982; Kossel et al., 1995), and elimination of all auditory input during early development causes a shift of the dendritic orientation of non-pyramidal neurons in 
auditory cortex towards the horizontal (tangential) plane (McMullen et al., 1988). Thus vertical orientation in our cultures may have been reduced by lack of sensory input, compared to vertical orientation in vivo, and our estimate of vertical dendritic bias in vitro should be regarded as a lower estimate of vertical bias in the intact brain.

A second caveat is that biolistically transfecting neurons with GFP may have altered their normal development and shape. Preliminary studies (X.J., P.H.M. and A.A., unpublished observations) have revealed no apparent differences in electrophysiological and morphological properties between GAD67-GFP expressing and non-expressing GABAergic neurons in cultured slices. In addition, previous studies of pyramidal cells biolistically transfected with GFP in vitro (Lo et al., 1994; McAllister et al., 1995) have revealed seemingly normal morphologies. We therefore expect that biolistic transfection and GAD67-GFP expression do not alter the morphology of non-pyramidal cells.

A third concern is that the dendritic orientation of the neurons in our sample was altered by the slicing procedure, since some dendrites would be truncated during the slicing. However the effect of truncation on our cultured slices was most likely negligible, since the cultures were prepared from animals less than one week old, in which the diameter (in the horizontal plane) of the dendritic tree of non-pyramidal cells is less than $100 \mu \mathrm{m}$ (Parnavelas and Uylings, 1980; McMullen et al., 1988). Therefore, only neurons with cell bodies $50 \mu \mathrm{m}$ or less from either cut surface, or less than $30 \%$ of all neurons in a $350 \mu \mathrm{m}$ thick slice, suffered any truncation at all, and these would have been truncated on one side only and most of them by a negligible amount. Moreover, it is quite likely that the more severely truncated neurons did not survive in the long-term culture, leaving only intact or mildly truncated neurons. Most importantly, truncation had 
absolutely no effect on the calculated IOP, since the truncation occurred in a plane parallel to the plane of the projection, and therefore both dendrites oriented vertically and dendrites oriented horizontally were truncated to the same extent.

\section{Classification schemes of non-pyramidal neocortical neurons and dendritic orientation}

Neocortical non-pyramidal, GABAergic neurons have been classified in a multitude of ways, based on a variety of morphological, electrophysiological and immunocytochemical criteria. Although morphological cell types can be defined on the basis of cell body shape (Cobas et al., 1987) or dendritic arbors (Feldman and Peters, 1978; Peters and Regidor, 1981; Prieto et al., 1994), most modern classification schemes follow the lead of Cajal (DeFelipe and Jones, 1988) in classifying non-pyramidal neurons by relying heavily on their axonal arborization patterns (Jones, 1975; Szentagothai, 1978; Meyer, 1983). Axonal arborization patterns are predictive of the type of target favored by each inhibitory neuron (Somogyi et al., 1998), and most classifications now recognize at least three major types: basket cells, favoring somata and proximal dendritic shafts ( Somogyi et al., 1983; DeFelipe et al., 1986); double bouquet cells (described most often in primates and carnivores, rarely in rodents), favoring distal dendritic shafts and spines ( Somogyi and Cowey, 1981; DeFelipe and Fairen, 1988); and chandelier cells, making synapses exclusively on initial segments of axons (Fairen and Valverde, 1980; Peters et al., 1982; Somogyi et al., 1982). These classes are also distinguishable by molecular markers: basket and chandelier cells most often contain parvalbumin, while double bouquet cells contain calbindin (DeFelipe et al., 1989; Hendry et al., 1989; DeFelipe et 
al., 1990; Williams et al., 1992; Peters and Sethares, 1997; Kawaguchi and Kubota, 1998). Falling outside this classification are several classes of neuropeptide-containing cortical interneurons, e.g., Martinotti cells, characterized by an ascending axon forming an extended arbor in layer I, and containing somatostatin, Substance $\mathrm{P}$ and/or Neuropeptide Y (Kuljis and Rakic, 1989; Wahle, 1993; Kawaguchi and Kubota, 1996), and bipolar cells, containing vasoactive intestinal peptide (Connor and Peters, 1984; Morrison et al., 1984; Bayraktar et al., 2000; Cauli et al., 2000). Finally, some morphological and/or immunocytochemical types also show characteristic firing patterns (Kawaguchi and Kubota, 1997). A definitive identification of a non-pyramidal neuron as belonging to one of these classes requires immunocytochemical identification, electron microscopical examination of its postsynaptic targets and/or electrophysiological characterization, in addition to knowledge of its dendritic and axonal morphologies, and was therefore outside the scope of the present study. Nevertheless, based on dendritic and axonal morphology, our sample of neurons expressing GAD67-GFP appeared to include representatives of many of the putative or confirmed GABAergic cell classes observed previously with the Golgi and intracellular staining methods, including some types with specific immunocytochemical identities. For example, our sample contained representatives of at least four of the six types of smooth non-pyramidal cells described in monkey somatosensory cortex by Jones (1975) (see Results for specific comparisons with previous studies). Our characterization of GAD67-GFP expressing neurons according to the level of vertical bias in their dendritic tree is not intended to add yet another system of classification, and we have not attempted to equate a specific level of vertical orientation bias with specific classes of non-pyramidal cells. Indeed, it appears from our own and 
previous studies that a vertical dendritic orientation bias is a property superimposed, to varying degrees, on all classes of non-pyramidal GABAergic neurons.

\section{What dendritic measurements tell us about dendritic development}

Our analysis shows that dendritic length of non-pyramidal, putative GABAergic neurons is strongly correlated with soma cross sectional area, with number of dendritic ends and with total dendritic coverage area (Fig. 3.4), confirming and expanding previous findings (McMullen et al., 1984). The first of these correlations, the correlation between soma size and dendritic length, most likely reflects the need for a larger cell body to support a larger dendrite. The other correlations may be rooted in basic rules of dendritic

development. For example, the linear relationship between number of end points and dendritic length suggests that the average length that a dendrite grows between branch points is similar between different neurons, implying a common underlying mechanism involved in determining dendritic bifurcation. The linear relationship between total dendritic length and dendritic coverage area suggests that dendrites branch so that a unit of cortical area (in the nearly planar organotypic slice) is always sampled by the same total dendritic length. The 3-dimensional analogue of this last correlation remains to be investigated.

\section{Possible mechanisms of vertically biased dendritic outgrowth}

How dendrites acquire a vertical orientation bias is not known. An attractive hypothesis accounting for vertically biased growth is that developing neurons sense a piato-white matter gradient of a diffusible or surface-attached molecule. If a single 
extracellular gradient is to account for extension of processes both towards and away from the pia, one needs to assume that the receptive or signal transducing mechanism in the neuron is asymmetrically distributed, causing opposite poles of the neuron to extend neurites in opposite directions, in response to the same gradient. Evidence for precisely such a mechanism has recently been reported, indicating that the same diffusible morphogen, Semaphorin 3A, can simultaneously behave as an attractant for apical dendrites of cortical pyramidal neurons and as a repellent for their axons, by virtue of an asymmetric distribution of the enzyme guanylate cyclase (Polleux et al., 2000). The organotypic slice preparation could potentially be used to test such models. Interestingly, our analysis demonstrates that multipolar neurons did not form a continuum with respect to their index of polarization; rather, there was a well-separated population (NP cells, about $20 \%$ of neurons in our sample) with a statistical spread of indices of polarization around the value of 0 , indicating purely random dendritic orientations. An intriguing and testable possibility is that this population lacked the molecular machinery to detect or to transduce the postulated extracellular gradient.

\section{Functional significance of directionally biased dendritic trees}

Our results imply that a vertical orientation bias, which is characteristic of dendrites of pyramidal cortical cells, is also a feature of non-pyramidal neurons - not only of the bipolar and bitufted types, but also of those with "stellate" or multipolar morphologies. What advantage(s) may be conferred on the information processing capabilities of the neocortex by vertically elongated dendritic trees? The major afferents to primary sensory and motor cortical areas are thalamocortical axons, which are 
organized along the horizontal (tangential) dimensions in a precise topological order (Hohl-Abrahao and Creutzfeldt, 1991; Agmon et al., 1995), and terminate in narrow vertical (radial) columns and in specific laminar patterns (LeVay and Gilbert, 1976; Jensen and Killackey, 1987; Landry et al., 1987; Agmon et al., 1993). A columnar pattern of terminations, although with a fractured topology and with a different laminar distribution, is also formed by long-range corticocortical axons (Jones et al., 1975; Goldman and Nauta, 1977; Code and Winer, 1986; DeFelipe et al., 1986; Chapin et al., 1987; Ojima et al., 1991; Saleem et al., 1993; Pucak et al., 1996). In turn, both excitatory and inhibitory cortical neurons of all layers extend much of their local axonal projections along the vertical dimension (Lorente de No, 1949; Somogyi et al., 1981; Bernardo et al., 1990; Kritzer and Goldman-Rakic, 1995; Fujita and Fujita, 1996; Zhang and Deschenes, 1997; Lubke et al., 2000; Porter et al., 2001), again with specific laminar distributions (Lund and Boothe, 1975). These organizational principles ensure that afferent information pertaining to specific features of sensory space will be distributed and processed within relatively narrow radial modules, whether in primary (Hubel and Wiesel, 1977; Mountcastle, 1997) or in high-order (Fujita et al., 1992; Britten, 1998) cortical areas. By extending their dendritic trees vertically, pyramidal and non-pyramidal cortical neurons can potentially sample and integrate afferent and reentrant inputs terminating at different laminar positions and representing different stages of information processing, while retaining the specificity of location, modality and/or features unique to their own module. A similar organizational rule, manifested as dendritic arbors elongated in parallel to a topologically ordered system of afferent fibers and orthogonal to the plane of the mapping, is found also in other brain areas, such as the dorsal cochlear nucleus 
(Blackstad et al., 1984; Berrebi and Mugnaini, 1991), the inferior and superior colliculi (Rockel and Jones, 1973; Langer and Lund, 1974), the reticular thalamic nucleus (Montero et al., 1977; Liu et al., 1995; Crabtree, 1996) and the cerebellar cortex (Voogd and Bigare, 1980; Mulle et al., 1987; Wiklund et al., 1990).

\section{APPENDIX}

As explained in Methods, to calculate the WACAV one takes the sum of the lengths of the projections of all dendritic segments on the vertical axis, and divides it by the sum of all dendritic lengths. The calculation can be done either in two-dimensions (using 2-dimensional coordinates) or, if a suitable dataset is available, in 3-dimensions. We show here that the 2-dimensional and the 3-dimensional WACAV values will be different, but that when calculated in 2-dimensions, the WACAV of neurons with randomly oriented dendrites is 0.64 , regardless of whether the neurons have developed in a plane (e.g. in the organotypic slice) or in 3-dimensional space (in vivo).

We start by calculating the average WACAV of a planar neuron with randomly oriented dendrites. We simulate the neuron by dividing it into a large number of small dendritic segments, and represent each segment as a unit vector forming a random angle with the vertical axis (this is equivalent to the "stick analysis" of (Glaser et al., 1979). Since the cosine is symmetric and since we consider the upward and downward directions equivalent, we can restrict the discussion to a quarter-circle between 0 and $\pi / 2$. The normalized probability that a random angle will fall within the infinitesimal arc segment $(\theta, \theta+\mathrm{d} \theta)$ is the ratio of the length of the arc segment to the quarter circle, or 
$(2 / \pi) \cdot d \theta$. The average of the cosines of all angles (the WACAV of a randomly oriented dendritic tree) would therefore be 0.64 , given by the integral

$$
\frac{2}{\pi} \int_{0}^{\pi / 2} \cos \vartheta \cdot d \vartheta=\frac{2}{\pi}
$$

Next we calculate the 3-dimensional WACAV of a neuron with dendrites randomly oriented in 3-dimensional space. Calculations are simplified by using spherical coordinates, with $\theta$ being the angle from the vertical $(Z)$ axis and $\phi$ being the angle of the projection of the vector on the horizontal $(\mathrm{X}-\mathrm{Y})$ plane relative to the positive $\mathrm{X}$ axis. In space, the normalized probability of occurrence of a randomly oriented vector within the infinitessimal solid arc bounded by $(\theta, \theta+\mathrm{d} \theta)$ and $(\phi, \phi+\mathrm{d} \phi)$ is the ratio of the area of the solid arc to the area of the $1 / 8$ unit sphere, or $(2 / \pi) \cdot \sin \theta \cdot d \theta \cdot d \phi$. The 3 -dimensional WACAV of a random neuron is therefore given by the integral

$$
\frac{2}{\pi} \int_{0}^{\pi / 2} \int_{0}^{\pi / 2} \cos \vartheta \cdot \sin \vartheta \cdot d \vartheta \cdot d \phi=\frac{1}{2}
$$

Thus, if one has a true 3-dimensional dataset describing the neuron, the WACAV should be calculated as described in Methods using 3-dimensional dot products and norms, and any significant departure from 0.5 will indicate non-random dendritic growth.

Often, however, only a 2-dimensional dataset is available, describing the projection of the neuron on the plane of the drawing (for example, when tracing a neuron using a camera lucida device). In this case, calculating the WACAV in 2-dimensions would give the same sum of projections as in the 3-dimensional case, since the projection of a vector on the vertical axis is not altered by first projecting it on a vertical plane, but the (apparent) lengths of the projected dendrites would be smaller than their real 3- 
dimensional lengths. The length of the projection of a unit vector on the vertical (X-Z) plane is given by $\left(\cos ^{2} \theta+\sin ^{2} \theta \cdot \cos ^{2} \phi\right)^{1 / 2}$, so for a set of unit vectors randomly oriented in space, the average projected length of a vector is given by

$$
\frac{2}{\pi} \int_{0}^{\pi / 2} \int_{0}^{\pi / 2} \sqrt{\cos ^{2} \vartheta+\sin ^{2} \vartheta \cdot \cos ^{2} \phi} \cdot \sin \vartheta \cdot d \vartheta \cdot d \phi=\frac{\pi}{4}
$$

Since this quantity appears in the denominator when calculating the WACAV, one needs to divide the 3-D WACAV (which is $1 / 2$ ) by $\pi / 4$, to account for the distortion due to the projection. The WACAV of a neuron with randomly oriented dendrites would therefore be, on average, $2 / \pi$, the same as in the planar case. 


\section{Acknowledgements}

This study was supported by National Institutes of Health grants HD33463 (A.A.) and EY12152 (P.H.M.) and by OTKA grant T-029369 (G.Sz.). We thank Drs. Albert Berrebi,

Paul Brown and Ron Millecchia for critical comments on the manuscript, Dr. Arie Gingold for helpful discussions on mathematical methods, and Cary Johnson, Colette Ramsburg and Jubin Ryu for excellent technical support. 


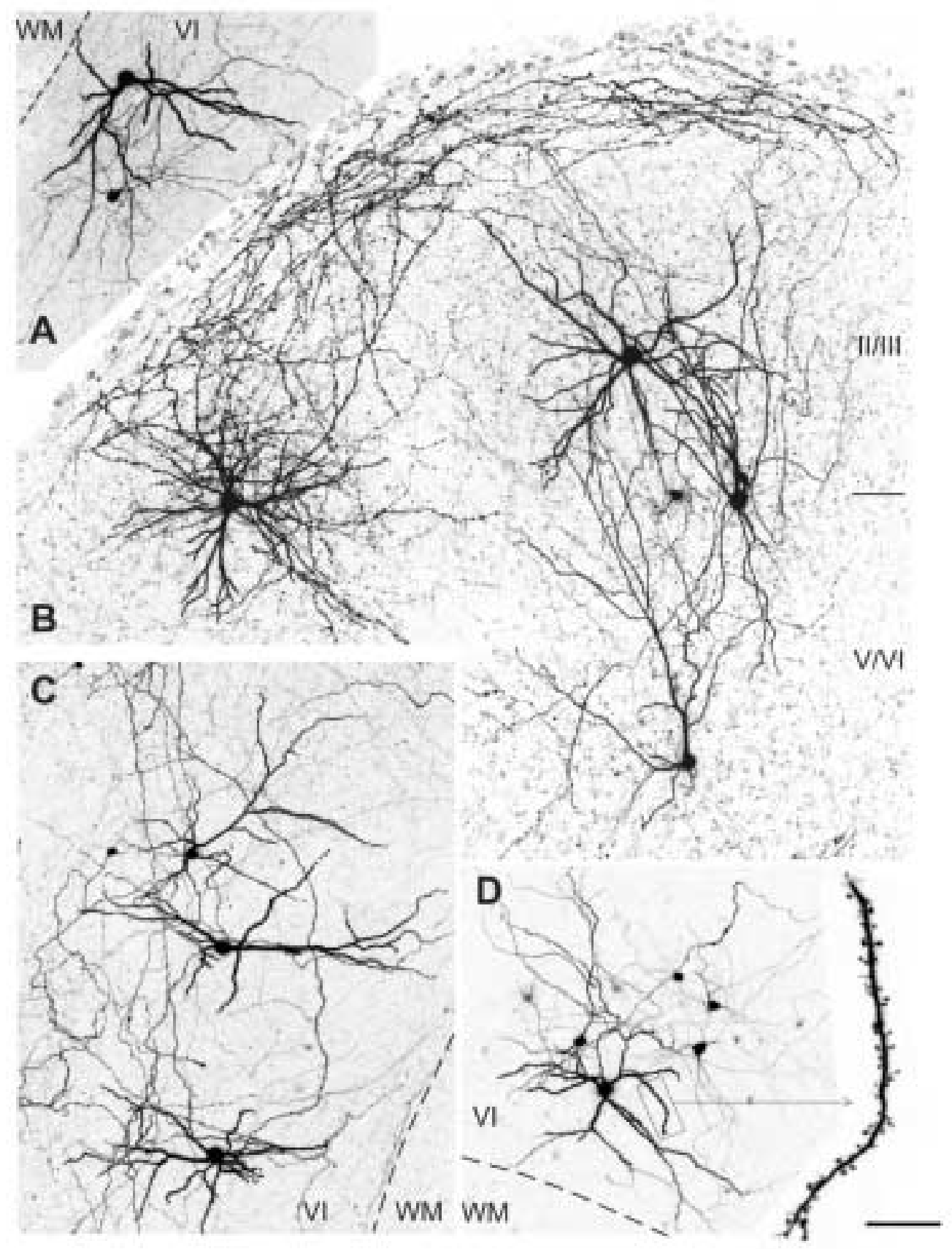


Figure 3.1. Confocal images of representative GAD67-GFP expressing neurons. Each panel is a projection of confocal images taken at multiple focal planes (Z-stacks) and superimposed. Dashed lines in A,C,D indicate white matter (WM) boundary. A, a large fan-shaped neuron in lower layer VI; pia is towards the lower right. B, a highpower montage of several microscope fields, including two large multipolar neurons in the upper layers; note the extended axonal arbor in layer I, emanating from the leftmost multipolar neuron. Pial surface is seen at the top of the image. The horizontal line at right represents the approximate border between the superficial (II/III) and deep (V/VI) layers; layer IV was not identifiable in this part of the cortex. C, GFP-expressing neurons in layer VI, including two inverted pyramidal cells (top two neurons); pial surface is towards the left. D, a multipolar neuron in lower layer VI; pia is upwards. Inset shows enlarged spiny dendritic segment. Scale bar represents $100 \mu \mathrm{m}$ except for inset in D, 15 $\mu \mathrm{m}$. 

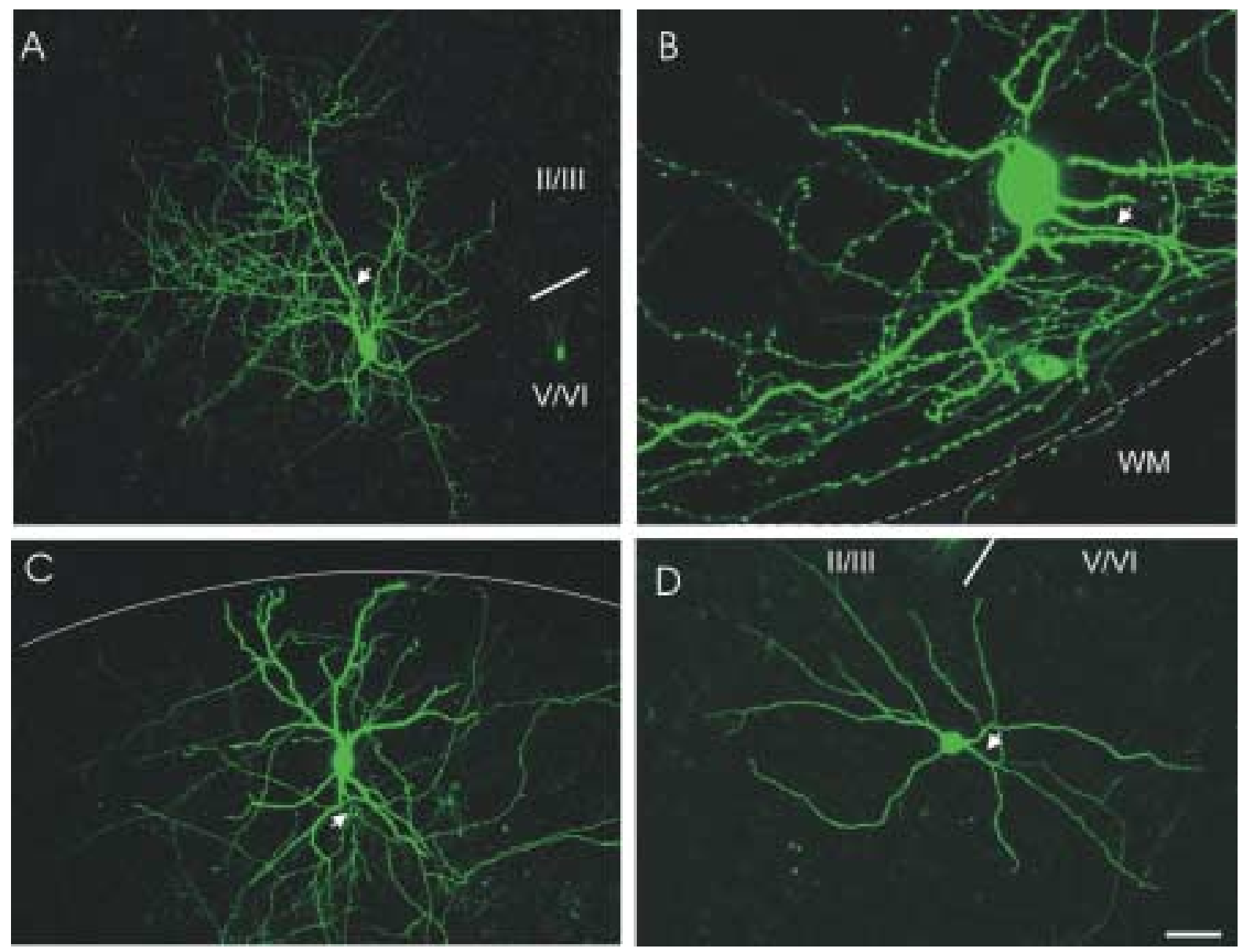

Figure 3.2. Confocal images (projected Z-stacks) of representative GAD67-GFP expressing neurons with extensive local axonal arborizations. A, a bitufted neuron in the middle layers with an ascending axon. B, a deep layer VI multipolar neuron with horizontally extended dendrites and a horizontally arborizing, varicose axon. C, a bitufted neuron in the upper layers with several horizontally directed axonal branches. D, A multipolar neuron in layer I with horizontal axonal branches in layers I and II/III. In all panels, arrows point to the initial segment of the axon, identified on the original stack of confocal images. Pial surface is indicated by the solid line in $\mathrm{C}$, and is upward and to the left in A,B,D. Dashed line in B indicates the white matter boundary. The diagonal lines in $\mathrm{A}$ and $\mathrm{D}$ represent the estimated border between upper (II/III) and lower (V/VI) layers and are drawn parallel to the pia/white matter boundaries; layer IV was not clearly identifiable. Scale bar: $50 \mu \mathrm{m}$ in $\mathrm{A}, \mathrm{C} ; 60 \mu \mathrm{m}$ in $\mathrm{D} ; 12 \mu \mathrm{m}$ in B. 


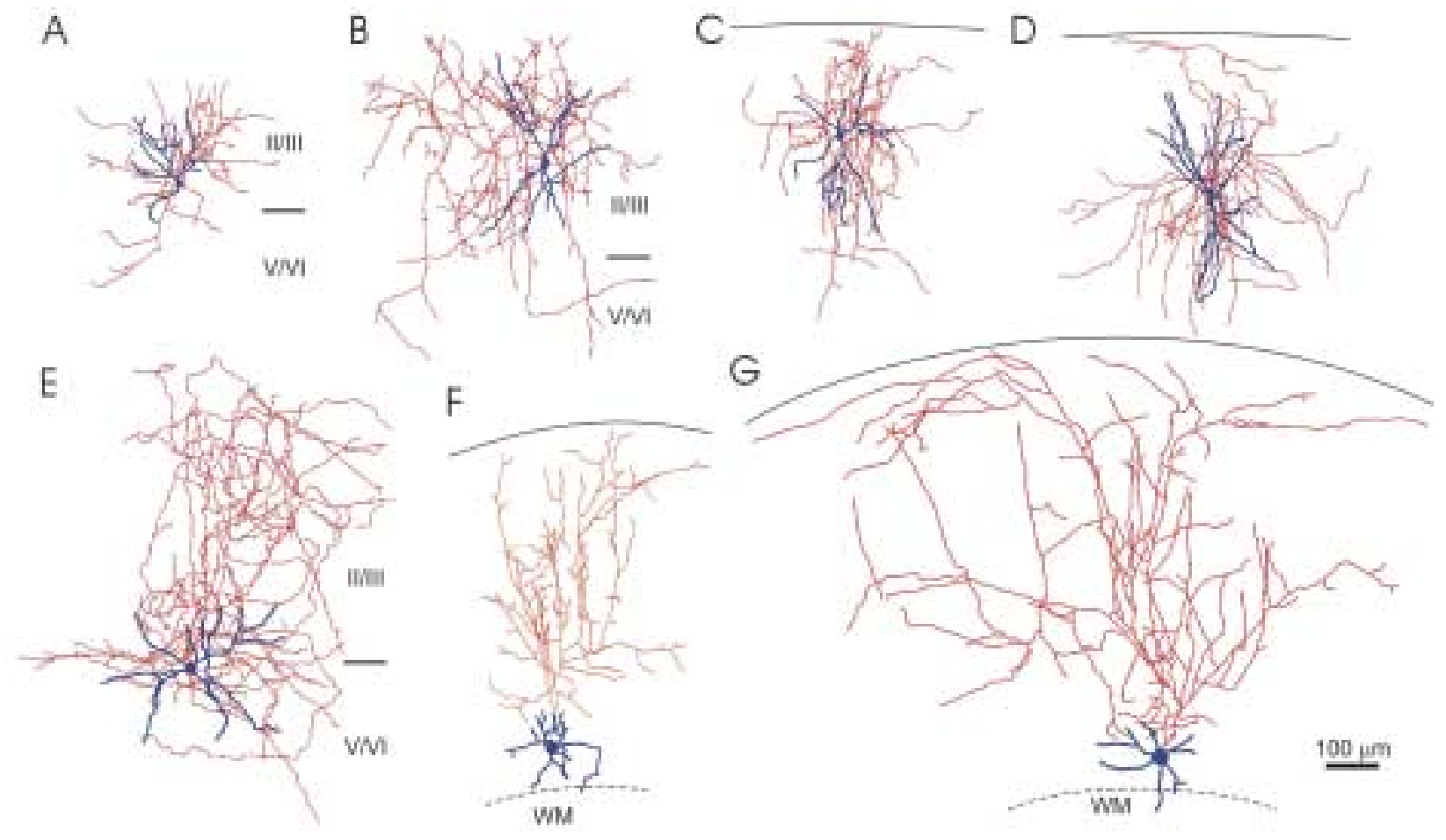

Figure 3.3. Computer-assisted tracings of neurons with representative axonal morphologies. Dendrites and cell bodies are shown in blue, axons in red. For clarity, dendrites and axons are represented as lines of uniform width. Pia, white matter and laminar boundaries indicated as in Figs. 3.1-2. See Results for identification of the different morphological cell types. 

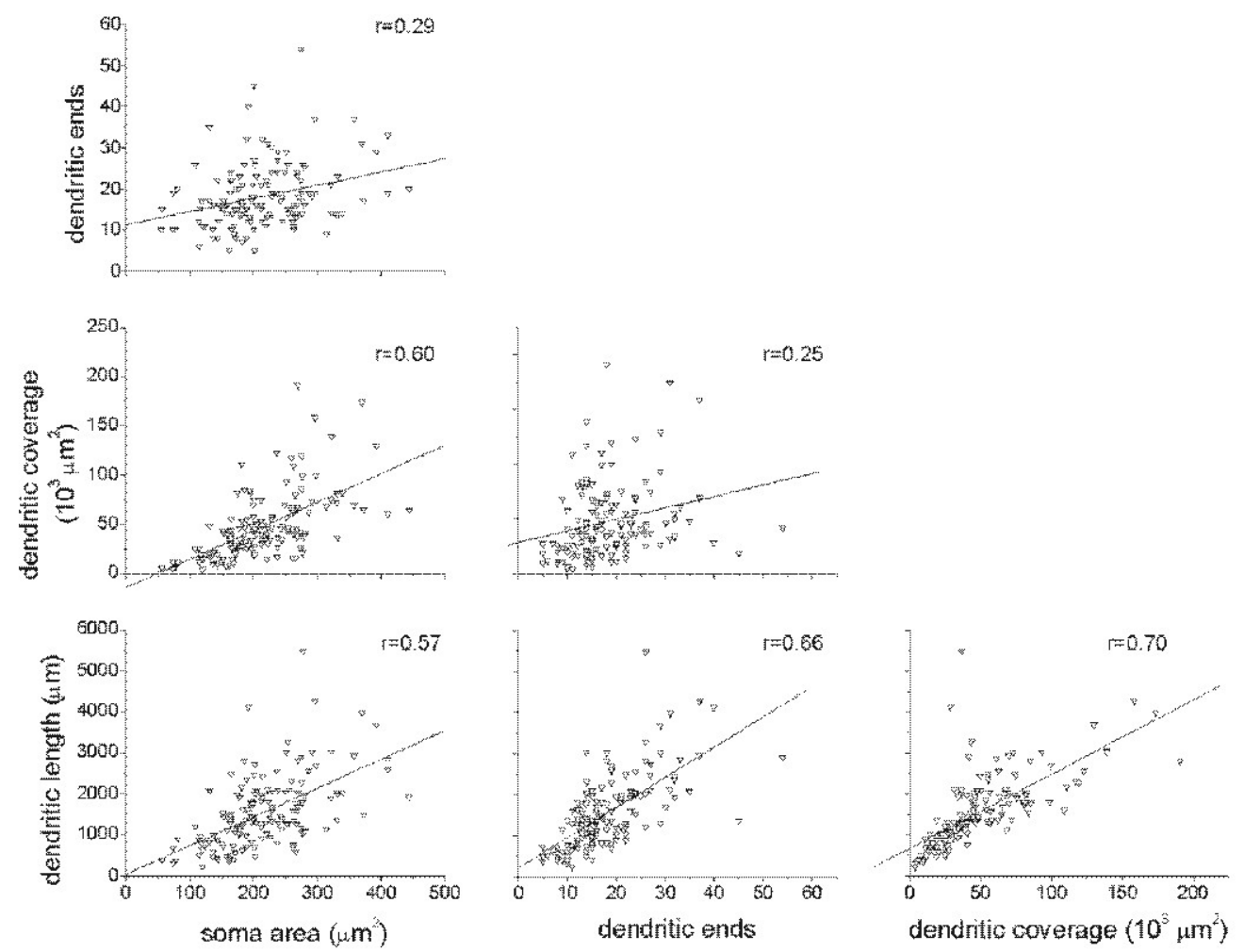

Figure 3.4. Scatterplot matrix of 4 morphometric somatodendritic parameters.

Lines represent best-fit (least squares) linear regressions, and were not forced to pass through the origin of axes. Five outlier neurons with soma area $>500 \mu^{2}$ were excluded from this analysis. The correlation coefficients for the six paired correlations are indicated on the plots. Probabilities that the regression slope was 0 were $p<0.0001$, except for top left $(\mathrm{p}<0.001)$ and middle right $(\mathrm{p}<0.005)$. 
A

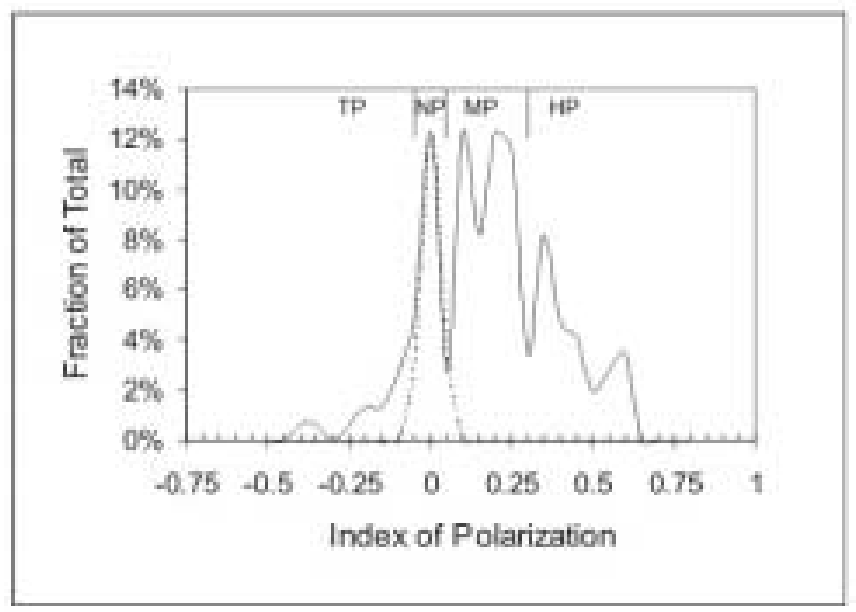

B

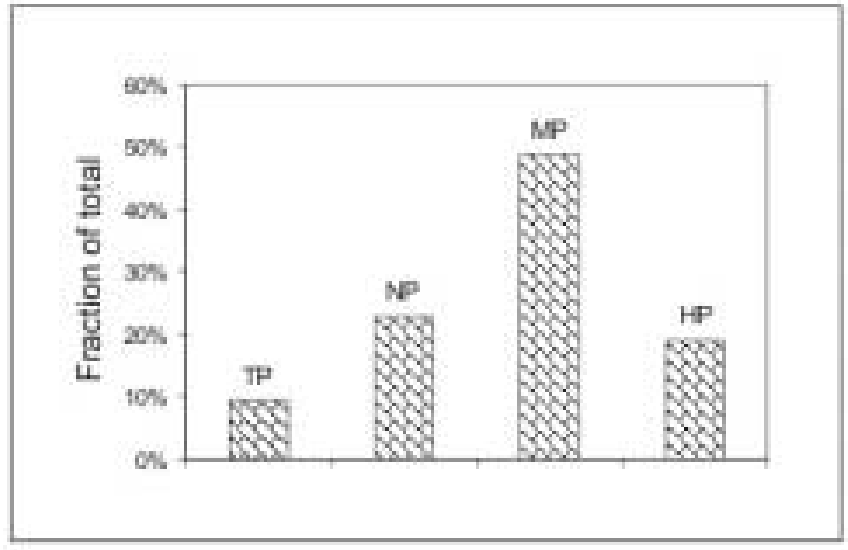

Figure 3.5. Classification of GAD67-GFP expressing multipolar neurons according to the degree of vertical bias in their dendritic trees. A, a smoothed histogram of the index of polarization (IOP, see Methods) of all neurons (solid line), with a superimposed histogram of the IOP of 10,000 simulated neurons (dashed line). Vertical lines above graph indicate the cutoff values for dividing the sample into tangentially polarized (TP, IOP $<-0.05$ ), non-polarized (NP, $-0.05<\mathrm{IOP}<0.05$ ), moderately-polarized (MP, $0.05<\mathrm{IOP}<0.3)$ and highly-polarized (HP, IOP $>0.3)$ neurons. $\mathrm{B}$, the fraction of neurons in our sample falling into each category. 

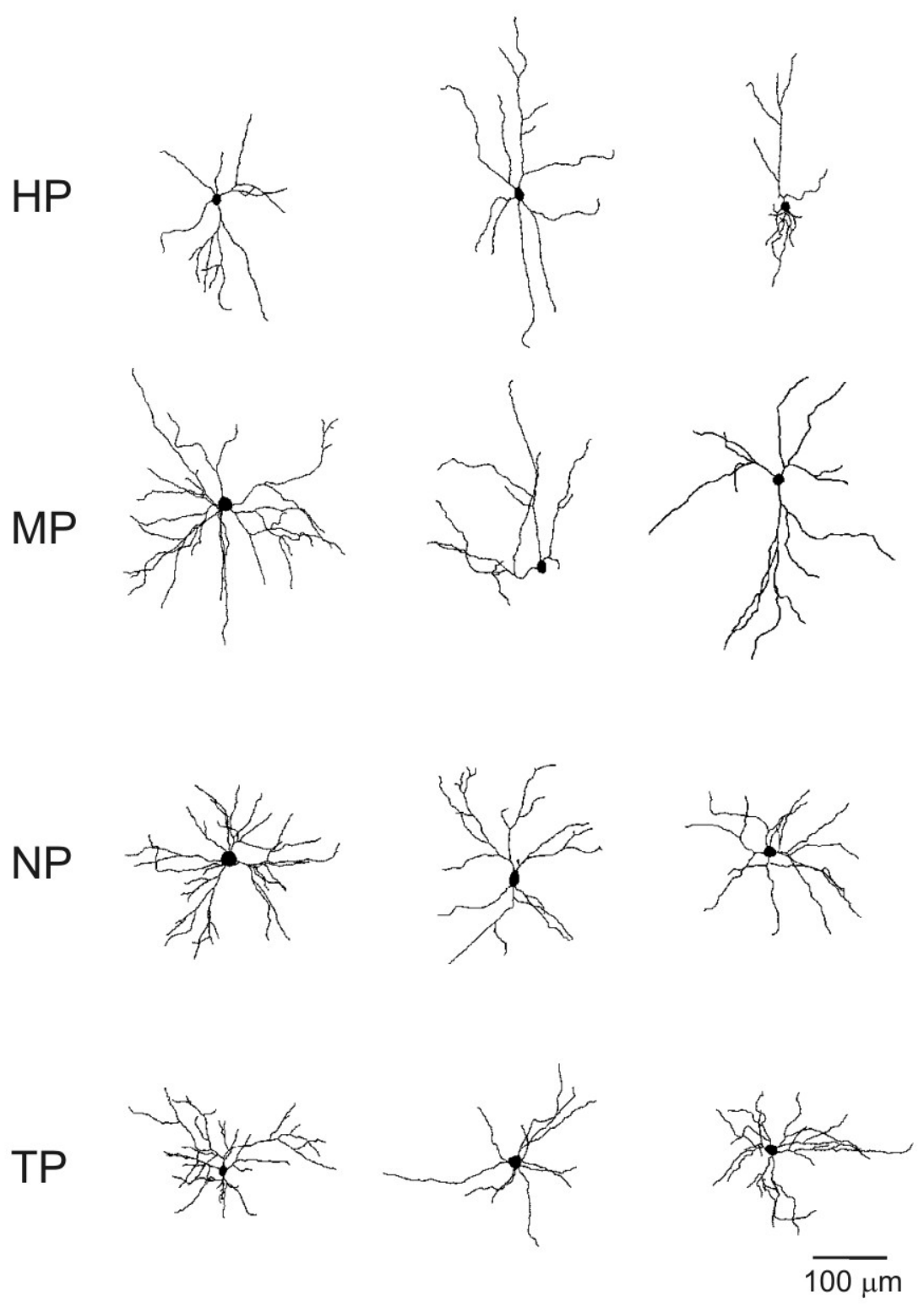

Figure 3.6. Tracings of dendritic trees of representative multipolar neurons from the 4 classes defined in Fig. 3.4. Note that the computed degree of vertical polarization often, but not always, agrees with the visually perceived one. Pia is upwards in all panels. 


\section{REFERENCES}

Agmon, A., Yang, L. T., Jones, E. G., and O'Dowd, D. K. (1995) Topological precision in the thalamic projection to neonatal mouse barrel cortex. J Neurosci 15: 549-61.

Agmon, A., Yang, L. T., O'Dowd, D. K., and Jones, E. G. (1993) Organized growth of thalamocortical axons from the deep tier of terminations into layer IV of developing mouse barrel cortex. J Neurosci 13: 5365-82.

Akhtar, N. D., and Land, P. W. (1991) Activity-dependent regulation of glutamic acid decarboxylase in the rat barrel cortex: effects of neonatal versus adult sensory deprivation. J Comp Neurol 307: 200-13.

Annis, C. M., Robertson, R. T., and O'Dowd, D. K. (1993) Aspects of early postnatal development of cortical neurons that proceed independently of normally present extrinsic influences. J Neurobiol 24: 1460-80.

Bayraktar, T., Welker, E., Freund, T. F., Zilles, K., and Staiger, J. F. (2000) Neurons immunoreactive for vasoactive intestinal polypeptide in the rat primary somatosensory cortex: morphology and spatial relationship to barrel-related columns. J Comp Neurol 420: 291-304.

Behan, M., Kroker, A., and Bolz, J. (1991) Cortical barrelfields in organotypic slice cultures from rat somatosensory cortex. Neurosci Lett 133: 191-4.

Benson, D. L., Huntsman, M. M., and Jones, E. G. (1994) Activity-dependent changes in GAD and preprotachykinin mRNAs in visual cortex of adult monkeys. Cereb Cortex 4 : 40-51.

Bernardo, K. L., McCasland, J. S., Woolsey, T. A., and Strominger, R. N. (1990) Local intra- and interlaminar connections in mouse barrel cortex. J Comp Neurol 291: 231-55.

Berrebi, A. S., and Mugnaini, E. (1991) Distribution and targets of the cartwheel cell axon in the dorsal cochlear nucleus of the guinea pig. Anat Embryol 183: 427-54.

Black, M. M., and Baas, P. W. (1989) The basis of polarity in neurons. Trends Neurosci 12: 211-4.

Blackstad, T. W., Osen, K. K., and Mugnaini, E. (1984) Pyramidal neurones of the dorsal cochlear nucleus: a Golgi and computer reconstruction study in cat. Neuroscience 13: 827-54.

Bolz, J., Novak, N., Gotz, M., and Bonhoeffer, T. (1990) Formation of target-specific neuronal projections in organotypic slice cultures from rat visual cortex. Nature 346: 359-62. 
Bolz, J., Novak, N., and Staiger, V. (1992) Formation of specific afferent connections in organotypic slice cultures from rat visual cortex cocultured with lateral geniculate nucleus. J Neurosci 12: 3054-70.

Borges, S., and Berry, M. (1978) The effects of dark rearing on the development of the visual cortex of the rat. J Comp Neurol 180: 277-300.

Britten, K. H. (1998) Clustering of response selectivity in the medial superior temporal area of extrastriate cortex in the macaque monkey. Vis Neurosci 15: 553-8.

Cao, Y., Wilcox, K. S., Martin, C. E., Rachinsky, T. L., Eberwine, J., and Dichter, M. A. (1996) Presence of mRNA for glutamic acid decarboxylase in both excitatory and inhibitory neurons. Proc Natl Acad Sci U S A 93: 9844-9.

Carder, R. K., and Hendry, S. H. (1994) Neuronal characterization, compartmental distribution, and activity- dependent regulation of glutamate immunoreactivity in adult monkey striate cortex. J Neurosci 14: 242-62.

Cauli, B., Porter, J. T., Tsuzuki, K., Lambolez, B., Rossier, J., Quenet, B., and Audinat, E. (2000) Classification of fusiform neocortical interneurons based on unsupervised clustering. Proc Natl Acad Sci U S A 97: 6144-9.

Chapin, J. K., Sadeq, M., and Guise, J. L. (1987) Corticocortical connections within the primary somatosensory cortex of the rat. J Comp Neurol 263: 326-46.

Cobas, A., Welker, E., Fairen, A., Kraftsik, R., and Van der Loos, H. (1987) GABAergic neurons in the barrel cortex of the mouse: an analysis using neuronal archetypes. J Neurocytol 16: 843-70.

Code, R. A., and Winer, J. A. (1986) Columnar organization and reciprocity of commissural connections in cat primary auditory cortex (AI). Hear Res 23: 205-22.

Coleman, P. D., Flood, D. G., Whitehead, M. C., and Emerson, R. C. (1981) Spatial sampling by dendritic trees in visual cortex. Brain Res 214: 1-21.

Colonnier, M. L. (1966). The Structural Design of the Neocortex. In Brain and Conscious Experience, J. C. Eccles, ed. (New-York: Springer-Verlag).

Connor, J. R., and Peters, A. (1984) Vasoactive intestinal polypeptide-immunoreactive neurons in rat visual cortex. Neuroscience 12: 1027-44.

Crabtree, J. W. (1996) Organization in the somatosensory sector of the cat's thalamic reticular nucleus. J Comp Neurol 366: 207-22. 
DeFelipe, J., Conley, M., and Jones, E. G. (1986) Long-range focal collateralization of axons arising from corticocortical cells in monkey sensory-motor cortex. J Neurosci 6: 3749-66.

DeFelipe, J., and Fairen, A. (1988) Synaptic connections of an interneuron with axonal arcades in the cat visual cortex. J Neurocytol 17: 313-23.

DeFelipe, J., Hendry, S. H., Hashikawa, T., Molinari, M., and Jones, E. G. (1990) A microcolumnar structure of monkey cerebral cortex revealed by immunocytochemical studies of double bouquet cell axons. Neuroscience 37: 655-73.

DeFelipe, J., Hendry, S. H., and Jones, E. G. (1986) A correlative electron microscopic study of basket cells and large GABAergic neurons in the monkey sensory-motor cortex. Neuroscience 17: 991-1009.

DeFelipe, J., Hendry, S. H., and Jones, E. G. (1989) Visualization of chandelier cell axons by parvalbumin immunoreactivity in monkey cerebral cortex. Proc Natl Acad Sci U S A 86: 2093-7.

DeFelipe, J., and Jones, E. G. (1988). Cajal on the Cerebral Cortex (New York: Oxford University Press).

Erlander, M. G., Tillakaratne, N. J., Feldblum, S., Patel, N., and Tobin, A. J. (1991) Two genes encode distinct glutamate decarboxylases. Neuron 7: 91-100.

Esclapez, M., Tillakaratne, N. J., Kaufman, D. L., Tobin, A. J., and Houser, C. R. (1994) Comparative localization of two forms of glutamic acid decarboxylase and their mRNAs in rat brain supports the concept of functional differences between the forms. J Neurosci 14: 1834-55.

Escobar, M. I., Pimienta, H., Caviness, V. S., Jr., Jacobson, M., Crandall, J. E., and Kosik, K. S. (1986) Architecture of apical dendrites in the murine neocortex: dual apical dendritic systems. Neuroscience 17: 975-89.

Fairen, A., and Valverde, F. (1980) A specialized type of neuron in the visual cortex of cat: a Golgi and electron microscope study of chandelier cells. J Comp Neurol 194: 76179.

Feldman, M. L., and Peters, A. (1978) The forms of non-pyramidal neurons in the visual cortex of the rat. J Comp Neurol 179: 761-93.

Ferrer, I., Fabregues, I., and Condom, E. (1986) A Golgi study of the sixth layer of the cerebral cortex. I. The lissencephalic brain of Rodentia, Lagomorpha, Insectivora and Chiroptera. J Anat 145: 217-34. 
Fitzpatrick, D., Lund, J. S., Schmechel, D. E., and Towles, A. C. (1987) Distribution of GABAergic neurons and axon terminals in the macaque striate cortex. J Comp Neurol 264: 73-91.

Fujita, I., and Fujita, T. (1996) Intrinsic Connections in the macaque inferior temporal cortex. J Comp Neurol 368: 467-86.

Fujita, I., Tanaka, K., Ito, M., and Cheng, K. (1992) Columns for visual features of objects in monkey inferotemporal cortex. Nature 360: 343-6.

Gabbott, P. L., Dickie, B. G., Vaid, R. R., Headlam, A. J., and Bacon, S. J. (1997) Localcircuit neurones in the medial prefrontal cortex (areas 25, 32 and 24b) in the rat: morphology and quantitative distribution. J Comp Neurol 377: 465-99.

Glaser, E. M., Van der Loos, H., and Gissler, M. (1979) Tangential orientation and spatial order in dendrites of cat auditory cortex: a computer microscope study of Golgiimpregnated material. Exp Brain Res 36: 411-31.

Goldman, P. S., and Nauta, W. J. (1977) Columnar distribution of cortico-cortical fibers in the frontal association, limbic, and motor cortex of the developing rhesus monkey. Brain Res 122: 393-413.

Harris, R. M., and Woolsey, T. A. (1981) Dendritic plasticity in mouse barrel cortex following postnatal vibrissa follicle damage. J Comp Neurol 196: 357-76.

Hendry, S. H., and Jones, E. G. (1988) Activity-dependent regulation of GABA expression in the visual cortex of adult monkeys. Neuron 1: 701-12.

Hendry, S. H., Jones, E. G., Emson, P. C., Lawson, D. E., Heizmann, C. W., and Streit, P. (1989) Two classes of cortical GABA neurons defined by differential calcium binding protein immunoreactivities. Exp Brain Res 76: 467-72.

Hohl-Abrahao, J. C., and Creutzfeldt, O. D. (1991) Topographical mapping of the thalamocortical projections in rodents and comparison with that in primates. Exp Brain Res 87: 283-94.

Houser, C. R., Hendry, S. H., Jones, E. G., and Vaughn, J. E. (1983) Morphological diversity of immunocytochemically identified GABA neurons in the monkey sensorymotor cortex. J Neurocytol 12: 617-38.

Hubel, D. H., and Wiesel, T. N. (1969) Anatomical demonstration of columns in the monkey striate cortex. Nature 221: 747-50.

Hubel, D. H., and Wiesel, T. N. (1977) Ferrier lecture. Functional architecture of macaque monkey visual cortex. Proc R Soc Lond B Biol Sci 198: 1-59. 
Jensen, K. F., and Killackey, H. P. (1987) Terminal arbors of axons projecting to the somatosensory cortex of the adult rat. I. The normal morphology of specific thalamocortical afferents. J Neurosci 7: 3529-43.

Jin, X., Mathers, P., and Agmon, A. (2000). Unitary gabaergic postsynaptic currents evoked by minimal stimulation of neocortical inhibitory interneurons biolistically transfected with green fluorescent protein. In Soc. Neurosci. Abst., pp. 91.

Jin, X., Mathers, P., Szabo, G., Katarova, Z., and Agmon, A. (1999). Visualizing Living GABAergic Neurons Expressing Green Fluorescent Protein. In Fifth IBRO World Congress of Neuroscience (Jerusalem, Israel, pp. 49.

Jones, E. G. (1975) Varieties and distribution of non-pyramidal cells in the somatic sensory cortex of the squirrel monkey. J Comp Neurol 160: 205-67.

Jones, E. G., Burton, H., and Porter, R. (1975) Commissural and cortico-cortical "columns" in the somatic sensory cortex of primates. Science 190: 572-4.

Katarova, Z., Mugnaini, E., Sekerkova, G., Mann, J. R., Aszodi, A., Bosze, Z., Greenspan, R., and Szabo, G. (1998) Regulation of cell-type specific expression of lacZ by the 5'-flanking region of mouse GAD67 gene in the central nervous system of transgenic mice. Eur J Neurosci 10: 989-99.

Kaufman, D. L., Houser, C. R., and Tobin, A. J. (1991) Two forms of the gammaaminobutyric acid synthetic enzyme glutamate decarboxylase have distinct intraneuronal distributions and cofactor interactions. J Neurochem 56: 720-3.

Kawaguchi, Y., and Kubota, Y. (1997) GABAergic cell subtypes and their synaptic connections in rat frontal cortex. Cereb Cortex 7: 476-86.

Kawaguchi, Y., and Kubota, Y. (1998) Neurochemical features and synaptic connections of large physiologically-identified GABAergic cells in the rat frontal cortex. Neuroscience 85: 677-701.

Kawaguchi, Y., and Kubota, Y. (1996) Physiological and morphological identification of somatostatin- or vasoactive intestinal polypeptide-containing cells among GABAergic cell subtypes in rat frontal cortex. J Neurosci 16: 2701-15.

Kisvarday, Z. F., Gulyas, A., Beroukas, D., North, J. B., Chubb, I. W., and Somogyi, P. (1990) Synapses, axonal and dendritic patterns of GABA-immunoreactive neurons in human cerebral cortex. Brain 113: 793-812.

Klostermann, O., and Wahle, P. (1999) Patterns of spontaneous activity and morphology of interneuron types in organotypic cortex and thalamus-cortex cultures. Neuroscience 92: $1243-59$. 
Kossel, A., Lowel, S., and Bolz, J. (1995) Relationships between dendritic fields and functional architecture in striate cortex of normal and visually deprived cats. J Neurosci 15: 3913-26.

Kritzer, M. F., and Goldman-Rakic, P. S. (1995) Intrinsic circuit organization of the major layers and sublayers of the dorsolateral prefrontal cortex in the rhesus monkey. $\mathbf{J}$ Comp Neurol 359: 131-43.

Kuljis, R. O., and Rakic, P. (1989) Multiple types of neuropeptide Y-containing neurons in primate neocortex. J Comp Neurol 280: 393-409.

Landry, P., Diadori, P., Leclerc, S., and Dykes, R. W. (1987) Morphological and electrophysiological characteristics of somatosensory thalamocortical axons studied with intra-axonal staining and recording in the cat. Exp Brain Res 65: 317-30.

Langer, T. P., and Lund, R. D. (1974) The upper layers of the superior colliculus of the rat: a Golgi study. J Comp Neurol 158: 418-35.

LeVay, S., and Gilbert, C. D. (1976) Laminar patterns of geniculocortical projection in the cat. Brain Res 113: 1-19.

Liu, X. B., Warren, R. A., and Jones, E. G. (1995) Synaptic distribution of afferents from reticular nucleus in ventroposterior nucleus of cat thalamus. J Comp Neurol 352: 187202.

Lo, D. C., McAllister, A. K., and Katz, L. C. (1994) Neuronal transfection in brain slices using particle-mediated gene transfer. Neuron 13: 1263-8.

Lorente de No, R. (1992) The cerebral cortex of the mouse (a first contribution--the "acoustic" cortex). Somatosens Mot Res 9: 3-36.

Lorente de No, R. (1949). Cerebral cortex: architecture, intracortical connections, motor projections. In Fulton's Physiology of the Nervous System, J. F. Fulton, ed. (London: Oxfored University Press), pp. 274-301.

Lubke, J., Egger, V., Sakmann, B., and Feldmeyer, D. (2000) Columnar organization of dendrites and axons of single and synaptically coupled excitatory spiny neurons in layer 4 of the rat barrel cortex. J Neurosci 20: 5300-11.

Lund, J. S., and Boothe, R. G. (1975) Interlaminar connections and pyramidal neuron organisation in the visual cortex, area 17, of the macaque monkey. J Comp Neurol 159: 305-334.

Lund, J. S., Boothe, R. G., and Lund, R. D. (1977) Development of neurons in the visual cortex (area 17) of the monkey (Macaca nemestrina): a Golgi study from fetal day 127 to postnatal maturity. J Comp Neurol 176: 149-88. 
Lund, J. S., Hawken, M. J., and Parker, A. J. (1988) Local circuit neurons of macaque monkey striate cortex: II. Neurons of laminae 5B and 6. J Comp Neurol 276: 1-29.

Martin, D. L., and Rimvall, K. (1993) Regulation of gamma-aminobutyric acid synthesis in the brain. J Neurochem 60: 395-407.

Massengill, J. L., Smith, M. A., Son, D. I., and O'Dowd, D. K. (1997) Differential expression of K4-AP currents and Kv3.1 potassium channel transcripts in cortical neurons that develop distinct firing phenotypes. J Neurosci 17: 3136-47.

Mattson, M. P. (1999) Establishment and plasticity of neuronal polarity. J Neurosci Res 57: 577-89.

McAllister, A. K., Lo, D. C., and Katz, L. C. (1995) Neurotrophins regulate dendritic growth in developing visual cortex. Neuron 15: 791-803.

McMullen, N. T., and Glaser, E. M. (1982) Morphology and laminar distribution of nonpyramidal neurons in the auditory cortex of the rabbit. J Comp Neurol 208: 85-106.

McMullen, N. T., Glaser, E. M., and Tagamets, M. (1984) Morphometry of spine-free nonpyramidal neurons in rabbit auditory cortex. J Comp Neurol 222: 383-95.

McMullen, N. T., Goldberger, B., and Glaser, E. M. (1988) Postnatal development of lamina III/IV nonpyramidal neurons in rabbit auditory cortex: quantitative and spatial analyses of Golgi-impregnated material. J Comp Neurol 278: 139-55.

McMullen, N. T., Goldberger, B., Suter, C. M., and Glaser, E. M. (1988) Neonatal deafening alters nonpyramidal dendrite orientation in auditory cortex: a computer microscope study in the rabbit. J Comp Neurol 267: 92-106.

Meyer, G. (1983) Axonal patterns and topography of short-axon neurons in visual areas 17, 18, and 19 of the cat. J Comp Neurol 220: 405-38.

Meyer, G., and Ferres-Torres, R. (1984) Postnatal maturation of nonpyramidal neurons in the visual cortex of the cat. J Comp Neurol 228: 226-44.

Micheva, K. D., and Beaulieu, C. (1995) Postnatal development of GABA neurons in the rat somatosensory barrel cortex: a quantitative study. Eur J Neurosci 7: 419-30.

Miller, M. W. (1986) Maturation of rat visual cortex. III. Postnatal morphogenesis and synaptogenesis of local circuit neurons. Brain Res 390: 271-85.

Montero, V. M., Guillery, R. W., and Woolsey, C. N. (1977) Retinotopic organization within the thalamic reticular nucleus demonstrated by a double label autoradiographic technique. Brain Res 138: 407-21. 
Morrison, J. H., Magistretti, P. J., Benoit, R., and Bloom, F. E. (1984) The distribution and morphological characteristics of the intracortical VIP-positive cell: an immunohistochemical analysis. Brain Res 292: 269-82.

Mountcastle, V. B. (1997) The columnar organization of the neocortex. Brain 120: 70122.

Mulle, C., Delhaye-Bouchaud, N., and Mariani, J. (1987) Peripheral maps and synapse elimination in the cerebellum of the rat. I. Representation of peripheral inputs through the climbing fiber pathway in the posterior vermis of the normal adult rat. Brain Res 421: 194-210.

Novak, N., and Bolz, J. (1993) Formation of specific efferent connections in organotypic slice cultures from rat visual cortex cocultured with lateral geniculate nucleus and superior colliculus. Eur J Neurosci 5: 15-24.

Ojima, H., Honda, C. N., and Jones, E. G. (1991) Patterns of axon collateralization of identified supragranular pyramidal neurons in the cat auditory cortex. Cereb Cortex 1 : 80-94.

Oliva, A. A., Jr., Jiang, M., Lam, T., Smith, K. L., and Swann, J. W. (2000) Novel hippocampal interneuronal subtypes identified using transgenic mice that express green fluorescent protein in GABAergic interneurons. J Neurosci 20: 3354-68.

Ottersen, O. P., and Storm-Mathisen, J. (1984) Glutamate- and GABA-containing neurons in the mouse and rat brain, as demonstrated with a new immunocytochemical technique. J Comp Neurol 229: 374-92.

Parnavelas, J. G., and Uylings, H. B. (1980) The growth of non-pyramidal neurons in the visual cortex of the rat: a morphometric study. Brain Res 193: 373-82.

Peters, A., Proskauer, C. C., and Ribak, C. E. (1982) Chandelier cells in rat visual cortex. J Comp Neurol 206: 397-416.

Peters, A., and Regidor, J. (1981) A reassessment of the forms of nonpyramidal neurons in area 17 of cat visual cortex. J Comp Neurol 203: 685-716.

Peters, A., and Sethares, C. (1997) The organization of double bouquet cells in monkey striate cortex. J Neurocytol 26: 779-97.

Peters, A., and Sethares, C. (1991) Organization of pyramidal neurons in area 17 of monkey visual cortex. J Comp Neurol 306: 1-23. 
Pinto Lord, M. C., and Caviness, V. S., Jr. (1979) Determinants of cell shape and orientation: a comparative Golgi analysis of cell-axon interrelationships in the developing neocortex of normal and reeler mice. J Comp Neurol 187: 49-69.

Polleux, F., Morrow, T., and Ghosh, A. (2000) Semaphorin 3A is a chemoattractant for cortical apical dendrites [see comments]. Nature 404: 567-73.

Porter, J. T., Johnson, C. K., and Agmon, A. (2001) Diverse types of interneurons generate thalamus-evoked feedforward inhibition in the mouse barrel cortex. J Neurosci in press.

Prieto, J. J., Peterson, B. A., and Winer, J. A. (1994) Morphology and spatial distribution of GABAergic neurons in cat primary auditory cortex (AI). J Comp Neurol 344: 349-82.

Pucak, M. L., Levitt, J. B., Lund, J. S., and Lewis, D. A. (1996) Patterns of intrinsic and associational circuitry in monkey prefrontal cortex. J Comp Neurol 376: 614-30.

Ramon y Cajal-Agueras, S., Lopez-Mascaraque, L., Ramo, C., Contamina-Gonzalvo, P., and de Carlos, J. A. (1989) Layers I and VI of the visual cortex in the rabbit. A correlated Golgi and immunocytochemical study of somatostatin and vasoactive intestinal peptide containing neurons. J Hirnforsch 30: 163-73.

Ren, J. Q., Aika, Y., Heizmann, C. W., and Kosaka, T. (1992) Quantitative analysis of neurons and glial cells in the rat somatosensory cortex, with special reference to GABAergic neurons and parvalbumin-containing neurons. Exp Brain Res 92: 1-14.

Ribak, C. E. (1978) Aspinous and sparsely-spinous stellate neurons in the visual cortex of rats contain glutamic acid decarboxylase. J Neurocytol 7: 461-78.

Rockel, A. J., and Jones, E. G. (1973) The neuronal organization of the inferior colliculus of the adult cat. I. The central nucleus. J Comp Neurol 147: 11-60.

Saleem, K. S., Tanaka, K., and Rockland, K. S. (1993) Specific and columnar projection from area TEO to TE in the macaque inferotemporal cortex. Cereb Cortex 3: 454-64.

Seay-Lowe, S. L., and Claiborne, B. J. (1992) Morphology of intracellularly labeled interneurons in the dentate gyrus of the immature rat. J Comp Neurol 324: 23-36.

Sieg, F., Obst, K., Gorba, T., Riederer, B., Pape, H. C., and Wahle, P. (1998) Postnatal expression pattern of calcium-binding proteins in organotypic thalamic cultures and in the dorsal thalamus in vivo. Brain Res Dev Brain Res 110: 83-95.

Somogyi, P., and Cowey, A. (1981) Combined Golgi and electron microscopic study on the synapses formed by double bouquet cells in the visual cortex of the cat and monkey. $\mathrm{J}$ Comp Neurol 195: 547-66. 
Somogyi, P., Cowey, A., Halasz, N., and Freund, T. F. (1981) Vertical organization of neurones accumulating 3H-GABA in visual cortex of rhesus monkey. Nature 294: 761-3.

Somogyi, P., Freund, T. F., and Cowey, A. (1982) The axo-axonic interneuron in the cerebral cortex of the rat, cat and monkey. Neuroscience 7: 2577-607.

Somogyi, P., Kisvarday, Z. F., Martin, K. A., and Whitteridge, D. (1983) Synaptic connections of morphologically identified and physiologically characterized large basket cells in the striate cortex of cat. Neuroscience 10: 261-94.

Somogyi, P., Tamas, G., Lujan, R., and Buhl, E. H. (1998) Salient features of synaptic organisation in the cerebral cortex. Brain Res Brain Res Rev 26: 113-35.

Steffen, H., and Van der Loos, H. (1980) Early lesions of mouse vibrissal follicles:: their influence on dendrite orientation in the cortical barrelfield. Exp Brain Res 40: 419-31.

Stoppini, L., Buchs, P. A., and Muller, D. (1991) A simple method for organotypic cultures of nervous tissue. J Neurosci Methods 37: 173-82.

Szabo, G., Katarova, Z., Kortvely, E., Greenspan, R. J., and Urban, Z. (1996) Structure and the promoter region of the mouse gene encoding the $67-\mathrm{kD}$ form of glutamic acid decarboxylase. DNA Cell Biol 15: 1081-91.

Szentagothai, J. (1978) The Ferrier Lecture, 1977. The neuron network of the cerebral cortex: a functional interpretation. Proc R Soc Lond B Biol Sci 201: 219-48.

Szentagothai, J. (1975) The 'module-concept' in cerebral cortex architecture. Brain Res 95: 475-96.

Tieman, S. B., and Hirsch, H. V. (1982) Exposure to lines of only one orientation modifies dendritic morphology of cells in the visual cortex of the cat. J Comp Neurol 211: 353-62.

Uylings, H. B., Ruiz-Marcos, A., and van Pelt, J. (1986) The metric analysis of threedimensional dendritic tree patterns: a methodological review. J Neurosci Methods 18: $127-51$.

Voogd, J., and Bigare, F. (1980). Topographical distribution of olivary and corticonuclear fibers in the cerebellum: A review. In The Inferior Olivary Nucleus, J. Courville, C. de Montigny and Y. Lamarre, eds. (New York: Raven Press), pp. 207-234.

Wahle, P. (1993) Differential regulation of substance P and somatostatin in Martinotti cells of the developing cat visual cortex. J Comp Neurol 329: 519-38.

White, E. L., and Peters, A. (1993) Cortical modules in the posteromedial barrel subfield (Sml) of the mouse. J Comp Neurol 334: 86-96. 
Wiklund, L., Rossi, F., Strata, P., and van der Want, J. J. (1990) The rat olivocerebellar system visualized in detail with anterograde PHA-L tracing technique, and sprouting of climbing fibers demonstrated after subtotal olivary lesions. Eur J Morphol 28: 256-67.

Williams, S. M., Goldman-Rakic, P. S., and Leranth, C. (1992) The synaptology of parvalbumin-immunoreactive neurons in the primate prefrontal cortex. J Comp Neurol 320: 353-69.

Winer, J. A. (1984) The non-pyramidal cells in layer III of cat primary auditory cortex (AI). J Comp Neurol 229: 512-30.

Woolsey, T. A., and Van der Loos, H. (1970) The description of a cortical field composed of discrete cytoarchitectonic units. Brain Res 17: 205-242.

Zhang, Z. W., and Deschenes, M. (1997) Intracortical axonal projections of lamina VI cells of the primary somatosensory cortex in the rat: a single-cell labeling study. J Neurosci 17: 6365-79.

Zhou, F. M., and Hablitz, J. J. (1996) Morphological properties of intracellularly labeled layer I neurons in rat neocortex. J Comp Neurol 376: 198-213. 


\section{Chapter Four}

BDNF Mediates Activity-Dependent Dendritic Growth in Developing Non-pyramidal Neocortical Interneurons in Vitro 


\section{ABSTRACT}

Brain-derived neurotrophic factor (BDNF), whose expression and release are enhanced by neuronal activity, promotes postnatal development of GABAergic inhibition in the cerebral and cerebellar cortices, possibly adjusting the strength of inhibition to the level of excitatory activity in the tissue. BDNF was shown to induce dendritic growth in neocortical pyramidal neurons, but its effects on morphological development of nonpyramidal, GABAergic neocortical interneurons remain unknown. Here we show that BDNF mediates depolarization-induced dendritic growth and branching in cortical nonpyramidal interneurons. To visualize non-pyramidal interneurons, we used a gene gun to transfect organotypic cortical slice cultures from early postnatal mice with DNA encoding green fluorescent protein (GFP) driven by the glutamic acid decarboxylase 67 (GAD67) promoter. Individual GAD67-GFP expressing neurons were imaged at 5-day intervals, and their dendritic morphology reconstructed from confocal stacks, analyzed quantitatively and compared between imaging sessions. GAD67-GFP expressing neurons growing in control medium exhibited a $20 \%$ increase in total dendritic length over a 5-day period, but when either $200 \mathrm{ng} / \mathrm{ml} \mathrm{BDNF}$ or $10 \mathrm{mM} \mathrm{KCl}$ was added to the medium, this increase nearly doubled, and was accompanied by a significant increase in dendritic branch points. Blocking action potentials with TTX did not prevent the BDNFinduced growth, but antibodies against BDNF blocked the growth-promoting effect of $\mathrm{KCl}$, indicating that BDNF mediated the effect of depolarization. BDNF could be acting during cortical development to maintain a global balance between excitation and inhibition and/or to remodel dendritic trees of inhibitory interneurons by favoring growth of branches opposite more active excitatory synapses. 


\section{INTRODUCTION}

GABAergic inhibition, although already functional at birth (Agmon et al., 1996; Wells et al., 2000), exhibits a protracted period of postnatal maturation, lasting for several weeks in the cerebral cortex (Komatsu and Iwakiri, 1991; Agmon and O'Dowd, 1992; Sutor and Luhmann, 1995; Cohen et al., 2000) and elsewhere (Rorig and Grantyn, 1993; Ramoa and McCormick, 1994). Some of these developmental changes are postsynaptic, e.g. in chloride transport mechanisms (Plotkin et al., 1997; Lu et al., 1999; Rivera et al., 1999) and $\mathrm{GABA}_{\mathrm{A}}$ receptor subunit composition (Fritschy et al., 1994; Tia et al., 1996; Dunning et al., 1999). Most changes, however, are presynaptic, and involve biochemical (Balcar et al., 1992; Micheva and Beaulieu, 1995; Guo et al., 1997), morphological (Miller, 1986) and electrophysiological (Massengill et al., 1997) differentiation of inhibitory neurons, and formation of GABAergic synapses (Micheva and Beaulieu, 1996; De Felipe et al., 1997; Marty et al., 2002). The overall outcome of this prolonged GABAergic maturation is that inhibition in the early postnatal brain is less efficacious at counteracting excitation, possibly opening a developmental window for enhanced plasticity during an early postnatal "critical" period (Agmon and O'Dowd, 1992; Kirkwood and Bear, 1994; Rozas et al., 2001).

An attractive hypothesis that accounts for the delayed maturation of GABAergic inhibition suggests that inhibition is upregulated by neuronal excitation, thereby establishing a negative feedback loop that counteracts the developmental increase in glutamatergic excitation, albeit with a lag (Marty et al., 1997; Bolton et al., 2000; Turrigiano and Nelson, 2000). A candidate mediator of these effects of activity is brainderived neurotrophic factor (BDNF), a neurotrophin acting on TrkB receptors and 
implicated in neuronal development and plasticity (Thoenen, 1995; Bonhoeffer, 1996; McAllister et al., 1999). BDNF enhances GABA release and uptake (Widmer and Hefti, 1994; Yamada et al., 2002) and promotes differentiation of inhibitory neurons (Nawa et al., 1994; Marty et al., 1996b; Vicario-Abejon et al., 1998; Mertz et al., 2000). Moreover, activity-induced enhancement of GABAergic mechanisms can be reproduced by BDNF and/or prevented by BDNF inhibitors (Marty et al., 1996a; Rutherford et al., 1997; Marty et al., 2000; Seil and Drake-Baumann, 2000), suggesting that BDNF may mediate developmental maturation of inhibition. Consistent with this hypothesis, GABAergic neurotransmission is underdeveloped in TrkB knockout mice (Rico et al., 2002) and enhanced in BDNF-overexpressing mice (Bao et al., 1999; Huang et al., 1999; but see Olofsdotter et al., 2000 and Henneberger et al., 2002 for an apparently paradoxical enhancement of inhibition in BDNF-underexpressing mice).

In the neocortex, BDNF promotes dendritic growth and complexity in excitatory, pyramidal cells (McAllister et al., 1995; McAllister et al., 1997; Horch et al., 1999; Niblock et al., 2000; Yacoubian and Lo, 2000), but its postulated effects on nonpyramidal, inhibitory interneurons remain unexplored. Here we used a novel preparation (Jin et al., 2001) to follow the long-term dendritic development of individual GFPexpressing cortical interneurons in organotypic cultures. We report that both BDNF and depolarization enhance dendritic growth in non-pyramidal interneurons, and that the effect of depolarization is dependent upon endogenous release of BDNF.

\section{MATERIALS AND METHODS:}

Organotypic Culture Preparation: Organotypic cortical slice cultures were prepared as previously described (Stoppini et al., 1991; Jin et al., 2001). Postnatal day 1-3 mouse 
pups were anesthetized by cooling, decapitated, and the brains rapidly removed and immersed in ice-cold artificial cerebrospinal fluid (ACSF, containing $126 \mathrm{mM} \mathrm{NaCl}, 3.0$ $\mathrm{mM} \mathrm{KCl}, 1.3 \mathrm{mM} \mathrm{MgSO} 4,2.5 \mathrm{mM} \mathrm{CaCl}_{2}, 1.2 \mathrm{mM} \mathrm{NaH}_{2} \mathrm{PO}_{4}, 26 \mathrm{mM} \mathrm{NaHCO}$, and 20 $\mathrm{mM}$ dextrose, saturated with 95\%:5\% $\mathrm{O}_{2}: \mathrm{CO}_{2}$ ). Under sterile conditions in a laminar flow hood, $350 \mu \mathrm{m}$-thick coronal brain slices of parietal cortex were cut with a Vibraslicer (WPI, Sarasota, FL). Slices were then placed on $30 \mathrm{~mm}$ Millicell membrane inserts (Millipore, Bedford, MA), usually two slices/insert, and the inserts placed in individual wells of 6-well plates containing $1 \mathrm{ml}$ of culture medium. The culture medium was composed of $46 \%$ Eagle's basal medium, $25 \%$ Earle's balanced salt solution, $25 \%$ horse serum, $1 \%$ mixture of penicillin $(10,000$ units $/ \mathrm{ml})$-streptomycin $(10 \mathrm{mg} / \mathrm{ml})$-glutamine (29.2 $\mathrm{mg} / \mathrm{ml}$ )(all from Invitrogen, Carlsbad, CA). Glucose was added to reach a final concentration of $6.5 \mathrm{mg} / \mathrm{ml}$. The $\mathrm{pH}$ was adjusted to 7.2 . The slices were kept in a humidified incubator at $35^{\circ} \mathrm{C}$ with a $5 \% \mathrm{CO}_{2}$-enhanced atmosphere, and the medium was changed twice per week. After 2-3 days in culture, slices were transfected using a Helios gene gun (Bio-Rad, Hercules, CA).

Gene Gun Mediated Transfection: GAD67-GFP plasmid DNA was cloned from a 10.3 kb segment of the mouse GAD67 promoter region (Szabo et al., 1996; Katarova et al., 1998) fused in-frame to EGFP (Clontech, Palo Alto, CA), as described (Jin et al., 2001). CMV-GFP plasmid DNA ("Green Lantern") was purchased from Invitrogen. Gene gun cartridges were prepared according to the manufacturer's protocol with slight modifications: for each 25" plastic tube, $12 \mathrm{mg}$ gold particles (1.6 $\mu \mathrm{m}$ diameter) were mixed with $25 \mu \mathrm{g}$ plasmid DNA resuspended in $0.05 \mathrm{mg} / \mathrm{ml}$ polyvinylpyrrolidone (PVP) 
in ethanol, and precipitated onto the internal wall of the plastic tube. Slices were bombarded with one cartridge per insert under 120 PSI helium pressure.

Confocal Microscopy: Confocal images were first acquired at least 2 days after gene gun transfection, to allow complete GFP filling of distal dendrites. Cultured brain slices were removed by excising the underlying Millicell membrane from the plastic insert (leaving it adherent to the culture), and placed under sterile conditions, membrane side up, in an imaging chamber filled with fresh oxygenated ACSF at room temperature. The imaging chamber was made of two round glass coverslips separated by $4 \mathrm{~mm}$, held by a stainless steel frame with a $17 \mathrm{~mm}$ wide circular opening to allow imaging. Well-separated neurons with bright GFP expression were selected for imaging. Neurons were imaged with a 20X/ 0.7NA dry objective on an inverted Zeiss LSM510 laser-scanning confocal microscope, using the $488 \mathrm{~nm}$ argon laser line and a 505-550 $\mathrm{nm}$ bandpass emission filter. Image stacks (typically 10-20 optical sections/stack) were collected at 1.5-2.5 $\mu \mathrm{m}$ Z-axis steps through the full extent of the dendritic tree, and saved for offline tracing and analysis. Images were taken with the lowest practical laser intensity and the shortest practical illumination time to limit photodynamic damage, and slices were kept outside the incubator for less than one hour per session. This imaging protocol was found not to cause any apparent ill effects to the imaged neurons or the slice culture, as most neurons maintained a normal morphology during imaging and upon the next imaging session 5 days later, and some remained viable even after repeated imaging over several weeks (see Fig. 4.4B). At the end of each imaging session, low power (10X) images were taken in fluorescence and transmission modes to record the locations of the GFP-expressing 
neurons in the cortex relative to the pia and white matter. The slices with their adherent membranes were then placed back into multi-well plates under sterile conditions, and returned to the incubator. The same neurons were imaged again 5 days later.

Pharmacological Treatments: In some slices, one or more of the following were added to the culture medium: $200 \mathrm{ng} / \mathrm{ml}$ recombinant human BDNF (Alomone labs, Jerusalem, Israel), $250 \mathrm{ng} / \mathrm{ml}$ recombinant human neurotrophin-4/5 (NT4/5) (courtesy of Genentech, South San Francisco, CA), $50 \mu \mathrm{g} / \mathrm{ml}$ rabbit anti-BDNF polyclonal antibody (Chemicon

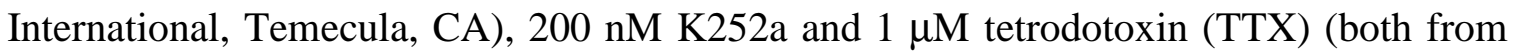
Alomone Labs). Treatments were refreshed upon medium change. Pharmacological treatments started the day following the first imaging session; treatments lasted therefore 4 out of the 5 days between imaging sessions. Control experiments (slices growing in normal medium) were interspersed throughout the treatment experiments, but their results were pooled during data analysis.

Biocytin filling and histochemistry: To verify that GFP fluorescence revealed the full dendritic morphology, a subset of GFP expressing neurons were filled with biocytin after confocal imaging. For biocytin filling, slices with the underlying Millicell membranes were transferred to a submersion recording chamber and continuously superfused with ACSF saturated with $95 \% \mathrm{O}_{2}: 5 \% \mathrm{CO}_{2}$ at room temperature. GFP-expressing neurons were visualized with a 40X, 0.8 NA water immersion objective under an Olympus BX50 upright microscope equipped with fluorescence and differential interference contrast optics and a Hamamatsu CCD camera. Patch pipettes were pulled from $1.5 \mathrm{~mm}$ outer 
diameter glass capillary tubes (WPI, Sarasota, FL) and filled with a solution of $136 \mathrm{mM}$ potassium gluconate, $2 \mathrm{mM} \mathrm{MgCl} 2,0.6 \mathrm{mM}$ EGTA, $10 \mathrm{mM}$ HEPES, $2 \mathrm{mg} / \mathrm{ml}$ biocytin, adjusted to $\mathrm{pH} 7.3$ and $275-285$ mOsm. Whole-cell recordings were done using the Axopatch 200A patch-clamp amplifier (Axon Instruments, Foster City, CA). The recordings were maintained for $\sim 1 \mathrm{hr}$ to allow for complete diffusion of biocytin. At the end of each recording session, the slices were fixed overnight in $0.1 \mathrm{M}$ phosphate buffered saline (PBS) with $4 \%$ paraformaldehyde at $4^{\circ} \mathrm{C}$. After a rinse in PBS, the slices were incubated for $2 \mathrm{hr}$ with $\mathrm{ABC}$ solution (Vector Laboratories, Burlingame, CA), followed by additional rinses in PBS and staining with diaminobenzidine (DAB, 0.7 $\mathrm{mg} / \mathrm{ml})$ and $\mathrm{H}_{2} \mathrm{O}_{2}(0.3 \%)$ in PBS. The reaction was stopped by transferring the slices to cold PBS.

Immunocytochemistry: For immunocytochemistry, GAD67-GFP transfected slices were treated with $20 \mu \mathrm{g} / \mathrm{ml}$ colchicine in culture medium for 24 hours. After fixation for 1 hour at room temperature and overnight at $4^{\circ} \mathrm{C}$ in $4 \%$ paraformaldehyde in PBS, the slices were rinsed 3 times in PBS and blocked for 1 hour in PBS containing 5\% normal horse serum and $1 \%$ Triton $\mathrm{X}-100$. Slices were then incubated for $2-3$ days at $4{ }^{\circ} \mathrm{C}$ with one or two of the following antibodies in PBS containing 2\% normal horse serum and $1 \%$ Triton X-100: 1:1000 rabbit anti-GABA antibody (Sigma-RBI, A2052), 1:1000 mouse monoclonal anti-parvalbumin (Sigma, P3088), 1:1000 rabbit polyclonal anti-calbindin D28k (Chemicon, AB1778), and 1:100 rabbit polyclonal anti-somatostatin (Chemicon, AB5494). Slices were washed three times in PBS, and followed by one or both of the following secondary antibodies: 1:1000 Alexa 546 goat anti-rabbit $\operatorname{IgG}\left(\mathrm{ab}^{\prime}\right)_{2}$ fragments, 
1:500 Alexa 633 goat anti-mouse $\operatorname{IgG}\left(\mathrm{ab}^{\prime}\right)_{2}$ fragments (all from Molecular Probes), in PBS for 1-2 hours. The slices were then washed in PBS and coverslipped for confocal imaging.

Neuronal Tracing: Neurons with strong GFP fluorescence throughout their dendritic tree were reconstructed digitally from the confocal image stacks using Neurolucida software (Microbrightfield, Colchester, VT). GFP expressing neurons which were filled with biocytin were traced a second time with Neurolucida after processing the DAB reaction, using a 20X/ 0.7 NA objective and a CCD video camera attached to an Olympus AX50 microscope.

Data analysis: Quantitative analysis on the traced data was done using Neuroexplorer software (Microbrightfield). Numerical parameters calculated included maximal soma cross area, total dendritic length (TDL), number of primary dendrites and total dendritic branch points (TDBP). Numerical data generated from the second imaging session (Day 5) were divided by the value derived from the first imaging session (Day 0) to yield a ratio; geometrical means and standard errors of the ratios were then calculated for each treatment group and for the control group.

Statistics: Exact, distribution-independent permutation tests (Good, 1999) were used to compare experimental treatments with control. Computations were done with MathCad (MathSoft, Cambridge, MA). All comparisons were made pairwise, between each experimental group and the control group. Unless noted otherwise, the test statistic was 
the difference between the means of the two groups under comparison. This statistic was calculated for 10,000 random permutations of the data, and the fraction of values equal to or more extreme than the experimental observation was doubled, to yield a 2-tailed $p$ value. No adjustments were made for multiple comparisons (Rothman, 1990; Savitz and Olshan, 1998).

\section{RESULTS}

\section{Transfecting GABAergic interneurons with GAD67-GFP}

To visualize non-pyramidal cortical interneurons, we used a gene gun to transfect cortical organotypic slices with a DNA construct in which the GAD67 promoter drives the expression of GFP (Jin et al., 2001). Since the GAD protein is a high fidelity marker for GABAergic neurons (Mugnaini and Oertel, 1985), the GAD67-GFP construct was expected to label specifically inhibitory interneurons. Two days after transfection, a few to a few dozen neurons per slice expressed GFP fluorescence at varying levels of intensity (Fig. 4.1A). In strongly fluorescent neurons, minute morphological details were discernible, including dendritic filopodia and spines and fine axonal arborizations (Fig. 4.1C). To confirm that GAD67-GFP expression is restricted to GABAergic interneurons, we compared the morphology of GAD67-GFP expressing neurons to that of neurons transfected with a GFP construct driven by the nonspecific cytomegalovirus (CMV) promoter (CMV-GFP). With the notable exception of spiny stellate cells, which are restricted to layer 4 of some primary sensory areas, all non-pyramidal neurons in the cerebral cortex are GABAergic interneurons (Houser et al., 1983; Meinecke and Peters, 1987; Prieto et al., 1994). Neocortical neurons with a long vertical dendrite extending 
toward the pia and several additional primary dendrites growing in all other directions were defined as pyramidal, while all the other neurons were defined as non-pyramidal interneurons. In GAD67-GFP transfected slices, GFP expressing neurons were almost exclusively non-pyramidal (99.2\%, N=262 neurons in 38 slices) (Figure 4.1, A and C); in contrast, CMV-GFP expressing neurons were divided about evenly between pyramidal (45\%) and non-pyramidal (55\%) morphologies ( $\mathrm{N}=71$ neurons in 9 slices) (Figure 4.1, B and D). The higher percentage of non-pyramidal neurons in CMV-GFP transfected slices compared to their known incidence in vivo (15-25\%, Ren et al., 1992; Micheva and Beaulieu, 1995) could reflect either increased viability of GABAergic neurons in organotypic cultures, a higher efficacy of the CMV promoter in GABAergic neurons, or alternatively misclassification of some pyramidal neurons as non-pyramidal due to truncation of their apical dendrites during the slicing procedure. Nevertheless, the virtual lack of neurons with pyramidal morphology, among hundreds of GAD67-GFP expressing cells, strongly suggests that GAD67-GFP expression was restricted to GABAergic interneurons.

To further confirm that GAD67-GFP expressing neurons were GABAergic interneurons, we immunostained GAD67-GFP transfected slices for GABA or for one of the GABAergic neuronal markers parvalbumin, calbindin and somatostatin (Kawaguchi and Kubota, 1997) (Figure 4.2; only anti-GABA and anti-parvalbumin staining shown). GAD67-GFP expressing neurons were rarely immunopositive for any of the markers tested unless the slices were first treated with colchicine, which enhances immunolabeling of somata, presumably by preventing axonal transport (Ribak et al., 1978). In slices treated for $24 \mathrm{hrs}$ with colchicine, $16 \%$ of the GAD67-GFP-expressing 
neurons were found to be immunopositive for GABA (Fig. 4.2A; N=68 neurons in 27 slices), $6.7 \%$ for calbindin ( $\mathrm{N}=74$ neurons in 15 slices), $7.4 \%$ for parvalbumin (Fig. 4.2B; $\mathrm{N}=189$ neurons in 26 slices) and $3.5 \%$ for somatostatin ( $\mathrm{N}=113$ neurons in 10 slices). The percentage of GAD67-GFP expressing neurons immunopositive for these markers was

considerably lower than the known incidence of these markers in the neocortex, possibly reflecting a lower than normal level of these molecules in GAD67-GFP expressing cells. This in turn could reflect competition between the exogenous GAD67 promoter and endogenous GAD67 (and other) promoters for limited transcription factors. Nevertheless, these results are consistent with the conclusion that GAD67-GFP expressing neurons were GABAergic interneurons.

\section{Dendritic development of non-pyramidal interneurons in organotypic slice cultures}

Since GFP expression in our cultures revealed the detailed morphology of living neurons, we were able to follow the morphological development of individual neurons over time, by imaging the same neuron two or more times at 5-day intervals, digitally reconstructing the 3-D dendritic morphology of the neuron from stacks of confocal images, and quantifying the total dendritic length (TDL) and total dendritic branch points (TDBP) at each imaging time point. However, since organotypic slices grow thinner and more translucent with time in culture, and since the level of GFP expression often appeared to increase with time in culture, we were concerned that any apparent increase in dendritic length could be the result of incomplete visualization or incomplete GFP filling of dendrites at the earliest imaging time point. To test this possibility, we compared dendritic filling and visualization between GFP and biocytin, a much smaller 
molecule commonly used for reconstruction of neuronal morphology after intracellular recordings. Seven GFP expressing neurons were imaged with a confocal microscope, then injected with biocytin through a patch pipette, processed for the histochemical DAB reaction and traced with a computerized system. The 3-D dendritic morphology was then compared between reconstructed confocal images and biocytin tracings of the same neuron (Fig. 4.3). We found that in older neurons, dendritic reconstructions from GFP and biocytin closely overlapped, after adjusting for shrinkage (Fig. 4.3A). In some of the younger neurons, however, GFP tracings from confocal stacks missed a terminal portion of one or two dendritic branches, as evident from comparison to the biocytin image (Fig. 4.3B, upper tracing, arrow). This was not caused by insufficient GFP filling, but rather by loss of optical signal from dendritic branches growing deep into the tissue, as illustrated by the X-Z projection in Fig. 4.3B (lower tracing, arrow). This situation was easy to identify, since in such cases dendrites gradually disappeared from view while focusing deeper into the tissue, and such dendrites were therefore excluded from analysis in all images taken from that particular neuron.

We first followed the growth of GFP-expressing neurons in normal medium. When first imaged, cultures were as young as equivalent postnatal day 7 (EP7; Equivalent Postnatal day = postnatal day at culturing + days in vitro) and as old as EP22 (Fig. 4.4A,B). We quantified dendritic growth by calculating the ratio between TDL at second imaging (Day 5) and TDL at first imaging (Day 0). This ratio is plotted in Fig. 4.4C against equivalent postnatal day at first imaging. The mean TDL ratio was $1.22 \pm 0.07$ ( $\mathrm{N}=19$ neurons) for neurons first imaged at EP10 or earlier (left of vertical dotted line), but was $1.01 \pm 0.03$ ( $\mathrm{N}=26)$ for neurons first imaged at older ages (right of 
dotted line). The difference between groups was highly significant $(\mathrm{p}=0.0008)$. These data suggest that during the first 2 weeks in organotypic culture, cortical non-pyramidal interneurons are still undergoing morphological differentiation, consistent with previous reports (Caeser et al., 1989; Gotz and Bolz, 1989; Annis et al., 1993). Since we were interested in studying regulation of dendritic growth during early postnatal development, all subsequent experiments were done on the younger age group.

\section{BDNF, but not NT4/5, enhanced dendritic growth in non-pyramidal interneurons}

To investigate the role of BDNF and activity in regulating dendritic growth of non-pyramidal interneurons, we followed the morphological development of individual GAD67-GFP expressing neurons over a 5-day period, and compared ratios of total dendritic length (TDL) and branch points (TDBP) between neurons from cultures treated with $200 \mathrm{ng} / \mathrm{ml} \mathrm{BDNF}$, or one of several other treatments, to neurons from untreated control cultures. Representative neurons are illustrated in Figs. 4.5-6, and a summary plot of all experiments is presented in Fig. 4.7. As illustrated in Figs. 4.5A, growth in control conditions was modest (note the small rightward shift in the cumulative histogram). As reported above, the mean TDL ratio (i.e. TDL at Day 5: TDL at Day 0, calculated per neuron and then averaged) was $1.22 \pm 0.07(\mathrm{~N}=19)$; this change was significantly different from 1 ( $\mathrm{p}=0.01$, sign test), but there was no significant change in TDBP $(\mathrm{p}=0.7)$. In contrast, GAD67-GFP expressing neurons developing in the presence of BDNF (Fig. 4.5B) exhibited considerably more growth. The mean TDL ratio in the presence of BDNF

was $1.42 \pm 0.05(\mathrm{~N}=27)$, representing a fractional increase (42\%) nearly double that in control medium (22\%). BDNF also promoted branching of existing dendrites (but not 
addition of primary dendrites): the mean TDBP ratio was $1.25 \pm 0.09$. Both TDL and TDBP ratios in the BDNF group were significantly different from the control group $(\mathrm{p}=0.03$ and $\mathrm{p}=0.01$, Fig. $4.7 \mathrm{~A}, \mathrm{~B}$, respectively). These results indicate that BDNF promotes dendritic growth and complexity in non-pyramidal cortical interneurons.

The effect of neurotrophins on dendritic growth of neocortical pyramidal neurons is dependent on intact electrical and synaptic activity (McAllister et al., 1996). To test whether the BDNF effect on non-pyramidal, GABAergic interneurons was activity dependent, we allowed cultures to develop in the presence of both $200 \mathrm{ng} / \mathrm{ml} \mathrm{BDNF}$ and $1 \mu \mathrm{M}$ TTX (Fig. 4.5C). Under these conditions, there was still enhanced dendritic growth in GAD67-GFP expressing neurons, and the mean TDL ratio was $1.62 \pm 0.11(\mathrm{~N}=17$, $p=0.001$ compared to control; Fig. 4.7A). TTX did seem to prevent branching (Fig. 4.7B; $p=0.6$ ). These data suggest that, unlike the effect of BDNF on pyramidal neurons, the enhancing effect of BDNF on dendritic growth of GABAergic interneurons does not require sodium-dependent electrical activity.

To study the role of endogenous BDNF during normal growth, we compared dendritic growth in control slices to growth in cultures in which endogenous BDNF was neutralized with a high titer $(50 \mu \mathrm{g} / \mathrm{ml})$ of anti-BDNF antibodies, shown to block the effect of endogenous BDNF (Ghosh et al., 1994; Marty, 2000; Seil and Drake-Baumann, 2000) or in which Trk signaling was blocked by $200 \mathrm{nM}$ of the Trk signaling inhibitor K252a (Knusel and Hefti, 1992). Under both conditions dendritic growth was significantly reduced compared to control (Fig. 4.7A; TDL ratios were $1.07 \pm 0.04, \mathrm{~N}=21$, $p=0.03$ for anti-BDNF, and $0.99 \pm 0.05, \mathrm{~N}=14, p=0.006$ for K252a), Finally, we tested the effect of the neurotrophin NT4/5, which also activates TrkB receptors and is expressed in 
the cortex during early development (Maisonpierre et al., 1990; Timmusk et al., 1993). NT4/5 (250 ng/ml) had no enhancing effect on dendritic growth or branching of nonpyramidal interneurons; indeed, growth in NT4/5 was significantly reduced (Fig. 4.7A, $1.07 \pm 0.05, \mathrm{~N}=14, p=0.03)$, possibly because NT4/5 competed with endogenous BDNF over TrkB binding sites.

\section{Effect of neuronal activity on GABAergic neuron dendritic growth}

Electrical activity can increase several parameters of GABAergic function (Rutherford et al., 1997; Marty et al., 2000), but its effect on dendritic growth of cortical GABAergic neurons is not known. We tested the effect of electrical activity on GAD67GFP expressing neurons by incubating slice cultures in a medium containing $10 \mathrm{mM} \mathrm{KCl}$ (Fig. 4.6A), which depolarizes cortical neurons and causes action potential firing (Franklin et al., 1995; Tongiorgi et al., 1997; Vaillant et al., 2002). GAD67-GFP neurons cultured in a high $\mathrm{KCl}$ medium exhibited enhanced growth and branching compared to control (the mean TDL and TDBP ratios were $1.39 \pm 0.06$ and $1.22 \pm 0.09$, respectively, $\mathrm{N}=24)$. The effect on branch points was statistically significant $(\mathrm{p}=0.03)$, however the effect on dendritic length was only marginally so ( $\mathrm{p}=0.08$; Fig. 4.7).

Since electrical activity enhances cortical BDNF levels (Castren et al., 1992; Tongiorgi et al., 1997), the effect of high $\mathrm{K}^{+}$could have been mediated through activitydependent release of BDNF. We tested this possibility by neutralizing endogenous BDNF with anti-BDNF antibodies (Fig. 4.6B). Dendritic growth and branching in a medium supplemented with $10 \mathrm{mM} \mathrm{KCl}$ and $50 \mu \mathrm{g} / \mathrm{ml}$ anti-BDNF was not significantly different from the control group ( $\mathrm{p}=0.3$ and 0.8 for TDL and TDBP ratios, respectively, $\mathrm{N}=11$; Fig. 
4.7), indicating that the dendritic growth-promoting effect of high $\mathrm{KCl}$ was dependent on extracellular BDNF.

To test whether normal growth is dependent on electrical activity, we cultured slices in $1 \mu \mathrm{M}$ TTX. The median TDL in TTX did not change (Fig. 4.6C), indicating that TTX counteracted the increase in median TDL that occurs in normal medium. Mean TDL was $0.96 \pm 0.03(\mathrm{~N}=12)$, very significantly different from control $(\mathrm{p}=0.0002$; Fig. 4.7), suggesting that sodium-dependent electrical activity is required for normal dendritic growth.

Finally, to test whether BDNF and depolarization affect dendritic growth in a similar manner, we used Sholl analysis to quantify dendritic growth within consecutive concentric rings around the cell body, and compared Sholl plots showing the increase in dendritic length over a 5-day growth period between control, BDNF and high $\mathrm{K}^{+}$ conditions (Fig. 4.8). As illustrated, dendritic growth was distributed within a radius of about $300 \mu \mathrm{m}$ around the cell body, with the most growth occurring between 100 and 200 $\mu \mathrm{m}$ from the cell body. No significant differences were evident between growth patterns in $\mathrm{BDNF}$ and high $\mathrm{K}^{+}$, consistent with the conclusion that growth under both conditions was mediated by the same cellular mechanisms.

\section{DISCUSSION}

In this study we tested whether exogenous BDNF or depolarization by high $\mathrm{K}^{+}$ enhance dendritic growth of non-pyramidal cortical interneurons expressing GAD67-GFP in organotypic slice cultures, and whether there was cross-dependency between the effects of BDNF and depolarization. Short-term (minutes to hours) changes in dendritic 
morphology were previously tracked in living GFP-expressing cortical neurons in vitro (Fischer et al., 1998; Engert and Bonhoeffer, 1999; Horch et al., 1999; Maletic-Savatic et al., 1999; Wu et al., 2001) or in vivo (Lendvai et al., 2000), but our study is the first, to our knowledge, to follow the morphological development of the same neocortical neurons over several days and even weeks. By imaging the same GFP expressing neurons at 5-days intervals, we demonstrated that (1) both BDNF and elevate $\mathrm{K}^{+}$enhanced dendritic growth of non-pyramidal neurons, that (2) the effect of BDNF is not dependent on neuronal activity, but that (3) the $\mathrm{KCl}$-induced dendritic growth is dependent on release of endogenous BNDF. Taken together, these observations suggest a role for BDNF in regulating morphological maturation of GABAergic interneurons in the developing neocortex and potentially mediating activity-induced dendritic remodeling in the adult.

\section{BDNF effects on pyramidal and non-pyramidal cortical interneurons are qualitatively different}

Exogenous or endogenous BDNF, NT3 and NT4/5 have been shown to promote dendritic elongation and branching in neocortical pyramidal cells developing in organotypic cultures (McAllister et al., 1995; McAllister et al., 1997; Horch et al., 1999; Niblock et al., 2000; Yacoubian and Lo, 2000), but BDNF effects on non-pyramidal, inhibitory interneurons were not studied previously. Our results show that activation of TrkB receptors by BDNF, but not by NT4/5, promotes dendritic elongation and branching in developing neocortical non-pyramidal interneurons. In our study, a 4-day treatment with $200 \mathrm{ng} / \mathrm{ml}$ BDNF caused a $40 \%$ increase in TDL of neocortical 
interneurons, which is roughly comparable with a previously described effect of BDNF on hippocampal interneurons (Marty et al., 1996b). In contrast, a 36-hr treatment with $200 \mathrm{ng} / \mathrm{ml} \mathrm{BDNF}$ doubled the TDL and TDBP of layer 4 pyramidal neurons in the ferret (McAllister et al., 1995). We noted several other differences between the published effects of BDNF on neocortical pyramidal neurons and the effects on non-pyramidal neurons reported here: BDNF did not increase the number of primary dendrites in nonpyramidal neurons, but did so in pyramidal cells (McAllister et al., 1995; McAllister et al., 1996; Horch et al., 1999); TTX did not prevent enhancement by BDNF of nonpyramidal cell dendritic growth, but did prevented some of the effects of BDNF on pyramidal cells (McAllister et al., 1996); and BDNF-induced dendritic branches were stable for at least several weeks in non-pyramidal cells, but were highly unstable in pyramidal neurons (Horch et al., 1999). Taken together, these comparisons suggest that BDNF effects on pyramidal and non-pyramidal neurons are qualitatively different, possibly because these two classes of cells express different complements of TrkB receptors, e.g. different complements of full-length and truncated isoforms (Yacoubian and Lo, 2000).

\section{Depolarization promotes dendritic growth in non-pyramidal cortical interneurons}

We found that adding $10 \mathrm{mM} \mathrm{KCl}$ to our organotypic cultures promoted dendritic growth and branching of non-pyramidal interneurons to a level similar to that induced by $200 \mathrm{ng} / \mathrm{ml}$ BDNF. Even though the effect on dendritic growth was significant only at the $\mathrm{p}=0.08$ level, possibly because of the relatively mild depolarization expected from 10 $\mathrm{mM} \mathrm{KCl}$, it is consistent with the significant effect of $\mathrm{KCl}$ on dendritic branching, and 
with the highly significant effect of TTX in preventing normal dendritic growth, since the two treatments are expected to affect activity levels in opposite directions: depolarization by $\mathrm{KCl}$ is likely to increase the rate of spontaneous action potentials and synaptic activity, and thereby also to activate voltage-sensitive calcium conductances (Franklin et al., 1995; Tongiorgi et al., 1997; Vaillant et al., 2002), while blocking sodium channels with TTX is likely to eliminate spontaneous action potentials and considerably reduce spontaneous synaptic activity, thereby also reducing $\mathrm{Ca}^{++}$influx. Our data suggest, therefore, that normal dendritic growth of cortical interneurons requires action potentials, and can be enhanced by activity. Depolarization-induced enhancement and/or TTXinduced suppression of dendritic growth have been previously demonstrated in some systems (Magowan and Price, 1996; Reitstetter and Yool, 1998; Vaillant et al., 2002) but not in others (Riccio and Matthews, 1987; Dalva et al., 1994; Campbell et al., 1997; Rajan and Cline, 1998). Notably, changes were not observed in dissociated cortical neurons in vitro (Mattson et al., 1988; Kossel et al., 1997; Ramakers et al., 1998). The effects of electrical and synaptic activity on dendritic length and complexity (as distinct from effects on dendritic spines and filopodia) were not studied previously in organotypic cortical cultures. If, as we propose, the effect of depolarization was mediated by extracellular BDNF (see below), then the failure to observe this effect in dissociated cultures could be due to the lower density of neurons in these cultures compared to organotypic slices, and to dilution of the released BDNF to non-effective levels. 


\section{Depolarization effects are mediated by BDNF release by pyramidal neurons}

Depolarization can promote dendritic growth in a cell-autonomous manner, e.g. through calcium-dependent phosphorylation of the dendritic protein MAP2 (Quinlan and Halpain, 1996; Sanchez et al., 2000; Wu et al., 2001; Vaillant et al., 2002). Alternatively, depolarization can enhance dendritic growth through cell-cell signaling (Matsutani and Yamamoto, 1998; Nedivi et al., 1998). Our results suggest that the activity-dependent dendritic growth in our experiments was mediated by cell-cell signaling with BDNF being the signal, since the $\mathrm{KCl}$-induced growth was prevented by antibodies to BDNF. In the cerebral cortex, BDNF is expressed only by pyramidal neurons, but TrkB, the preferred receptor for BDNF, is found in both pyramidal cells and GABAergic interneurons (Cellerino and Maffei, 1996; Rocamora et al., 1996; Gorba and Wahle, 1999). Like NGF (Griesbeck et al., 1999), BDNF expression and release is enhanced by excitatory synaptic and electrical activity, as has been demonstrated in vitro (Ghosh et al., 1994; Wetmore et al., 1994; Goodman et al., 1996; Gorba et al., 1999) and in vivo, both during postnatal development (Rossi et al., 1999) and in the adult (Zafra et al., 1990; Isackson et al., 1991; Castren et al., 1992; Suzuki et al., 1995; Rocamora et al., 1996; Yan et al., 1997). We therefore propose that depolarization-induced synthesis and release of BDNF from pyramidal neurons, retrogradely from dendrites (Davies, 1996; Haubensak et al., 1998; Hartmann et al., 2001; Kojima et al., 2001) or anterogradely from axon terminals (Fawcett et al., 1998; Fawcett et al., 2000; Kohara et al., 2001), activated TrkB receptors on GABAergic neurons and enhanced their dendritic growth. In addition, it is possible that depolarization also enhanced TrkB expression on the recipient interneurons themselves (Tongiorgi et al., 1997; Meyer-Franke et al., 1998). 


\section{BDNF and activity-dependent maturation of GABAergic function}

We found that depolarization induced dendritic growth of cortical non-pyramidal interneurons in vitro, and that this effect was BDNF-dependent. A larger dendritic tree is likely to receive more axodendritic (mostly excitatory) synapses and thus enhance GABAergic function in the network. Electrical and synaptic activity in vitro have previously been shown to promote, and their blockade to reverse, an increase in the level of expression of GABA and GABAergic markers (Marty et al., 1996a; Rutherford et al., 1997) and an increase in the density of GABAergic synapses (Marty et al., 2000; Seil and Drake-Baumann, 2000). Similar to the effects demonstrated here, in the very same studies these effects of activity were reproduced by exogenous BDNF and prevented by BDNF blockers, and/or, conversely, the effects of activity blockade were reproduced by BDNF blockers and prevented by exogenous BDNF, indicating that activity exerts its effects via BDNF-TrkB signaling. Various other aspects of GABAergic maturation were shown to be dependent upon or enhanced by BDNF in vitro (Widmer and Hefti, 1994; Murphy et al., 1998; Yamada et al., 2002) and in vivo (Nawa et al., 1994; Huang et al., 1999). Thus, BDNF may play a major role in regulating the maturation of the GABAergic inhibitory system, and may act during development to keep the level of GABAergic inhibition in step with the level of excitatory activity, thereby maintaining activity homeostasis in the network (Marty et al., 1997; Bolton et al., 2000; Turrigiano and Nelson, 2000). In the adult, BDNF may also mediate the effects on dendritic morphology of other physiological parameters, such as hormonal state (Barbany and Persson, 1992; Toran-Allerand, 1996; Murphy et al., 1998). Finally, in addition to its 
global effect on the balance between excitation and inhibition, BDNF could also act very locally, by virtue of its anterograde release from synaptic terminals (Altar et al., 1997; Fawcett et al., 1998; Hartmann et al., 2001; Kohara et al., 2001) and the dendritic targeting of its receptor protein (Fryer et al., 1996) and mRNA (Tongiorgi et al., 1997), to promote growth of dendritic branches receiving active synapses at the expense of branches opposite less active synapses. Thus, BDNF could mediate dynamic sculpting of dendritic fields, providing a cellular substrate for activity-dependent modulation of neuronal circuits, both during development and in adult learning. 


\section{Acknowledgements}

We thank Drs. Albert Berrebi and Janet Cyr for helpful comments on the manuscript, Jeff Altemus, Cary Johnson and Colette Ramsburg for excellent technical support, and Dr. Gabor Szabo for providing the GAD67 promoter. This work was supported by NIH grants HD33463 (AA) and EY12152 (PHM). 

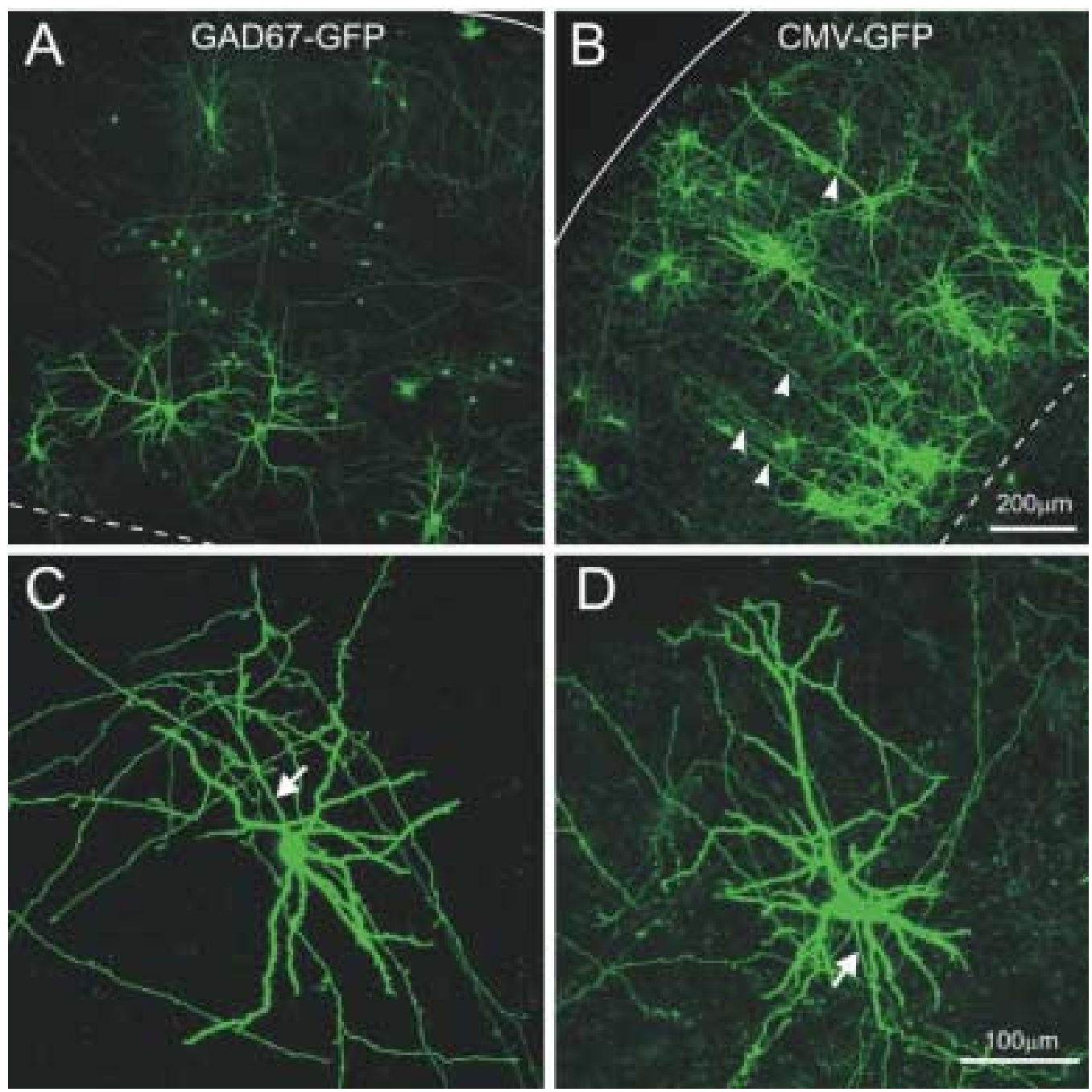

Figure 4.1. Gene-gun mediated transfection of mouse cortical slice cultures. A and C, neurons labeled by transfection with GAD67-GFP DNA, imaged at low (10X) and high (20X) power, respectively. B and D, neurons labeled by transfection with CMVGFP DNA, imaged at low and high power, respectively. A-D are from different slices. Note that in the GAD67-GFP transfected slices, only non-pyramidal neurons expressed GFP, while CMV-GFP transfection labeled both pyramidal and non-pyramidal neurons. Arrowheads in B indicate apical dendrites of pyramidal neurons. Arrows in C and D indicate the initial segment of the axon, which exits towards the pial surface in the interneuron (C) and towards the white matter in the pyramidal neuron (D). Solid white lines indicate the pial surface; dotted white lines indicate the border with the white matter. 


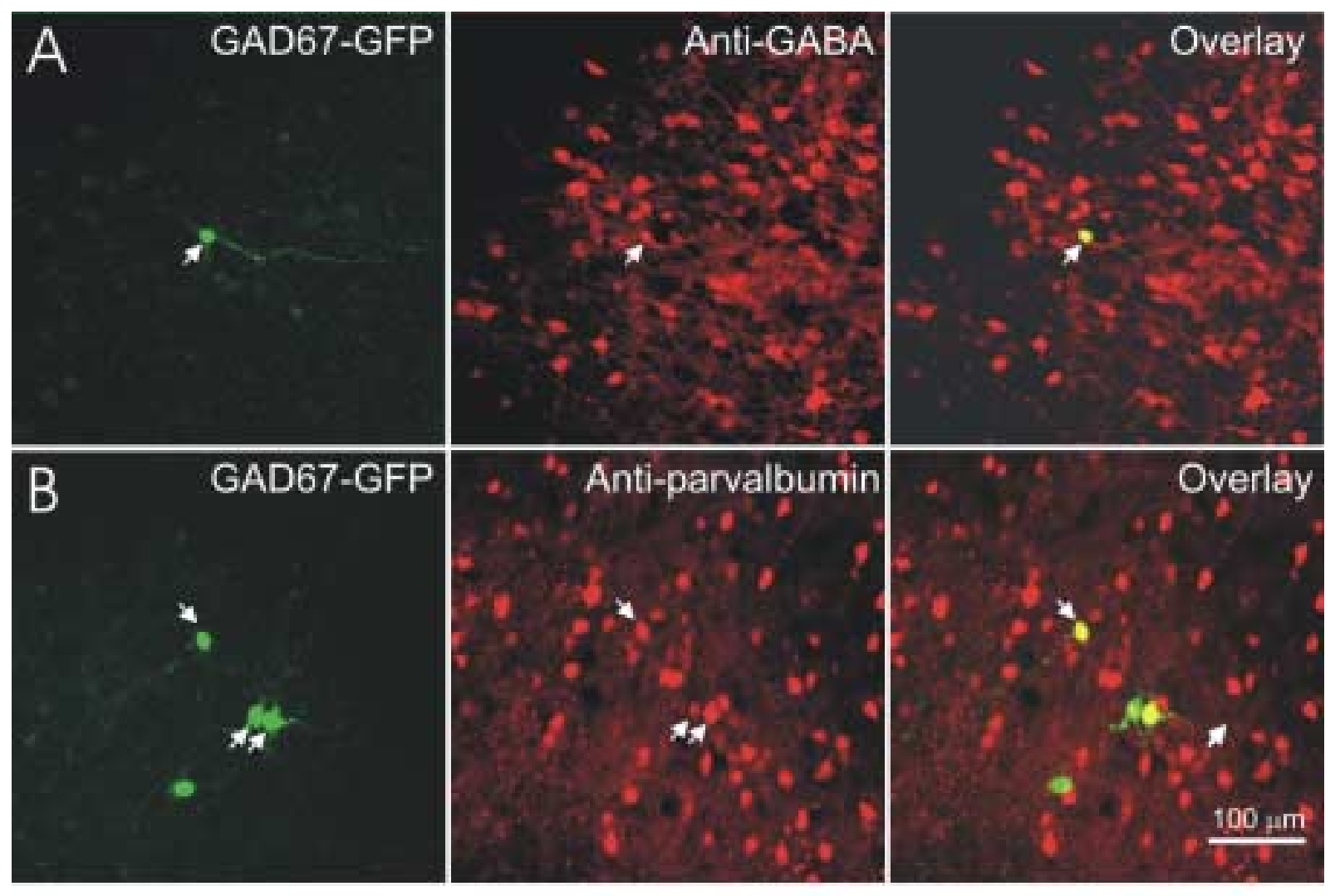

Figure 4.2. GAD67-GFP expressing neurons immunopositive for GABA and GABAergic neuronal markers. Sample images of GAD67-GFP expressing neurons (pseudocolored green) and neurons immunoreactive to a monoclonal anti-GABA antibody (A) and a monoclonal anti-parvalbumin antibody (B) (pseudocolored red). Arrows indicate immunopositive GAD67-GFP expressing neurons. 

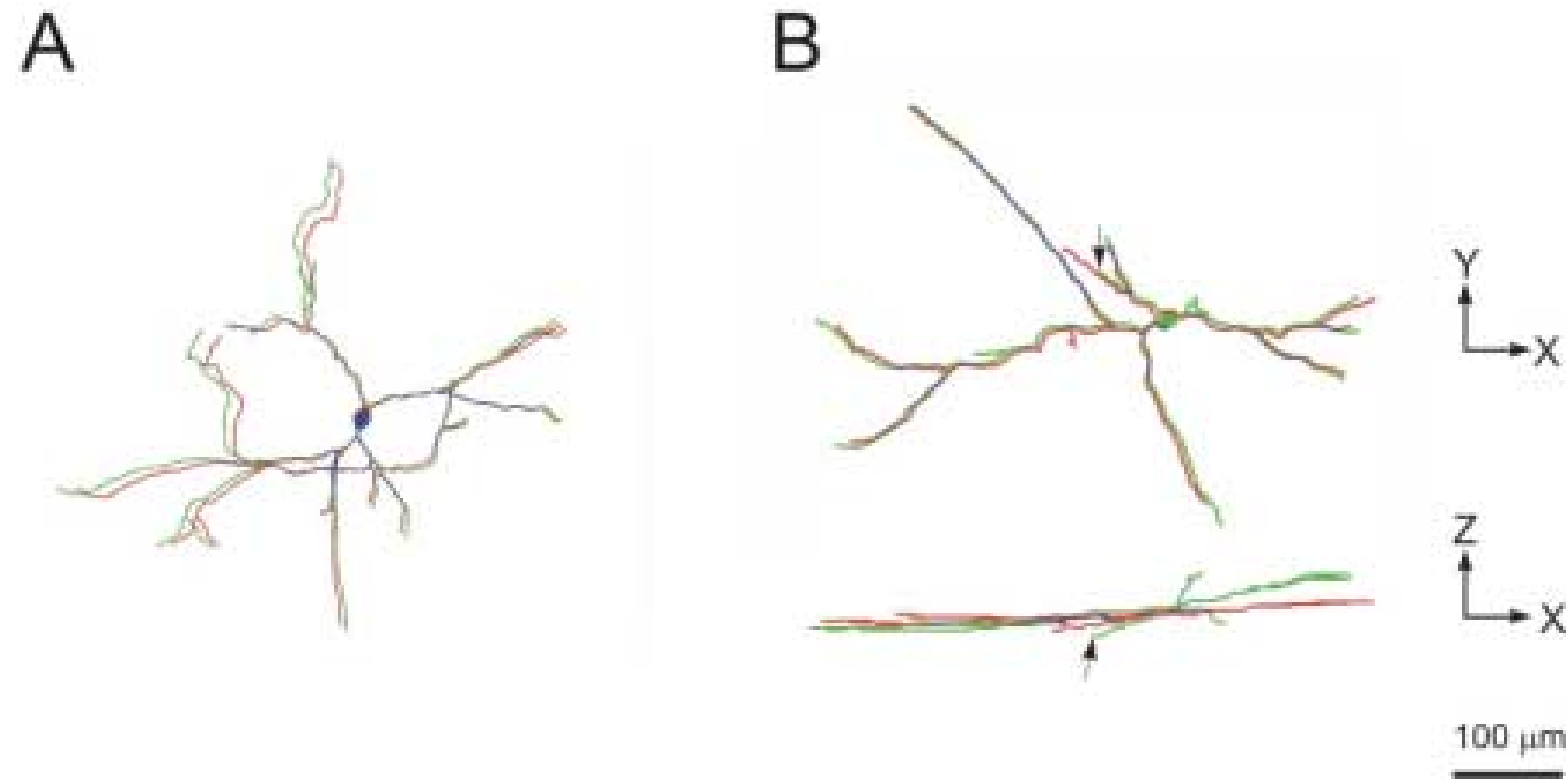

Figure 4.3. Comparison between GAD67-GFP fluorescence and biocytin labeling. GAD67-GFP expressing neurons were imaged 3 weeks (A) or 3 days (B) after transfection, then injected with biocytin through a patch pipette. 3-D reconstruction of the dendritic tree from the confocal images (green) are superimposed on a 3-D reconstruction from the biocytin tracing of the same neurons (red). Note that the GFP fluorescence was at least as extensive as the biocytin labeling, but one secondary dendrite in the younger neuron appeared shorter in the confocal image compared to the corresponding biocytin tracing (B, upper tracing, arrow). The part of the dendrite missing from the confocal reconstruction was located deep in the slice, as shown by the $\mathrm{X}-\mathrm{Z}$ image of the same neuron (B, lower tracing, arrow). 

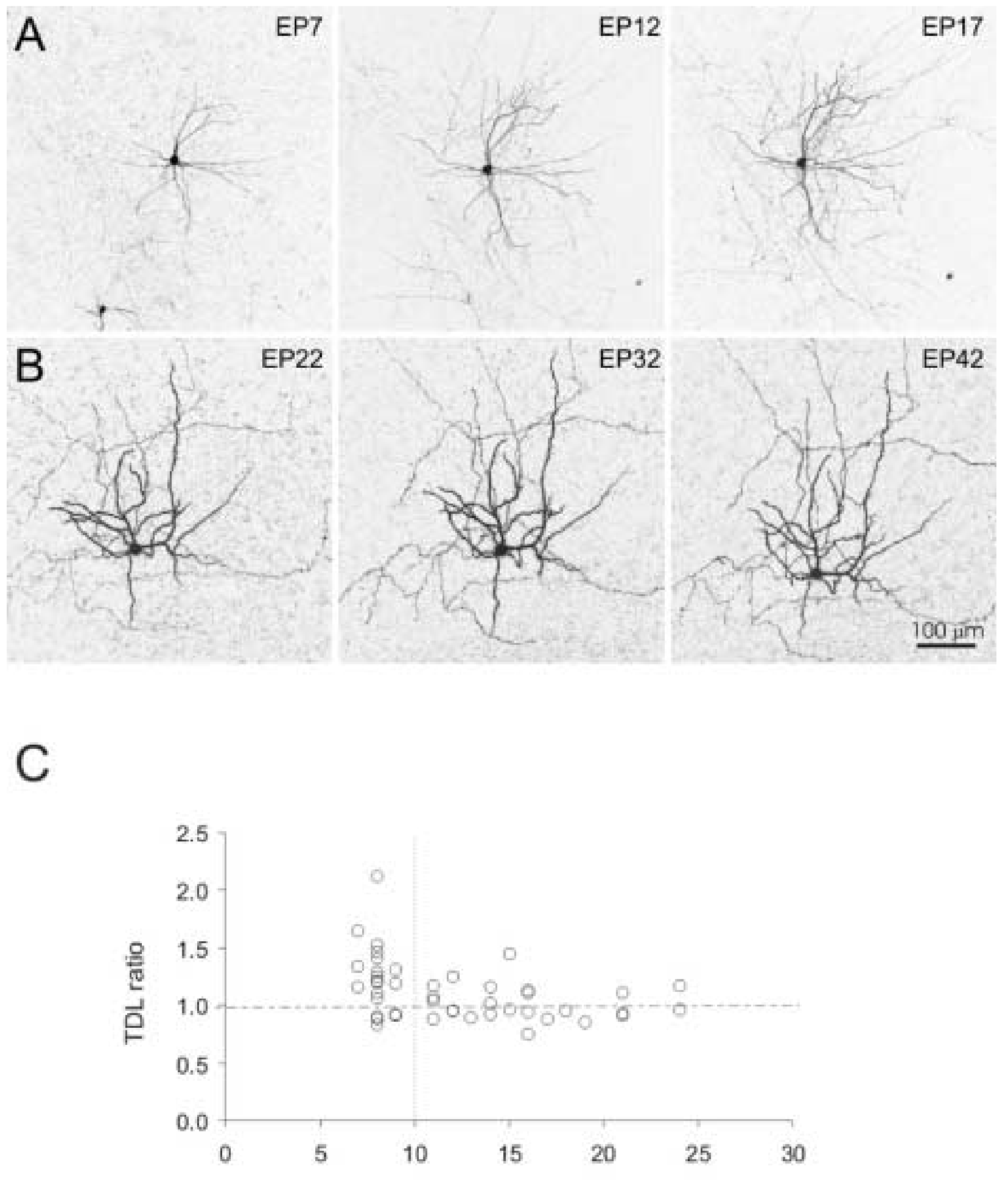

Equivalent postnatal age at first imaging 
Figure 4.4. Dendritic outgrowth of GAD67-GFP expressing neurons in control medium. A, projected stacks of confocal images of a representative GAD67-GFP expressing neuron first imaged at equivalent postnatal day 7 (EP7) and again 5 and 10 days later. B, another neuron first imaged at EP22 and again 10 and 20 days later. C, total dendritic length (TDL) growth ratio of all neurons in our sample during a 5-day period in normal medium, plotted against the equivalent age at first imaging. A TDL ratio of 1 (dashed line) indicates no change. Note that dendritic growth was more pronounced in neurons first imaged at EP7-9 (left of the vertical dashed line) compared to neurons first imaged at later ages (right of the vertical dashed line). 
A Control
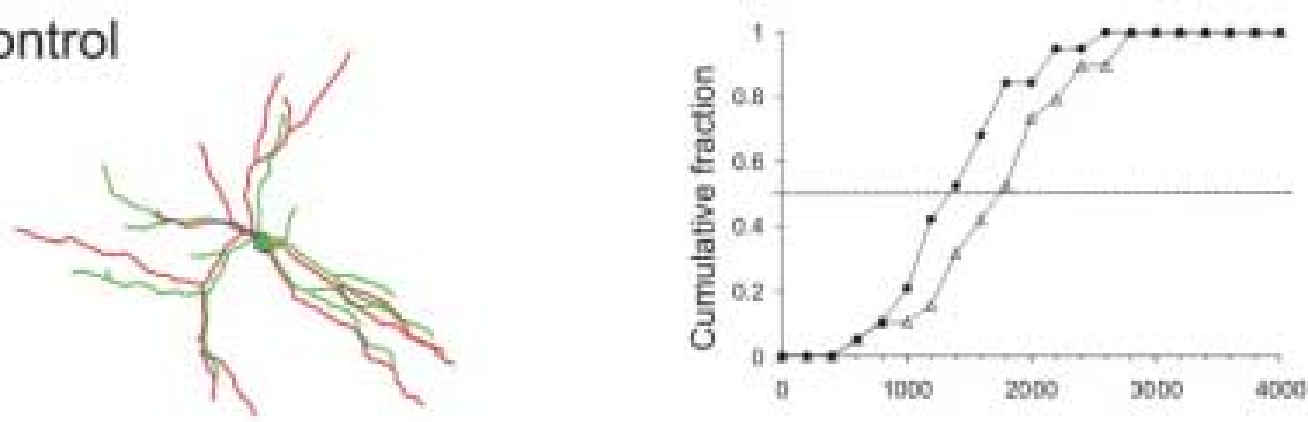

B BDNF
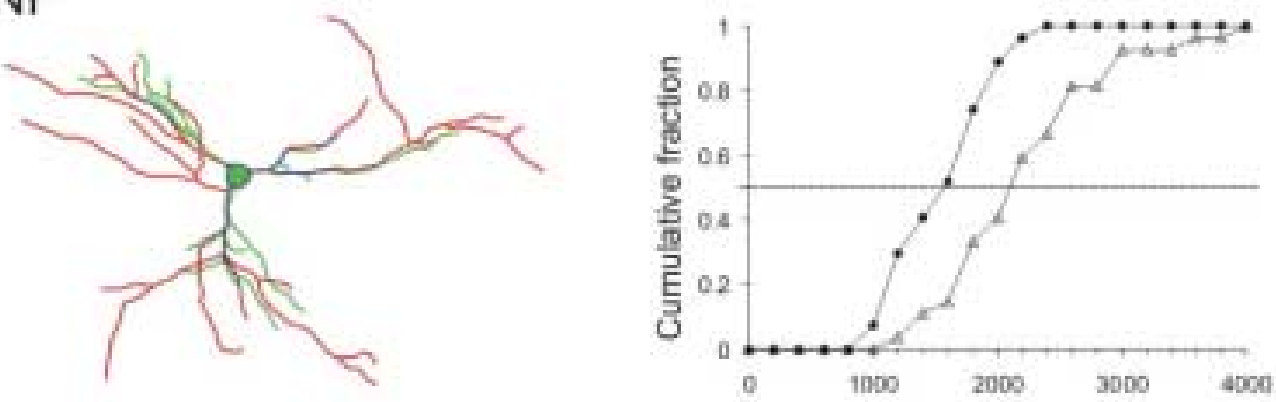

C BDNF+TTX
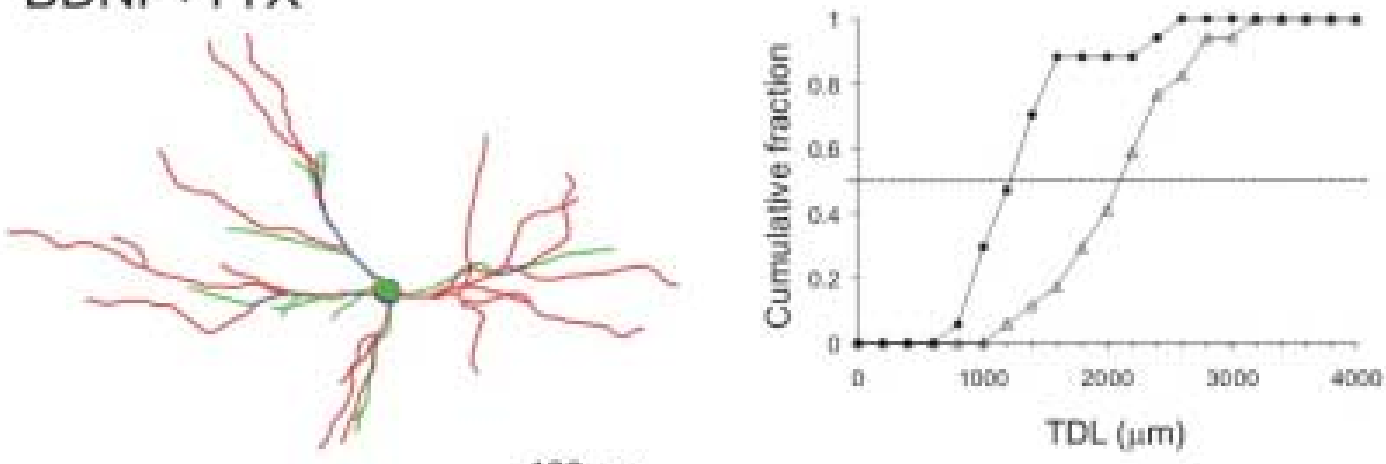

$100 \mu \mathrm{m}$ 


\section{Figure 4.5. BDNF enhanced dendritic outgrowth of GAD67-GFP expressing}

neurons independently of neuronal activity. Left column: morphological reconstructions of representative dendritic trees of neurons before (green) and after (red) a 5-day period in culture medium supplemented by one of the following: no supplement (A), $200 \mathrm{ng} / \mathrm{ml}$ BDNF (B) or $200 \mathrm{ng} / \mathrm{ml} \mathrm{BDNF}$ and $1 \mu \mathrm{M}$ TTX (C). Right column: cumulative histogram of TDL in each treatment group. Each data point represents the fraction of neurons in the treatment group with TDL value equal to or smaller than the corresponding x-value. Filled circles represent TDL at Day 0 (before treatment), open triangles represent TDL at Day 5 (after treatment). Note that the rightward shift of the curves (indicating an overall increase in total dendritic length) was considerably larger in the BNDF and BDNF + TTX conditions, compared to control. The change in the median value can be estimated from the shift of the curves measured along the dashed line at the $\mathrm{y}=0.5$ position. 

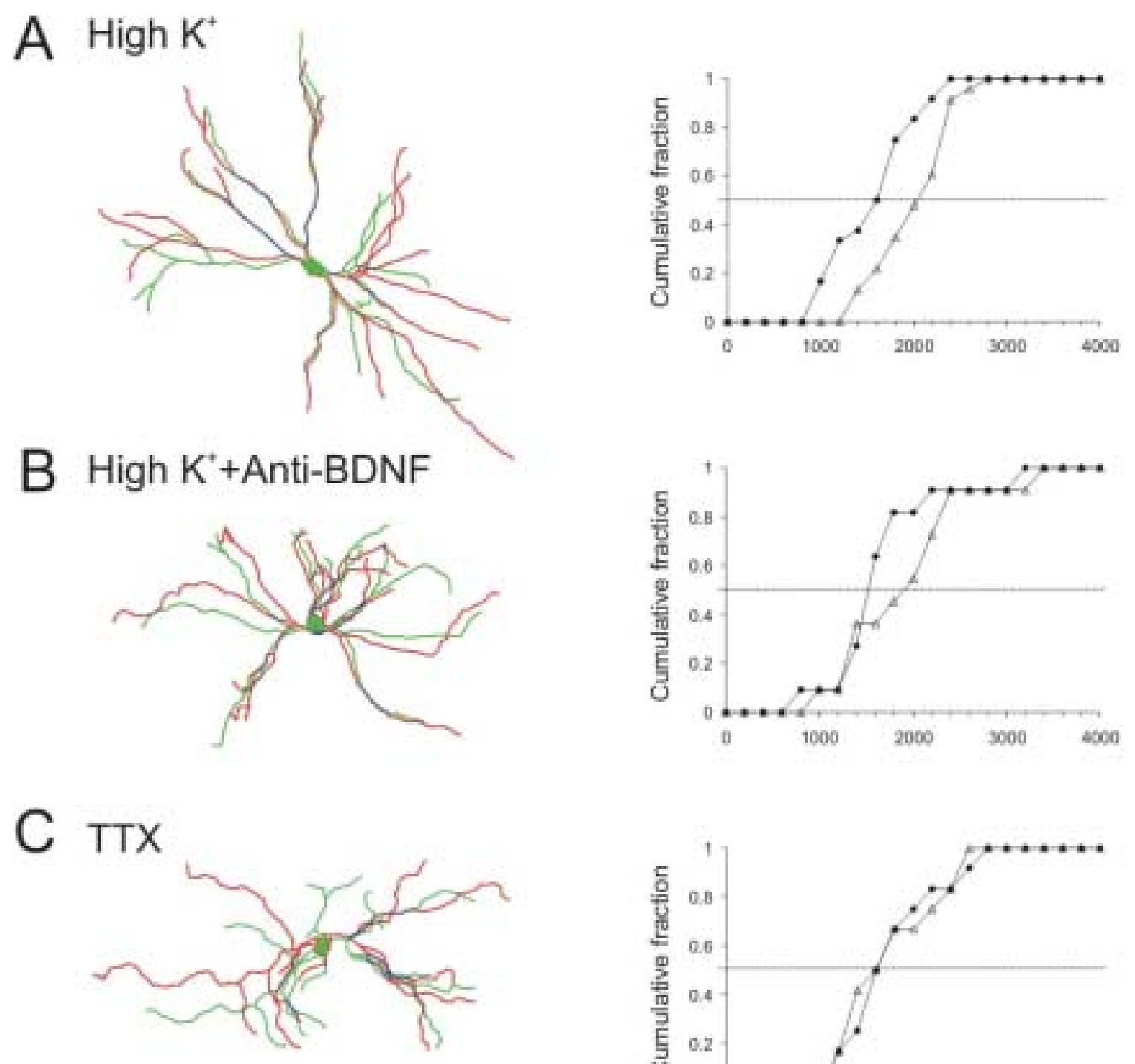

$100 \mu \mathrm{m}$
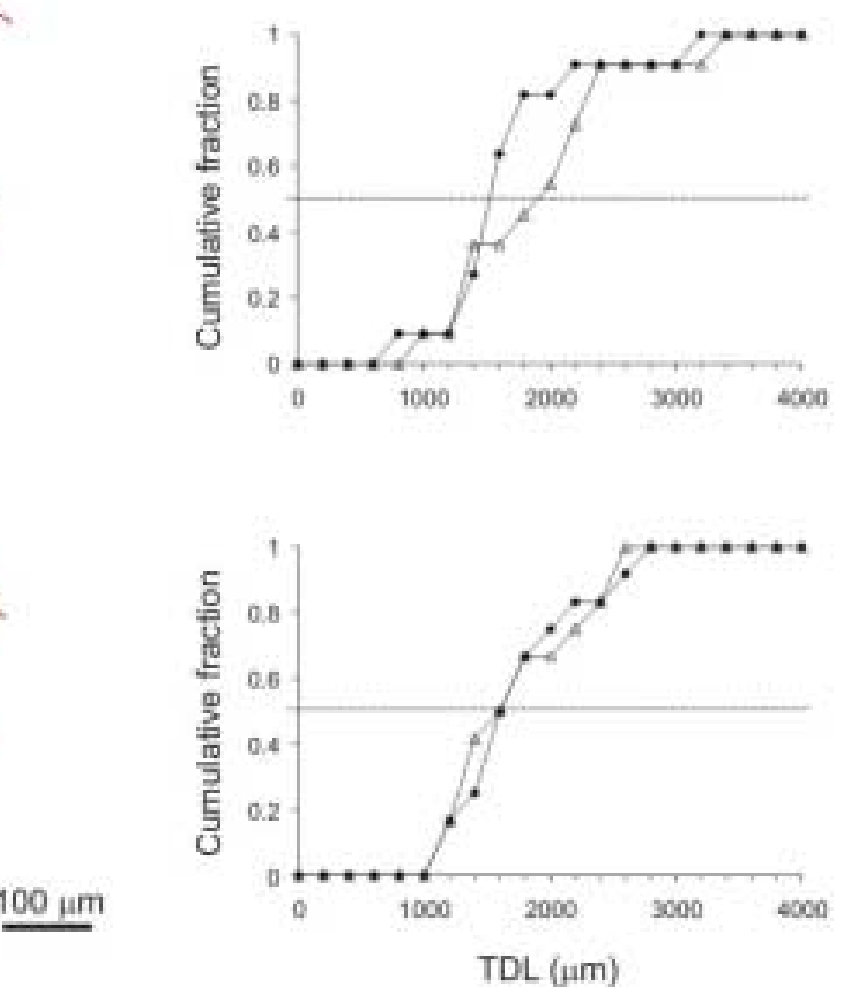

Figure 4.6. High KCl-induced enhancement of dendritic growth in GAD67-GFP expressing neurons was dependent on BDNF. Left column: morphological reconstructions of representative dendritic trees of neurons before (green) and after (red) a 5-day period in culture medium supplemented by one of the following: $10 \mathrm{mM} \mathrm{KCl}$ (A), $10 \mathrm{mM} \mathrm{KCl}$ and $50 \mu \mathrm{g} / \mathrm{ml}$ anti-BDNF (B) or $1 \mu \mathrm{M}$ TTX (C). Right column: cumulative histogram of TDL in each treatment group (see Fig. 5 legend for details). Note the rightward shift of the curve in high $\mathrm{KCl}$ but the smaller shift in high $\mathrm{KCl}+$ antiBDNF and no shift in TTX. 
A

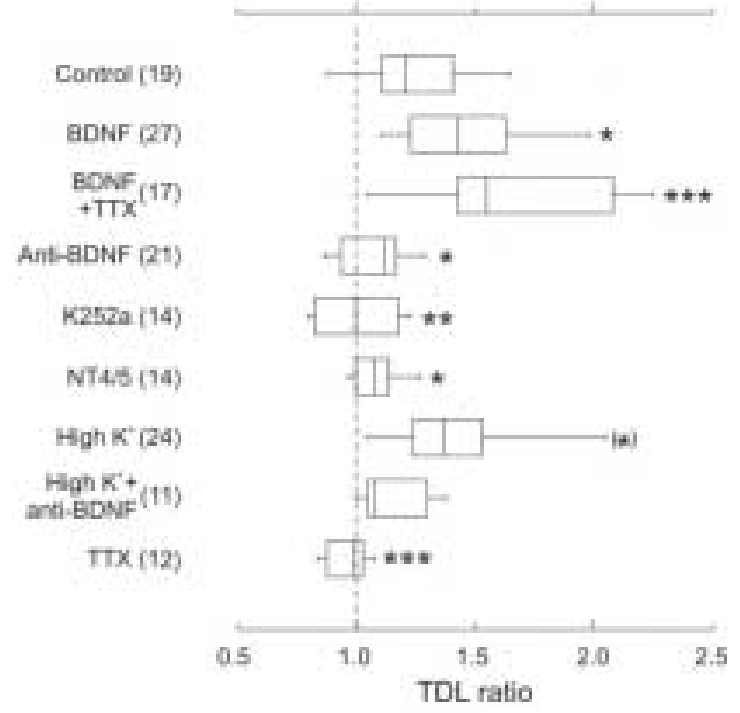

B

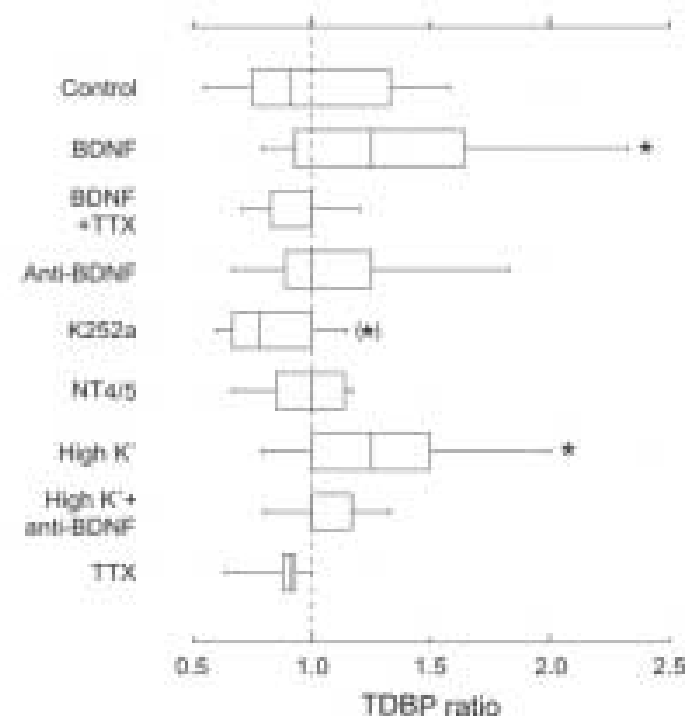

Figure 4.7. Summary plot of the effects of all tested treatments on dendritic growth and branching. A, ratio change in TDL; $\mathbf{B}$, ratio change in TDBP. Each box spans the $25^{\text {th }}$ to $75^{\text {th }}$ percentile of the datapoints, with the median represented by a vertical line inside the box. The whiskers span the $5^{\text {th }}$ to $95^{\text {th }}$ percentiles. The number of neurons tested is indicated in parenthesis after the treatment label in A, and applies also to B. The dashed vertical line at $\mathrm{x}=1$ indicates no change. ${ }^{(*)} p<0.1,{ }^{*} p<0.05,{ }^{*} p<0.01$, $* * * p<0.005 ; p$-values are from pairwise comparisons with the control group (see Methods for details). 


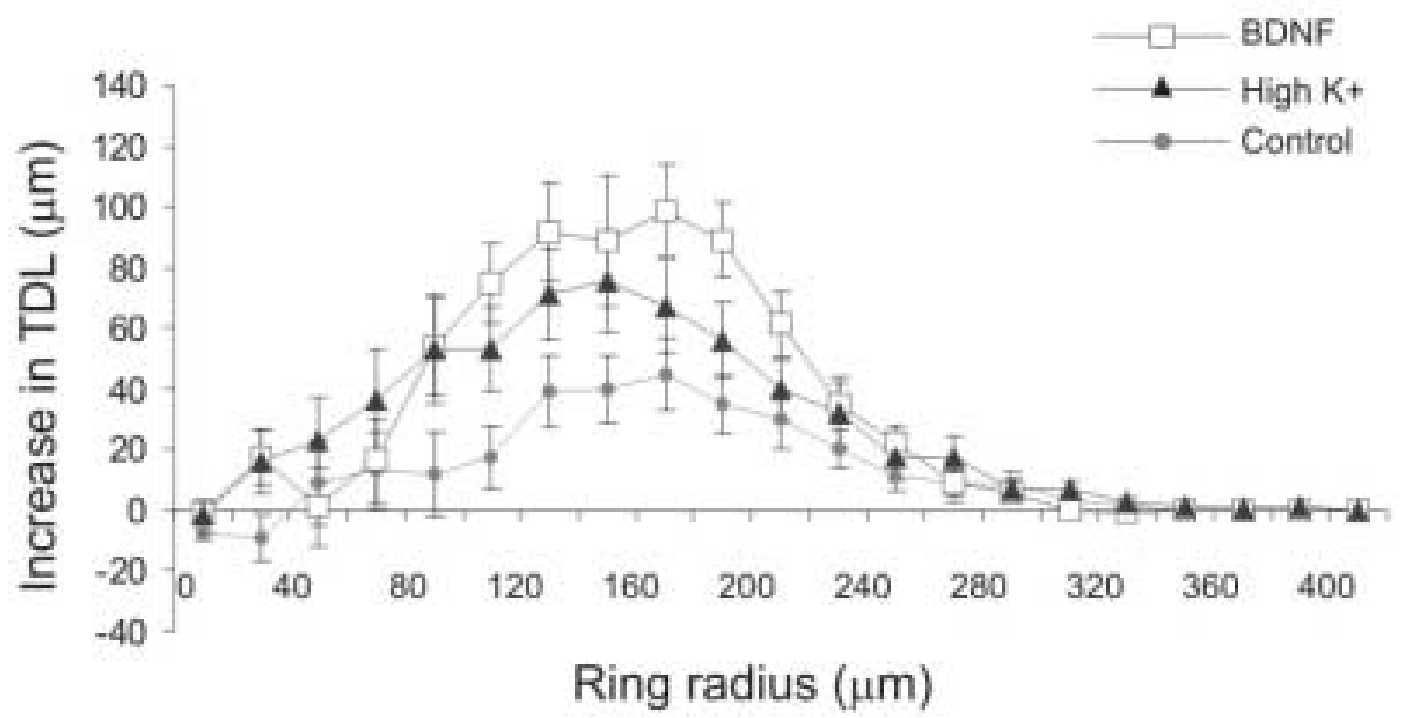

Figure 4.8. Sholl analysis of change in average total dendritic length (TDL) during a 5-day period. Absolute increase in TDL in the control, high $\mathrm{K}^{+}$and $\mathrm{BDNF}$ groups (legend) was calculated separately for each consecutive, $20 \mu \mathrm{m}$-wide concentric ring, and averaged between neurons. Note that the High $\mathrm{K}^{+}$and BDNF groups exhibited a greater average increase in TDL, compared to control, but the radial extent of the increase was similar between all 3 groups. 


\section{REFERENCES}

Agmon, A., Hollrigel, G., and O'Dowd, D. K. (1996) Functional GABAergic synaptic connection in neonatal mouse barrel cortex. J Neurosci 16: 4684-95.

Agmon, A., and O'Dowd, D. K. (1992) NMDA receptor-mediated currents are prominent in the thalamocortical synaptic response before maturation of inhibition. J Neurophysiol 68: $345-9$.

Altar, C. A., Cai, N., Bliven, T., Juhasz, M., Conner, J. M., Acheson, A. L., Lindsay, R. M., and Wiegand, S. J. (1997) Anterograde transport of brain-derived neurotrophic factor and its role in the brain. Nature 389: 856-60.

Annis, C. M., Robertson, R. T., and O'Dowd, D. K. (1993) Aspects of early postnatal development of cortical neurons that proceed independently of normally present extrinsic influences. J Neurobiol 24: 1460-80.

Balcar, V. J., Zetzsche, T., and Wolff, J. R. (1992) Glutamate decarboxylase in developing rat neocortex: does it correlate with the differentiation of GABAergic neurons and synapses? Neurochem Res 17: 253-60.

Bao, S., Chen, L., Qiao, X., and Thompson, R. F. (1999) Transgenic brain-derived neurotrophic factor modulates a developing cerebellar inhibitory synapse. Learn Mem 6: 276-83.

Barbany, G., and Persson, H. (1992) Regulation of Neurotrophin mRNA Expression in the Rat Brain by Glucocorticoids. Eur J Neurosci 4: 396-403.

Bolton, M. M., Lo, D. C., and Sherwood, N. T. (2000) Long-term regulation of excitatory and inhibitory synaptic transmission in hippocampal cultures by brain-derived neurotrophic factor. Prog Brain Res 128: 203-18.

Bonhoeffer, T. (1996) Neurotrophins and activity-dependent development of the neocortex. Curr Opin Neurobiol 6: 119-26.

Caeser, M., Bonhoeffer, T., and Bolz, J. (1989) Cellular organization and development of slice cultures from rat visual cortex. Exp Brain Res 77: 234-44.

Campbell, G., Ramoa, A. S., Stryker, M. P., and Shatz, C. J. (1997) Dendritic development of retinal ganglion cells after prenatal intracranial infusion of tetrodotoxin. Vis Neurosci 14: 779-88.

Castren, E., Zafra, F., Thoenen, H., and Lindholm, D. (1992) Light regulates expression of brain-derived neurotrophic factor mRNA in rat visual cortex. Proc Natl Acad Sci U S A 89: $9444-8$. 
Cellerino, A., and Maffei, L. (1996) The action of neurotrophins in the development and plasticity of the visual cortex [published erratum appears in Prog Neurobiol 1996 Oct;50(2-3):333]. Prog Neurobiol 49: 53-71.

Cohen, A. S., Lin, D. D., and Coulter, D. A. (2000) Protracted postnatal development of inhibitory synaptic transmission in rat hippocampal area CA1 neurons. J Neurophysiol 84: 2465-76.

Dalva, M. B., Ghosh, A., and Shatz, C. J. (1994) Independent control of dendritic and axonal form in the developing lateral geniculate nucleus. J Neurosci 14: 3588-602.

Davies, A. M. (1996) Paracrine and autocrine actions of neurotrophic factors. Neurochem Res 21: 749-53.

De Felipe, J., Marco, P., Fairen, A., and Jones, E. G. (1997) Inhibitory synaptogenesis in mouse somatosensory cortex. Cereb Cortex 7: 619-34.

Dunning, D. D., Hoover, C. L., Soltesz, I., Smith, M. A., and O'Dowd, D. K. (1999) GABA(A) receptor-mediated miniature postsynaptic currents and alpha- subunit expression in developing cortical neurons. J Neurophysiol 82: 3286-97.

Engert, F., and Bonhoeffer, T. (1999) Dendritic spine changes associated with hippocampal long-term synaptic plasticity. Nature 399: 66-70.

Fawcett, J. P., Alonso-Vanegas, M. A., Morris, S. J., Miller, F. D., Sadikot, A. F., and Murphy, R. A. (2000) Evidence that brain-derived neurotrophic factor from presynaptic nerve terminals regulates the phenotype of calbindin-containing neurons in the lateral septum. J Neurosci 20: 274-82.

Fawcett, J. P., Bamji, S. X., Causing, C. G., Aloyz, R., Ase, A. R., Reader, T. A., McLean, J. H., and Miller, F. D. (1998) Functional evidence that BDNF is an anterograde neuronal trophic factor in the CNS. J Neurosci 18: 2808-21.

Fischer, M., Kaech, S., Knutti, D., and Matus, A. (1998) Rapid actin-based plasticity in dendritic spines. Neuron 20: 847-54.

Franklin, J. L., Sanz-Rodriguez, C., Juhasz, A., Deckwerth, T. L., and Johnson, E. M., Jr. (1995) Chronic depolarization prevents programmed death of sympathetic neurons in vitro but does not support growth: requirement for $\mathrm{Ca} 2+$ influx but not Trk activation. $\mathrm{J}$ Neurosci 15: 643-64.

Fritschy, J. M., Paysan, J., Enna, A., and Mohler, H. (1994) Switch in the expression of rat GABAA-receptor subtypes during postnatal development: an immunohistochemical study. J Neurosci 14: 5302-24. 
Fryer, R. H., Kaplan, D. R., Feinstein, S. C., Radeke, M. J., Grayson, D. R., and Kromer, L. F. (1996) Developmental and mature expression of full-length and truncated TrkB receptors in the rat forebrain. J Comp Neurol 374: 21-40.

Ghosh, A., Carnahan, J., and Greenberg, M. E. (1994) Requirement for BDNF in activitydependent survival of cortical neurons. Science 263: 1618-23.

Good, P. I. (1999). Resampling Methods (Boston: Birkhauser).

Goodman, L. J., Valverde, J., Lim, F., Geschwind, M. D., Federoff, H. J., Geller, A. I., and Hefti, F. (1996) Regulated release and polarized localization of brain-derived neurotrophic factor in hippocampal neurons. Mol Cell Neurosci 7: 222-38.

Gorba, T., Klostermann, O., and Wahle, P. (1999) Development of neuronal activity and activity-dependent expression of brain-derived neurotrophic factor mRNA in organotypic cultures of rat visual cortex. Cereb Cortex 9: 864-77.

Gorba, T., and Wahle, P. (1999) Expression of TrkB and TrkC but not BDNF mRNA in neurochemically identified interneurons in rat visual cortex in vivo and in organotypic cultures. Eur J Neurosci 11: 1179-90.

Gotz, M., and Bolz, J. (1989) Development of vasoactive intestinal polypeptide (VIP)containing neurons in organotypic slice cultures from rat visual cortex. Neurosci Lett 107: 6-11.

Griesbeck, O., Canossa, M., Campana, G., Gartner, A., Hoener, M. C., Nawa, H., Kolbeck, R., and Thoenen, H. (1999) Are there differences between the secretion characteristics of NGF and BDNF? Implications for the modulatory role of neurotrophins in activity- dependent neuronal plasticity. Microsc Res Tech 45: 262-75. [pii].

Guo, Y., Kaplan, I. V., Cooper, N. G., and Mower, G. D. (1997) Expression of two forms of glutamic acid decarboxylase (GAD67 and GAD65) during postnatal development of the cat visual cortex. Brain Res Dev Brain Res 103: 127-41.

Hartmann, M., Heumann, R., and Lessmann, V. (2001) Synaptic secretion of BDNF after high-frequency stimulation of glutamatergic synapses. Embo J 20: 5887-97.

Haubensak, W., Narz, F., Heumann, R., and Lessmann, V. (1998) BDNF-GFP containing secretory granules are localized in the vicinity of synaptic junctions of cultured cortical neurons. J Cell Sci 111: 1483-93.

Henneberger, C., Juttner, R., Rothe, T., and Grantyn, R. (2002) Postsynaptic action of BDNF on GABAergic synaptic transmission in the superficial layers of the mouse superior colliculus. J Neurophysiol 88: 595-603. 
Horch, H. W., Kruttgen, A., Portbury, S. D., and Katz, L. C. (1999) Destabilization of cortical dendrites and spines by BDNF. Neuron 23: 353-64.

Houser, C. R., Hendry, S. H., Jones, E. G., and Vaughn, J. E. (1983) Morphological diversity of immunocytochemically identified GABA neurons in the monkey sensorymotor cortex. J Neurocytol 12: 617-38.

Huang, Z. J., Kirkwood, A., Pizzorusso, T., Porciatti, V., Morales, B., Bear, M. F., Maffei, L., and Tonegawa, S. (1999) BDNF regulates the maturation of inhibition and the critical period of plasticity in mouse visual cortex. Cell 98: 739-55.

Isackson, P. J., Huntsman, M. M., Murray, K. D., and Gall, C. M. (1991) BDNF mRNA expression is increased in adult rat forebrain after limbic seizures: temporal patterns of induction distinct from NGF. Neuron 6: 937-48.

Jin, X., Mathers, P. H., Szabo, G., Katarova, Z., and Agmon, A. (2001) Vertical bias in dendritic trees of non-pyramidal neocortical neurons expressing GAD67-GFP in vitro. Cereb Cortex 11: 666-78.

Katarova, Z., Mugnaini, E., Sekerkova, G., Mann, J. R., Aszodi, A., Bosze, Z., Greenspan, R., and Szabo, G. (1998) Regulation of cell-type specific expression of lacZ by the 5'-flanking region of mouse GAD67 gene in the central nervous system of transgenic mice. Eur J Neurosci 10: 989-99.

Kawaguchi, Y., and Kubota, Y. (1997) GABAergic cell subtypes and their synaptic connections in rat frontal cortex. Cereb Cortex 7: 476-86.

Kirkwood, A., and Bear, M. F. (1994) Hebbian synapses in visual cortex. J Neurosci 14: 1634-45.

Knusel, B., and Hefti, F. (1992) K-252 compounds: modulators of neurotrophin signal transduction. J Neurochem 59: 1987-96.

Kohara, K., Kitamura, A., Morishima, M., and Tsumoto, T. (2001) Activity-dependent transfer of brain-derived neurotrophic factor to postsynaptic neurons. Science 291: 241923.

Kojima, M., Takei, N., Numakawa, T., Ishikawa, Y., Suzuki, S., Matsumoto, T., KatohSemba, R., Nawa, H., and Hatanaka, H. (2001) Biological characterization and optical imaging of brain-derived neurotrophic factor-green fluorescent protein suggest an activity- dependent local release of brain-derived neurotrophic factor in neurites of cultured hippocampal neurons. J Neurosci Res 64: 1-10.

Komatsu, Y., and Iwakiri, M. (1991) Postnatal development of neuronal connections in cat visual cortex studied by intracellular recording in slice preparation. Brain Res 540: $14-24$. 
Kossel, A. H., Williams, C. V., Schweizer, M., and Kater, S. B. (1997) Afferent innervation influences the development of dendritic branches and spines via both activity-dependent and non-activity-dependent mechanisms. J Neurosci 17: 6314-24.

Lendvai, B., Stern, E. A., Chen, B., and Svoboda, K. (2000) Experience-dependent plasticity of dendritic spines in the developing rat barrel cortex in vivo. Nature 404: 87681.

Lu, J., Karadsheh, M., and Delpire, E. (1999) Developmental regulation of the neuronalspecific isoform of $\mathrm{K}-\mathrm{Cl}$ cotransporter $\mathrm{KCC} 2$ in postnatal rat brains. J Neurobiol 39: 55868.

Magowan, G., and Price, D. J. (1996) Trophic and outgrowth-promoting effects of K(+)induced depolarization on developing thalamic cells in organotypic culture. Neuroscience 74: 1045-57.

Maisonpierre, P. C., Belluscio, L., Friedman, B., Alderson, R. F., Wiegand, S. J., Furth, M. E., Lindsay, R. M., and Yancopoulos, G. D. (1990) NT-3, BDNF, and NGF in the developing rat nervous system: parallel as well as reciprocal patterns of expression. Neuron 5: 501-9.

Maletic-Savatic, M., Malinow, R., and Svoboda, K. (1999) Rapid dendritic morphogenesis in CA1 hippocampal dendrites induced by synaptic activity. Science 283: 1923-7.

Marty, S. (2000) Differences in the regulation of neuropeptide Y, somatostatin and parvalbumin levels in hippocampal interneurons by neuronal activity and BDNF. Prog Brain Res 128: 193-202.

Marty, S., Berninger, B., Carroll, P., and Thoenen, H. (1996) GABAergic stimulation regulates the phenotype of hippocampal interneurons through the regulation of brainderived neurotrophic factor. Neuron 16: 565-70.

Marty, S., Berzaghi Mda, P., and Berninger, B. (1997) Neurotrophins and activitydependent plasticity of cortical interneurons. Trends Neurosci 20: 198-202.

Marty, S., Carroll, P., Cellerino, A., Castren, E., Staiger, V., Thoenen, H., and Lindholm, D. (1996) Brain-derived neurotrophic factor promotes the differentiation of various hippocampal nonpyramidal neurons, including Cajal-Retzius cells, in organotypic slice cultures. J Neurosci 16: 675-87.

Marty, S., Wehrle, R., Alvarez-Leefmans, F. J., Gasnier, B., and Sotelo, C. (2002) Postnatal maturation of $\mathrm{Na}+, \mathrm{K}+, 2 \mathrm{Cl}-$ cotransporter expression and inhibitory synaptogenesis in the rat hippocampus: an immunocytochemical analysis. Eur J Neurosci 15: 233-45. 
Marty, S., Wehrle, R., and Sotelo, C. (2000) Neuronal activity and brain-derived neurotrophic factor regulate the density of inhibitory synapses in organotypic slice cultures of postnatal hippocampus. J Neurosci 20: 8087-95.

Massengill, J. L., Smith, M. A., Son, D. I., and O'Dowd, D. K. (1997) Differential expression of K4-AP currents and Kv3.1 potassium channel transcripts in cortical neurons that develop distinct firing phenotypes. J Neurosci 17: 3136-47.

Matsutani, S., and Yamamoto, N. (1998) GABAergic neuron-to-astrocyte signaling regulates dendritic branching in coculture. J Neurobiol 37: 251-64.

Mattson, M. P., Dou, P., and Kater, S. B. (1988) Outgrowth-regulating actions of glutamate in isolated hippocampal pyramidal neurons. J Neurosci 8: 2087-100.

McAllister, A. K., Katz, L. C., and Lo, D. C. (1996) Neurotrophin regulation of cortical dendritic growth requires activity. Neuron 17: 1057-64.

McAllister, A. K., Katz, L. C., and Lo, D. C. (1999) Neurotrophins and synaptic plasticity. Annu Rev Neurosci 22: 295-318.

McAllister, A. K., Katz, L. C., and Lo, D. C. (1997) Opposing roles for endogenous BDNF and NT-3 in regulating cortical dendritic growth. Neuron 18: 767-78.

McAllister, A. K., Lo, D. C., and Katz, L. C. (1995) Neurotrophins regulate dendritic growth in developing visual cortex. Neuron 15: 791-803.

Meinecke, D. L., and Peters, A. (1987) GABA immunoreactive neurons in rat visual cortex. J Comp Neurol 261: 388-404.

Mertz, K., Koscheck, T., and Schilling, K. (2000) Brain-derived neurotrophic factor modulates dendritic morphology of cerebellar basket and stellate cells: an in vitro study. Neuroscience 97: 303-10.

Meyer-Franke, A., Wilkinson, G. A., Kruttgen, A., Hu, M., Munro, E., Hanson, M. G., Jr., Reichardt, L. F., and Barres, B. A. (1998) Depolarization and cAMP elevation rapidly recruit TrkB to the plasma membrane of CNS neurons. Neuron 21: 681-93.

Micheva, K. D., and Beaulieu, C. (1995) Postnatal development of GABA neurons in the rat somatosensory barrel cortex: a quantitative study. Eur J Neurosci 7: 419-30.

Micheva, K. D., and Beaulieu, C. (1996) Quantitative aspects of synaptogenesis in the rat barrel field cortex with special reference to GABA circuitry. J Comp Neurol 373: 340-54.

Miller, M. W. (1986) Maturation of rat visual cortex. III. Postnatal morphogenesis and synaptogenesis of local circuit neurons. Brain Res 390: 271-85. 
Mugnaini, E., and Oertel, W. H. (1985). An atlas of the distribution of GABAergic neurons and terminals in the rat CNS as revealed by GAD immunohistochemistry. In Handbook of Chemical Neuroanatomy, A. Bjorklund and T. Hokfelt, eds. (Amsterdam: Elsevier).

Murphy, D. D., Cole, N. B., and Segal, M. (1998) Brain-derived neurotrophic factor mediates estradiol-induced dendritic spine formation in hippocampal neurons. Proc Natl Acad Sci U S A 95: 11412-7.

Nawa, H., Pelleymounter, M. A., and Carnahan, J. (1994) Intraventricular administration of BDNF increases neuropeptide expression in newborn rat brain. J Neurosci 14: 375165.

Nedivi, E., Wu, G. Y., and Cline, H. T. (1998) Promotion of dendritic growth by CPG15, an activity-induced signaling molecule. Science 281: 1863-6.

Niblock, M. M., Brunso-Bechtold, J. K., and Riddle, D. R. (2000) Insulin-like growth factor I stimulates dendritic growth in primary somatosensory cortex. J Neurosci 20: 4165-76.

Olofsdotter, K., Lindvall, O., and Asztely, F. (2000) Increased synaptic inhibition in dentate gyrus of mice with reduced levels of endogenous brain-derived neurotrophic factor. Neuroscience 101: 531-9.

Plotkin, M. D., Snyder, E. Y., Hebert, S. C., and Delpire, E. (1997) Expression of the Na$\mathrm{K}-2 \mathrm{Cl}$ cotransporter is developmentally regulated in postnatal rat brains: a possible mechanism underlying GABA's excitatory role in immature brain. J Neurobiol 33: 78195.

Prieto, J. J., Peterson, B. A., and Winer, J. A. (1994) Morphology and spatial distribution of GABAergic neurons in cat primary auditory cortex (AI). J Comp Neurol 344: 349-82.

Quinlan, E. M., and Halpain, S. (1996) Emergence of activity-dependent, bidirectional control of microtubule- associated protein MAP2 phosphorylation during postnatal development. J Neurosci 16: 7627-37.

Rajan, I., and Cline, H. T. (1998) Glutamate receptor activity is required for normal development of tectal cell dendrites in vivo. J Neurosci 18: 7836-46.

Ramakers, G. J., Winter, J., Hoogland, T. M., Lequin, M. B., van Hulten, P., van Pelt, J., and Pool, C. W. (1998) Depolarization stimulates lamellipodia formation and axonal but not dendritic branching in cultured rat cerebral cortex neurons. Brain Res Dev Brain Res 108: 205-16. 
Ramoa, A. S., and McCormick, D. A. (1994) Enhanced activation of NMDA receptor responses at the immature retinogeniculate synapse. J Neurosci 14: 2098-105.

Reitstetter, R., and Yool, A. J. (1998) Morphological consequences of altered calciumdependent transmembrane signaling on the development of cultured cerebellar Purkinje neurons. Brain Res Dev Brain Res 107: 165-7.

Ren, J. Q., Aika, Y., Heizmann, C. W., and Kosaka, T. (1992) Quantitative analysis of neurons and glial cells in the rat somatosensory cortex, with special reference to GABAergic neurons and parvalbumin-containing neurons. Exp Brain Res 92: 1-14.

Ribak, C. E., Vaughn, J. E., and Saito, K. (1978) Immunocytochemical localization of glutamic acid decarboxylase in neuronal somata following colchicine inhibition of axonal transport. Brain Res 140: 315-32.

Riccio, R. V., and Matthews, M. A. (1987) Effects of intraocular tetrodotoxin on the postnatal development of the dorsal lateral geniculate nucleus of the rat: a Golgi analysis. J Neurosci Res 17: 440-51.

Rico, B., Xu, B., and Reichardt, L. F. (2002) TrkB receptor signaling is required for establishment of GABAergic synapses in the cerebellum. Nat Neurosci 5: 225-33.

Rivera, C., Voipio, J., Payne, J. A., Ruusuvuori, E., Lahtinen, H., Lamsa, K., Pirvola, U., Saarma, M., and Kaila, K. (1999) The K+/Cl- co-transporter KCC2 renders GABA hyperpolarizing during neuronal maturation. Nature 397: 251-5.

Rocamora, N., Welker, E., Pascual, M., and Soriano, E. (1996) Upregulation of BDNF mRNA expression in the barrel cortex of adult mice after sensory stimulation. J Neurosci 16: 4411-9.

Rorig, B., and Grantyn, R. (1993) Glutamatergic and GABAergic synaptic currents in ganglion cells from isolated retinae of pigmented rats during postnatal development. Brain Res Dev Brain Res 74: 98-110.

Rossi, F. M., Bozzi, Y., Pizzorusso, T., and Maffei, L. (1999) Monocular deprivation decreases brain-derived neurotrophic factor immunoreactivity in the rat visual cortex. Neuroscience 90: 363-8.

Rothman, K. J. (1990) No adjustments are needed for multiple comparisons. Epidemiology 1: 43-6.

Rozas, C., Frank, H., Heynen, A. J., Morales, B., Bear, M. F., and Kirkwood, A. (2001) Developmental inhibitory gate controls the relay of activity to the superficial layers of the visual cortex. J Neurosci 21: 6791-801. 
Rutherford, L. C., DeWan, A., Lauer, H. M., and Turrigiano, G. G. (1997) Brain-derived neurotrophic factor mediates the activity-dependent regulation of inhibition in neocortical cultures. J Neurosci 17: 4527-35.

Sanchez, C., Diaz-Nido, J., and Avila, J. (2000) Phosphorylation of microtubuleassociated protein 2 (MAP2) and its relevance for the regulation of the neuronal cytoskeleton function. Prog Neurobiol 61: 133-68.

Savitz, D. A., and Olshan, A. F. (1998) Describing data requires no adjustment for multiple comparisons: a reply from Savitz and Olshan. Am J Epidemiol 147: 813-4; discussion 815 .

Seil, F. J., and Drake-Baumann, R. (2000) TrkB receptor ligands promote activitydependent inhibitory synaptogenesis. J Neurosci 20: 5367-73.

Seil, F. J., Drake-Baumann, R., Leiman, A. L., Herndon, R. M., and Tiekotter, K. L. (1994) Morphological correlates of altered neuronal activity in organotypic cerebellar cultures chronically exposed to anti-GABA agents. Brain Res Dev Brain Res 77: 123-32.

Stoppini, L., Buchs, P. A., and Muller, D. (1991) A simple method for organotypic cultures of nervous tissue. J Neurosci Methods 37: 173-82.

Sutor, B., and Luhmann, H. J. (1995) Development of excitatory and inhibitory postsynaptic potentials in the rat neocortex. Perspect Dev Neurobiol 2: 409-19.

Suzuki, F., Junier, M. P., Guilhem, D., Sorensen, J. C., and Onteniente, B. (1995) Morphogenetic effect of kainate on adult hippocampal neurons associated with a prolonged expression of brain-derived neurotrophic factor. Neuroscience 64: 665-74.

Szabo, G., Katarova, Z., Kortvely, E., Greenspan, R. J., and Urban, Z. (1996) Structure and the promoter region of the mouse gene encoding the $67-\mathrm{kD}$ form of glutamic acid decarboxylase. DNA Cell Biol 15: 1081-91.

Thoenen, H. (1995) Neurotrophins and neuronal plasticity. Science 270: 593-8.

Tia, S., Wang, J. F., Kotchabhakdi, N., and Vicini, S. (1996) Developmental changes of inhibitory synaptic currents in cerebellar granule neurons: role of $\mathrm{GABA}(\mathrm{A})$ receptor alpha 6 subunit. J Neurosci 16: 3630-40.

Timmusk, T., Belluardo, N., Metsis, M., and Persson, H. (1993) Widespread and developmentally regulated expression of neurotrophin-4 mRNA in rat brain and peripheral tissues. Eur J Neurosci 5: 605-13.

Tongiorgi, E., Righi, M., and Cattaneo, A. (1997) Activity-dependent dendritic targeting of BDNF and TrkB mRNAs in hippocampal neurons. J Neurosci 17: 9492-505. 
Toran-Allerand, C. D. (1996) Mechanisms of estrogen action during neural development: mediation by interactions with the neurotrophins and their receptors? J Steroid Biochem Mol Biol 56: 169-78.

Turrigiano, G. G., and Nelson, S. B. (2000) Hebb and homeostasis in neuronal plasticity. Curr Opin Neurobiol 10: 358-64.

Vaillant, A. R., Zanassi, P., Walsh, G. S., Aumont, A., Alonso, A., and Miller, F. D. (2002) Signaling mechanisms underlying reversible, activity-dependent dendrite formation. Neuron 34: 985-98.

Vicario-Abejon, C., Collin, C., McKay, R. D., and Segal, M. (1998) Neurotrophins induce formation of functional excitatory and inhibitory synapses between cultured hippocampal neurons. J Neurosci 18: 7256-71.

Wells, J. E., Porter, J. T., and Agmon, A. (2000) GABAergic inhibition suppresses paroxysmal network activity in the neonatal rodent hippocampus and neocortex. J Neurosci 20: 8822-30.

Wetmore, C., Olson, L., and Bean, A. J. (1994) Regulation of brain-derived neurotrophic factor (BDNF) expression and release from hippocampal neurons is mediated by nonNMDA type glutamate receptors. J Neurosci 14: 1688-700.

Widmer, H. R., and Hefti, F. (1994) Stimulation of GABAergic neuron differentiation by NT-4/5 in cultures of rat cerebral cortex. Brain Res Dev Brain Res 80: 279-84.

Wu, G. Y., Deisseroth, K., and Tsien, R. W. (2001) Spaced stimuli stabilize MAPK pathway activation and its effects on dendritic morphology. Nat Neurosci 4: 151-8.

Yacoubian, T. A., and Lo, D. C. (2000) Truncated and full-length TrkB receptors regulate distinct modes of dendritic growth. Nat Neurosci 3: 342-9.

Yamada, M. K., Nakanishi, K., Ohba, S., Nakamura, T., Ikegaya, Y., Nishiyama, N., and Matsuki, N. (2002) Brain-derived neurotrophic factor promotes the maturation of GABAergic mechanisms in cultured hippocampal neurons. J Neurosci 22: 7580-5.

Yan, Q., Rosenfeld, R. D., Matheson, C. R., Hawkins, N., Lopez, O. T., Bennett, L., and Welcher, A. A. (1997) Expression of brain-derived neurotrophic factor protein in the adult rat central nervous system. Neuroscience 78: 431-48.

Zafra, F., Hengerer, B., Leibrock, J., Thoenen, H., and Lindholm, D. (1990) Activity dependent regulation of BDNF and NGF mRNAs in the rat hippocampus is mediated by non-NMDA glutamate receptors. Embo J 9: 3545-50. 


\section{Chapter Five}

\section{General Discussion}




\section{DISCUSSION}

\section{Summary and significance of the current study}

Cortical GABAergic interneurons play a crucial role in the normal function of the cerebral cortex by mediating synaptic inhibition. Abnormal development and function of GABAergic interneurons may underlie various central nervous system disorders such as epilepsy, schizophrenia and bipolar disorders. As discussed in Chapter 1, impairment in one or more components of the GABAergic system may contribute to the development of hyperexcitability, leading to epilepsy (Sloviter, 1987; Janjua et al., 1991; Bekenstein and Lothman, 1993). Similarly, abnormal GABAergic inhibition and disinhibition are found in schizophrenia and bipolar disorder (Benes and Berretta, 2001). Many now believe that such a disturbance of GABAergic inhibition may be related to a perturbation of the early development of GABAergic neurons. The technique we developed to label living GABAergic neurons with GFP will provide a new approach for addressing questions related to the development of GABAergic neurons in vivo and in vitro.

Dendrites are the sites where the neuron receives most of its synaptic input from other neurons. Dendrites are crucially important for synaptic integration and summation and for morphological and functional plasticity (Matus and Shepherd, 2000). Proper dendritic development of GABAergic neurons is therefore crucial to normal GABAergic function in the cortical network. Therefore, our study of the dendritic development of GABAergic neurons may not only help us understand how GABAergic neurons develop and establish synaptic connections, but may also contribute to our understanding of epilepsy and related diseases, and further our efforts to prevent such disorders. 
Because of their capacity to promote neuronal growth and survival, BDNF and other neurotrophic factors may have therapeutic value for treating brain injuries and for ameliorating the symptoms of neurodegenerative diseases (Martinez-Serrano and Bjorklund, 1996; Alberch et al., 2002). Several studies have shown that certain cell types can be genetically modified to express neurotrophins, and then grafted into a CNS lesion site to promote its repair. For example, transplantation of genetically engineered BDNFsecreting neural stem cells or fibroblasts improves the survival of rat neostriatum neurons (Rubio et al., 1999), and promotes the regeneration of rubrospinal axons (Liu et al., 1999). A thorough understanding of neurotrophin effects and mechanisms of action in the developing brain is essential for their therapeutic use in neuronal stem cell transplantation and in gene therapy. Our study on the effects of BDNF on dendritic growth of GABAergic interneurons may therefore contribute to the application of BDNF to the treatment of diseases in which GABAergic interneurons degenerate or are dysfunctional

\section{Activity-dependent and activity-independent mechanism underlying dendritic development}

The precise interconnection of neurons in the brain requires tight developmental regulation of dendritic trees and axonal arbors, both in size and complexity and in orientation. In this study, we demonstrated regulation of these two aspects of dendritic development in GABAergic cortical interneurons by showing that their dendrites have a vertical orientation bias and are developmentally regulated by neuronal activity through BDNF signaling. 
Biases in the orientation of dendrites with respect to functional borders have been observed in different cortical areas. In the somatosensory cortex of rodents, tactile information from the whiskers forms a one-to-one projection to structurally and functionally defined regions in layer 4 termed barrels (Woolsey and Van der Loos, 1970; Killackey, 1973). Neurons in each barrel respond primarily to input from a single vibrissa, as thalamocortical afferents activated from a given vibrissa are anatomically confined to a given barrel (Agmon et al., 1993; Catalano et al., 1996). Spiny stellate and inhibitory interneurons in each barrel have dendrites that tend to be confined within the boundary of a single barrel (Woolsey et al., 1975; Steffen and Van der Loos, 1980; Petersen and Sakmann, 2001; Porter et al., 2001), and are directionally biased towards the center of the barrel. Similarly, in the visual cortex of primate (Katz et al., 1989) and cat (Kossel et al., 1995), where input from the lateral geniculate nucleus is segregated into ocular dominance columns, dendrites of spiny stellate cells in layer 4 tend to be confined to a single ocular dominance column. Neurons with somata close to the boundary between columns have dendrites that are biased away from this border, towards the center of the column. In these examples, the formation of dendritic biases was shown to be dependent on neuronal activity (Kossel et al., 1995; Hannan et al., 2001), possibly through the release of neurotrophic factors such as BDNF (Singh et al., 1997; Vitalis et al., 2002), through the effect of the excitatory neurotransmitter glutamate (Pearce et al., 1987), or through the formation of synapses (Kossel et al., 1997).

Another kind of directional bias is exhibited by cortical pyramidal neurons, which have a prominent apical dendrite directed toward the pial surface, and are therefore vertically oriented. As discussed in Chapter 3, the growth of apical dendrites towards the 
pial surface is regulated by a diffusible factor, semaphorin 3A (Sema3A), present at high levels near the marginal zone. Sema3A is chemoattractive to apical dendrites and chemorepellent to axons, possibly due to asymmetric localization of soluble guanylate cyclase in the developing neurons (Polleux et al., 2000). This kind of directional growth seems to be determined by genetically programmed molecular signals, and serves to form a structural basis for the vertical flow of information in the cortical column, as discussed in Chapter 3.

In our study (Chapter 3), we used a novel computational metric of dendritic polarization, and demonstrated that dendrites of about two thirds of cortical GABAergic interneurons have a highly significant tendency to extend along the vertical axis of the cortex, indicating that GABAergic neurons conform to the fundamental columnar organization of the cerebral cortex. It is likely that mechanisms similar to those responsible for the vertical orientation of apical dendrites of pyramidal neurons underlie the formation of vertically oriented dendrites in cortical GABAergic interneurons, even though we cannot rule out the possibility that neuronal activity plays a role in this process.

Several previous studies have described the existence of vertical bias in cortical interneurons, but our study extends previous results in two respects. One is the use of biolistic transfection in organotypic cultures to label cortical GABAergic neurons. This ensures both clear visualization of dendritic detail and high specificity, in contrast to previous studies, which were mainly based on the Golgi method with randomly labeled neurons. The second is the use of a novel quantitative method to describe the vertical bias by generating a single index. This method should prove generally useful in the 
quantification of dendritic or axonal orientation relative to a functional or structural border, and in quantitative comparisons between neurons developing under different conditions.

Using the same method of GAD67-GFP transfection, we showed (Chapter 4) that dendritic development of cortical GABAergic neurons is regulated by neuronal activity through the release of endogenous BDNF. The patterns and level of neuronal activity are important factors in many aspects of the development of neurons, including neurite differentiation, synapse formation and elimination, and neurochemical expression, as reviewed in Chapter 1. Neuronal activity regulates the expression of GABA, the number of GABAergic synapses and the strength of GABAergic inhibition. Since GABAergic inhibition modulates the excitability of cortical circuits, this results in a negative feedback mechanism that ensures that cortical inhibition scales up or down with the level of excitation so that the system can maintain a homeostatic level of activity.

In summary, the dendritic development of cortical excitatory neurons has been shown to have two components: an intrinsic, genetically programmed component, and an activity-dependent component. In our study, we showed that similar activity-independent and activity-dependent processes are involved in the dendritic development of inhibitory GABAergic neurons as well.

\section{Application of GAD67-GFP transfection to the study of GABAergic neurons}

In the last decade, the biolistic gene transfer technique has found broad applications in biology in general, and in neuroscience specifically, from plant cells (Klein et al., 1992), to the organotypic brain slice culture (Lo et al., 1994; Wellmann et 
al., 1999), and to the recent in vivo transfection of brain tissue (Sato et al., 2000; Zhang and Selzer, 2001). Patterns of transfection have also progressed, from earlier nonspecific labeling (Jiao et al., 1993; Lo et al., 1994) to genes with specific localization or function. Biolistic gene transfer has been used for nonspecific and specific labeling of different neuronal types (McAllister et al., 1995; Jin et al., 2001; Klimaschewski et al., 2002), for specific visualization of subcellular proteins (Marrs et al., 2001), and for knockout of internal proteins (Malin and Nerbonne, 2000; Nakayama et al., 2000; Marsh et al., 2001). Because GAD67-GFP is expressed selectively by cortical GABAergic interneurons in the developing brain, biolistic cotransfection of GAD67-GFP DNA with other genes in organotypic slice cultures should prove to be a powerful tool for addressing questions related to the development of cortical GABAergic interneurons.

One of our original goals in developing the GAD67-GFP transfection technique was to facilitate electrophysiological recordings from GABAergic neurons, because the scarcity of this class of neurons makes it difficult to target them for recording. In the early postnatal period, GABAergic neurons are even more difficult to identify because of their immature morphological, neurochemical and electrophysiological properties. Biolistic transfection with GAD67-GFP DNA will not only allow direct targeting of GFP-expressing GABAergic neurons, but will also facilitate dual recordings to analyze electrical or chemical interconnection between GABAergic interneurons, or between interneurons and pyramidal neurons. These applications were described and demonstrated in Chapter 2.

Our understanding of many basic developmental mechanisms of the nervous system, such as axonal pathfinding and synapse formation and elimination, is largely 
based on the study of 'simple' nervous systems or of the mammalian peripheral nervous system, e.g. the neuromuscular junction. Studies addressing these basic questions in the mammalian brain often focus on the 'principal' (typically excitatory, glutamatergic) neurons. The reason for this neglect of inhibitory neurons may be twofold. First, in contrast to the principal neurons, GABAergic interneurons are usually less numerous, project locally, and are interspersed between the more numerous principal cells. Secondly, unlike principal neurons, inhibitory interneurons are a highly diverse group of neurons. These features make inhibitory neurons difficult to study. With the use of the biolistic transfection with GAD67-GFP DNA, it is now possible to identify these neurons and visualize them in living tissue with great structural detail. Here we studied the dendritic development of cortical GABAergic neurons; a straightforward direction for future studies is to explore their axonal dynamics and synapse formation.

Recent evidence suggests that pyramidal neurons and GABAergic interneurons of the cerebral cortex are generally derived from distinct proliferative zones. Cortical projection (pyramidal) neurons originate from the cortical ventricular zone, and then migrate radially into the cortical mantle, whereas many cortical interneurons originate from the basal telencephalon and migrate tangentially into the developing cortex, then seek the ventricular zone before moving radially to take up their positions in the cortical plate (Anderson et al., 2001; Nadarajah et al., 2002; Nadarajah and Parnavelas, 2002). The molecular mechanisms that underlie migration of GABAergic interneurons are not well understood; it is speculated that a combination of chemoattractant and chemorepellent molecules may be involved in this lateral migration. Several genes have been suggested to be involved in the guidance of interneuron migration. Mice deficient 
in the homeobox genes $D l x 1 / 2$ show no detectable cell migration from the subcortical telencephalon to the neocortex and retain only $25 \%$ of cortical GABAergic neurons (Anderson et al., 1997). Studies with mice deficient for the $N k x 2.1$ or Mash1 genes also show a significant reduction in cortical GABAergic neurons (Casarosa et al., 1999; Sussel et al., 1999). Additionally, trkB-signaling acting via PI3-kinase activation also plays an important role in controlling interneuron migration in the developing cerebral cortex (Polleux et al., 2002). The use of biolistic transfection in embryonic brain slice cultures, or organotypic slice culture of GAD67-GFP transgenic mice, would allow time-lapse imaging of the migration of the GFP labeled GABAergic neurons, which will not only reveal the routes and patterns of their migration, but also help to elucidate the underlying molecular mechanisms. For example, introduction of the Dlx $1 / 2$ gene by cotransfection of GAD67-GFP and Dlx1/2 DNA is predicted to rescue migration of GABAergic neurons from the LGE to the neocortex in Dlx 1/2 mutant mice. Conversely, cotransfection with GAD67-GFP DNA and a construct to knock out trkB signaling should reduce the migration of GABAergic neurons, since TrkB signaling is shown to promote interneuron migration.

Recently, GAD67-GFP transgenic mice were developed by the Agmon and Mathers laboratories using the same construct used for biolistic transfection. Like the method of biolistic transfection, GAD67-GFP transgenic mice will be useful for morphological, electrophysiological, and molecular study of GABAergic neurons, and will greatly increase our understanding of their development and function in the cerebral cortex and elsewhere. 


\section{REFERENCES}

Agmon, A., Yang, L. T., O'Dowd, D. K., and Jones, E. G. (1993) Organized growth of thalamocortical axons from the deep tier of terminations into layer IV of developing mouse barrel cortex. J Neurosci 13: 5365-82.

Alberch, J., Perez-Navarro, E., and Canals, J. M. (2002) Neuroprotection by neurotrophins and GDNF family members in the excitotoxic model of Huntington's disease. Brain Res Bull 57: 817-22.

Anderson, S. A., Eisenstat, D. D., Shi, L., and Rubenstein, J. L. (1997) Interneuron migration from basal forebrain to neocortex: dependence on Dlx genes. Science 278: 474-6.

Anderson, S. A., Marin, O., Horn, C., Jennings, K., and Rubenstein, J. L. (2001) Distinct cortical migrations from the medial and lateral ganglionic eminences. Development 128: 353-63.

Bekenstein, J. W., and Lothman, E. W. (1993) Dormancy of inhibitory interneurons in a model of temporal lobe epilepsy. Science 259: 97-100.

Benes, F. M., and Berretta, S. (2001) GABAergic interneurons: implications for understanding schizophrenia and bipolar disorder. Neuropsychopharmacology 25: 1-27.

Casarosa, S., Fode, C., and Guillemot, F. (1999) Mash1 regulates neurogenesis in the ventral telencephalon. Development 126: 525-34.

Catalano, S. M., Robertson, R. T., and Killackey, H. P. (1996) Individual axon morphology and thalamocortical topography in developing rat somatosensory cortex. J Comp Neurol 367: 36-53.

Hannan, A. J., Blakemore, C., Katsnelson, A., Vitalis, T., Huber, K. M., Bear, M., Roder, J., Kim, D., Shin, H. S., and Kind, P. C. (2001) PLC-beta1, activated via mGluRs, mediates activity-dependent differentiation in cerebral cortex. Nat Neurosci 4: 282-8.

Janjua, N. A., Mori, A., and Hiramatsu, M. (1991) Gamma-aminobutyric acid uptake is decreased in the hippocampus in a genetic model of human temporal lobe epilepsy. Epilepsy Res 8: 71-4.

Jiao, S., Cheng, L., Wolff, J. A., and Yang, N. S. (1993) Particle bombardment-mediated gene transfer and expression in rat brain tissues. Biotechnology (N Y) 11: 497-502.

Jin, X., Mathers, P. H., Szabo, G., Katarova, Z., and Agmon, A. (2001) Vertical bias in dendritic trees of non-pyramidal neocortical neurons expressing GAD67-GFP in vitro. Cereb Cortex 11: 666-78. 
Katz, L. C., Gilbert, C. D., and Wiesel, T. N. (1989) Local circuits and ocular dominance columns in monkey striate cortex. J Neurosci 9: 1389-99.

Killackey, H. P. (1973) Anatomical evidence for cortical subdivisions based on vertically discrete thalamic projections from the ventral posterior nucleus to cortical barrels in the rat. Brain Res 51: 326-31.

Klein, T. M., Arentzen, R., Lewis, P. A., and Fitzpatrick-McElligott, S. (1992) Transformation of microbes, plants and animals by particle bombardment. Biotechnology (N Y) 10: 286-91.

Klimaschewski, L., Nindl, W., Pimpl, M., Waltinger, P., and Pfaller, K. (2002) Biolistic transfection and morphological analysis of cultured sympathetic neurons. J Neurosci Methods 113: 63-71.

Kossel, A., Lowel, S., and Bolz, J. (1995) Relationships between dendritic fields and functional architecture in striate cortex of normal and visually deprived cats. J Neurosci 15: 3913-26.

Kossel, A. H., Williams, C. V., Schweizer, M., and Kater, S. B. (1997) Afferent innervation influences the development of dendritic branches and spines via both activity-dependent and non-activity-dependent mechanisms. J Neurosci 17: 6314-24.

Liu, Y., Kim, D., Himes, B. T., Chow, S. Y., Schallert, T., Murray, M., Tessler, A., and Fischer, I. (1999) Transplants of fibroblasts genetically modified to express BDNF promote regeneration of adult rat rubrospinal axons and recovery of forelimb function. $\mathrm{J}$ Neurosci 19: 4370-87.

Lo, D. C., McAllister, A. K., and Katz, L. C. (1994) Neuronal transfection in brain slices using particle-mediated gene transfer. Neuron 13: 1263-8.

Malin, S. A., and Nerbonne, J. M. (2000) Elimination of the fast transient in superior cervical ganglion neurons with expression of KV4.2W362F: molecular dissection of IA. J Neurosci 20: 5191-9.

Marrs, G. S., Green, S. H., and Dailey, M. E. (2001) Rapid formation and remodeling of postsynaptic densities in developing dendrites. Nat Neurosci 4: 1006-13.

Marsh, D. R., Holmes, K. D., Dekaban, G. A., and Weaver, L. C. (2001) Distribution of an NMDA receptor:GFP fusion protein in sensory neurons is altered by a C-terminal construct. J Neurochem 77: 23-33.

Martinez-Serrano, A., and Bjorklund, A. (1996) Protection of the neostriatum against excitotoxic damage by neurotrophin-producing, genetically modified neural stem cells. J Neurosci 16: 4604-16. 
Matus, A., and Shepherd, G. M. (2000) The millennium of the dendrite? Neuron 27: 4314.

McAllister, A. K., Lo, D. C., and Katz, L. C. (1995) Neurotrophins regulate dendritic growth in developing visual cortex. Neuron 15: 791-803.

Nadarajah, B., Alifragis, P., Wong, R. O., and Parnavelas, J. G. (2002) Ventricle-directed migration in the developing cerebral cortex. Nat Neurosci 5: 218-24.

Nadarajah, B., and Parnavelas, J. G. (2002) Modes of neuronal migration in the developing cerebral cortex. Nat Rev Neurosci 3: 423-32.

Nakayama, A. Y., Harms, M. B., and Luo, L. (2000) Small GTPases Rac and Rho in the maintenance of dendritic spines and branches in hippocampal pyramidal neurons. $\mathbf{J}$ Neurosci 20: 5329-38.

Pearce, I. A., Cambray-Deakin, M. A., and Burgoyne, R. D. (1987) Glutamate acting on NMDA receptors stimulates neurite outgrowth from cerebellar granule cells. FEBS Lett 223: 143-7.

Petersen, C. C., and Sakmann, B. (2001) Functionally independent columns of rat somatosensory barrel cortex revealed with voltage-sensitive dye imaging. J Neurosci 21 : 8435-46.

Polleux, F., Morrow, T., and Ghosh, A. (2000) Semaphorin 3A is a chemoattractant for cortical apical dendrites. Nature 404: 567-73.

Polleux, F., Whitford, K. L., Dijkhuizen, P. A., Vitalis, T., and Ghosh, A. (2002) Control of cortical interneuron migration by neurotrophins and PI3- kinase signaling. Development 129: 3147-60.

Porter, J. T., Johnson, C. K., and Agmon, A. (2001) Diverse types of interneurons generate thalamus-evoked feedforward inhibition in the mouse barrel cortex. J Neurosci 21: 2699-710.

Rubio, F., Kokaia, Z., Arco, A., Garcia-Simon, M., Snyder, E., Lindvall, O., Satrustegui, J., and Martinez-Serrano, A. (1999) BDNF gene transfer to the mammalian brain using CNS-derived neural precursors. Gene Ther 6: 1851-66.

Sato, H., Hattori, S., Kawamoto, S., Kudoh, I., Hayashi, A., Yamamoto, I., Yoshinari, M., Minami, M., and Kanno, H. (2000) In vivo gene gun-mediated DNA delivery into rodent brain tissue. Biochem Biophys Res Commun 270: 163-70.

Singh, T. D., Mizuno, K., Kohno, T., and Nakamura, S. (1997) BDNF and trkB mRNA expression in neurons of the neonatal mouse barrel field cortex: normal development and plasticity after cauterizing facial vibrissae. Neurochem Res 22: 791-7. 
Sloviter, R. S. (1987) Decreased hippocampal inhibition and a selective loss of interneurons in experimental epilepsy. Science 235: 73-6.

Steffen, H., and Van der Loos, H. (1980) Early lesions of mouse vibrissal follicles:: their influence on dendrite orientation in the cortical barrelfield. Exp Brain Res 40: 419-31.

Sussel, L., Marin, O., Kimura, S., and Rubenstein, J. L. (1999) Loss of Nkx2.1 homeobox gene function results in a ventral to dorsal molecular respecification within the basal telencephalon: evidence for a transformation of the pallidum into the striatum. Development 126: 3359-70.

Vitalis, T., Cases, O., Gillies, K., Hanoun, N., Hamon, M., Seif, I., Gaspar, P., Kind, P., and Price, D. J. (2002) Interactions between TrkB signaling and serotonin excess in the developing murine somatosensory cortex: a role in tangential and radial organization of thalamocortical axons. J Neurosci 22: 4987-5000.

Wellmann, H., Kaltschmidt, B., and Kaltschmidt, C. (1999) Optimized protocol for biolistic transfection of brain slices and dissociated cultured neurons with a hand-held gene gun. J Neurosci Methods 92: 55-64.

Woolsey, T. A., Dierker, M. L., and Wann, D. F. (1975) Mouse SmI cortex: qualitative and quantitative classification of golgi- impregnated barrel neurons. Proc Natl Acad Sci U S A 72: 2165-9.

Woolsey, T. A., and Van der Loos, H. (1970) The structural organization of layer IV in the somatosensory region (SI) of mouse cerebral cortex. The description of a cortical field composed of discrete cytoarchitectonic units. Brain Res 17: 205-42.

Zhang, G., and Selzer, M. E. (2001) In vivo transfection of lamprey brain neurons by gene gun delivery of DNA. Exp Neurol 167: 304-11. 


\section{APPENDIX: DETAILED METHODS}

\section{Organotypic Culture Preparation}

Organotypic cortical slice cultures were prepared using the method of Stoppini et al., 1991. Before the experiment, a six-well plastic plate (Falcon, Becton Dickinson Labware, Franklin lake, NJ) was filled with $1 \mathrm{ml}$ culture medium in each well. Culture medium was composed of $46 \%$ Eagle's basal medium, 25\% Earle's balanced salt solution, $25 \%$ horse serum, $1 \%$ mixture of penicillin (10,000 units/ml)-streptomycin (10 $\mathrm{mg} / \mathrm{ml}$ ) -glutamine (29.2 mg/ml), (all from Invitrogen, Carlsbad, CA), 3\% 22\%-glucose solution (for a final concentration of $6.5 \mathrm{mg} / \mathrm{ml}$ ). The $\mathrm{pH}$ was adjusted to 7.2. Millicell membrane inserts (outer diameter $30 \mathrm{~mm}$, height $5 \mathrm{~mm}$; Millipore, Bedford, MA) were placed in each well, and the plate was kept in a humidified incubator at $35^{\circ} \mathrm{C}$ with a $5 \%$ $\mathrm{CO}_{2}$-enriched atmosphere until use.

All slice preparation procedures were performed under sterile conditions in a laminar flow hood. The working space of the hood was covered by autoclaved paper towels. All metal instruments and glassware were autoclaved before the experiment. Postnatal day 2-7 mouse or rat pups (postnatal day 0 being the first 24 hours after birth; postnatal day 2-3 pups gave best results) were deeply anesthetized by metofane or halothane inhalation or (in pups younger than P3) by cooling in ice. A small amount of $70 \%$ alcohol solution was used to rub the pup's head and neck with a sterile paper towel. Pups were decapitated with a sterile razor blade, the skull carefully peeled away and the brains removed and immersed in ice-cold artificial cerebrospinal fluid (ACSF) in a petri dish (ACSF contained $126 \mathrm{mM} \mathrm{NaCl}, 3.0 \mathrm{mM} \mathrm{KCl}, 1.3 \mathrm{mM} \mathrm{MgSO}_{4}, 2.5 \mathrm{mM} \mathrm{CaCl}_{2}, 1.2$ $\mathrm{mM} \mathrm{NaH} 2 \mathrm{PO}_{4}, 26 \mathrm{mM} \mathrm{NaHCO}_{3}$, and $20 \mathrm{mM}$ dextrose, saturated with 95\%:5\% $\mathrm{O}_{2}: \mathrm{CO}_{2}$ ). 
A vertical cut was made at the level of the tectum. The brain anterior to the cut, containing the neocortex, was glued to the Vibraslicer stage, with the cut surface facing down and the dorsal side facing forward. Coronal brain slices were cut with a Vibraslicer (WPI, Sarasota, FL). The olfactory bulb and the frontal cortex region (about 1000-1500 $\mu \mathrm{m}$ from the olfactory bulb) were cut and discarded, and 350- $\mu \mathrm{m}$ thick coronal slices of the parietal cortex were then cut. The slices were transferred into ice-cold ACSF in a glass petri dish. A total of 4-6 slices were cut from each brain (depending on the age of the pups). The slices were then individually transferred, together with a small volume of ACSF, onto the Millicell membrane inserts, usually 2 slices on each insert. The position and orientation of the slices on the membrane were carefully adjusted so that they were located at the center of the membrane, parallel to each other. Excess ACSF remaining on the membrane was aspirated, leaving the slices covered with only a thin layer of film of liquid. The slices were kept in a humidified incubator at $35^{\circ} \mathrm{C}$ with a $5 \% \mathrm{CO}_{2}$-enriched atmosphere, and the medium was changed twice a week. Gene gun transfection was done after 2-3 days in vitro.

\section{Gene Gun Cartridge Preparation}

Cultured slices were transfected using a Helios gene gun (Bio-Rad, Hercules, CA). Cartridges were prepared according to the manufacturer's protocols with slight modification as follows:

1) At the beginning of the experiment, a 25 " long teflon tube $(0.125$ " outer diameter, 0.093' inner diameter; 'Tefzel' tubing, Bio-Rad) was rinsed once with $100 \%$ ethanol, 
inserted into the tubing prep station, and continuously flushed with high purity nitrogen at 0.5-0.4 liter per minute (LPM) for $15 \mathrm{~min}$.

2) $3 \mathrm{ml}$ of $0.02 \mathrm{mg} / \mathrm{ml}$ polyvinylpyrrolidone (PVP) in ethanol was prepared by adding $3 \mu 120 \mathrm{mg} / \mathrm{ml}$ stock solution (of PVP in 100\% ethanol) to $3 \mathrm{ml} 100 \%$ ethanol in a $5 \mathrm{ml}$ centrifuge tube. The tube was capped tightly.

3) $12 \mathrm{mg}$ gold particles $(1.0 \mu \mathrm{m}$ or $1.6 \mu \mathrm{m}$ diameter, Bio-Rad; no apparent difference in results was noted with the two bead sizes) were weighed in a $1.5 \mathrm{ml}$ microfuge tube. 100 $\mu l 0.05 \mathrm{M}$ spermidine was added into the microfuge tube, the solution was vortexed and sonicated for 1-2 min.

4) $25 \mu \mathrm{g}$ plasmid GAD67-GFP or CMV-GFP DNA at $1 \mu \mathrm{g} / \mu 1$ in distilled water was added. The solution was vortexed, followed by slow addition of $100 \mu \mathrm{l} 1 \mathrm{M} \mathrm{CaCl}_{2}$ during slow vortexing and allowed to stand for $10 \mathrm{~min}$.

5) The microfuge tube was spinned and the supernatant was removed. $1 \mathrm{ml}$ of $100 \%$ ethanol was added into the microfuge tube. The microfuge tube was vortexed, then sonicated briefly to break up the gold clumps.

6) This washing procedure in $100 \%$ ethanol was repeated two more times, but the second and third washes used little or no sonication if there were no visible gold clumps in the tube.

7) The DNA coated gold particles were then resuspended in $1 \mathrm{ml}$ of the 1:1000 PVP solution prepared in step 2, and the solution transferred to a $5 \mathrm{ml}$ centrifuge tube. The remaining $2 \mathrm{ml}$ PVP solution was used twice to rinse the microfuge tube and transfer the remaining gold particles in the microfuge tube into the centrifuge tube. 
8) The gold suspension in the centrifuge tube was well vortexed, and drawn into the 25 " teflon tube (step 1) by a $10 \mathrm{ml}$ syringe. The $3 \mathrm{ml}$ solution filled about 24 " of the tube. After $4 \mathrm{~min}$ (for $1.6 \mu \mathrm{m}$ particles) or $5 \mathrm{~min}$ (for $1.0 \mu \mathrm{m}$ gold particles), allowing the DNA coated particles to precipitate onto the tubing wall, the supernatant was slowly removed with a peristaltic pump at a constant preset speed of $5.5 \mathrm{ml} / \mathrm{min}$.

9) The tube was immediately rotated for $\sim 1$ minute to distribute the gold particles evenly on the tubing wall.

10) While continuously rotating the tube, high purity nitrogen was turned on for $5 \mathrm{~min}$ at 0.3-0.4 LPM to dry out the ethanol.

11) The tubing was cut into $40-450.5$ " pieces and the ensuing cartridges stored in a parafilm-sealed vial at $4{ }^{\circ} \mathrm{C}$.

\section{Gene Gun-Mediated Transfection}

Slice transfection was done under sterile conditions in a laminar flow hood. A spacer (provided by the manufacturer) was attached to the barrel of the gene gun and wiped with $70 \%$ ethanol. To reduce the helium shock wave and distribute the gold particles more evenly, a nylon mesh (Tetko, 420 Saw Mill River Road, Elmsford, NY10532) with a grid separation of $70 \mu \mathrm{m}$ was attached to a plastic ring on the far end of the spacer (Wellmann et al., 1999). The spacer was brought in direct contact with the plastic ring of the Millicell membranes. Slices were bombarded with one cartridge per insert under $120 \mathrm{psi}$ helium pressure, and immediately returned to the incubator. 


\section{Confocal Microscopy}

Confocal images were taken at least 2 days after gene gun transfection, to allow complete GFP filling of distal dendrites. Under sterile conditions, the Millicell membrane was cut around each slice (leaving the membrane adherent to the culture), and the slices placed, membrane side up, in an imaging chamber filled with a small amount of freshly oxygenated ACSF at room temperature. The ACSF was filtered with a $0.2 \mu \mathrm{m} 25$ mm inorganic membrane filter (Whatman International Ltd, Maldstone, England). The imaging chamber was made of two $25 \mathrm{~mm}$ round glass coverslips separated by $4 \mathrm{~mm}$, held by a stainless steel frame with a $17 \mathrm{~mm}$ wide circular opening to allow imaging. A sterile plastic petri dish cover was placed on the top of the imaging chamber to ward of contamination.

Strongly fluorescent, well-separated neurons were selected for imaging. An inverted Zeiss LSM510 laser-scanning confocal microscope was used to capture images. Neurons were generally imaged with a 20X, 0.7NA objective, using the $488 \mathrm{~nm}$ argon laser line and a 505-550 $\mathrm{nm}$ bandpass emission filter. Image stacks were collected at $\sim 1.5-2.5 \mu \mathrm{m} \mathrm{Z}$-axis steps through the full extent of the dendritic tree. Stacks were superimposed digitally, but in most cases the full 3-D dataset was saved for further analysis. Images were taken with the lowest practical laser intensity (about 7.5-10\% of the output of an Argon laser source with a $15 \mathrm{~mW}$ maximum power) and the shortest practical illumination time to limit photodynamic damage and bleaching, and slices were kept outside the incubator for less than one hour per session. This imaging protocol was found not to cause any apparent ill effects to the imaged neurons or the slice culture, as most neurons maintained a normal morphology during imaging and upon the next 
imaging session 5 days later, and some remained viable even after repeated imaging over several weeks (see Fig. 4.4B). At the end of each imaging session, images were taken at a lower magnification (10X objective, $0.5 \mathrm{NA}$ ) in fluorescence and transmission modes to record the locations of the GFP-expressing neurons relative to the pia and white matter. After imaging, the slices with their adherent membranes were removed from the imaging chamber and placed, under sterile conditions, in multi-well plates, membrane side down, on top of the remaining part of the original Millicell membranes, and returned to the incubator. The same neurons could be imaged again in this fashion, at 5 days interval for as many as $3-5$ times.

\section{Immunocytochemistry:}

For immunocytochemistry, GAD67-GFP transfected slices were treated with 20 $\mu \mathrm{g} / \mathrm{ml}$ colchicine in culture medium for 24 hours. Slice cultures were cut out (leaving them adherent to the membrane), and washed once in 0.1M PBS. The slices were then fixed for $1 \mathrm{hr}$ at room temperature and overnight at $4{ }^{\circ} \mathrm{C}$ in $4 \%$ paraformaldehyde in $0.1 \mathrm{M}$ PBS. The slices were rinsed 3X in $0.1 \mathrm{M}$ PBS (15 min each rinse) and blocked for $1 \mathrm{hr}$ in 0.1M PBS containing 5\% normal horse serum (Sigma) and 1\% Triton X-100 (Fisher Scientific). Slices were incubated for $2-3$ days at $4^{\circ} \mathrm{C}$ in PBS containing $2 \%$ normal horse serum and $1 \%$ Triton $\mathrm{X}-100$, with one or two of the following antibodies: 1:1000 rabbit anti-GABA antibody (Sigma-RBI, A2052), 1:1000 mouse monoclonal antiparvalbumin (Sigma, P3088), 1:1000 rabbit polyclonal anti-calbindin D28k (Chemicon, AB1778), and 1:100 rabbit polyclonal anti-somatostatin (Chemicon, AB5494). Following incubation, slices were washed 3 times in $0.1 \mathrm{M}$ PBS (15 min each rinse), 
followed by incubation in one or both of the following secondary antibodies: 1:1000 Alexa 546 goat anti-rabbit $\operatorname{IgG}\left(\mathrm{ab}^{\prime}\right)_{2}$ fragments, or 1:500 Alexa 633 goat anti-mouse IgG $\left(a b^{\prime}\right)_{2}$ fragments (all from Molecular Probes), in 0.1 M PBS for 1-2 hrs. The slices were then washed in 0.1 M PBS and coverslipped with a drop of PBS for confocal imaging. Imaging was done on an inverted Zeiss LSM510 laser-scanning confocal microscope. The slices were imaged with a 20X, 0.7NA objective and a 10X, 0.5NA objective, using the $488 \mathrm{~nm}$ argon laser line and a 505-530 nm bandpass emission filter for GFP, $543 \mathrm{~nm}$ HeNe laser line and a 560-615 nm bandpass emission filter for Alexa 546, and a $\mathrm{HeNe}$ 633 laser line and a 650 long pass emission filter for Alexa 633. To prevent bleedthrough of signal, excitation was done sequentially, one laser line at a time.

\section{Electrophysiological recording}

Whole-cell Recordings: For whole cell recordings, slices were cut with their adherent Millicell membrane, transferred to a recording chamber and superperfused with $95 \%$ $\mathrm{O}_{2}: 5 \% \mathrm{CO}_{2}$ bubbled ACSF at room temperature for $\geq 1 \mathrm{~h}$ before recording began. Patch pipettes were pulled from $1.5 \mathrm{~mm}$ outer diameter glass capillary tubes (WPI, Sarasota, FL) on a Flaming-Brown pipette puller (Sutter Instruments, Novato, CA). GFP and non GFP-expressing neurons were identified under an Olympus BX50 microscope equipped with fluorescence and differential interference contrast (DIC) optics and a Hamamatsu CCD camera, using a 40X, 0.8NA water immersion objective. Whole-cell recordings were performed using the Axopatch 200B patch-clamp amplifier (Axon Instruments, Foster City, CA). Records were low-pass filtered at $2-5 \mathrm{kHz}$, digitized at $10-20 \mathrm{kHz}$, 
saved to disk, and analyzed off-line. Data acquisition and processing was done with software written in LabView (National Instruments, Austin, TX).

For voltage-clamp recordings of postsynaptic currents (PSCs), patch pipettes were filled with a cesium methanesulfonate based internal solution containing (in $\mathrm{mM}$ ): 136 cesium methanesulfonate, $2 \mathrm{MgCl}_{2}$, 0.6 EGTA, 10 HEPES, biocytin 5, pH 7.3, 275-285 mOsm. For current-clamp recording of action potentials, potassium methanesulfonate was substituted for cesium methanesulfonate.

Unitary IPSCs recording: To evoke unitary IPSCs, a patch pipette filled with $0.9 \% \mathrm{NaCl}$ was placed close to the soma of a GFP-expressing neuron. Postsynaptic currents were recorded from neurons close to the axonal arbor of the GFP-expressing neuron using another patch pipette. The GFP-expressing presynaptic cell was stimulated with $100 \mu \mathrm{sec}$ anodal current pulses elicited every 10 seconds using a Master- 8 pulse generator and stimulus isolation unit (AMPI, Jerusalem, Israel); stimulation intensity was gradually increased until an all-or-none, minimal postsynaptic response was seen (usually between 6-15 $\mu \mathrm{A}$ stimulus intensity). PSCs were recorded under different holding potentials between $-70 \mathrm{mV}$ to $30 \mathrm{mV}$ to determine their reversal potential. The AMPA receptor antagonist $\mathrm{CNQX}$ and the $\mathrm{GABA}_{\mathrm{A}}$ receptor antagonist bicuculline were then added in sequence to test if the postsynaptic currents were mediated through AMPA or GABA receptors, respectively. 


\section{Biocytin filling and histochemistry}

To verify that GFP fluorescence revealed the full dendritic morphology, a subset of GFP expressing neurons were filled with biocytin after confocal imaging. For biocytin filling, whole-cell recordings were done as described above, and the recordings were maintained for $\sim 1 \mathrm{hr}$ to allow for complete diffusion of biocytin. At the end of each recording session, the slices were fixed overnight in $0.1 \mathrm{M}$ phosphate buffered saline (PBS) with $4 \%$ paraformaldehyde at $4{ }^{\circ} \mathrm{C}$. After three washes in PBS, the slices were incubated for $2 \mathrm{hr}$ with $\mathrm{ABC}$ solution (Vector Laboratories, Burlingame, CA), followed by $3 \mathrm{X}$ rinses in $\mathrm{PBS}$ and staining with diaminobenzidine (DAB, $0.7 \mathrm{mg} / \mathrm{ml}$ ) and $\mathrm{H}_{2} \mathrm{O}_{2}$ $(0.3 \%)$ in PBS. The reaction was stopped by transferring the slices to cold PBS.

\section{REFERENCES}

Stoppini, L., Buchs, P. A., and Muller, D. (1991) A simple method for organotypic cultures of nervous tissue. J Neurosci Methods 37: 173-82.

Wellmann, H., Kaltschmidt, B., and Kaltschmidt, C. (1999) Optimized protocol for biolistic transfection of brain slices and dissociated cultured neurons with a hand-held gene gun. J Neurosci Methods 92: 55-64. 


\title{
Xiaoming Jin
}

\author{
Current address: Department of Neurology and Neurological Sciences \\ Room M016 \\ Stanford University Medical Center \\ 300 Pasteur Drive \\ Stanford, CA 94305 \\ Updated 11/06/02
}

\section{Educational Background}

1997-2002, West Virginia University, Department of Neurobiology and Anatomy, and the Neuroscience Program. Ph.D. in Anatomy.

1996-1997, Palmer College of Chiropractic, Department of Anatomy, Davenport, Iowa. 1989-1992, Zhejiang College of Traditional Chinese Medicine (TCM), Department of

Acupuncture and Moxibustion, Hangzhou, China. Master of Medicine.

1984-1989, Zhejiang College of TCM, Department of TCM. Bachelor of Medicine,

\section{Research Experience}

1997-2002. Graduate student. West Virginia University. Department of Neurobiology and Anatomy. Advisor: Dr. Ariel Agmon.

- Visualizing GABAergic neurons in brain slice culture by using gene gun mediated transfection with GAD67-GFP DNA construct.

- Neurotrophic factors and neuronal activity in the regulation of morphological development of cortical GABAergic neurons in brain slice culture.

- Characterization of GAD67-GFP transgenic mice.

1992-1996. TCM physician. Zhejiang institute of TCM.

- Clinical study of hook needle in the treatment of tennis elbow.

- Regular clinical practice of acupuncture and TCM.

1989-1992. Graduate student. Zhejiang college of TCM. Advisor: Dr. Yuanliang Liu.

- Effect of electro-acupuncture in the treatment of Kanamycin caused hearing loss in guinea pig. Master thesis research. Advisor: professor Liu Yuanliang.

- Scalp and ear acupuncture in the treatment of retarded children.

\section{Teaching Experience}

1997-2001. Teaching assistant, West Virginia University, Department of Neurobiology and Anatomy.

- Histology lab for medical and dental students, attended lectures, taught in the lab and graded exams. Spring 1998 and Spring 1999.

- Gross human anatomy lab for medical students. Taught in the gross anatomy lab. Spring 2000, Spring 2001 and Fall 2001.

1999-2001. Taichi instructor, West Virginia University, School of Physical Education, Life Activity Program.

- Instructed simplified Taichi (24 forms) class, three sessions each year.

1993-1995. Instructor and English interpreter, Zhejiang TCM Institute.

- Acted as clinical instructor and English interpreter for foreign students in shortterm clinical training in acupuncture and moxibustion. 
1996. Private tutor, Palmer College of Chiropractic.

- Teaching acupuncture to a group of chiropractic students.

1991. Graduate student teaching practice, Zhejiang College of TCM, China.

- Taught medical students the course of 'Meridian and Acupuncture points'. 1991 Spring semester.

\title{
Professional Association Memberships
}

Society for Neuroscience (Student member since 1999).

\section{Awards and Fellowship}

2001. Graduate student travel award, Society for Neuroscience.

\section{Publication}

1. $\underline{X}$. Jin, P. Mathers and A. Agmon (2002). BDNF mediates activity-dependent dendritic growth in developing non-pyramidal neocortical interneurons in vitro. (submitted).

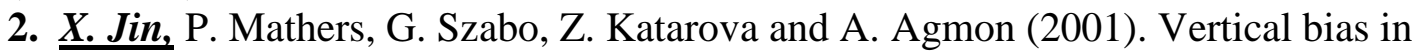
dendritic trees of non-pyramidal neocortical neurons expressing GAD67-GFP in vitro. Cereb Cortex. $2001 \mathrm{Jul}$; 11(7):666-78.

3. Liu Y, Fang J, Sun D, Jin X, Wu Y, Wang Y, Song R. (1999). An experimental study of electroacupuncture on auditory impairment caused by kanamycin in guinea pigs. J. Tradit Chin Med. 1999 Mar; 19 (1): 59-64.

4. Y. Ding, $\underline{X}$. Jin, Y. Liu (1994). Preventive effect of electro-acupuncture on frequency following responses in kanamycin-caused hearing loss in guinea pig. J. of Shaangxi Tradit Chin Med Col, 1994 Aug; (8): 34-36.

5. Weizu Ling (1993). Experimental acupuncture and moxibustion (1993). Shanghai Science \& Technology Press. Y. Liu and $\underline{\boldsymbol{X} \text {. Jin }}$ "Chapter Two: Meridian Phenomena".

\begin{abstract}
s
1. X. Jin, P. Mathers, A. Agmon (2001). Brain-Derived Neurotrophic Factor enhances morphological differentiation of non-pyramidal neurons biolistically transfected with GAD67-EGFP in neocortical slice cultures. In: Society for Neuroscience $31^{\text {st }}$ Annual meeting. San Diego.

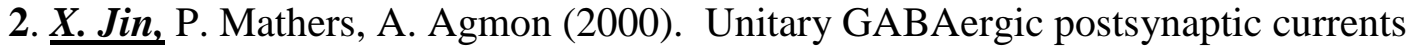
evoked by minimal stimulation of neocortical inhibitory interneurons biolistically transfected with green fluorescent protein. In: Society for Neuroscience $30^{\text {th }}$ Annual meeting, P91. New Orleans.

3. $\underline{X}$. Jin, P. Mathers, G. Szabo, Z. Katarova, A. Agmon (1999). Visualizing living GABAergic neurons expressing green fluorescent protein. In: Fifth IBRO World Congress of Neuroscience, P49. Jerusalem, Israel.
\end{abstract}

